\title{
Hollow Men: Colonial Forms, Irish Subjects, and the Great Famine in Modernist Literature, 1890-1930
}

Aaron Matthew Percich

Follow this and additional works at: https://researchrepository.wvu.edu/etd

\section{Recommended Citation}

Percich, Aaron Matthew, "Hollow Men: Colonial Forms, Irish Subjects, and the Great Famine in Modernist Literature, 1890-1930" (2016). Graduate Theses, Dissertations, and Problem Reports. 6399.

https://researchrepository.wvu.edu/etd/6399

This Dissertation is protected by copyright and/or related rights. It has been brought to you by the The Research Repository @ WVU with permission from the rights-holder(s). You are free to use this Dissertation in any way that is permitted by the copyright and related rights legislation that applies to your use. For other uses you must obtain permission from the rights-holder(s) directly, unless additional rights are indicated by a Creative Commons license in the record and/ or on the work itself. This Dissertation has been accepted for inclusion in WVU Graduate Theses, Dissertations, and Problem Reports collection by an authorized administrator of The Research Repository @ WVU.

For more information, please contact researchrepository@mail.wvu.edu. 
Hollow Men: Colonial Forms, Irish Subjects, and the Great Famine in Modernist Literature, $1890-1930$

\title{
Aaron Matthew Percich
}

A dissertation submitted to the Eberly College of Arts and Sciences at West Virginia University in partial fulfillment of the requirements for the degree of Doctor of Philosophy in English.

\author{
Lisa Weihman, Ph.D., Chair \\ Dennis W. Allen, Ph.D. \\ Gwen Bergner, Ph.D. \\ John B. Lamb, Ph.D. \\ Enda Duffy, Ph.D. \\ Department of English \\ Morgantown, West Virginia \\ 2016
}

Keywords:

Irish Literature, British Literature, Great Famine, Postcolonial Studies, Badiou, Modernism

Copyright 2016 Aaron Matthew Percich 


\begin{abstract}
Hollow Men: Colonial Forms, Irish Subjects, and the Great Famine in Modernist Literature, 1890-1930
\end{abstract}

\title{
Aaron Matthew Percich
}

This dissertation traces the impact and influence of Ireland's Great Famine (145-1852) on the formal developments of Irish and British modernism. The Famine is arguably the founding event for colonial Ireland's entry into modernity. This forceful event and forced legacy allows us to rethink modernism's developmental trajectory; rather than a movement deriving out of metropolitan experimentation, I argue for modernism's colonial roots. Colonial events like the Famine or what I term colonial atrocities are marked by mass death and cultural degradation, and further facilitated by the technological, ideological, and exploitative practices deriving from modernity. Representative practices that arise in response to atrocity-like stream of consciousness, fragmentation, large and elusive allusions - precede and develop ahead of the later consolidation of these practices as "modernism."

At its most ambitious, this dissertation's philosophical, postcolonial, and formal emphases allow us to rethink the ontological notions of modernity and postcolonial theory while also recasting the relations between colonialism and modernism as generative rather than antagonistic. For writers composing in the aftermath of colonial atrocities, a viable anti-colonial and resistant narrative can be fashioned once the atrocity as pitfall of despair and victimization is seen in another light. My conception of atrocity becomes a mode of analysis that fits Alain Badiou's philosophy of the event. The Famine, then, is the event that generates truth and revolutionary subjects capable of shifting atrocity's legacies from victimization and dehumanization to an egalitarian force opposed to colonial hegemony. On a textual level, I see these revisionary Famine legacies played out in the formal practices of Bram Stoker's Dracula, Rudyard Kipling's Kim, and James Joyce's A Portrait of the Artist as a Young Man and Ulysses. 
"When he opened the third seal, I heard the third living creature call out, 'Come!' I looked, and there was a black horse! Its rider held a pair of scales in his hand, and I heard what seemed to be a voice in the midst of the four living creatures saying, "A quart of wheat for a day's pay, and three quarts of barley for a day's pay," (Revelation 6: 5-6)

\begin{abstract}
With blood, and each sate sullenly apart
Immediate and inglorious; and the pang

Of famine fed upon all entrails - men

Happier were those pierced by

the sword

than those pierced by hunger,

whose life drains away, deprived

of the produce of the field.
\end{abstract}

And War, which for a moment was no more, Did glut himself again;- - a meal was bought

Gorging himself in gloom: no love was left;

All earth was but one thought—and that was death,

Died, and their bones were tombless as their flesh;

The meagre by the meagre were devoured,

- Lord Byron, "Darkness" (11. 38-46)

(Lamentations 4: 9)

"The town belonging to the colonized people, or at least the native town, the Negro village, the medina, the reservation, is a place of ill fame, peopled by men of evil repute. They are born there, it matters little where or how; they die there, it matters not where, nor how ... The native town is a hungry town, starved of bread, of meat, of shoes, of coal, of light" - Frantz Fanon, The 


\section{Acknowledgements}

The paradox of academic study generally and writing a dissertation specifically is that so much of the work is solitary and often self-centered yet so much of what makes this work successful is communal and the often vast number of people who lend a needed hand. I have so many people to thank and so little space to work with. Even more restrictive are the limits of my memory and so any omissions are unintended.

I would first like to thank those teachers who played such a foundational role in my journey. At Villanova University, Crystal Lucky, Helen Lang, and Michael Tomko shaped my desire and skills for academic inquiry. I am indebted to your various specialties and styles, but most of all to your consistent passion, compassion, and openness to engaging the mind and the spirit. At West Virginia University, Katy Ryan, Constinia Charbonnette, and Jenny Douglas each played important and various roles in my continuing formation. I am indebted to your regard for my writing, my thinking, and my continued growth as a person. Each of you has modeled for me what a transformative teacher looks like and I hope to reach those heights someday.

I would like to thank the members of my committee who directly shaped this project. In classes and conversations, Dennis Allen, Gwen Bergner, and John Lamb were patient, always helpful, and ever willing to share their insights into a project that I was equally discovering and drafting. I am grateful for their time and attention as scholars, but even more so for their support and care as friends. I would like to also thank Enda Duffy for his special generosity and interest in this project. Your work inspired my love for James Joyce and my desire to apply for doctoral studies in literature. I have been equally humbled and exhilarated by your effusive praise and piercing questions throughout this process.

I would like to offer a special thanks to Lisa Weihman. Your support and criticism has been steadfast and always welcome. I would not have managed the personal and professional hurdles I encountered without your help. Your roles as scholar, teacher, and advisor have shown me the most affirming and inspiring parts of the academic life. I hope that my professional and personal approach to the academy forever mirrors the one you have gifted to me.

I would also like to thank my parents, Dave and Kay Percich. You may not have always understood what I was doing or why, but you always asked questions and you always took an interest. Your constant, unbounded support and love have played a central if often easy to forget role in making this project and my journey possible.

Finally, I would like to thank my wife, Michelle Percich. Your marks on this project are perhaps the most imperceptible yet easily the most indelible. In our nearly five years of marriage you have always, as Colossians 3: 12 puts it, "clothe[d] yoursel[f] with compassion, kindness, humility, meekness, and patience." Throughout the twists and turns, inside and outside of this project, your overflowing compassion and kindness has kept me rooted. Your patience in listening to my brainstorms has been invaluable and you continue to radiate the absolute best I hope to be in our work and life together. As I complete this project, I truly know and affirm that you are, in the most perfect sense, il miglior fabbro. 
TABLE OF CONTENTS

Acknowledgements iv

Chapter I.

$\begin{array}{lr}\text { Chapter II. } & 50\end{array}$

$\begin{array}{ll}\text { Chapter III. } & 92\end{array}$

$\begin{array}{lr}\text { Chapter IV. } & 129\end{array}$

$\begin{array}{lr}\text { Coda } & 172\end{array}$

$\begin{array}{lr}\text { Endnotes } & 178\end{array}$

$\begin{array}{lr}\text { Works Cited } & 193\end{array}$ 


\title{
Chapter I. The Great Famine, English Letters, and Irish Colonial Forms
}

\author{
Weary men, what reap ye?-Golden corn for \\ the stranger.
}

What sow ye? - human corses that wait for the avenger. (1-2)

From the cabins and the ditches in their charred, uncoffin'd masses, For the Angel of the Trumpet will know them as he passes.

A ghastly spectral army, before the great God we'll stand, And arraign ye as our murderers, the spoilers of our land! (45-48)

-Lady Jane Francesca Wilde, “The Famine Year”

"That corpse you planted last year in your garden, "Has it begun to sprout? Will it bloom this year? (71-72)

Unreal City, Under the brown fog of a winter dawn, A crowd flowed over London Bridge, so many, I had not thought death had undone so many. (60-63)

-T.S. Eliot, The Waste Land

This study begins with a striking poetic connection that is highly suggestive in spite of dissimilar contexts between Irish Famine-era and later British modernist poetry. Although scholars clearly position Oscar Wilde as a decadent and key precursor to modernism, his mother, Lady Jane Francesca Wilde (1826-1896), has not received similar recognition. During Ireland's Great Famine (1845-1852), the Wildes were relatively free from starvation and illness yet Francesca Wilde's conscience was by no means unscathed. Adopting the pseudonym "Speranza," she wrote nationalist poetry for the Nation newspaper, including one of the earliest and most visceral denunciations of England's role in the Famine, "The Stricken Land" (later renamed "The Famine Year") in 1847. "The Stricken Land" attempts to get at the truth of the 
Famine, specifically its implications for Ireland's colonial and national states, by focusing on the material ramifications of this event upon Irish subjects. The poem opens with a horrific transubstantiation of the Irish subject: "Weary men, what reap ye? - Golden corn for the stranger. / What sow ye? - human corses that wait for the avenger" (Wilde "The Famine Year" 11. 1-2). The transubstantiation of Irish "corses" into crops "sow[n]" for later "reap[ing]" is just the first of a litany of various iterations of degraded Irish subjects throughout the poem including "a gaunt crowd on a highway"; "One by one they're falling round us, their pale faces to the sky;" and "whitening bones" (11. 15, 33, 44). Ultimately, these "uncoffin'd masses" accumulate into "A ghastly spectral army" that will take vengeance upon "the spoilers of our land!" $(11.45,47,48)$. This subjective transformation, and the visceral metaphors that conceptualize it, aim at arguably the central problem of atrocious events like the Famine, namely, what ultimately survives the horrors that colonialism contributes to, either implicitly or explicitly? On the one hand, the poem argues, not much: "One by one they're falling round us, their pale faces to the sky; / We've no strength left to dig them graves - there let them lie" (11. 33-34). The forced resignation here admits to the overwhelming violence and material deficits of illness and starvation that "let them lie." However, the poem also gestures towards an intractable truth that vengeance and revolution, even if supernatural, will manifest in Ireland: "A ghastly spectral army, before the great God we'll stand, / And arraign ye as our murderers, the spoilers of our land!" (11. 47-48).

“The Stricken Land," like much Famine-era poetry and writings, has a fundamentally apocalyptic and providential tone, yet far from a strident division from later modernist literature these aspects overlap in considerable ways. Wilde's poem has a more than titular connection to one of the greatest and most "modernist" of poems, T.S. Eliot's (1888-1965) The Waste Land (1922). Like Wilde's poem, where "whitening bones ... rise as witnesses," Eliot's is similarly 
witnessing to unimaginable death, albeit in World War I's wake (1. 43). Even more saliently, Wilde's thematic and metaphoric configurations echo hauntingly in Eliot's own poem despite their vast temporal, cultural, and periodic divergences. Eliot's wasted land is similarly stricken, "April is the cruelest month, breeding / Lilacs out of the dead land," and Wilde's sown Irish corpses have their own strange touchstones in "That corpse you planted last year in your garden, / Has it begun to sprout? Will it bloom this year?" (Eliot 11. 1-2, 71-72). ${ }^{1}$ Whereas Eliot's masses are far less vengeful than Wilde's, they are similarly provocative and a resistant legacy of mass death in an "Unreal City" in which "A crowd flowed over London Bridge, so many, / I had not thought death had undone so many" (11. 60, 62-63). At a basic level, these suggestive and often eerily direct connections indicate a far closer proximity between Famine-era Irish writing and modernism, especially in the latter's artificially demarcated "metropolitan" provenance. Particularly in Ireland, metropolitan and colonial are cast in sharpest ideological relief, since, as Declan Kiberd and numerous other critics have demonstrated, "Ireland functioned as a sort of political and social laboratory in which, parabolically, the English could test their most newfangled ideas" (Inventing Ireland 23). ${ }^{2}$ Colonial in origin, these ideas, whether economic practices like the plantation system or social and anti-terrorist measures like a police force or mugshots, cast into colonial relief important inflections on British modernity and cultural forms. ${ }^{3}$ Further focusing this approach on events like the Famine, what I will call colonial atrocities, provides a revisionary account of colonial culture and its influential role in modernism that accords with Eliot's own later goal, highlighted in "Tradition and the Individual Talent" (1919), of "liv[ing] in what is not merely the present, but the present moment of the past" in order to forge a "conscious[ness] not of what is dead, but of what is already living" (Selected Prose 30). 
Eliot's goal provides an overarching structure to this project as its works to reconcile the colonial past with modernity's present while still affirming the living power of colonial subjects. Focusing on the "present moment of the past" reaffirms the ways literary and cultural critique must not only move through boundaries, but must also account for the ways the past remains imbedded yet often unseen in present moments. It is in this "present moment" that the project makes a clear intervention in modernity and modernism as opposed to a postmodern move. ${ }^{4}$ Modernity and modernism as entwined and closely aligned concepts is arguably cast into sharpest relief in colonial contexts. ${ }^{5}$ In a sidelong way, modernist scholarship has recognized this conjunction in its rethinking of World War I as a particularly meaningful moment when the modern subject was "born" and twentieth-century writing and culture were dramatically altered by the war's unprecedentedly subject-centered violence, shock, and awe. ${ }^{6}$ The same processes and collateral damage of WW I are even more preeminent in colonial events like the Famine where technological and ideological "progress" results in unparalleled collateral damage, including mass death and cultural degradation. Events like these are "colonial atrocities," a term I use to distinguish them from war (broadly-conceived) and genocide. Another significant difference is these atrocities, unlike WW I, remained largely unremarked in modernist and even postcolonial studies. ${ }^{7}$ Colonial atrocities are crucial histories and contexts that are essential inand-of-themselves, but they also provide a key lens for penetrating the overly familiar postcolonial paradigm of "'us' and 'them"” that far too often reifies difference as settled, clear, and perpetual (Sen 175). ${ }^{8}$ In thinking beyond his binary I conceptualize atrocity as a modality that inaugurates novel and radical alternatives to both imperialist and anti-colonialist forces and forms. Colonial atrocities are dynamic in that they possess localized distinctions in events like the Famine, Indian Mutiny (1857-1858), or the Morant Bay rebellion (1865) while also fitting 
into a global paradigm of shared legacies, including mass death and cultural degradation and common colonial facilitations through the technological and ideological deformations of modernity, that produces "spectre of comparisons" (Anderson 2). Alain Badiou's philosophy of the event, read through a colonial context, provides a theoretical intervention that shifts our thinking on atrocity, its relations to culture, but most of all its realization in the world of subjects and suffering. Beyond an abstract theoretical maneuver, the event privileges and empowers the subject as agent for dynamic and lasting change.

Badiou's philosophy of the event provides an ideal framework for these interventions as he offers new ways of approaching being, subject, truth, and event. His evental conception departs from the Hegelian or Heideggerian event as general socio-historical category in favor of a particularized event that accesses real ontology. The event is openly critical of postmodern relativism and in this critique offers a distinct revision of modernity that is not a regressive repetition. The event's critical edge is its connection to authentic ontology, conceived as an "illegal contingency" that is capable of producing a "new discourse, and hence the new subject" (Badiou Saint Paul 81, 103). New discourses and subjects ultimately manifest out of four distinct fields in which events occur: love, politics, science, and art. Significantly, the event does not offer a utopian salve or even an incisive prevention against human propensities towards violence and exploitation. Rather, the event and its central ramification, truth, operate with the acknowledged albeit hopeful risk that it is only through the human subject that a transformative present might be inaugurated. Evental novelty, whether discursive or subjective, is grounded upon ontology and therefore provides a fundamental point of access for thinking through epistemological labyrinths and false discourses of the subject and agency. These latter points are by no means solely implicated in hegemony and the state, but they are essential ways to think 
and reify difference within hegemony. As a result, the event's manifestation of truth is antithetical to statist division and difference precisely in that truth is localized and contextualized in terms of the event's contexts yet it remains always already "addressed to all without exception" (74). Truth's egalitarian contours ultimately "constitut[e] the event" and therefore pose "nothing less than a wholly new architectonic and thematic principle" that if properly agitated for will result in profound, innovative transformations (Ethics 68). Formally and structurally, truth is then distilled out of practical realization, itself predicated upon localized praxis and universal prescription, whose form is "singular" while "neither structural, nor axiomatic, nor legal" (Saint Paul 14). Whereas truth inaugurates an architectonic rupturing of form and structure in order to reassemble the new, statist responses always attempt to coopt the event through a "constructivist vision" that revises the radical into the ideological, thereby ensuring "there is no place for an event to take place" (Being and Event 289). The ideological façade of this "constructivist vision" and the truth's universal and unchanging character both ensure that no matter how successful hegemony is in asserting itself and rewriting antithetical discourses, forms, and subjects, events recur throughout history in slightly different forms with the same truth at its center. ${ }^{9}$ Far from abstraction, Badiou emphasizes repeatedly that "truthprocedures ... constitut[e] the singularly human, within the animal universe" and by extension "a procedure of truth is never anything other than the seizing of materiality" (Ethics 132, 133). At its core, pursuing truth in an evental context is a human endeavor that separates the human from the animal, and in this most crucial and inherent sense the event underscores the dignity of all subjects regardless of ideological objections, whether imperialist, progressive, national, or other. This requires a deep reconceptualization of ideas and is therefore abstract in a sense, but only as 
the pathway that leads to truth. Through Badiou's emphasis on truth as a "seizing of materiality" the subject is given primacy and responsibility for bearing abstract concept into coherent act. ${ }^{10}$

A subject- and material-centric intervention can shift our thinking from how modernism reacted to colonialism to a profound rethinking of modernism's colonial roots. It is in this rethinking that a far more basic elaboration of the periphery as transformative of the center occurs without the simplistic binary of colony and metropole. Far from simple influence or commentary, the colonies were the genesiac touchstones for formulating aesthetic practices, experiments, and ways of thinking that developed into what we recognize today as modernism. Although I examine the Famine from a deferred perspective, focusing on texts from 1880-1930, this is not a study of trauma or historical revisionism. Rather, I read back from modernism to the Famine in order to flesh out those aesthetic forms that constitute canonical modernism yet are nevertheless rooted in colonial experiences and cultures. Throughout this study I will highlight how the Famine's oblique presence is the flashpoint for radical formal developments from an early proto-modernism represented by Bram Stoker's Dracula and Rudyard Kipling's Kim to the acknowledged heights of high modernism in James Joyce's Ulysses. The general frameworks of Badiou's evental philosophy and postcolonial theory inform my reasoning in identifying the Famine across disparate texts and writers whether or not those texts and writers are clearly "Irish" or even clearly discussing the Famine. My first chapter focuses on Bram Stoker's Dracula as one of the earliest modern novels. Stoker's Irishness and the novel's connections to the Famine have both been recently elaborated by several critics. What I will focus on is greatly enlarging these ideas and linking them clearly together. Dracula's proto-modernist epistolary form is reflects Famine-era reporting and a more properly evental response to British imperialism. The epistolary circulation and absent colonial subject coincide in dissolving 
imperial letters and subjects via an alternative colonial subject whose autonomy literally escapes the actions, thoughts, and words of the British contingent. That Dracula even escapes death lends further support to a different colonial subject through the event. In Dracula, I see an Irish-centric playing out of the Famine event in Stoker's formal developments. My second chapter shifts the first's English-centric preoccupation into a global diasporic framework. Like Stoker's epistolary form, I read Rudyard Kipling's Kim through a largely ignored formal context in which the novel is invisibly divided between an English narrator and Kim's Irish subject. Further exasperating this divide are the fluid cross-colonial connections Kim engages in that are ultimately configured out of atrocity contexts, namely the Famine and Mutiny. These atrocity contexts foreground Kim's autonomy by activating an Irish "I" beneath the increasingly impotent narratives of the English "eye" overlooking him. Kim's subjectivity becomes so radical that it escapes the racialized contexts that buttress colonial narratives and especially much of Kim criticism. These two chapters reinforce the Famine event's latent ramifications on imperial narrative, subject formation, and history from an aesthetic perspective. My final chapter turns to a clearly modernist text, James Joyce's Ulysses and the Famine's place in Joyce's oeuvre. Whereas several scholars have recently and necessarily clarified the place of the Famine in Joyce's work, what I want to locate is a very different Famine. It is Joyce, of the first three, who fundamentally reworks Famine histories and legacies in such stark differences that the question is not where is the Famine in Joyce, but what Famine is in Joyce. A revised Famine narrative is the critical thread that links Stephen Dedalus' awakening to a reformulated Irish colonial scene. I trace Joyce's alignment of radical form with Dedalus' subjective development between Stephen Hero and A Portrait of the Artist as a Young Man before culminating in the "Proteus" episode of 
Ulysses as the way the event's presence in an aesthetic framework can result in a radically new historical and cultural perspective.

\section{Postcolonial Ontologies}

In spite of the Famine having "ended" in Ireland over 150 years ago, it continues to leave a lasting and persistent mark upon Irish literature and culture. ${ }^{11}$ In a speech delivered in Chicago in 1996, then President of Ireland Mary Robinson linked the past and present in reflecting on the Famine then and its analogues today, "The terrible realities of our past hunger present themselves to us as nightmare images. The bailiff. The famine wall. The eviction. The workhouse. The coffin ship. And yet how willing are we to negotiate those past images into the facts of present-day hunger? How ready are we to realise that what happened to us may have shaped our Irish identity, but is not an experience confined to us as a people?" Robinson directly challenges distinctions and divisions, whether historical, national, or temporal, when it comes to events like the Famine, especially when understood as colonial events. The "nightmare images" she cites, "bailiff," "famine wall," "eviction," "coffin ship," are certainly localized to midnineteenth century Ireland yet she just as insistently casts them as the shadows of present-day hunger in a far broader, global legacy of postcolonial populaces. ${ }^{12}$ Robinson's local/global dynamic is equally evident in John Waters' recent metaphoric casting of "the Famine, the most extreme oppression of the violence inflicted on the Irish nation by the tyranny of the coloniser, [a]s the door by which that colonial experience can be assessed" (28). Waters' oppressive violence shapes a "door" that accurately symbolizes the threshold one crosses in atrocities like the Famine, which lead to Robinson's equal emphasis that the Famine indelibly "shaped our Irish identity" just as it opens to a wider "experience" "not" "confined" to Ireland solely. The Famine represents a singular event, in fact the deadliest famine in recorded history, that claimed 
approximately 2.5 million Irish between 1845 and 1855 (accounting for birth rate declines, deaths, and immigration) and further prompted a continuing torrent of 4 million migrants between the years 1856 and $1930 .{ }^{13}$ Additionally, Ireland's communal, social, and sexual mores were radically altered by the Famine and even those Irish who left Ireland and constitute the largest diaspora in the world continue to bear the marks of the Famine, especially in terms of their higher incidences of mental illness relative to other diasporic peoples and a keenly embodied colonial identity that Liam Greenslade locates in the "collective, political unconsciousness [of] every Irish person [a]s orientated towards being for the colonial, and hence English, Other" (“"White skin, white masks"” 219). ${ }^{14}$ These specific frameworks of the Irish as England's "colonial" "Other" did not originate out of the Famine, but they were arguably consolidated by the event's mass death and migratory legacies. Although the Famine arguably shapes the Irish as a particularly intimate and evocative colonial other in the British imaginary, it is also clear in its diffusion throughout British culture that the Famine event was never solely Irish-centric. Since, as Chris Morash has insightfully noted, "the literature of the Famine ... exists as a series of tangents to the elusive event itself" and thus "we encounter only the ghosts of the dead, who are, as ever, absent," it is unsurprising how transgressive these "ghosts" and absences are, whether in Irish, British, or broader colonial literature and culture (Writing the Famine 187).

The Famine's tangential ghosts certainly inhabit Irish literature and culture yet they are also similarly present in wider British narratives. Remarkably, Charles Dickens' (1812-1870) A Christmas Carol (1843) stages one of Ebenezer Scrooge's earliest and sharpest turn of hearts through a culturally symbolic sense of hunger and loss that predates yet while later emblematize the Famine. Scrooge encounters a horrifying image of "wretched, abject, frightful, hideous, 
miserable" and "wolfish" children starving beneath the Ghost of Christmas Present's robes (Dickens 61). John Leech provides the illustration of these figures, which superficially stand for Ignorance and Want, yet it is Leech who later illustrates Famine scenes in Punch and thus depicts the Irish in remarkably similar imagery. Leech's famished Irish, among other reports and images of the Famine in British periodicals, further inspire Emily Brontë's (1818-1848) Wuthering Heights (1847). ${ }^{15}$ Anthony Trollope's (1815-1882) The Kellys and the O'Kellys: A Novel (1848) begins "during the first two months of the year 1844" yet never explicitly mentions the Famine (7). With less "repression or evasion" of the Famine, as Terry Eagleton terms it, American writers like Edgar Allan Poe (1809-1849), Sarah Orne Jewett (1849-1909), and Eugene O'Neill (1888-1953) dealt variously and generally with the Famine in terms of its mass transatlantic migration. ${ }^{16}$ Seán O’Faoláin's Come Back to Erin (1940) provides a caustic reflection on Irish American communities through Irish-born protagonist Frankie Hannafey, who bemoans their regressive nationalism, "Their minds had not moved a step since the days of the Famine, the Land Leaguers, 'poor ould Oireland,' the Parnellites and anti-Parnellites"' (289). The consistently deep repression of the Famine in British narratives was not mirrored in the approximately fourteen novels and over one hundred poems published in Ireland between 1847 and 1900 that, like William Carleton's (1794-1869) The Black Prophet (1846), generally address "the irresistible pressure of famine" in Ireland both at the time and earlier (Morash "Making memories" 41; 247). ${ }^{17}$ The Famine indelibly marks many late-nineteenth and early-twentieth century Irish texts, either implicitly in Emily Lawless' characterization of western Ireland as a "hungry-looking country" in Hurrish (1886) or far more explicitly in Canon Patrick Augustine Sheehan's (1852-1913) Glenanaar (1905) and its litany of Famine images, including "Gaunt specters," "Mothers ... [with] milkless breasts," and "wayside ... corpse[s] ... darkened by lines 
of green around the mouth, the dry juice of grass and nettles" (104; 98-199). In spite of these consistent yet varying Famine legacies in Irish and British literature, scholars into the early 1990s persisted in overlooking the Famine's presence as Eagleton's queries exemplifies: "Where is the Famine in the literature of the Revival? Where is it in Joyce" (13). ${ }^{18}$ These questions are rooted in the Famine's "fundamental indeterminacy" and the "epistemological elusiveness of the past itself" (Morash Writing the Famine 3). An epistemological lens ultimately blinds us, as Chris Morash asserts, because the "Famine lacks a recognizable narrative shape" and is therefore marked by disparate yet recurring tropes and symbols that "posses[s] a hard-edged clarity ... refined through decades of repetition" whereby each "image reinforces its place in the discursive world of the Famine, and increases the number of texts to which it makes silent reference" ("afterword on silence" 303; Fearful Realities 115; "Making memories" 51). Thus we see a continuity in Famine representations and narratives yet a continuity forever ephemeral. Beyond narrative or cultural images and symbols, this ephemerality has material, indeed ontological, roots, as Máire Ní Grianna, a survivor from Rannafast, County Donegal, illustrates in her succinct reflection on the Famine, "Mharbh an gorta achan rud" (The Famine killed everything) (qtd. in Kinealy Death-Dealing 155). ${ }^{19}$

The Famine's distinctions define it against related colonial atrocities but each one converges in their ultimate ramifications of mass death and cultural degradation; in other words, atrocities persist because they "killed everything." These fatal legacies inform Joyce's characterization of "Dublin ... [as] the centre of paralysis" as well as other colonial thinkers like Frantz Fanon who similarly evoke a paralyzed colonial "world divided into compartments, a motionless, Manicheistic world, a world of statues" (Letters 134; Wretched 41 ) ${ }^{20}$ This divisively static colonial façade perpetuates a "people's lethargy" and a reductive cultural production or 
"borrowed estheticism" (179) that coincides with an insidiously superficial embrace of an "objectivity" that displaces the "much more fundamental substance" of the subject, thereby reducing the latter to "mummified fragments" and "symbols of negation and outworn contrivances" redolent of ideologically-charged and progressive subjectivities (180). Fanon's juxtaposition of "fundamental substance" and "mummified fragments" clarifies the stakes of a postcolonial ontology predicated upon a living wholeness against the fatal fragmentation that is part and parcel to colonialism. His explicitly cultural focus is a key seam in a broader understanding of postcolonial ontology inherent to Elleke Boehmer's definition of "postcoloniality" as the "condition in which colonized peoples seek to take their place, forcibly or otherwise, as historical subjects" (Colonial and Postcolonial 3). Postcoloniality and its ontological determination of subjectivity are cast into sharp relief through atrocity. Although not speaking to atrocity solely, Edward Said identifies the sharp contrast drawn between nationalistic productions, especially those undergirding colonialism, that "consign truth exclusively to themselves and relegate falsehood and inferiority to outsiders" (Reflections 176). He further delineates this opposition as the particular wedge refined in the "modern era" where "immense aggregates of humanity loiter as refugees and displaced persons" under the auspices of "exile ... [a]s fundamentally a discontinuous state of being. Exiles are cut off from their roots, their land, their past" (177). Although Said's reflections elucidate contemporary exile and modernity, they are especially if implicitly symptomatic of colonialism. In fact, it is colonialism whose constellated histories, subjects, and cultures comprise the broad exilic and fragmented frameworks that constitute the always already global world today. In spite of the ontological grounds elucidated above, both postcolonial theory and modernist studies generally engage with colonialism's legacies of alienation, violence, and mass death not through ontology, but 
epistemology. Michel Foucault arguably looms largest as a singular influence promulgating an intellectual historiography, what he more aptly terms an archaeology of knowledge that allows a critic to excavate the boundaries of thought that delimited a historical period through an unconscious operation that displaces the subject and reacts against both phenomenological and traditional historiographic inquiries. ${ }^{21}$ His influence on postcolonial theory is central to rethinking a postcolonial ontology that is ultimately and currently orientated towards an epistemologically-centered death drive.

Foucault is an acknowledged intellectual forefather for Said, but just as much a precursor - albeit one face in a theoretical crowd - for Bhabha's and Spivak's postcolonial ascension. Beyond the common critiques of both theorists is one I want to focus on as perhaps the most pressing. ${ }^{22}$ The epistemological-foci of these approaches ultimately, if inadvertently, forecloses any viable transcendence of the postcolonial schema from a theoretical or even philosophical perspective at its most basic level. In fact Spivak voices this critique of "the implicit" and analogous "working[s]" of postcolonial theory with imperial ideology evident in the "axiomatics of imperialism in the vocabulary of radical critique" (Critique 409) and the ways "critical intimacy" engenders such implication (425). Intimately connected with this "critical intimacy" is a specific historical revisionism that anthropologist Nicholas Thomas identifies as a misreading, namely the postcolonial theoretical view that "the work of colonial discourse is essentially to diminish or deny difference, whereas it might be argued that in many contexts it is equally concerned to deny similarity" (51). What links these two critiques are the epistemologicallycentered horizons that encompass them and the inherently fraught avenues of attempting to penetrate discursive forms and paradigms of difference based solely on free-floating textuality. This is perhaps most clearly shown in Spivak's own trajectory from "the Subaltern cannot speak" 
to a later revisionary "acknowledge[ment] [of] a responsibility toward the trace of the other, not to mention toward other struggles" through "something other than silence and nonexistence, a violent aporia between subject and object status" ("Can the Subaltern" 308; Critique 198, 304). Although theoretically foregrounded, Spivak's own rehearsal of terms like "trace of the other" and "something other than silence" uncomfortably gesture toward a colonial subject incapable of autonomy, agency, and perhaps even life. The latter implication is brought home in Spivak's avowal to "a responsibility towards ... the other" that is interrupted and interpreted as not the other, but "the trace of the other." As a self-avowed deconstructionist, Spivak lauds her work as a "definitive modification of a Heideggerian program" that nevertheless remains implicated in Heidegger's ontological project. In postulating a radically discursive and epistemologicallydriven subject, Spivak's own criticism lists into Hegelian and Heideggerian trajectories into what Giorgio Agamben calls an "initiat[ion] ... into a negativity" that corresponds with a broader framework of "negativity and ungroundedness" typically ascribed to an uncritical metaphysics $(84,85)$. This disavowed metaphysics nevertheless functions as what Basil Hallward terms a "negative theology" which postulates a subject who is "inaccessible to relations of nomination, situation, and evaluation" (423; 30). ${ }^{23}$ As Amar Acheraïou perceptively asserts, "no cultural representations of difference, even the most dialogical or inclusive, can be completely independent of the economy of power, prejudice, and essentialism" and it is particularly the latter, in a definitively Heideggerian context, that places the postcolonial subject of Bhabha and Spivak in a literal dead-end (Questioning Hybridity 93).

Heidegger's philosophy foregrounds an ontology that is essentially the foundation for any epistemologically-centered approach to the subject. Agamben's earlier inflections on "negativity and ungroundedness" in many ways signal the grounds Heidegger's ontological pursuit leads, 
namely death. Heidegger is very clear on this in his own ontological philosophy, avowing, "The full existential-ontological conception of death may now be defined as follows: death, as the end of Dasein, is Dasein's ownmost possibility—non-relational, certain and as such indefinite, not to be outstripped. Death is, as Dasein's end, in the Being of this entity towards its end" (Being and Time 303). Heidegger succinctly reiterates this later, "Death is Dasein's ownmost possibility," and thus the ontological impasse ends with death as the only real means of transcending the world and thereby further haunts any ontological premises within postcolonial theory's subjective paradigms (307). Heidegger's ontological death drive is a literal dead-end for a transcendent postcolonial theory, but it is also the promise of an alternative to an epistemologically-centered postcolonial theory that, in Søren Kierkegaard's words, “must essentially begin from the beginning" (51). Philosophy is a key beginning for thinking through these issues since philosophy's "aim," according to Gilles Deleuze, "is not to rediscover the eternal or the universal, but to find the conditions under which something new is produced" (Dialogues VII ). These "conditions" of novelty have a universal directive in that they become the keystone for conceptualizing "the best of all worlds [a]s not the one that reproduces the eternal, but the one in which new creations are produced, the one endowed with a capacity for innovation or creativity" (The Fold 79). Deleuze's emphasis on "innovation" and "creativity" is ultimately life affirming as these "conditions" produce novelty, itself the byproduct of Badiou's event as it manifests truth in the world. Truth that derives out of the event is not the abstract "eternal" that Deleuze reacts against, but rather an emphatically material pursuit that Kierkegaard aptly describes: "Truth is not something you can appropriate easily and quickly. You certainly cannot sleep or dream yourself into the truth. No, you must be tried, do battle, and suffer if you are to acquire truth for yourself" (51). Truth's materially-grounded aspects, 
specifically its implication in "battle" and "suffer[ing]," cast it "not [as] a sum of statements, no[r] a definition, no[r] a system of concepts, but a life" (52).

In the trajectory from suffering to battle to life, we see not only the event's promise, but also the faulty ends where British imperialism intersects with postcolonial theory. Early in The Location of Culture, Bhabha thinks the "unhomely" world as the staging point for a privileged postcolonial subject for whom "amnesia" is an impetus for solidarity: "I am looking for the join ... I want to join ... I want to join"' (26-27). Whereas Bhabha's amnesia promotes an essentially positive solidarity, there is a parallel and earlier expression of solidarity through amnesia within British imperial thought. Cambridge historian Sir John Robert Seeley (1834-1895) saw the Empire as "the great fact of modern English history" and amnesia as central to it: "We seem ... to have conquered and peopled half the world in a fit of absence of mind" $(15,12-13) .{ }^{24}$ Seeley's imperial amnesia is an entirely unhomely concept that ultimately elides the mass death and inherent violence of imperial progress behind amnesiac "fit[s]." This general imperial amnesia is also an earlier contextualized aspect of localized colonial interactions, particularly in Ireland during the Famine. Then, Sir Charles Edward Trevelyan (1807-1886), Assistant Secretary to HM Treasury and primary director of relief polices in Ireland, saw the devastation wrought during "Black '47," the Famine's worst year, yet later recounted in his memoir, "The Irish Crisis" published in the Edinburgh Review (1848), "In the third year (1847) the disease had nearly exhausted itself. It appeared in different parts of the country, but the plants generally exerted fresh vigour and outgrew it," (30). ${ }^{25}$ So entrenched and transformative was this amnesiac response that Trevelyan regarded the Famine as a "salutary revolution" that "educed permanent good out of transient evil" (1). Ultimately, this "permanent good" did not decimate as much as diagnose Ireland as "sign" such "that the case of Ireland is at last understood. Irish affairs are no 
longer a craft and mystery. The abyss has been fathomed. The famine has acted with a force which nothing could resist, and has exposed to view the real state of the country, so that he who runs may read" (138). ${ }^{26}$

Trevelyan's amnesiac revisionism and "abyss[al]" "read[ing]" of Ireland underscores the extreme deformations an epistemologically-focused and radically discursive inquiry can pose. Radical is central here since, according to the $O E D$, "radical" is literally grounded in "roots" and "fundamental to or inherent in the natural processes of life" and this further reinforces how any truly radical critique is one grounded in an ontologically-centered subject ("Radical"). It is ontology rather than epistemology that can penetrate the lingering power of colonial atrocity. With the Famine in mind, contemporary Irish poet Eavan Boland gestures towards the ontological in her reflections on the Famine's contemporary presence as "an event that happened in history but whose effects - in terms of silences and avoidances — continues to happen outside it" and thus these "effect[s] must in turn be shaped by these silences" (213). Boland's mixed tenses of "happened" and "happen" highlight the powerful persistence of colonial atrocities like the Famine that not only deform history, but in some sense indelibly transgress it as she makes clear in a later fragmented passage: "The making of history. The unmaking of it" (218). Boland lays out atrocity's radical grounding as both "making" and "unmaking" history in a discrete simultaneity or ideally productive tension. In this sense, colonial atrocities are equally constructive and destructive, thus ontology, which effectively engages with both, rather than epistemology is the means to work through Heidegger's ontological transcendence as solely death-driven. Although literature cannot actively intervene in reality in the sense of "saving" colonial subjects or refugees in situ, it can and does incisively transform those "useful modes of social adaptation, creative dissent, techniques of survival, and conceptions of the future 
transmitted from generation to generation" that political theorist Ashis Nandy argues "are deeply influenced by the way in which large groups of human beings have lived and died, and have been forced to live and forced to die" (Bonfire of Creeds 445). Faced with social conflict and survival, generational change and mortality, Edward Said, in a far too under-used point, offers an ontologically-grounded approach to addressing corporeal suffering. Whether society's or the individual's suffering, Said's concept of “worldliness" offers a key approach to mediating textuality and reality (World 35). He specifically emphasizes the worldliness of texts in order to lay bare the "conditions set by and in the world" which animate the "network of often colliding forces" in which "a text in its actually being a text is a being in the world" (33). A text's worldliness locates the potential for texts to be caught within conflicted frameworks, including those that undergird hegemony, while retaining the power to agitate against them. This ontological framework for the text clarifies the conflicted terrain of a given text while preserving the needed mediator of such conflicts, the subject. A textually-based ontological intervention not only preserves conflict within the text, but also preserves the subject even when afflicted by an annihilated past or the haunted present. It is in this context that Paul Ricoeur's "debt we owe the dead" adds a further impetus to the subject, whether within or without the text, particularly in the various subjective engagements postcolonial legacies propose (Time 185-186).

\section{Atrocity's Debts/Depths}

Atrocity's vivid scenes and violent legacies are a profound paradox to the generally amnesiac responses they generate in imperial subjects. Strikingly, this amnesia too often extends to "Postcolonial studies" which in Spivak's evocative critique, "unwittingly commemorat[es] a lost object" and "become[s] an alibi unless it is placed within a general frame" (Critique 1). Her oblique reference to "a lost object" vibrates with the generally amnesiac responses to atrocity in 
theoretical and historical accounts of colonialism. Jacques Rancière, in a different albeit related context, sees an inherently amnesiac response to the dichotomy between speech and visuality such that "speech institutes a certain visibility ... [that] forbids the visible from showing on its own, from showing the unspeakable, the horror of the gouged-out eyes" (18). Although an Oedipal reflection on tragedy, Rancière's elaboration provides a key context for delineating the mechanism that reduces atrocity to a theoretical and historically "lost object" according to the logic of a "knowing that obliges one to withdraw from the world of visibility" (19). Tragedy's "unspeakable" "horror[s]" are entirely congruent with atrocity and the withdrawal "from the world of visibility" is a key index for the ways British imperialism eclipses and indeed disavows atrocity. Joseph Chamberlain's (1836-1914) 1897 speech "The True Conception of Empire" is exemplary of this disavowal. As Secretary of State for the Colonies, Chamberlain articulates a clear seam of amnesiac justifications: "No doubt ... when these conquests have been made, there has been bloodshed, there has been loss of life among the native populations, loss of still more precious lives among those who have been sent out to bring these countries into some kind of disciplined order, but it must be remembered that that is the condition of the mission we have to fulfil" (213). In Chamberlain's reflection, the imperial "mission" justifies the inherent losses, whether "precious" English "lives" or "native" "bloodshed," through an amnesiac subtext that elides any number of violent distinctions that define the Famine, the Mutiny, the Morant Bay rebellion, or the future concentration camps of the Second Boer War. It is easy to critique Chamberlain's amnesia, his historical revisionism, and his empty justifications, but more constructively we can go beyond absent-minded ideologies to the embodied places and events that necessitate them. 
Early colonial intellectuals repudiated amnesiac progress like Chamberlain's by focusing on atrocity as the clearest distillation of colonialism's corrosive impact on colonized and colonizer. Colonialism, in Aimé Césaire's brilliant reflection, "works to decivilize the colonizer, to brutalize him in the truest sense of the word" and thus "no one colonizes innocently ... no one colonizes with impunity" $(11,170)$. Of course, colonialism's chief fruits are the "hideous butcheries" perpetrated within the colonies:

these heads of men, these collections of ears, these burned houses, these Gothic invasions, this steaming blood, these cities that evaporate at the edge of the sword, are not so easily disposed of. They prove that colonization, I repeat, dehumanizes even the most civilized man; that colonial activity, colonial enterprise, colonial conquest, which is based on contempt for the native and justified by that contempt, inevitably tends to change him who undertakes it; that the colonizer, who in order to ease his conscience gets into the habit of seeing the other man as an animal, accustoms himself to treating him like an animal, and tends objectively to transform himself into an animal. It is this result, this boomerang effect of colonization, that I wanted to point out. (19)

In this lengthy quote, Césaire's opening move from the corporeal dismemberment of "Gothic invasions" to "th[o]se cities that evaporate at the edge of the sword" outlines generally atrocity's contours. His subsequent emphasises on "dehumaniz[ation]" and "animal" further bear out the corrosive impact of atrocity on all peoples. Césaire clearly and importantly frames atrocity without ever saying it - as an exemplar of colonialism's utterly deforming practices. This trajectory extends the colonial "boomerang" into mid-twentieth century Europe with "Hitler" and his genocidal reign (15). This trajectory underscores colonialism as cause rather than symptom of 
a powerful regression in which "civilization acquires another dead weight, a universal regression takes place, a gangrene sets in, a center of infection begins to spread" and this "poison ... instilled into the veins of Europe" that leads to "savagery" (13). Césaire's analytical power and hopeful potential both derive out of atrocity. Similarly, W.E.B. Du Bois found in atrocity a necessary and profoundly expansive influence on his theories of modern violence and suffering. Slavery's trenchant legacies into the twentieth century inspired Du Bois' famous declaration, "the problem of the Twentieth Century is the problem of the color-line" (100). A visit to the Warsaw ghettos in the aftermath of Nazi atrocities in 1949 prompted Du Bois to revise the "problem" of the twentieth-century from "not even solely a matter of color and physical and racial characteristics" but a broader problem that "cut across lines of color and physique and belief and status and was a matter of cultural patterns, perverted teaching and human hate and prejudice, which reached all sorts of people and caused endless evil to all men" (472). Du Bois offers an added diagnosis of twentieth century problems rooted in what Césaire identifies as the chief fruits of colonialism, atrocity. ${ }^{27}$ For both thinkers, atrocity looms large as a central axis in which the twentieth century revolves around. What Du Bois points the way to is a promising path through atrocity and its fruits, not only mass death but very simply evil.

Atrocity's local and global forms within colonialism allow it encapsulate specific colonial practices and broader systemic ends. Furthermore, the term's historically contingent and theoretically malleable properties make it a comprehensive mode for engaging with colonial cultural productions. Like "genocide," "atrocity" is a distinctly contemporary term linked to international law and the nation-state. A clear difference between genocide and atrocity is the former's explicitly planned and knowingly perpetrated character. ${ }^{28}$ The two remain linked by the collateral damage - equally cultural and corporeal - left in the wake of such incomprehensible 
evil. Atrocity's various definitions highlight this connection with the incomprehensible: "Savage enormity," "An atrocious deed," or "an act of extreme cruelty and heinousness" ("atrocity"). Atrocity's horrors further link various events such as the Famine, the Jamaican Rebellion, and the Indian Rebellion within broader colonial paradigms. Philosopher and social critic Achille Mbembe demonstrates the local and the global in his account of various African atrocities:

More precisely, it is the current face of arbitrariness in its comedy and stark horror, a real shadow that, while totally devoid of beauty, does not lack clarity; not just any arbitrariness, but arbitrariness as human and contingent violence with the distinctive feature of committing acts of destruction that, in their starkness, scale, and 'knock-out' effects, have the peculiar characteristic of concealing human suffering, burying it in an infinite circle, so to speak, everywhere. (On the Postcolony 13)

Mbembe insightfully notes that within atrocity's "stark horror" lies a "clarity" that glimpses "human suffering." This thread privileges the human subject in the midst of "destructi[ve]" and horror-inducing acts of atrocity yet arguably the greatest horror is the way such "acts of destruction" not only deform and destroy life and culture, but in doing so "concea[1]" these very acts. Mbembe ends upon an "everywhere" that speaks to the way colonial atrocity in its global breadth and repetition serves to bury culpability and collateral damage by "burying it in an infinite circle" that renders forgettable what is often unfathomable. In this vicious "circle," narrative retellings of atrocity too often exasperate the obfuscating ramifications of atoricty through a largely apolitical dichotomy in which "Either one counts the cadavers or one tells the story of the victims" (Ricoeur Time and Narrative 188). 
Too many narrative accounts of atrocity are grounded on an amnesiac subtext whose regressive response lists into a solely victimizing discourse. Beyond just consigning victims into euphemistic obscurity, this dichotomy readily fosters an ideological narrowing that privileges what Edward Said calls the "murderous essentializations" of a "European apocalypse" that becomes the "only history, the only fate, the only culture and transgression worth thinking about" (Musical Elaborations 51-52). Said does not explicitly reference atrocity yet an implicit dismissal of atrocity is part of the danger in decrying "European apocalypse[s]" as the "only history" which effectively consigns autonomy, agency, and alternative solely within a Eurocentric appraisal of history and culture. The event foregrounds alternative as the starting point or the "possibility of intervention" (Badiou Being 209). Events are only ever "retroactively given meaning" and this further accords with atrocity's legacies, which are only comprehensible ex post facto (203). This retroactive possibility offers a viable alternative that is not simply a shift in choices but a more fundamental "upsurge of a new present, and not in that of productive continuity" (203; Logics of Worlds 480). An evental "upsurge" defies "continuity" and is fundamentally antithetical to the Eurocentric implications Said cautions against. Furthermore, atrocities underscore a central paradox in power relations, even those most dramatically polarized between the oppressive state and obliterated subject, that postcolonial critic Eóin Flannery identifies, "the exercise of power is intimate with the experience of powerlessness" (126). Flannery's insight is equally logical and political, equally a conceptual and historical proposition that historian Partha Chatterjee further echoes in asserting, "Dominance ... cannot exhaust the claims to subjectivity, for even the dominated must always retain an aspect of autonomy. Otherwise, power would cease to be a relation; it would no longer be constituted by 
struggle" (137). In the relations between power and autonomy we can clearly see the necessary place atrocity occupies in illuminating state machinations but also crucially disrupting them.

Atrocity's greatest paradox is its potential as a site for transformation despite the unfathomable violence, destructive aftermath, and attempted suppression of the subject. Even British colonial administrators hinted at this enduring element of atrocity. George Nathaniel, Marquess Curzon (1859-1925), former Viceroy of India, gestured towards an enduring legacy of imperialism that bound colonizer and colonized together as he explained the Empire's global impact, "It is part of us. It is our bone and flesh of our flesh. We cannot get away from it. We cannot deny our own progeny. We cannot disown our own handiwork. The voyage which our predecessors commenced we have to continue. We have to answer our helm, and it is an Imperial helm, down all the tides of Time" (318). Curzon's initial embodied focal point - "our bone and flesh of our flesh" - recasts colonialism from faulty to familial: "our own progeny." Curzon links an idealized "Imperial" mandate to the unbroken rolling of "Time" that defies any way to dispute or disavow England's "handiwork" as easily laid aside. The empire as embodied in both center and periphery provides the suture that Césaire will later flesh out more fully around the concept of atrocity and that is the "truth ... that this policy [colonialism] cannot but bring about the ruin of Europe itself, and that Europe, if it is not careful, will perish from the void it has created around itself' (57). Curzon's embodied emphasis provides a key path into Césaire's conceptual "void." Significantly, Césaire's language is highly suggestive of the event and its connections to Being, a more forceful and promising void. These connected strands of bodies and Being implicit in Curzon and explicit in Césaire - underscore the breadth and depth of atrocity's abyssal force as it deforms imperial claims to progress, civilization, and the subject. The corrosiveness of colonialism, which afflicts both colonizer and colonized, further marks the 
potential inherent within the link between bodies and Being, namely the evental subject. This link informs the evental subject's own form as an "operative disposition of the traces of the event and of what they deploy in the world" (Logics of Worlds 33). The evental subject as "traces" "deploy[ed] [with]in the world" functions particularly well in the tangential aftermath of atrocity and it further brings into the world a subjective form that defies prefabricated bodies and subjects. The evental subject is thus a "militant figure" whose activity defies the general subjective dichotomy between a res extensa (object of a situation) or a cognitively-centered res cogitans (2). Conceived outside this dichotomy, the evental subject highlights human life as the "unaccountable infinity" that transgresses a given situation yet the evental subject's transgression is far different, indeed antithetical to imperial power as Badiou lauds a powerful alternative precisely through "subjective weakness" (Saint Paul 10, 54). The twin pillars for thinking the evental subject, "infinity" and "subjective weakness," reinforce a central and enduring paradox that is aptly applied to atrocity. After all, atrocity's destruction and disempowerment is a specific instantiation of the wider helplessness and unbridled power that colonialism and modernity project.

Atrocity, like colonialism and modernity, seems to operate at a remove from subject-level interactions in such a way that precludes or at best problematizes intervention. That atrocity and colonialism are grounded on power relations supports their inherent disempowering auras, but so too modernity's ostensibly inexorable progress echoes similarly. ${ }^{29}$ Returning to Seeley's historical reflections on the British Empire clarifies this remove, especially in his comments on progress as a specter, "history ... [is] haunted by the idea of development, of progress," and the central role spectral progress plays in structuring relations between subject and state, "individuals are important in history in proportion, not to their intrinsic merit, but to their 
relation to the State" $(9,11)$. Modernity generally and colonialism specifically, especially as the latter derives out of the former, are clearly haunted by progress and this spectral relation parallels the similarly spectral relations between subject and state. In this sense, the subject itself becomes ever more spectrally removed as it fails to accord with the state. Atrocity brutally reifies this spectrality in its concentrated destruction of subjects. Atrocity also casts into sharp relief progress as too often a euphemism for “evil," especially in Ricouer's sense-echoing others_ of the term as "always doing wrong to another, making another suffer, whether directly or indirectly" (Evil 37). Ricoeur's initial definition of evil emphasizes its active and far-reaching qualities. Consequently, he further notes the "relational - dialogical - structure" of any "evil committed by one [and] replicated in the evil undergone by another; it is at this major interface that the cry of lament is most bitter, when one person feels himself the victim of another's wickedness.” By foregrounding action and subject, Ricoeur conceptualizes an objective approach to a particularly subjective experience that further highlights evil as both intimate praxis and expansive network. Evil's relational and dialogical frameworks equally highlight praxis and network, which not only frames atrocity in manageable ways but also the wider twentieth century and its particularly pervasive "monstrous violence" and the "banality of evil" (Kristeva 138; Arendt Eichmann). In this "totalitarian century" atrocity is particularly apt for rethinking those historical grounds that are so often "brought to light with exhumation" (Badiou The Century 2; Crossland 243). Even more incisively, atrocity clarifies the fruits of evil—-"terror, betrayal, disaster"-which an "ethics of truths - as opposed to the impotent morality of human rights - tries to ward off, in the singularity of its reliance on a truth in progress" (Badiou Ethics 71). Atrocity as spectacle foregrounds the violence, terror, and death that so often overwhelm comprehension yet it is precisely this spectacular framework and its deep connections with truth 
that situate atrocity as a particularly resonant place for realizing viable alternatives. At its most basic level because there is truth there is also evil since the latter's "form of multiple-being" ultimately "arises as the (possible) effect of the Good itself. That is to say: it is only because there are truths, and only to the extent that there are subjects of those truths, that there is Evil" (61). Evil's presence in the world, far from denying truth, underscores truth's essentiality and acuity. Truth is the event's central ramification and the means for a transformative present. Securing a deep and lasting transformation, then, is formulated in the fraught passage that can educe "Good" out of "Evil."

What atrocity's victimizing legacies and degrading disempowerment obscure is the transformative latency of truth and evental subjects. Seeing this latency within atrocity can take the form of Gary White Deer's (a contemporary Choctaw artist and activist based in County Donegal, Ireland) reflection on the Famine as a "sacred memory" (qtd. in Kinealy "Great Irish Famine" 251). Calling the Famine a "sacred memory" literally penetrates atrocity's violent and evil contexts in order to elucidate an alternative, one that is historically and presently visible in White Deer himself who represents the Oklahoma Choctaw Nation's donation to Ireland of $\$ 170$ in 1847. Ireland's "sacred memory" is an authentically radical departure from established norms, particularly an imperial/colonial binary that generally reinforces colonial atrocity's ostensibly limitless depths. Conceptually, White Deer's revision and the colonial binary paradigm illustrate a key tension between the subject and community that Stephen Toulmin sees as conceptual, "Each of us thinks his own thoughts: our concepts we share with our fellowmen" (35-italics his). Toulmin's dichotomy provides a necessary distinction for thinking through atrocity's ramifications, particularly in the usually subjective, i.e. individualistic, foci of victim discourse against the far more empowering conceptual contexts of a "sacred memory" that recognizes 
personal dignity and communal connections that link the living and the dead. Furthermore, victim discourse operates through tropes of shame, lack, and deprivation that offer a false empowerment which may address grievances but does little to address broader historical and social forms that undergird these grievances. ${ }^{30}$ The event not only offers a radical intervention in these historical and social forms, but this particular evental intervention through atrocity also promises an incisive deformation of atrocity's legacies, namely "the creation of new singularities of Evil" (Badiou Ethics 64). The event's universality and atrocity's evil singularity allow us to rethink atrocity as a central modality in postcolonial studies. Universality and singularity ensure that cultural, temporal, and social distinctions are preserved while simultaneously providing a broad paradigm for engaging colonialism on a global horizon, and by extension effectively conceptualizing egalitarian approaches to subject and state.

\section{Modernity's Lost Object}

Atrocity's place in postcolonial studies as a "lost object" similarly plays a central role in thinking about the grounds and parameters of modernity in its historical, literary, and cultural ramifications. Luke Gibbons insightfully situates modernity at the heart of an postcolonial experience in what he terms "the shock of modernity" and its forcible impact: "Irish culture experienced modernity before its time. This is not unique to Ireland, but is the common inheritance of cultures subjected to the depredations of colonialism" (Transformations 6). Whereas this "shock" is vivid, it is hardly always visible even among contemporary criticism of modernity and modernism. Seemingly unconnected, historian J.J. Lee's criticism of Famine historiography focuses on its assumed historical knowledge, "Discussion about whether the Famine constituted a watershed often seems to take for granted that we know what happened during the Famine. We don't'" (qtd. in Gkotzaridis 193). Lee's criticism specifically addresses 
the historian's focus on eyewitness and related records of the Famine yet in doing so he reinforces the paradox art historian David Brett identifies in the Famine's "remarkably understudied" contexts in terms of its "index[ing] of ... appalling nature, and the difficulties involved in representing it" (36). Without dismissing some necessary critical pressure on eyewitness and piecemeal histories, Brett's figuring of the Famine's “appalling[ly]" difficult representational contexts gestures towards the wider invisibility and difficulty involved in historicizing or even conceptualizing atrocity. Likewise, Gibbons' colonial shock of modernity reinforces a particularly Irish grappling with these facets that is equally the forced conflict of widely divergent colonial contexts like the transatlantic "slave trade," which is characterized by Achille Mbembe as "ha[ving] ramifications that remain unknown to us; to a large extent, the trade was the event through which Africa was born to modernity" (On the Postcolony 13). ${ }^{31}$ What becomes clear in this often conflicted and uneven historical terrain is how modernity as process within colonies contributes to modernity as product in atrocities. Ultimately, this interaction also gestures towards the way colonial forms took shape and prefigure later aesthetic and metropolitan configurations that are seen as sui generis and termed "modernism."

Seeing modernism without a clear colonial antecedent further reinforces a too often preconceived and in fact abstractly realized account of modernity's relations to culture and the subject. Marshall Berman's account of "be[ing] modern" is seen as the condition of being "in an environment that promises us adventure, power, joy, growth, transformation of ourselves and the world - and, at the same time, that threatens to destroy everything we have, everything we know, everything we are" (15). This affirmation of "power" and "joy" is also a universal condition, in fact the condition of "Modern environments and experiences [that] cut across all boundaries of geography and ethnicity, of class and nationality, of religion and ideology: in this sense, 
modernity can be said to unite all mankind." Berman's links between "adventure, power, joy, growth, transformation" and the threat of "destr[uction]" to subject and world allude silently to colonial contexts even as his own study and many others explicitly ignore it. ${ }^{32}$ Berman's own modern contexts reflect the relations between colonial and metropolitan frameworks as highlighted in Joseph Conrad's (1857-1924) Heart of Darkness (1899) through his narrator, Marlow, who reflects on his childlike "passion for maps" and "the glories of exploration" that lead one into the "many blank spaces on the earth" (8) that are then populated with brutalities, " The conquest of the earth, which mostly means the taking it away from those who have a different complexion or slightly flatter noses than ourselves, is not a pretty thing when you look into it too much"' (21). "Modernity," as Mbembe reaffirms, is at "the origin of multiple concepts of sovereignty — and therefore of the biopolitical" and it is precisely the all-too-often abstracted "biopolitical" that is occluded until one "look[s] into it too much" ("Necropolitics" 13). Atrocity foregrounds the biopolitical, which further emphasizes the material ramifications of modernity's technological, ideological, cultural, or social forms. ${ }^{33}$ This ensures a far deeper engagement with a potentially abstracted representational field, one Simon Gikandi sees as the metropolitancentric forces that "need to minimize the role of the Other in the emergence of modernism as a style" ("Picasso, Africa" 468). This need reflects an "aesthetic ideology" which profoundly "desire[s] to encounter the Other in its ugliness and terror and then purify it" in order to enrich and maintain a putatively "symmetrical economy" (471). Gikandi's "symmetrical economy" frames the broad modernism discourse that was glimpsed in particular ways in modern Irish beginning with the Act of Union (1800), which Terry Eagleton reads as "a metropolitan narrative was overlaid on a colonial one, to produce a radically undecidable text" (132). 
Atrocity importantly holds together the radically material — the violent annihilation of human subjects—and the equally undecidable - the representation of such annihilation. In terms of the Famine, historian Cormac Ó Gráda identifies both aspects in the overwhelmingly oral nature of atrocity history and its undecidable representation within the "porosity of memory" that further lends itself in part, but also apart from, the "civilizing process" that continues to sanitize history into the contemporary period (Famine 39, 45). In linking "porosity" and "process," the Famine's historical legacies mirror those of the later Holocaust in terms of memory, specifically in how Henri Raczymow delineates "a memory devoid of memory, without content, beyond exile, beyond the forgotten" (100). Within British literature and culture, the Famine's "memory devoid of memory" delineates the way an Gorta Mór (Great Hunger) has been diffusively sanitized through "hunger" in modern culture and literature. Hunger is perhaps surprisingly significant in modernist literature, not the least as the titular focus of Knut Hamsun's Hunger (1890), arguably the first definitively modernist novel. Hamsun's hunger is predominantly psychological and symbolic, even as the novel does touch upon material poverty and deprivation, and so anticipates the clear privileging of hunger as a solely psychological and sexual sign exemplified in Sigmund Freud's work. In Three Contributions to the Theory of Sex (1905), Freud early focuses on "the fact of sexual need in man and animal [a]s expressed in biology by the assumption of a 'sexual impulse"” that analogically subsumes hunger into a psychological and largely symbolic aspect of "this impulse[, which] is made analogous to the impulse of taking nourishment, and to hunger" (1). Freud's psychologizing hierarchy is further clarified by the "picture" of these "impulse[s]" in the "satiated child sink[ing] back from the mother's breast, and fall[ing] asleep with reddened cheeks and a blissful smile" and thus forming a "picture ... typical of the expression of sexual gratification in later life." (44). Freud's analogical transformation of 
hunger into sexual needs presages the wider allusive and largely symbolic ways hunger functions in a large swathe of modernist literature. ${ }^{34}$ Ezra Pound's loose translation of an Anglo-Saxon poem The Seafarer (1911), for example, symbolizes the seafaring protagonists' "mood" through "hunger": "Chill its chains are; chafing sighs / Hew my heart round and hunger begot / Mereweary mood" (Poems 11. 10-12). Pound's archaic verse is a fittingly anachronistic positing of "hunger begot" into a psychological remove that Ashis Nandy so powerfully presents as the "reactive, rootless search for meaning in total control, order and predictability" (Edge of Psychology 104). ${ }^{35}$ Seeing Nandy's critique in terms of psychological and modernist engagements with hunger leads us to Franz Kafka's apt, albeit perhaps unintentional, depiction of the fatal finale of "The Hunger Artist" (1922) who expires in his cage: “Well, clear this out now! said the overseer, and they buried the hunger artist, straw and all. Into the cage they put a young panther" (231-232).

As opposed to analogizing hunger for purposes of control and order, we can find a paradoxically more attuned power in disorder and weakness. Atrocity is particularly a site of gross disorder and weakness yet one that is also crucially and forcibly material. Albert Camus' (1913-1960) The Plague, for all its existential questions, remains rooted against the kinds of slippery analogies and metaphors atrocity might lend itself to: "And since a dead man has no substance unless one has actually seen him dead, a hundred million corpses broadcast through history are no more than a puff of smoke in the imagination" (38). Camus provides the central pitfall to psychologizing hunger, namely the shifting of event and subject into "the imagination" where both can waft and dissipate in "a puff of smoke." In spite of the power of culturally or symbolically reading modernity, the modernist concept of hunger from Hamsun to Freud and beyond ends up too often effacing the visceral realities of colonial subjects subjected to hunger. 
A modernist text that differs sharply from this symbolic hunger is Pádraic Ó Conaire's Exile (1910), the first modernist text in Irish. Ó Conaire's novel relates the journey of the crippled Irishman Micil O'Maolain to London, his survival, and ultimate death. Although hunger resonates in multiple ways- -I was hungry that night, with a hunger that was not only of the body, but of the heart and mind and soul"-Ó Conaire consistently foregrounds its corporeal primacy: "pangs of hunger [that] ... recede as death was coming closer, until intoxication, then madness, would come over you" and its pervasively signifying effects upon his body_-"looking at my emaciated face, at my long skinny fingers, and at the swollen blue veins in my hands, my forehead and my neck" - and his mind - "nothing is coming except gloomy thoughts, dark gloomy thoughts, and the delirium of hunger..." $(81,21,102,150)$. Exile's Irish-language form situates it clearly in a colonial modernist context, just as its viscerally corporeal relation of hunger encompasses both material and symbolic traces of hunger while privileging the former. This privileging is central to reading modernism's colonial contexts since in so many crucial and "materia[1]" ways, "modernity is fundamentally linked to European cultural, social and economic context[s] in which it was produced" (Acheraïou Rethinking Postcolonialism 119). These material bases further cast into relief the "inherent narrativity of historical representation" and the critical necessity Eóin Flannery sees in clarifying the tensions inherent to a representational matrix that intimately links history, literature, and society (24). For postcolonial Ireland, the Famine looms largest in configuring this matrix and the single most pervasive sign of the Famine, according to Eavan Boland, is a "deeper silence: a human one ... A silence in which stories were not told, in which memories were not handed on, in which the ordinary sorrow and devastation of a people was neither named nor recorded" (Irish Hunger 221). 
The Famine's "deeper silence" ultimately afflicts both representational and subjective forms, and this silence further evokes the Famine's paradoxical absences as particularly apt places for presence. Atrocity broadly maps this paradoxical presence as it registers differently in metropolitan and colonial approaches to atrocities like the Famine. T.S. Eliot glosses both approaches in his memorable phrase from The Waste Land, "These fragments I have shored against my ruins" (1. 430). Whereas a metropolitan-based aesthetic looks at these "ruins" as varied possibilities for appropriating and creating cultural renewal out of decadence, the colonial context inevitably sees these "ruins" as the immediate, in fact singular possibility or barest act of cultural survival and representation in the wake of overwhelming violence. Eliot's colonial "ruins" then are the starkly silent remainders that delineate, both culturally and corporeally, modernity's dead ends, which Theodor Adorno's reflections on modernity and novelty, perhaps unknowingly, assert in casting the "new [a]s akin to death" and naturally marked by violence: "Scars of damage and disruption are the modern's seal of authenticity" (21, 23). In Adorno's visceral imagery the divergent cultural productions of metropolis and colony are cast into relief in novelty's aesthetic relations with death and modernity's authenticity as historically grounded in scars. ${ }^{36}$ Although this latter dichotomy may not always be clear within the writings of various modernists, a clearly self-conscious vein of self-criticism was clear and clearly evoked in Ezra Pound's dictum, "Make it new"- a self-conscious recasting of modernist aesthetics from ancient Chinese anecdotes — which underscored modernism's ontological DNA. ${ }^{37}$ With similar selfconsciousness, Virginia Woolf asserted modernism's historically novel origins with marked specificity in her essay "Character in Fiction" (1924): "on or about December 1910 human character changed ... The change was not sudden and definite like that. But a change there was, nevertheless" (421). These novel impulses persist into modernism's ostensible languishing in the 
1930s as T.S. Eliot significantly begins his essay "The Function of Criticism" (1933), "From time to time, every hundred years or so, it is desirable that some critic shall appear to review the past of literature, and set the poets and the poems in a new order. This task is not one of revolution, but of readjustment" (Selected Prose 17). Eliot tempers this "task" as a "readjustment" rather than a "revolution" yet what remains prominent is an emphatically profound revision to criticism's utility so that "errors ... of a different kind from the last [generation's]" may be subjected to "the greater amount of correction [a]s possible" (18). In each of these examples, Pound, Woolf, and Eliot self-critically assert novelty while also reframing. Implicit in each critical formulation is novelty or radical rupture as ultimately an inconsistent façade.

\section{Colonial Forms and Hollow Men}

Atrocity's radical ruptures position the colony as the place where revolutionary novelty and formal expression is possible. Both have resonances in the event, but form is particularly central to thinking the event and unfortunately largely forgotten in postcolonial thinking. ${ }^{38}$ "Artistic events are great mutations that almost always bear on the question of what counts, or doesn't count, as form" and it is equally important to recognize the depths to which aesthetic form literally formulates the way one thinks about the event's "active logical form," the subject (Badiou Philosophy and Event 68; Being and Event 63). Form and subject constitute the event's most granular transformations regardless of a given event's historical, social, or cultural particularities. These undifferentiated formal "mutations" further privilege the event and its particularities as the source of formal innovation rather than a specific writer, their tradition, or their social position. This framework extends to thinking colonial encounters between metropolitan and colonial not as "two distinct worlds facing each other" but rather, as Declan 
Kiberd emphasizes, "social worlds which are part of one another, though differently constituted" (Inventing Ireland 343-344). A “differently constituted" world unites metropolitan and colonial within a formal trajectory whose connections promise much for postcolonial theory. Too many of postcolonial theory's methodologies are "generally insensitive to questions of form," particularly, as Bart Moore-Gilbert points out, "the way form complicates the ostensible thematic meanings of literary versions of colonial discourse" (“"Bhabhal of Tongues”" 112). Form not only shifts the thematic and social terrains of colonial literature, but it also profoundly recontextualizes these themes and social tensions both through what is present and what is also absent. This formal and thematic tension underscores the importance not of the specific writer or artist, but rather the work and its connections to related and unrelated works.

The event's primacy and its relation to form help us see continuities between literary and non-literary works on atrocity. In terms of Irish writing on the Famine, John Mitchel (18151875) wrote explicitly and often on the Famine yet it is arguably Pádraic H.Pearse (1879-1916) who offers a particularly compelling, evental account of the Famine. Pearse's writings on the Famine are more allusive and tangential, which fits atrocity's layered and contrasting contours. ${ }^{39}$ Such a perspective is intensely postcolonial in grappling with atrocity's ramifications within the wider frameworks of modernity's shocks. After Pearse founded the bilingual St. Enda's School (Scoil Éanna), he wrote an educational treatise, "The Murder Machine” (1912), in which he claims, "What the modern world wants more than anything else, what Ireland wants beyond all other modern countries, is a new birth of the heroic spirit" (38). Shortly preceding this quote is an earlier subsection in the essay titled "Against Modernism." Pearse's "heroic spirit" is ultimately an anti-modernist force that recognizes a colonial desire for tradition and pre-colonial forms yet also situates this desire in a crucial self-consciousness that rejects the individuated 
"progress" of ideologically-charged reflections on modernism or imperialism. Neither a utopian impossibility nor traditionalist shibboleth, Pearse's "heroic spirit" and its "new birth" gesture towards a unitive colonial populace that transcends binary divisions. In a later essay, "The Psychology of a Volunteer" (1914), he explicitly disavows the divisions central to both imperial and colonial thinking, "I challenge again the Irish psychology of the man who sets up the Gael and the Palesman as opposing forces, with conflicting outlooks. We are all Irish" (105). Out of this rejection and asserted unity is the potential to forge a viable and revolutionary novelty: "All such memories, old and new, are part of Irish history, and he who would segregate Irish history and Irish men into two sections - Irish speaking and English speaking —is not helping toward achieving Ireland a Nation" (106). Contrary to potential assumptions, Pearse's emphatic unity as the initial step towards a postcolonial Ireland is essential and further detailed in "The Sovereign People" (1916), an essay that focuses on delineating those "repositories of the Irish tradition," including "stubborn physical resistance to England," rooted in the "great, splendid, faithful, common people - that dumb multitudinous throng which sorrowed during the penal night, which bled in '98, which starved in the Famine; and which is here still—what is left of it—unbought and unterrified" (345). Pearse explicitly links Irish tradition to the Famine while also framing these ideas in terms of "common people" rather than intelligentsia. "The Spiritual Nation" (1916) further delineates the contexts that support a lasting "true political independence" that fosters both "spiritual and intellectual independence" as the bulwark against any "unstable" regression of revolutionary agitation that "rest[s] merely on interests which change with time and circumstance" (299).

When thinking about the "common people" of postcolonial Ireland, W.B. Yeats likely does not come to mind yet his own reflections on the Famine and colonialism are akin to 
Pearse's. That they represent vastly different revolutionary temperaments and actions attests not to an incompatibility of revolutionary ideals, but rather the way a heroic colonial spirit informs widely divergent writers and texts. Yeats' review of Lionel Johnson's poetry in “Three Irish Poets" (1897) evokes strikingly similar language to Pearse on the issue of colonial legacies and transcendence: "IT is hardly an exaggeration to say that the spiritual history of the world has been the history of conquered races" (Uncollected Prose 70). Like Pearse, Yeats not only privileges colonial history as the history, but then further characterizes this as a "spiritual history." If a colonial inheritance of the "conquered races," able to access something crucial beyond the pale of victory and hegemony, is implicit here then Yeats explicitly clarifies this colonial context a year later in "Mr. Lionel Johnson and Certain Irish Poets" (1898). Yeats draws a distinction between "contemporary Irish poets" like Johnson whose poetry manifests "a singular fervour of belief ... in a spiritual life" and "contemporary English poets" who variously focus on the "glory," "order," or "passion of the world" (116). Also like Pearse, Yeats' "The Literary Movement in Ireland" (1899) is a wide-ranging lecture on Irish literature, culture, and history that touches upon "the years before the great famine" and extends its trajectory from Ireland's "old energies" to a renewed Ireland "rising up amid the wreck of the old kind" (185). This trajectory is clearly a colonial one in which Ireland and England clash, "Contemporary English literature takes delight in praising England and her Empire, the master-work and dream of the middle class ... [while] utter[ing] the ideals of the strong and wealthy. Irish intellect has always been preoccupied with the weak and with the poor" (187). This contrast locates Ireland's renewal paradoxically not in "strong" nor "wealthy" subjects but in an "Irish intellect" that focuses on the "weak" and the "poor." 
The Famine is a peripheral yet persistent presence in the writings of Pearse and Yeats that reflects the equally peripheral yet persistent presence of weak and impoverished subjects within the colony. Whether in terms of the Famine or the famished subject, we can see a clear albeit largely subterranean strain of resistance that becomes amplified through the event. The primary ramification of the event, "truth[,] is the work that takes place near the being of a vanished event of which the name alone remains" (Badiou Handbook 26). This "vanish[ing]" is the ephemeral touchstone where truth manifests. Furthermore, atrocities particularly evoke the vanishing "of which the name alone remains" in their elastic denominations. Whether the Famine, variously termed the Irish Potato Famine, the Great Famine, an Gorta Mór (Great Hunger), or an DrochShaol (the Bad Times), or the Indian "Mutiny," itself denominated variously as India's First War of Independence, the Indian Rebellion, the Great Rebellion, and Sepoy Mutiny, among others, atrocity events are constantly renamed. This gestures towards the contested nature of these events in ways that particularly evoke the event in what literary critic Daniel T. O'Hara termsthrough Badiou - "revisionary naming" or the practice of uncovering and denominating those excluded (163). Uncovering and naming the subject is one key ramification of the shifting denominations that atrocity begets. It also further accords with the evental subject as one that is essentially invisible, specifically in its antithetical formulation outside of ideological binaries and frameworks. Modernity further frames this kind of invisibility in particular ways according to economist Samir Amin's definition of modernity as the moment in which "human beings, individually and collectively, can and must make their own history" (13). Modernity's selfpossession and empowerment constitute the core of imperialism's progressive foundations. These foundations are built upon invisibility, which is particularly marked in literary constructions of "Empire as blank space or mystery" that "offer[s,]" according to Elleke 
Boehmer, "strategies of silence and sudden metamorphosis, which helped to end a plot, or resolved problems by erasing them" (Colonial and Postcolonial 28-29). The narrative foci of these strategies is writ large in the conceptual "mapping of the new imperial world system" that Fredric Jameson identifies as grounded upon the "impossible, since the colonized other who is its essential other component or opposite number has become invisible" (50). Aesthetic impossibility takes literal shape in "infinity ... [or] grey placelessness ... It is Empire which stretches the roads out to infinity ... [and] tak[es] on new forms" (57). Jameson cites E.M. Forster's Howards End (1910) as an exemplar of this "placelessness" but in Jacob's Room (1922) Virginia Woolf offers a specifically Irish colonial exemplar. Twice, the novel's titular protagonist, Jacob, explicitly reflects on Ireland, Home Rule, and Empire: "He was certainly thinking about Home Rule in Ireland — a very difficult matter. A very cold night" and "But then there was the British Empire which was beginning to puzzle him; nor was he altogether in favour of giving Home Rule to Ireland. What did the Daily Mail say about this?" $(78,111)$. Each passage ends with a large blank space that separates the text from the following paragraph and thus Woolf's typography creates a literal blank placelessness around "Ireland." An obliquely placeless Ireland is then elaborated throughout the wider text by its spectral presence, which accentuates a later reflection on modernity generally that Woolf relates in "Modern Fiction" (1925), a revision of an earlier essay "Modern Novels," as the freedom the "moderns" derive from delving "in[to] the dark places of psychology" that house "something hitherto ignored; at once a different outline of form becomes necessary, difficult for us to grasp, incomprehensible to our predecessors" (“Modern Fiction” 215-216).

The "hitherto ignored" and "incomprehensible" colonies, cast into sharp relief through atrocity, allusively register throughout a wide selection of modernist works. Whereas Jacob's 
Room literally leaves an ambiguous space for Ireland in the novel, other modernist texts delineate a far more dismissive and corrosively bereft place for colonial Ireland and Irish subjects. H. Rider Haggard's She (1887) is an early exemplar of this as the novel includes a strikingly solitary allusion to the Irish, particularly as the narrative is set in the heart of a mythical African kingdom and populated solely with British, quasi-Greek, and African subjects, as well as a white goddess. Nevertheless, Horace Holly, the narrator, is approaching "She" in the wake of a cowering African priest, who spontaneously brings Ireland into the text as Holly reflects, "It is so absurd to advance into the presence of savage royalty after the fashion of an Irishman driving a pig to market, for that is what we looked like, and the idea nearly made me burst out laughing then and there" (163). Haggard's brief and unaccountable reference to the Irish reinforces the peripheral yet persistent currency of Irish colonialism in British literature and thought. ${ }^{40}$ Less random and equally resonant, D.H. Lawrence's Lady Chatterley's Lover (1928) depicts Michaelis, one of Connie's earliest sexual liaisons, as a simianized Stage Irishman, "He wrote smart society plays" before London society dismissed him as a "down-at-heel Dublin street-rat" (17) who "was ... anti-English, and to the class that made this discovery this was worse than the dirtiest crime. He was cut dead, and his corpse thrown into the refuse can" (18). ${ }^{41}$ Yet he is ultimately peripheral to the novel and easily forgotten, despite his striking corporeality_ - "the silent, enduring beauty of a carved ivory Negro mask, with his rather full eyes, and the strong queerly-arched brows, the immobile, compressed mouth"- that resonates with cross-colonial "timelessness which the Buddha aims at, and which Negroes express sometimes" (20-21). ${ }^{42}$ Michaelis' racialized depiction extends to his sexual relationship with Connie where he functions as "an outsider" with a "hard, erect passivity" $(25,27)$. Beyond the sexual entendre is a colonial one, a clearly "outsider" persona wrapped in a paradoxically "hard 
... passivity" that parallels the paradoxical colonial subject who possesses both infantile innocence and adult cunning.

In the tortured representation of colonial Ireland in British literature and culture we glimpse the various depths of Luke Dodd's metaphor, "The Famine was a black hole" (100). Although abyssal language is used by the colonizer to comment on the centripetal forces pulling down the "civilizing" mission and culture, there is also the paradoxical yet no less powerful centrifugal force of these colonial black holes. Thinking the Famine's forces on British literature and culture inverts the hierarchical paradigm of metropole and colony as an initial step to recognizing the deeper evental forces that invest colony, subject, and history with visible resistance. ${ }^{43}$ Ultimately it is the Famine's centripetal pull that consolidates the fleeting and often invisible Irish contexts in so many proto- and modernist texts. These random Irish flashes further expand the meanings of these texts in clearer colonial veins. In this context, Yeats' symbolic critique of capitalism's impact on modernity in "The Statues," which he casts as "this filthy modern tide" that laps at British literature and culture "And by its formless, spawning, fury wrecked" the realist frameworks of earlier representational fields, is further implicated in a colonial rip tide (Collected Poems 11. 29-30). Similarly, these small and potentially elusive allusions riddle the contexts of other modernist works and poems, particularly T.S. Eliot's. Eliot's poetry equally if also implicitly plumbs these colonial depths with a distinctly Irish inflection that recognizes the general sense of being "no longer at ease here, in the old dispensation" where "Signs are taken for wonders" "In a wilderness of mirrors" (Complete Poems "Journey of the Magi" 1. 41, "Gerontion" 11. 16, 65). ${ }^{44}$ This unease, equally perched between "wonders" and "wilderness," channels a distinctly colonial potential in the evocative phrase "In a wilderness of mirrors" that captures both a periphery—wilderness—out there yet a 
paradoxically intimate reflection of "mirrors." It is precisely this kind of construction between periphery and intimacy that gestures towards colonial frameworks redolent of the same ideas. Yeats" "filthy modern tide" is both surface and depth, allowing us to read the underlying currents in Eliot's wider poetry as indicative of modernist and colonial intersections. Eliot's poetry is a particularly fertile place for locating modernity's lost or effaced colonial objects because he is an aesthetic hinge between fin de siècle decadence and modernist developments. ${ }^{45}$ These currents suggest another context within The Waste Land's closing section, "What the Thunder Said," and its lines referencing the Biblical account of the road to Emmaus: "Who is the third who walks always beside you? / When I count, there are only you and I together" (11. 359-360). Like the early paradox of wilderness periphery and reflected intimacy, the shadowy figure who is "always" there yet never "there" elaborates the always shadowy place occupied by the colonial subject, particularly one in alignment with an evental subjectivity.

Modernism already operates within the essential local and global paradigm that the event foregrounds in its critical operations. A poem by Eliot is localized to his distinctive style, historical and contemporary reflections, and aesthetic choices, but it is also always under modernity's general auspices and universal shifts, whether technological, social, or cultural. Modernity's paradigm is an ideal staging area for the evental subject, which also operates according to the same local and global relations. These relations frame the artistic event's most transgressive qualities, what Badiou characterizes as an "artistic configuration" that "designate[s] the fact that works - not a single work, but a system - configure a new subjectivity" (Philosophy 70). These "artistic configuration[s]" are linked by the event, which provides the impetus for thinking very disparate artists and texts across any number of potentially temporal, cultural, national, or social divides. Badiou also gives special place to poetry in representing the event and 
in doing so he further explores the importance of the event's primacy rather than the artist's or text's: "A truth begins with a poem of the void, continues through the choice of continuing, and comes to an end only in the exhaustion of its own infinity. No one is its master, but everyone can come to be inscribed within it" (Handbook 56). Central to Badiou's reflection here is the literal trajectory of "truth" and then "poem," as well as truth's endpoint in the "exhaustion of its own infinity." Although the poem stages the truth, it does so only in granting it a material dispensation. Furthermore, the poem is written and thought by a specific person, but truth's primacy ensures that no "master" of truth exists and therefore "everyone" can be "inscribed" by its ramifications.

Of all Eliot's poetry, arguably his clearest representation of evental subjectivity is found in "The Hollow Men" (1925), a poem B.C. Southard considers "extraordinarily difficult" in part because "its language and imagery are disarmingly simple" yet its "highly allusive" connections radiate out "to [the] point of obscurity" (202). From a literary perspective, the poem's allusive complexity certainly derives from its residual reworking of cast-off elements from The Waste Land. From an evental perspective, the poem is a crystalline lens for highlighting Being and truth precisely because its "disarmingly simple" presentation of "the ordeal of absence and of the bare place" is the artistic event's aesthetic ideal (Badiou Handbook 48). Aesthetic texts often evoke the event in its greatest transparency through "absence" and "bare place[s]" as the thematic touchstones for engaging with "the infinite of language [a]s the powerlessness immanent to the poem's effect of power" (25). In other words, the event's most incisive move is its paradoxical expression of power and fullness in the most powerless and empty places. "The Hollow Men" like any number of poems bearing witness to events provides a key example of the power struggle between hegemony and novelty in global and local frameworks centering upon the 
subject. In its title and recurring allusions, Eliot's poem evokes a number of hollowed subjects, especially from Joseph Conrad's Heart of Darkness, where Kurtz is described as "hollow at the core" and Shakespeare's Julius Caesar with Brutus' reference to "hollow men" (59; IV.II.23). Shakespeare notwithstanding, Eliot's focus on "hollow men" shares with Conrad the premise that modernity inherently hollows out subjectivity, staging in microcosm the "immense panorama of futility and anarchy which is contemporary history" (“Ulysses, Order, Myth" 480). Eliot's view of history and modernity coincides with his allusions to Shakespeare and Conrad in posing clear connections with an aesthetic or historical web that the poem links to.

Allusion here reinforces a broader context for thinking about individual works, particularly those that touch upon the state and oppression. Without losing distinction or rigor, the event's universality works off of these broadest concepts like oppression and then localizes them with even greater critical edges. In essence, aesthetic and historical objects allow us to read an individual poem's artistic development, its historical situation, and its reactions to contemporaneous issues, of which the event offers an added layer in "teach[ing] us that the world does not present itself as a collection of objects" (Badiou Handbook 29). An overly objective view misses the nuanced links between Conradian reflections on Belgian atrocities in the Congo and those earlier touchstones in Famine-era Ireland. In this context, Conrad's as well as Eliot's later recursive hollowness become far deeper in the light of Famine-era accounts rife with hollowness, whether in the Freeman's Journal article that highlights Fr. McGuane's fear that the blight will "thin the people" or an article in Belfast's The Vindicator from 18 April 1846 that cast famished Irish subjects as "staring through hollow eyes as if they had just risen from their shrouds, cried out that they could no longer endure the extremity of their distress, and that they must take that food which they could not procure, and without which they could not live" (Ó 
Cathaoir 15, 60). Journalism links clearly with fiction in William Carleton's own circulation of this hollowness trope in his Famine-era novels that feature hollow iterations, whether The Black Prophet's repeated references to "hollow eyes" and "a frightful hollownesss ... [of] voice" or The Squanders of Castle Squander's later representation of Irish tenants whose "misery and destitution ... w[as] so frightfully and pitiably visible in their hollow, dull eyes and wasted features" $(133,262$; vol. II 91). Whereas this hollow trajectory may or may not originate out of the Famine, it remains a foundational aspect of atrocity and its hollowing affects in various colonial spaces. It is hollowness, we might say, that is forged out of the colonial crucible. ${ }^{46}$ Superficially, Eliot's iterative hollow men signifies the corrupt agents of hegemonic forces, whether the Conradian imperial state or the Shakespearian statist conspiracy. "The Hollow Men" opens with a repetition that underscores the hollowed complicity of both allusions: "We are the hollow men / We are the stuffed men / Leaning together" (Collected Poems 11. 1-3). The inclusive, repeated pronoun "We" links the two connected subjects, "hollow" and "stuffed" "men," as does the spatial linkage of the third line with both sets of men "Leaning together." Structurally, hegemony is the focal point and the stanza's final three lines reinforce this: "Violent souls, but only / As the hollow men / The stuffed men" (11. 16-18). Situated between these lines is a floating stanza that encapsulates the persistent evental subject poised within the "Violent" oppositions of hegemony and revolutionary. Set off from the other stanzas in part I, we are given a paradoxical subjective form: "Shape without form, shade without colour, / Paralysed force, gesture without motion;" (11. 11-12). You would be hard pressed to find a similarly clear conception of the singularly paradoxical form of the evental subject—fleetingly imagined — in these two lines' tangle of concepts. Far from elucidating a deadlocked subject, Eliot's 'Shape without form" gives shape to a radically unformed and disconnected subject capable of rejecting 
the polarities, whether hegemonic or revolutionary, that constitute the status quo. The force of Eliot's Conradian recomposition further aligns this "Paralysed force" with modernity's colonial sedimentation. Section IV's setting is particularly Conradian in its allusive construction of a colonial panorama. In Heart of Darkness, as Marlowe reaches the Congo for the first time, he glimpses a horrid landscape populated by colonial refuse, both objects and subjects (in an imperialist gaze): "Then I nearly fell into a very narrow ravine, almost no more than a scar in the hillside" (17). Within this "narrow ravine" marked by "dim light" Marlow sees a mass of death and suffering: "“They were dying slowly_it was very clear. They were not enemies, they were not criminals, they were nothing earthly now — nothing but black shadows of disease and starvation, lying confusedly in the greenish gloom." In his account, the scene presents "some picture of a massacre or a pestilence" that leaves him "horror-struck" (18). The emphatic clarity of Marlow's vision (“it was very clear) provides a clear colonial lens for plumbing the depths of Eliot's poetic lines. Section III's opening lines, "This is the dead land / This is the cactus land," inaugurates a fatal, exotic terrain that is more clearly consolidated in section IV's opening (Collected Poems 11. 39-40):

The eyes are not here

There are no eyes here

In this valley of dying stars

In this hollow valley (11. 52-55)

What “The Hollow Men" so exemplary gives representative space to is the evental subject and the event. Eliot's own allusions reinforce the colonial periphery of the poem through elusive images and language. Yet this elusiveness betrays a stark clarity. In presenting a paradoxical subject hollowed out by modernity and then connecting this subject to a similarly "hollow 
valley" we descend into an empty horizon. This can apply in many ways, but as "The Hollow Men" makes clear in the end, the world ends "Not with a bang but a whimper" (1. 98). In many ways, the "bang" is precisely what we expect from hegemony and the power of states. That "the way the worlds ends" is a whimper is far more indicative of the weak and seemingly discarded, who in spite of such weakness are capable of collating the discarded pieces of the world into a powerful and enduring new one (11. 95-97). 


\section{Chapter II. "Invisible Scribes": Marking the Subjectivated Body in Dracula}

"The famine and the landlords have actually created a new race in Ireland. I have seen on the streets of Galway crowds of creatures more debased than the yahoos of Swift - creatures having only a distant and hideous resemblance to human beings. Grey-haired old men, whose idiot faces had hardened into a settled leer of mendicancy, simeous and semi-human; and women filthier and more frightful than harpies ... shrieking for their prey, like monstrous and unclean animals .... I have seen these accursed sights, and they are burned into my mind forever"

Sir Charles Gavan Duffy, founding editor of The Nation newspaper, provides an account of Western Ireland during the Famine that is a veritable horror story. His 1 September 1849 article in The Nation sees Irishmen and women as little more than "distant and hideous resemblance[s] to human beings" whose "simeous and semi-human" countenances speak to the Famine's "creat[ion] [of] a new race in Ireland" (qtd. in Ryder 51). Duffy's account is further significant in a cross-colonial context, specifically in how it precedes and lends its echoes to a similar colonial nightmare delineated in Joseph Conrad's Heart of Darkness (1899). In this foundational modernist text, Conrad's narrator Marlow articulates colonialism's remarkably similar ramifications, whether in a West Irish thoroughfare or a West African Jungle. Marlow, upon reaching Africa, arrives at a place on the river where many Africans "were dying slowly it was very clear ... they were ... nothing but black shadows of disease and starvation, lying confusedly in the greenish gloom. Brought from all the recesses of the coast in all the legality of time contracts, lost in uncongenial surroundings, fed on unfamiliar food, they sickened, became inefficient, and were then allowed to crawl away and rest" (Conrad 31). He continues to detail the grotesque menagerie of "others ... scattered in every pose of contorted collapse, as in some picture of a massacre or a pestilence. While I stood horror-struck, one of these creatures rose to his hands and knees and went off on all-fours towards the river to drink" (32). Marlow's "picture of a massacre or a pestilence" echoes the same dehumanizing horrors of colonial subjects 
reduced to "black shadows of disease and starvation" that are central to Duffy's account of "filthier and more frightful" Irish "idiot[s]" and "harpies." In spite of temporal and oceanic divides we ultimately see the same colonial scene based upon colonialism's violence and creation of new subjects. Beyond the key similarities in representation and dehumanization, Duffy's mid-Victorian account and Conrad's early modernist novella lends a further formal trajectory to rethinking the colonial roots of "the first great modern novel in British literature," namely Dracula (Wicke 467). ${ }^{47}$

Stoker's epistolary novel has been a fixture in Western culture since its inception, but its critical importance was not seen until the 1970s. Dracula criticism has since predominantly focused on psychoanalytic and sexual readings that, according to Robert Mighall, too often read against the grain of Victorian sexological discourse, which would have seen the novel's "terrors deriv[ing] not from ... submerged erotic anxiety," but "the failure of the erotic and the sexological to contain and explain away the monstrous and the supernatural" $(67) .{ }^{48}$ In other words, the psychological and the sexual are not the origins of Dracula's horrors, but potential ramifications of a still undisclosed horror. ${ }^{49}$ Different critical interventions, often Marxist, have tried to explicitly or implicitly identify this horror through material emphases. ${ }^{50}$ Each of these varying approaches - economic, , political, cultural, or racial-further inform a broad colonial avenue of scholarship that recognizes, in Malcolm Brown's perceptive phrase, "some Dracula lurked hidden in Whitehall" (145). Christine Ferguson has mapped the general cultural context of these colonial readings as the "anxiety paradigm" in which varied conflicts across the British fin de siècle were distilled into "a particular fictional villain [who] signifies a dissonant threat to an established social order" (229). ${ }^{51}$ Within these Victorian anxieties, Stephen D. Arata has influentially posited a "reverse colonization" model in which Dracula represents the threat of the 
periphery colonizing the British center. His argument rests on Jonathan Harker's articulated fear, "I was helping to transfer [Dracula] to London, where, perhaps, for centuries to come he might, amongst its teeming millions, satiate his lust for blood, and create a new and ever-widening circle of semi-demons to batten on the helpless (Stoker Dracula 53-54). Not only does Harker's mental instability within Transylvania cast serious doubts upon this fear, but Arata's paradigm is problematized by Dracula's centuries-long occupation of Transylvania, whose countryside should logically be flooded by an "ever-widening circle of semi-demons," in which the East's "teeming millions" have been transformed into just three subjects. This rather toothless colonizer suggests a far different specter, which in the context of Dracula's Irish origins means that Stoker's novel, although depicting a spectral subject that haunts London, in fact emphasizes an even more horrific specter, namely the Famine. ${ }^{52}$

My contention is that Dracula's epistolary and subjective forms evoke the Famine as the grounds for precipitating a reconstituted Irish subjectivity and coincident British subjective dissolution. Within the trajectory of the Famine generally and colonial texts like Heart of Darkness specifically, Dracula occupies a key place as a proto-modernist text that utilizes established formal practices, primarily epistolary, within a colonial context that predates their later designation as modernist. Unlike prior epistolary novels, Dracula focuses on a colonial subject whose circulation within British letters equally unsettle British narratives and subjects. The novel's letters, newspaper accounts, and journals self-referentially construct a unifying British subjectivity, both within metropolitan England and without on the colonial periphery, that attempts to efface Dracula's transformations yet within these very self-referential assertions and inscriptions the vampire's invisible colonial body circulates, shadows, and ultimately dissolves any sense of narrative, subjective, or imperial mastery. ${ }^{53}$ This chapter begins with a discussion of 
Dracula's epistolarity and its connections with colonial writing, particularly in Edward Said's trope of the "invisible scribe." The novel writes large the limitations and problematics of imperial narrative and mastery as it attempts to collate discursive pieces around an absent colonial subject. Next I trace out the racial contexts of Ireland and Dracula as they coincide in representing an unsettling colonial subject who seemingly blends in so well yet remains so different. What Ireland and Dracula elucidate are additional cracks in the British colonial mindset. That Dracula's subjectivity is vexingly corporeal, vacillating between corpse and corpus equally, reinforces this Irish vampire as an exemplary evental subject and figure of truth. ${ }^{54}$ These latter ramifications are most clear in the subsequent section of the chapter. The broader formal ruptures that literally constitute Dracula are radically embodied in Dracula's subjective rupturing of Jonathan and Mina Harker and his total transformation of Lucy. This British subjective crisis is textually and historically linked to the Great Famine and extends far beyond a reverse colonization. As Dracula reaches its climax, Dracula further entangles the links between corpses and corpus as the novel and the vampire each unsettle and transform British word and body.

\section{Irish Letters: Colonial Scribes and Evental Forms}

Dracula's proto-modernist form situates it at the nexus of emerging literary modernisms whose varying formal experimentations in Ireland and Britain are framed by the Empire's specter. It is largely literary contexts that ultimately frame Dracula's ostensibly imperial contexts vis-à-vis related pro-empire texts like H. Rider Haggard's She: A History of Adventure (1887) and the novel's coincident formal connections to literary antecedents, such as Wilkie Collins' The Woman in White (1859) and The Moonstone (1868), and Joseph Sheridan Le Fanu's

Carmilla (1872) ${ }^{55}$ Many critics fail to navigate between these two poles, which are significant in 
how diametrically opposed Dracula ultimately is to both. ${ }^{56}$ Stoker's novel ultimately declaims the imperial certitude that "without deliberately fashioned narrative there is no history worth telling, no fiction worth entertaining, no authority worth consulting" (Said 165). ${ }^{57}$ It is formally a proto-modernist novel whose differences from Collins and Le Fanu are predicated upon its mediation of "the extreme subjectivity of the eighteenth-century epistolary novel with the objectivity of journalistic accounts" within a definitively colonial space (Senf Dracula: Between 20). ${ }^{58}$ This formal and imperial symbiosis catalyzes English modernism's general disavowal of monological narrative. Many Victorian bourgeois novels employ a monological narrator, which structurally deploys the British Empire's narrative purview whereby “the colonizer's aim [i]s to impose a monopoly on discourse" partly "through the prisms of inherited tropes: Utopia, or the lawless wilderness; the Noble Savage or the unregenerate Primitive; the Garden of Eden or the Holy City; and Britannica as regnant over all" and also through "interlinked symbolic codes ... creat[ing] a textual environment which, while interactive, was also self-repeating, and often selfenclosed" (Boehmer Colonial and Postcolonial 55, 44-45). Although imperial ideals, "the effort to graft on to the colonized environment their own hermeneutic structures constantly met with difficulty" since "there was no necessary consonance between colonial imported metaphors and the colonized land" (92). Dracula's Famine allusiveness secures its epistolary form within an anti-colonial dynamic whose structured voids dissolve British colonial and narrative impositions. Epistolary fiction, with its decentered and various narrative practices, becomes, in a colonial mode, inherently antithetical to colonialism's literary monopoly of "inherited tropes" and "selfrepeating" practices.

Dracula's subjective absences, whether racial, textual, or narrative, literally embody the epistolary novel's formal ramifications. ${ }^{59}$ Alain Badiou's definition of "the epistolary novel" as 
"the novel of what traverses absence" distills the narrative and subjective complexities of Dracula and Dracula in terms of the event, respectively (Logic of Worlds 367). Badiou's emphasis on "travers[ing] absence" echoes across "the epistolary mode['s]" "discontinuous narrative, self-referentiality, deconstruction of plot, character, and story, and defamiliarization of the distance between life and text" that generate "possibilities for contrapuntal and referential interplay between narrating act, physical text, and narrative content" (Gilroy 8; Altman 162). Ultimately, the epistolary mode's "object" is "neither self-expression ... nor dialog between sender and receiver, but rather the relays, delays, and purloinings which constantly postpone the scenarios of idealized communication situations" (Beebee 58). Epistolary form revises the relations between "narrati[on]" and "text" by conceptualizing "absence" as a pathway toward self-referential narrative deconstruction and defamiliarization, which opens radical possibilities in perspective, inscription, and representation. Since "the very discreteness of the letter as a building block makes it theoretically impossible for the letter to enter seamlessly into a continuous narrative," the epistolary mode is inherently resistant to colonialism's monological imperative (Altman 183). This formal divergence is also culturally coded. Modern British national identity or Britishness consolidates during the French Revolution, a historical event that saturated English literary markets with Revolution-era epistolary novels. ${ }^{60}$ Threatening French cultural and racial valences resulted in the epistolary mode becoming ideologically contaminated by "the residue of a revolutionary subjectivity premised upon self-authorizing discourse" that "render[s] the letter and its analogues ... effectively unreadable and ... immune from certain sorts of narrative discipline" (Nicola Watson 20). French Revolutionary discourse altered the English horizons of the epistolary novel and served as a national touchstone that Linda Colley visualizes as "Britons ... look[ing] through the Catholic glass darkly ... to see themselves more 
clearly" ("Britishness and Otherness" 319). English letters would now be plagued by French shadows, but unremarked in this cultural binary is Michael de Nie's necessary addendum to Colley's "Catholic glass darkly": "this glass was crafted in Cork, Mayo, and Skibbereen as well as in Normandy and Gascony" (268).

British national and colonial anxieties, although filtered through French lenses, were forged out of more intimately Irish experiences, especially the Famine. Dracula's imperial resonances owe far more to Ireland than other colonial peoples or conflicts; Robert Knox's analysis of "the Celtic race presents the two extremes of what is called civilized man; in Paris we find the one; in Ireland, at Skibbereen and Derrynane, the other. Civilized man cannot sink lower than at Derrynane" (324-325). Ireland's racial degradation was so threatening to England that Knox averred a single solution to the Irish question: "the source of all evil lies in the race, the Celtic race of Ireland. There is no getting over historical facts ... The race must be forced from the soil; by fair means, if possible; still they must leave. England's safety requires it" (379). Not only will Irish absence secure England's safety, but Knox theorizes race as paramount over culture: "race becomes paramount; Nature takes the place of parchment" (298). Stoker's epistolarity, or "the use of the letter's formal properties to create meaning" (Altman 4), formally "traverses" (Irish) "absence" in inscribing the limits and fundamental dissolution of English imperial narrative and national subjectivity (Badiou Logic of Worlds 367). Dracula's evental subjectivity embodies this traversal and his circulation throughout the text will formally disrupt imperial narrative tenets predicated upon seamless invasions, cataloguing, and consistent boundaries. Dracula's epistolarity formally frames the text's beginning preface and bookending "Note" (Stoker Dracula 326). Like other "[e]pistolary texts" that "engender prefaces, preprefaces, and postfaces ... which dialogue with each other and with the text proper, and 
which are a continuation of the text's dialogical model," Dracula ruptures linear narrative from its opening preface (Altman 163):

All needless matters have been eliminated, so that a history almost at variance with the possibilities of later-day belief may stand forth as simple fact. There is throughout no statement of past things wherein memory may err, for all the records chosen are exactly contemporary, given from the standpoints and within the range of knowledge of those who made them. (Stoker Dracula 5)

This brief, anonymous preface is an editorial assertion of imperial sovereignty. "Varian[t]" "possibilities" in "history" "almost" become present, but their disavowal is secured by "eliminat[ing]" "all needless matters." Authoritative discipline resets the narrative into an ostensibly secure linearity that will be formally refuted as the narrative unfolds. Additionally, the "needless matters" "eliminated" will become clear; they are titular and subjective, namely Dracula's elision. For the anonymous preface, penned by an ally of the British contingent, the colonial subject is precisely that which introduces a variant history and necessitates the narrative imperium of "almost," a pause prior to reconstituting narrative perspectives, representations, and tropes. Fundamentally this sovereign assertion is disavowed by the end. The preface claims its "records" "are exactly contemporary" and without "err," but they are entirely subjective, and in Dracula British subjects are repeatedly inundated by madness and misinformation. With analytical hindsight, these same sovereign, subjective assertions mark British responses to the Famine. Officials roundly disputed the Famine's origins "well into October [1845]" where "almost everywhere in Ireland, the constabulary, along with journalists, magistrates and clergy, were still maintaining that the potatoes were safe and that the harvest would be good" (Ó Murchadha 29) and announced its premature ending following "Black '47" when Ireland's new 
Lord Lieutenant, the Earl of "Clarendon[,] initially believed the worst of the Famine was over, the view adopted by the majority of the Whig Party after the autumn of 1847" (Kinealy DeathDealing 119-120). The bewildering inconsistencies of Dracula's preface gesture towards the contradictory, subjective policies that attempted to narrativize the Famine.

The preface's untenable claims and illogical ignorance are cast into full relief in the novel's final “Note." Following Dracula's demise in Transylvania, Jonathan's notational summary attempts to authenticate the preface's initial grounds, but his intentions swiftly unravel: "I took the papers from the safe where they have been ever since our return so long ago. We were struck with the fact, that in all the mass of material of which the record is composed, there is hardly one authentic document ... We could hardly ask anyone, even did we wish to, to accept these as proofs of so wild a story" (Stoker Dracula 326-327). Although Dracula's compositional range encompasses letters; entries in journal, diary, phonograph; telegrams; newspaper stories; and transcriptions, Jonathan casually notes that not a single "authentic document" remains. Although at odds with the preface's confidently sovereign assertions, Harker's final "Note" is noteworthy for its calm resignation. As a metonymy for the British State and the rest of the contingent, Harker's writing embodies a naïve optimism, consolidated by his State interpellation, that requires a foreign addendum to the note in order to establish the unfathomable reality of the novel's formal structure; the Dutchman, Van Helsing, summarizes the British plight with his bewildering cry, “'We want no proofs; we ask none to believe us!”” (327).

The British contingent's imperial laws fail to secure narrative belief and underscore the subjective futility of colonialism's monological narratives. Formally, Dracula privileges an alternative, the Famine event's revised "law ... capable of structuring a subject devoid of all identity and suspended to an event whose only 'proof' lies precisely in its having been declared 
by a subject" (Badiou Saint Paul 5). This structural tension, subjectively embodied, figures Dracula as a radical colonial narrative whose function aligns inversely with Edward Said's founding relation between imperialism and writing. Said's "invisible scribe" conceptualizes imperialism's idealistic, relational mastery of the colonies in the "wordless imperial wish" for "obdurately material natives" to be "transformed from subservient beings into inferior humanity" and for "the colonizer" to be "transformed into an invisible scribe, whose writing reports on the Other and $\ldots$ insists on its scientific disinterestedness and ... the steady improvement $\ldots$ of primitives as a result of their contact with European civilization" (Culture 168). Dracula inverts Said's conception back upon the British contingent through Dracula. The preface and "Note" evoke "obdurately material" "imperial wish[es]" for narrative sovereignty that the wider novel disavows through interlaced formal, mental, and subjective fragmentation. Stoker's form renders the British contingent "obdurately material" through their representation via an amassing diversity of letters. Dracula, on the other hand, immaterially circulates through these letters yet retains a material presence in London as evidenced in Mina's first description of him on London's streets: "He kept staring; a man came out of the shop with a small parcel, and gave it to the lady, who then drove off. The dark man kept his eyes fixed on her, and when the carriage moved up Piccadilly he followed in the same direction, and hailed a hansom" (Stoker Dracula 155). Dracula, aside from Jonathan's personal knowledge, is an unacknowledged subject within London's materiality, its "parcel[s]," people, "carriage[s]," "hansom," and streets. London is thus free of of colonial tropes - Garden of Eden or wilds—while Dracula strolls with an assimilated air that rivals the Harkers.

Wider than Dracula's London revisions is Dracula's subjective embodiment as an "invisible scribe," a conception that augments the evental ramifications he manifests. Formally, 
the novel "exploits its own silences in" order to position Dracula himself" as "a personification of absence" who is nevertheless formally omnipresent (Seed 200). Van Helsing underscores this invisible scribe's omnipresence following Lucy's death when he maintains that "there remains a greater task: to find out the author (my emphasis) of all this sorrow and to stamp him out" (Stoker Dracula 193). Whereas the British contingent—-the Harkers, Drs. Van Helsing and Seward, Quincey Morris, and Lord Godalming — are authors of obdurately material writings that trace Dracula's invisible circulation, Van Helsing lauds the vampire as "the author." Dracula's circulation is both subjective and epistolary since "letters are inscriptions directed from a first person or persons to a second person or group of persons, but as matters of discourse they invariably entail—directly, implicitly, or by way of exclusion —-the position of a third person" (MacLean 177). Dracula's post-Famine, convergent subjective/epistolary presence in the novel embodies him as a "fragment of the process of truth" (Being and Event 15). Dracula's fragmentation literally embodies his truth-full subjectivity, which is positioned in striking opposition to the British contingent's attempts at collating a consolidated narrative whole. Dracula's fragmentation is striking in its titular instantiation at the novel's core, which structures an "ex-centered dimension ... which posits that all true universality is devoid of a center" (Badiou Saint Paul 19). Events fundamentally posit these ex-centered dimensions where truth constructs universality without a delimiting center. Dracula's evental subjectivity allows him to effect this universality in the narrative, but this movement is also replicated formally as Dracula is a novel where its titular character largely fades from view amidst amassed writings about him. The novel's epistolarity formally vacates the narrative center, denying the spatial possibility of narrative authority's discipline and disavowals.

\section{A New Race: Signs of the Famine}


The 1860s was a significant flashpoint for reconceiving British racial discourses. ${ }^{61}$ Robert J.C. Young argues that widespread racial violence afflicted British colonial networks and stimulated new approaches to race that were distilled out of three historical events: the 1857 Indian "Mutiny"; slavery debates during America's Civil War (1861-5); and Governor Edward John Eyre's brutal suppression of Jamaica's Insurrection in October $1865 .{ }^{62}$ The racial context of these violent events played a significant role in shifting British racial discourses from their primary grounding in Enlightenment perspectives of race as "nation" or "political-unit" (Baton VII) defined according to "lineage" or "origin" (XI) to a hierarchized, supremacist perspective grounded on relativist views that “the British were inherently, by 'blood,' a conquering, governing, and civilizing 'race'; the 'dark races' whom they conquered were inherently incapable of governing and civilizing themselves" (Brantlinger Rule of Darkness 21). Shifts in British racial discourse underscore how "debates" and "theories of race in the nineteenth century ... focused explicitly on the issue of sexuality and the issue of sexual unions between whites and blacks. Theories of race were thus also covert theories of desire" (Young 9). Each of the events listed above were framed by discursive anxieties of miscegenation, hybridity, interpersonal violence. Although these events foreground the racial dynamics contributing to Britain's increasingly virulent strains of racial discourses, the Great Famine is a largely unacknowledged precipitating event in these shifts. The Famine was framed by abject racist violence and although miscegenation was never an operative disclaimer in Ireland, desire was nevertheless a grounding dynamic for Irish administration, both before, during, and after the Famine.

In the British imagination, Ireland's colonial status changed with passage of the Act of Union (1800). Unlike other colonies where explicit sexual and somatic boundaries were highly visible and prosecuted, Ireland exhibited none of these boundaries, and the British solution to 
"the "Irish question"” rested on "reconstruct[ing] Ireland in its own image. The most commonly prescribed cure for Britannia's 'sick sister' Erin was anglicization, the transplantation of the qualities that supposedly made Britain first among nations" (de Nie 3). Erin's sickness was ultimately racial, as Robert Knox defined the Celt according to qualities of "war and plunder, bloodshed and violence, in which the race delights, []as their object" (319). Knox's racial impugning of "Celtic" Ireland formalized popular post-Famine conceptions in the British press that "those who survived the hunger ... returned to their violent habits with a vengeance, spewing more hatred toward Britain than ever before. While the Irish were believed to be naturally violent, in the wake of the famine and British charity the resumption of outrages and conspiracy seemed even more sinister and barbarous" (de Nie 122). Anxieties over "the Celtic race" and its "naturally violent" threat to "England's safety" coalesce as arguably the most significant strain of racial discourse animating Britain's mid-nineteenth century virulence. Although a black colonial insurrection in Jamaica captured British debates, Ireland was equally problematic, indeed parallel, in its ideological constitution as a colonial populace plagued by violence. "By March 1866 the Jamaican House of Assembly had surrendered its powers to the crown and Jamaica had become a crown colony" as a result of the specter of Morant Bay, but with coincident salience "the Liberal government had suspended habeas corpus in Ireland on account of the serious disturbances associated with Fenianism" (Hall "The nation within" 183). Colonial violence and racial hierarchy define the shifting tides of British racial discourse and although India, America, and Jamaica, with their vividly different racial paradigms, animate these shifts, Ireland's proximate and phenotypic non-difference fostered still greater anxieties, virulence, and violence. ${ }^{63}$ 
Fundamentally, British racial discourse shifted as a result of colonial events in the empire, but these shifts were emblematically domestic and dialectical. This is not a paradox, but rather a recognition that "the nineteenth century ... notion of a fixed English identity was doubtless a product of, and reaction to, the rapid change and transformation of both metropolitan and colonial societies which meant that, as with nationalism, such identities needed to be constructed to counter schisms, friction and dissent" (Young 3-4). ${ }^{64}$ This ideological fixity was easily maintained in India, Africa, or Jamaica where explicit epidermal difference rendered clear racial boundaries. This same difference failed to adhere to Irish bodies. These Irish bodies were also increasingly inundating England's domestic shorelines and cities as a result of post-Famine migrations. Liverpool was the overwhelming point of Irish entry; "by 1848 it was as intrinsic to the great emigration from Ireland as the potato or the failing land system itself. At least two of every three emigrants from Ireland during the 1830s and 1840s passed through Liverpool" (Scally 184). This Irish mass migration further inflamed popular British conceptions of "the Irish and the English as distinct races" with the Irish embodying "a palpable dread of contamination" equally pathological and social as "the Irish ... seem capable at the same time of infecting the English working class with their bad habits by virtue of the simple fact of contiguity" (McLean 51). The anxiety-laden ambiguity of Irish racial bodies in contrast to the visually-grounded certitude of other colonized subjects informs the construction of English ideological fixity as particularly vexed yet necessary within England's island domains. This necessity informs the stereotypical "Paddy," an Irish racial construct embodying the Irishman's "devolved condition" and "symbolized in numerous ways, such as drawing him with ape-like features, jokes about 'Mr. G'Orilla,' naming a new chimpanzee brought to the London Zoo in 1892 'Paddy,' and even comically positing in the pages of Punch that the 'Irish Yahoo' was the missing link between 
man and gorilla" (de Nie 11). Irish racial inhumanity manifested hierarchically as the Irish were always "inferior to the British" and "usually ranked above other dark-skinned peoples of the world," but "at times of severe crisis Irish superiority to the Hottentot and perhaps even Irish humanity were called into question along with the prospects of anglicization" (120). Irish racial oscillations are predicated upon Ireland's blurred lines of difference. Since "the idea of race ... shows itself to be profoundly dialectical: it only works when defined against potential intermixture, which also threatens to undo its calculations altogether" (Young 19). Whereas nonwhite sexual liaisons between British subjects and colonized Indians, Africans, or Jamaicans were certainly anxiety-laden unions necessarily framed by punitive juridical structures, it was nevertheless England's anxiety-laden Irish Union, especially in the post-Famine era, that foregrounded Irish epidermal specularity as ultimately inculcating more intransigent racial antinomies.

Color was the principle valence for Ireland's intransigent racial antinomies. In spite of its obvious contradictions and shortcomings, Mark M. Smith notes that "“race' [a]s a construct, an invented category that defies scientific verification [is] still underst[oo]d ... as a largely visual enterprise. 'Color' is always seen" (2). Race's visual economy operated to secure social boundaries, but it also saturated cultural constructs. Christine Bolt argues that "[c]olour symbolism in the English language" cohered into a fixed index: that by the Victorian period the word "black" had come to evoke evil, sin and treachery, ugliness, filth and degradation, night and funeral mourning, while "white", on the other hand, was associated with qualities like cleanliness, purity, beauty, virginity and peace (though it might occasionally have less reputable 
associations - as in whitewash, whited sepulchre, white-livered and white feather). (131-132)

English literary color palettes often reflected the clearly delimited logic of racial codification and classification systems. In Emily Brontë's Wuthering Heights (1847), for example, Heathcliff's "black eyes withdraw ... suspiciously under their brows" and his appearance is that of a "dirty, ragged, black-haired child" or a "gipsy" "imp of Satan" (3, 29, 32). Conrad's Heart similarly signifies racial blackness on the bodies of Africans who are "black shadows of disease" and "dog[s] in parody of breeches" or generally "some sorcerer, some witch-man" (Conrad 31, 51, 81). The coloring of otherness, encompassing racial, social, and cultural difference, clearly marks out these texts in ways that Dracula explicitly denies. Jonathan Harker's first clear description of Dracula paints a radically different picture as the vampire is "without a single speck of colour about anywhere" (Stoker Dracula 21). Dracula's ultra-white invisibility signifies a terrifying otherness uncontained within Victorian racial discourse's symbolic and cultural registers. ${ }^{65}$

Dracula is not only racially invisible, but his knowledge, acumen, and subjective circulation suggest a more intimate kinship invisibility. After failing to corporeally register Dracula, Harker engages him in conversation and finds that Dracula "know[s] and speak[s] English thoroughly!" (26). ${ }^{66}$ Even when their conversation progresses to London, Harker's home, "[Dracula] knew very much more than I did" and his "knowledge and acumen were wonderful" $(28,37)$. There is a latent anxiety in Harker's apprehension of Dracula's knowledge and its subtext is colonialism. Prior to reaching Dracula's castle, Harker researches the Transylvania landscape only to find no "map or work giving the exact locality of the Castle Dracula, as there are no maps of this country as yet to compare with our own Ordnance Survey 
maps" (10). Superficially, the Ordnance Survey signifies British imperial mastery, but its lack of mapping Transylvania underscores the fundamental lack in knowledge that both Harker and the Empire manifest before Dracula. ${ }^{67}$ Further imperial surety fails in Jonathan Harker's first extended study of Dracula's face:

His face was a strong - a very strong - aquiline, with high bridge of the thin nose and peculiarly arched nostrils; with lofty domed forehead, and hair growing scantily round the temples, but profusely elsewhere. His eyebrows were massive, almost meeting over the nose, and with bushy hair that seemed to curl in its own profusion... For the rest, his ears were pale and at the tops extremely pointed ... The general effect was one of extraordinary pallor. $(23)^{68}$

Dracula's visage echoes Victorian anti-Semitic descriptors to such an extent that Jules Zanger maintains a "sympathetic vibration" between "[Dracula $]$ and ... the archetypal Jew" that Jonathan never connects throughout the text. ${ }^{69}$ Jonathan exhibits an isolated instance of antiSemitism towards Immanuel Hildesheim, a "Hebrew of rather the Adelphi Theatre type, with a nose like a sheep, and a fez. His arguments were pointed with specie," but this anti-Jewish racism is almost entirely performative and class-based (302).$^{70}$ Jonathan's Jewish reading of Dracula is notable for its absence in light of Van Helsing's later lauding of Jonathan and Mina Harker's scientific knowledge: "So! You are physiognomist" (Stoker 168). ${ }^{71}$ The fact that none of these "physiognomist[s]" ascribe a Jewish reading to an ostensibly Jewish rendered vampire clearly invests Van Helsing's later description of Dracula's form with both textual and critical resonances: "within limitations," he can "appear at will when, and where, and in any of the forms that are to him" (209). Dracula's formlessness casts Mina's self-assured assertion that "II knew him at once from the description of others"' into self-assured denial (251). Dracula's racial 
formlessness, nee invisibility, subjectively disavows the British contingent's, as well as many critic's, attempts to fix him as a clearly defined, racialized other who "condenses" a litany of known "racial, cultural, sexual/heterosexual and gender tensions" (Hogle 206). This formlessness owes its racial foundations to Irishness and the fact that in Victorian racial discourses and the popular press, "rarely ... were [other raced subjects] regarded as below Paddy, and no group was more degraded or dehumanized in the pages of the press than Irish rebels and nationalist leaders" (de Nie 10).

Irish racial intransigence roots Dracula's radical qualities in its post-Famine titular subject, Dracula. Although largely ignored by many scholars, the Famine played a formative role in Stoker's life. His birth in Dublin to a middle-class Protestant family in "Black '47" renders the Famine a Stokerian birth right. ${ }^{72}$ Although Abraham Stoker's civil service position and Dublin residence largely inured the Stokers from the Famine's effects, they were not untouched. Famine-era Dublin was an industrialized urban trade and shipping center where "few died of starvation" but "the incidence of fever and dysentery, higher in Dublin than in the countryside in normal times, rose dramatically ... in 1846 and 1847 " as "Dublin[] resemble[ed] a gigantic refugee camp" (Ó Gráda 166, 173) and "food riots ... occurred" frequently, with the "claim[] that the attackers were ... from distant parts and ... not natives of Dublin" (Kinealy Great Irish Famine 128$).{ }^{73}$ Stoker was also bedridden as a child with an unknown illness and subjected to his mother's historical, mythic tales of Irish famines. Charlotte Stoker related narratives of "the cholera epidemic of 1832 in Sligo" with "ghosts, decomposing corpses, and staked bodies" (Belford 18) and these tales played a role in Stoker's inculcated belief "that his disabling childhood illness had resulted from contagion following in the potato famine's wake" (Valente 16). ${ }^{74}$ These childhood stories and beliefs supplemented Bram Stoker's later encounters with 
Irish myths steeped in supernatural accounts of disease and blood, such as "[t]he Dearg-due (the red bloodsucker)" who "was said to tempt men with her beauty and then suck their blood" or "Irish fairies ...bloodless, feared by children as bogeymen who would abduct them for their blood" (Belford 64). Dracula's Irishness indelibly arises out of these mythical and personal nexuses, especially in his phonic and lexical links to the Gaelic "phrase dhroch fhola, pronounced 'druck ulla,' meaning 'of bad blood"' $(264) .{ }^{75}$ Early in the novel, Dracula informs Harker that his homeland, Transylvania, was formed by famine and conflict: "the casualties of war proper being assisted by famine and disease" (Stoker Dracula 11). Transylvania is, especially in a famine context, a covert Ireland as Joseph Valente perceptively notes that "the literal meaning of' Dracula's homeland, "Transylvania, 'beyond the forest,' irresistibly suggests 'beyond the Pale,' which historically refers to the broad expanse of Ireland that remained outside and resistant to British military and political control for most of the colonial epoch" (51).

Transylvania's Irish-veneer is famished and conflicted, but it further converges with Ireland via Dracula's vampirism since the vampire is a monstrous image frequently attributed to Irish revolutionary activity. ${ }^{76}$ Although vampires are prominent British popular culture images, the vampire is also an intimate Famine image, one whose literary precedence further links Stoker's novel to the Famine. William Carleton's The Black Prophet, although focusing on Irish famines in 1817 and 1822, was published in 1846 during the Famine and one of its main characters, Sarah M'Gowan, is depicted as a vampire:

her lips were drawn back, displaying her beautiful teeth ... her face was pale with over-wrought resentment, and her deep-set eyes glowed with a wild and flashing fire that was fearful ... what added most to the terrible expression of her whole face was the exulting smile of cruelty which shed its baleful light over it ... into 
the fierce play of some beautiful vampire that was ravening for the blood of its awakening victim. (12)

Sarah M'Gowan's vampiric features anticipate Dracula's later "bright eyes, which seemed red in the lamplight" and his "face" that "was not a good face; it was hard, and cruel, and sensual, and his big white teeth, that looked all the whiter because his lips were so red, were pointed like an animal's" (Stoker Dracula 17, 155). Both Famine-era vampires indulge in blood as Sarah early on attacks her stepmother: “'I've tasted your blood and I like it—ha, ha, ha!'” (Carleton 13). Sarah's Famine-era death is also the result of disease. The connection between disease and famine is one Ciarán Ó Murchadha notes as "historically" consistent "in Ireland [where] famines had been accompanied by outbreaks of epidemic disease" (89). In contrast to Sarah, disease is not Dracula's end, but his origin; Dr. Van Helsing identifies the vampire's history in his embodied ability to "smile at death, as we know him" and "flourish in the midst of diseases that kill off whole peoples" (Stoker Dracula 279).

Dracula's Famine legacies are also closely connected to England through another literary antecedent, Emily Brontë's Wuthering Heights (1847). Terry Eagleton famously reads Wuthering Heights as a Famine novel in which "Heathcliff is a fragment of the Famine, and goes on a sort of hunger strike toward the end of his life, as indeed does Catherine Earnshaw" (11). Brontë's novel is also emblematic of the Famine in its vampiric description of Heathcliff. Nelly Dean wonders, in loaded language, whether Heathcliff "is ... a ghoul, or a vampire?" (Brontë 252). Nelly's bewilderment over this potential "hideous, incarnate demon" is linked to Heathcliff's increasingly "ghastly paleness" and ultimately emblematic of Nelly's description of his dead expression: "that frightful, life-like gaze of exultation ... and his parted lips and sharp, white teeth" $(252,251,256)$. These various, vampiric subjects foreground the Famine body as one that 
"evince[s] a materiality at once grossly substantial and elusively phantasmal, evoking a materialism that, far from offering a refuge of certitude, threatens instead to dissolve the familiar boundaries between self and world" (McLean 122). Dracula's excessive racial pallor—itself beyond (the) pale — further threatens to "dissolve the familiar materialism" of Victorian racial discourses and their ability to adhere to an Irish colonial subject. ${ }^{77}$

Dracula's radical connection to the Famine constructs an Irish vampire, but Alain Badiou's evental philosophy construes the Irish vampire as a Famine-evental truth. In this schema, Dracula functions as a "militant figure" that rises out of "the event alone, aleatory figure of non-being, [and] founds the possibility of intervention" (Badiou Saint Paul 2; Being and Event 209). A militant figure is an evental subject, one whose appearance is contingent upon an event irrupting into being. Through an evental subject, whose constituted subjectivity no longer observes the State's subjective ontological strictures, an "intervention" is possible and then conceptualized through the "subject," who as "finite instance of the truth, discerned realization of an indiscernible, forces decision, disqualifies the unequal, and saves the singular" (Being and Event 409). Events produce truths, but these truths as pure infinity can never be materialized; however, evental subjects bear these truths in material form. Once a subject testifies to the event and militantly upholds its egalitarian principles that subjective "body avers itself capable of producing effects that exceed the bodies-languages system (and such effects are called truths) [and] this body will be said to be subjectivated" (Logics of Worlds 45). ${ }^{78}$ A "subjectivated" body like Dracula's literally produces truths that disrupt State hegemony through assertions and actions, and particularly in the asserted actions of accruing more subjective followers. Formally, Dracula situates Dracula as literally an ungrammatical subject, largely absent from the book's textual field, who nevertheless invades the written sentences of the British contingent's 
novelistic corpus. Dracula's cultural, racial, and linguistic superseding of English imperial subjectivity are all material accoutrements that gesture toward the immaterial truth he subjectively manifests. This truth is fundamentally the disavowal of hegemonic notions of culture, race, and language through the Famine event that inaugurates a new subjective and national conception, Irishness, as egalitarian alternative. Dracula captures this alternative in its vampiric subjectivity and proto-modernist form. Ultimately, this British novel written by an Irish hand draws on clear literary antecedents, but then formally rewrites them as an example of protomodernist literature attempting to assert radical subjective and national imaginings within the shadowy violence of a white empire.

\section{Mirror, Mirror: Violent Inscriptions and Colonial Crises}

Dracula's formal and subjective difference is radically omnipresent as an antagonistic disavowal of monological narrative. Although these relations are specular and reflect the confrontation between colonized and colonizer, the novel's evental ramifications posit it at a radical remove from Homi Bhabha's emphasis on an "agonistic (rather than antagonistic)" account of postcolonial theory (153). Bhabha's "represent[ation]" of "colonialism as transactional rather than conflictual" produces "the effect of moving agency from the subject-asinsurgent-actor to textual performance is to defuse resistance as practice directed at undermining and defeating an oppressive opponent" (Parry 62, 66). Although narrative in scope, Dracula nevertheless layers its "antagonistic" and "conflictual" accounts of post-Famine Irish colonialism within an evental structure that inverts colonial violence and inflicts it upon British subjects. Beyond reductive vindictiveness, Dracula's violence presents an apocalyptic account of British colonialism, one in which colonialism's subjective, discursive, and corporeal violence is made manifest and repudiated. Jonathan Harker, the first person to see Dracula, is the first British 
subject to suffer subjective violence. As a metonymy for the British Empire, Harker's recursive writings, as well as those of the wider British contingent, attempt to formulate and fix colonial subjects yet their inscriptions operate through contradiction. Harker's colonial diary repeatedly represents Transylvania nee Ireland as a "picturesque" colonial landscape paradoxically rife with famine and disease: "goitre was painfully prevalent" (Stoker Dracula 11, 14, 15). Imperial authority is encapsulated by his native Transylvanian name, "word-bearer," but the word-bearing Englishman's linguistic authority belies his ignorance: "I could hear a lot of words often repeated, queer words, for there were many nationalities in the crowd; so I quietly got out my polyglot dictionary" (13). A written and spoken chasm exists between colonized and colonizer. What Dracula foregrounds amidst English representation is the ideological contradictions at colonialism's core. Victor Kiernan locates these contradictions in the ideological constructs that made colonial spaces like "Africa" a "truly" "Dark Continent, but darkness was one the invaders brought with them, the somber shadow of the white man" (Lords of Human 236). A novel of monstrosity, what Dracula truly demonstrates is the monstrous limits British subjects will go to uphold colonialism's status quo.

As Harker travels to Dracula's castle his diary functions as an idealistic signifier of the British State's recursive authority and representational power. As the novel unfolds, these ideological correlatives and their inscribed forms cast into relief their inherent illusiveness. Upon reaching the castle, the word-bearing Harker finds solace in writing: "I began to fear as I wrote in this book that I was getting too diffuse; but now I am glad that I went into detail from the first, for there is something so strange about this place and all in it that I cannot but feel uneasy" (Stoker Dracula 30). Writing is the British Empire's civilizing raison d'être or its authoritative grounding, as figured in Bhabha's delineation of the English book, whose "discovery ... installs 
the sign of appropriate representation" and "establishes both a measure of mimesis and a mode of civil authority and order" $(149,152) \cdot{ }^{79}$ For Harker, his diary's authoritative signs ultimately fail to shore up his colonial immunities as he is plagued by "strange" and "uneasy" specters that infect his "writing" and "diary": "It is nineteenth century up-to-date with a vengeance. And yet, unless my senses deceive me, the old centuries had, and have, powers of their own which mere 'modernity' cannot kill” (Stoker Dracula 40-41). Harker's unease is tied to his hosts' vampirism—Dracula and his three women — and the word-bearer's inscriptive staging within a colonial landscape further gestures toward other possibilities for the "powers" that "mere 'modernity' cannot kill." In the context of the Famine, Stuart McLean argues that "the phantasmagoria of death enacted in and around the mass grave belongs as much to the mythology of modernity as to the world of peasant belief" (128). Harker's own evocation is an oscillation between "the old centuries" and "modernity," distilling within a colonial space the violence and death colonialism bequeaths to native populations like the "Szgany" "gypsies" Harker characterizes as "without religion, save superstition, and they talk only in their own varieties of the Romany tongue" (Stoker Dracula 45). Colonialism's written effacements of "mass graves" and violence is the subtext of Harker's invocation of "modernity," a subtext cast into sharp relief in Marlow's later discovery of Kurtz's pamphlet in Heart of Darkness with its final handwritten inscription, "Exterminate all the brutes!" (Conrad 66).

Kurtz's pamphlet renders clearly what Harker's diary gestures to as subtext and reflects a profound ideological disjunction between Africa's "primeval" "darkness" (Conrad 41, 21) and Ireland's "picturesque" countryside full of people "just like the peasants at home" (Stoker Dracula 11). Like Dracula, Marlow's fragmented narration ultimately bridges the divide between center and periphery, Africa and Belgium, symbolized in Kurtz's echoing last words, 
“The horror! The horror!" (Conrad 85, 90). Removed from Africa’s jungles, Marlow entersBrussels, "the heart of a conquering darkness," to meet Kurtz's "Intended" in a domestic scene that frames his lies about Kurtz's last words (89). Frustrated and broken down, Marlow is on the verge of "“crying at her, "Don't you hear them!" The dusk was repeating them in a persistent whisper all around us, in a whisper that seemed to swell menacingly like the first whisper of the rising wind. "The horror! The horror!"”” (93). Kurtz's scream in Africa's heart finally registers in Europe's whispering wind. The repetitious "horror!" phonically records what writing refuses to: "mass graves," unbridled violence, and unimaginable degradations that echo Marlow's earlier reflections on "the conquest of the earth, which mostly means the taking it away from those who have a different complexion or slightly flatter noses than ourselves, is not a pretty thing when you look into it too much" (21).

In parallel to Marlow's colonial revelation in a "lofty" Belgian "drawing room," Harker's own revelations occurs in domestic confines while he shaves (90). Harker, the English wordbearer, begins shaving until Dracula abruptly appears: "I started, for it amazed me that I had not seen him, since the reflection of the glass covered the whole room behind me" (Stoker Dracula 30). Harker is assured that Dracula is materially present in the room, but his horror is magnified as realizes "there could be no error, for the man was close to me, and I could see him over my shoulder. But there was no reflection of him in the mirror! The whole room behind me was displayed; but there was no sign of a man in it, except myself' (30-31). Materially face-to-face, Harker finds "no reflection" or "sign" of Dracula, the ostensibly mirrored colonial subject. Although the mirror self-reflexively literalizes Harker's early comfort in writing's recursive power, both fail in this colonial mirror scene. Dracula's evental subjectivity invisibly annuls the colonial project's grounding principle "that there is an 'us' and 'a them,' each quite settled, clear, 
unassailably self-evident" (Said Culture XXV). The "unassailably self-evident" divisions between colonized and colonizer in Dracula falter via Dracula's evental subjectivity, which manifests "truth," "itself indifferent to the state of the situation ... This means that it is subtracted from the organization of subsets prescribed by that state. The subjectivity corresponding to this subtraction constitutes a necessary distance from the State and from what corresponds to the State in people's consciousness: the apparatus of opinion" (Badiou Being and Event 15). Dracula's subjectivity invisibility removes him from Harker's mirror, the text's wider horizons, and the British State's colonial purview. Dracula's singularity, opposed to the larger peasant population Harker easily identifies as "very picturesque" (Stoker Dracula 11), is paradoxically universal "through [his] commensurability with a truth" (Badiou Saint Paul 20). This quality transforms "anonymous individuals ... into vectors of humanity as a whole." Dracula's singular universality indexes a subjective structure that renders "us" and "them" inevident. What is unassailably self-evident in this colonial mirror scene is Dracula's threatening ability to invisibly penetrate, unsettle, and annul English subjectivity through truth-full anonymity.

Dracula's self-conscious mirror scene ends on a violent act that reifies the divide between English and evental subjects. Dracula's invisible presence vitiates Harker's English subjectivity and a consequent incisive break informs Dracula's breaking of the "shaving glass" and subsequent "withdr[a]w[al] without a word" (Stoker Dracula 30, 31). Dracula's violence ruptures the scene and reifies the divide between imperial word-bearer and colonial word(less)bearer. ${ }^{80}$ Beyond the evental ramifications dividing Harker from Dracula, this mirror scene also represents an emblematic colonial scene, one repetitive across "colonial writings $\ldots$ of scenes not merely of male bonding but of solidarity between men figured as self-mirroring and doubling" 
(Boehmer Colonial and Postcolonial 77). These scenes are often central mirrors of colonial ideology's recursive fitness and civilizing mission that Dracula significantly and directly deforms in broken "male bonding" and "self-mirroring" of this scene. ${ }^{81}$ This scene also problematizes common critical readings of these self-reflective scenes between colonized and colonizer figured variously by Fredric Jameson as the colonial oppositions between imperial self and colonial other or "the other face of a mirror, which it constitutively lacks, and which can never be made up or made good" (51) and Homi Bhabha's delineating the colonial other as "the shadow of colonized man ... [or] the otherness of the Self" (62-3). Although these colonial scenes and theories aptly distill Kurtz's conflicted transformation from high-minded idealist to genocidal advocate, they fail to account for Stoker's localized evental complexities.

\section{Bloodlett(er)ing: Corporeal Marks and Colonial Cries}

Jonathan Harker's domestic mirror scene in the colonial heartland emphasizes the latent violence at the heart of colonial encounters. Violence ultimately shatters the horror framing this scene, but Dracula's violence differs from the State's destructive violence. Dracula's explicit violence deforms colonialism's ideological authority prior to his more penetrating subjective violence that will dissolve it. Writing is again central to Dracula's subjective marking of Lucy. Whereas authors are fundamentally markers, and Dracula is literally produced by an authorial cabal, one author marks them all and his "invisible prescription[s]" are markedly transgressive (Badiou Logics of Worlds 204). ${ }^{82}$ Badiou imagines "invisible prescriptions" as markers of the artistic act and they take on added resonances within the invisible scribe. Dracula's epistolarity renders Lucy's subjective transformation akin to a translation, a colonial rendering that (re)marks, in Quincy Morris' and John Seward's respective words, "that poor pretty creature we all love" "of unequalled sweetness and purity" (Stoker Dracula 138, 192). Dracula's markings 
will render Lucy foreign to British state accounts and it is only fitting that his initial penetration of England is lost in translation. A Daily Telegraph correspondent recounts the "strange narrative" of the Demeter, the ship Dracula stows away on into England, "from the dictation of a clerk of the Russian consul, who kindly translated for me" (80). Dracula's deadly voyage to England indelibly evokes Irish Famine emigrants who departed Ireland for England "laden with the mark of illegality" and "carry[ing] the colonial history of their ancestors with them" (Scally 8). Their appearance in Liverpool "shocked" "most" English people who "shunned any contact with them, partly from the fear of infection but also from ... aversion to the sight of their helplessness and degradation" (168). Although Dracula will not be "shunned" by the British contingent, they will "fear" his "infecti[ous]" ability as he "carr[ies]" "colonial history" into the metropole and proceeds to subjectivate Lucy with "mark[s] of illegality."

The Daily Telegraph's inscribed translation fails to locate Dracula's authorial force behind the "strange narrative." Mina Murray pastes this article into her journal and proceeds to write about Dracula's initially unknown attack upon Lucy. His repeated corporeal markings will ultimately effect Lucy's subjective transformation: at Whitby's East Cliff Mina discovers Lucy's neck "pierced" with "two little red points like pinpricks"; when Drs. Van Helsing and Jack Seward enter the Westenra's Hillingham home and find Lucy's "throat" bears "two little wounds ... looking horribly white and mangled"; and once Lucy dies "[t]he wounds on the throat ... absolutely disappeared" (Stoker Dracula $89,134,145$ ). These material marks both catalyze and conceptualize the Famine event's subjective transformation; Dracula's marks materially link Lucy to Badiou's immaterial contention that "[e]very radical transformational action originates in a point, which, inside a situation, is an evental site" (Being and Event 176). For Badiou, the origin point grounds the event's material manifestation, the site; for Dracula, the origin point 
grounds the material manifestation of annulled British subjectivity towards an alternative. Lucy's subjectivated body irrupts out of Dracula's pointed markings. Dracula's voyage to England traces the Famine's migration in parallel with the Famine's traces upon Lucy's subjectivated body. From September 4-6, Jack Seward records Lucy's condition: "Patient still better today"; "Patient greatly improved"; "Terrible change for the worse" (Stoker Dracula 110). Lucy recovers from this "terrible change" on September 17 and writes "I am getting so strong again" before a final attack on September 20 leaves her "pale" and "faint" prior to death $(124,146)$. Although far lengthier, Lucy's trajectory parallels that of Famine-era typhus deaths in that "after perhaps five days of fever, a crisis occurred, involving heavy sweating and physical exhaustion, following which a few days of relief preceded a major relapse, or indeed several in succession before a victim died, effectively of exhaustion" (Ó Murchadha 90). Just prior to her death, Lucy is repetitively describes as "weak," "weakly," and "weaker" as she lapses from British imperial subjectivity to an evental alternative bearing the Famine's colonial traces (Stoker Dracula 139). Dracula's material/immaterial renderings upon Lucy's body clearly localize colonial conflicts between two inextricably linked sites: corpse and corpus. His pointed markings are a colonial threat rupturing physical and textual bodies. The British contingent combats this threat by miming Dracula's incisive marks upon Lucy with their own scientific incisions-four blood transfusions. Van Helsing understands that they must also limn Dracula's author-ity through compositional and disseminative control; in other words, British (re)marks must counter colonial marks. Van Helsing's apprehension prompts his determined solo entry into "Miss Lucy's old room" in order to "search for what may be. It is not well that her very thoughts go into the hands of strangers"” (148). His immaterial securing of Lucy's "very thoughts" will later materially manifest in Van Helsing's request, following Lucy's un-death, to her heir, Arthur Holmwood: 
I want you to give me permission to read all Miss Lucy's papers and letters ... I have them all here. I took them before we knew that all was yours, so that no strange hand might touch them—no strange eye look through words into her soul. I shall keep them, if I may; even you may not see them yet, but I shall keep them safe. No word shall be lost; and in good time I shall give them back to you. (153154)

Van Helsing twice emphasizes that "strange eyes" and "strange hands" must not behold Lucy's writings. By securing her writings, Van Helsing hopes to secure her body and although written records identify the relative source of Lucy's decline it is not enough to reclaim her. Whereas Dracula's "strange" marks subjectivate Lucy, the British contingent's familiar eyes and hands will only ensure her final, violent death.

In dealing with Lucy's subjectivated body, the British contingent utilizes only men: Van Helsing, Seward, Godalming, Morris, and Jonathan Harker. "The[ir] identification between men" accords with "the [wider] pages of colonialist fiction" where masculinist-dominated scenes "helped to sublimate the uncertainties of a confrontation with colonized peoples ... the stress on sameness encouraged the portrayal of otherness—all that was not white and not male - as feminine" (Boehmer Colonial and Postcolonial 77-78). Ernest Renan's La Poésie des Races Celtiques, published shortly after the Famine, situates this British masculinist scene opposite a saliently Irish one: "If it be permitted us to assign sex to nations as to individuals, we should have to say without hesitance that the Celtic race ... is an essentially feminine race" (Poetry of the 8). This masculinist and feminist opposition within the British contingent frames Lucy's transformation nationally and politically. Dracula has already deformed the British State's masculinist colonial bedrock in his incisive breakdown of Jonathan Harker yet his transformation 
of Lucy is far more thorough. Eclipsing British State-ments on masculine and civilizational proprieties, Dracula highlights Lucy's material shift from an ostensibly blond light of the west into “a dark-haired woman" (Stoker Dracula 187). ${ }^{83}$ Lucy's western light is ostensibly British, but her dark transformation suggests otherwise; whereas Harker spies an Anglo-Saxon vampire in Transylvania nee Ireland, one "fair, as fair as can be, with great, wavy masses of golden hair and eyes like pale sapphires" (42), Joseph Valente notes that Lucy is "plausibly" a "mythic personification of Erin, the 'Western Light"' (66). Lucy's Irish personification is further underscored not only by Dracula's transgressive marks, but precisely because her hair color effects an explicit transition from Anglo-Saxon light to "a dark-haired" rose, the symbol of Ireland (Róisin Dubh). Furthermore, Lucy's transformation is ideologically deformed by the British contingent who view this "dark-haired" Lucy as a "nightmare" and "devilish mockery of Lucy's sweet purity" (Stoker Dracula 190). Her nightmarish qualities ultimately derive from her recasting by the British as symbolic of Ireland. Although "smooth-limbed Erin, the simianized Paddies' opposite, was never dehumanized because she represented the more hopeful elements of Irish policy," this "innocent child in need of tutoring and protection from her savage brother" is here spectacularly recast as a demonic perversion of meek femininity (de Nie 264). Lucy's subjectivated body is completely transformed by the event and the British contingent's only recourse will be to transfix her evental subjectivity through retributive imperial violence.

Although Lucy is Dracula's only complete rupturing of British subjectivity, Mina is his most significant British target as the British contingent's chief authorial figure and the key to a permanent alternative. Mina's significance, like Lucy's, is also an Irish one, as she bears a "similarly Irish birth name" that "filiates her with native Celts of the name O'Muireadhaigh, which was anglicized to Murray sometime during the colonial occupation" (Valente 66). Mina's 
latent Irishness inflects both her position as Dracula's subjective focal point and her nodal position within Dracula's formal matrix of writers and readers. ${ }^{84}$ Although the entire British contingent authors various aspects of the narrative, Mina is the editorial and authorial pivot who like the foreign Van Helsing apprehends things that escape the British men. Early in the novel, Mina's reflections on her journal's soothing qualities stress writing's dynamism: "I am anxious, and it soothes me to express myself here; it is like whispering to one's self and listening at the same time" (Stoker Dracula 72). Mina's writing manifests a forceful emollience that is selfpalliative; these emollient qualities key writing's formalist, tactile relations to colonial contact in imperial narratives, "both sophisticated and crude," that "combin[e] motive (wealth) and justification (civilization) ... to give colonial masters virtually unbounded rights over the lands and subjects they claimed" (Boehmer Colonial and Postcolonial 38). Dracula foregrounds this emollient mastery in order to subject it to violent colonial tectonics. This formal oscillation defines Jonathan Harker's nuptial and confessional presentation of his journal to Mina with the loaded reflection: "You know I have had brain fever, and that is to be mad. The secret is here, and I do not want to know it" (Stoker Dracula 99-100). Harker's Transylvania visit culminates in material colonial contact with Dracula, which strikes him mad and requires a nuptial remove for any semblance of reflection on the "secret" lodged in his writing and his fearful refraining from "know[ing] it." Whereas writing is Mina's palliative, Jonathan's writings gesture towards something else that Mina reflectively identifies: "I wonder if there is any truth in it at all. Did he get his brain fever, and then write all those terrible things; or had he some cause for it all?" (161). Mina's eventually realizes that "there seems to be through it all some thread of continuity" that, "fever[ish]" or not, betrays an insidious cause and "continuity" within writing's selfconsciously hidden reserves. 
Dracula's variously authored texts cohere around a "secret" "continuity" that is subjectively, and largely secretively, Dracula. More pervasively this "continuity" manifests colonial violence's material resonances. Writings' emollience, particularly Mina's soothing palliative, attempts to overwrite this violence, but British corpuses perpetually struggle with a degrading corporeal textuality signified as forcefully unexpellable: Jonathan's contracted and secreted madness. The lines demarcating amassing corpus and mass (graves) corpses disjunctively dissolve in Mina's editing of the British contingent's texts. Stoker penned an early note on the novel that would become Dracula on 1 October 1873 in his Dublin journal for a "story of man who reflects everybody's self who meets him" (The Dublin Years 66). Dracula literally reflects Jonathan Harker in the Transylvania mirror scene and this scene limns Dracula's wider formal spectrality throughout Dracula. Dracula's spectral subjectivity, not to mention his undead monstrosity, aligns him with the "specter" whose "disruptive force .... appears to depend on the bringing together of specific historical contents with a vision of insurrectionary somaticity at seeming odds with canonical formations of historical knowledge" (McLean 128). This forceful spectrality and "insurrectionary somaticity" informs a key hinge between Lucy's and Mina's respective subjectivated bodies that provides the subtext for Mina's editorial inscription of Jack Seward's phonographic diary. Upon completion, Mina meets with Seward and notes that the recording "told me, in its very tones, the anguish of your heart. It was like a soul crying out to Almighty God. No one must hear them spoken ever again! See, I have tried to be useful. I have copied out the words on my typewriter, and none other need now hear your heart beat, as I did" (Stoker Dracula 197). Seward's diary provides a history of Lucy's death, which Mina did not witness. Significantly, Mina attempts to elide his "anguish" by "cop[ying] out" the "words," but this fails to fully contain Seward's somatic remainders: "I think that the cylinders which you 
gave me contained more than you intended me to know; but I can see that there are in your record many lights to this dark mystery." Mina's transcription stresses how Seward's diary as metonymy for the Empire's voices betrays the abject violence at the colonial project's heart. The diary's oral medium connects Seward's internal emotions, an "anguish[ed]" "soul crying out," in eerie echo to Lucy's final cries. Although attempting to efface Seward's "anguish" and secrete away "more than you intended me to know," Mina's transcription inadvertently dissolves the divisions between "light[]" and "dark" and their symbolic gesturing toward the imagined binary between written (English) word and spoken (colonial) cry.

Mina's absent, editorial hand links her to the present, authoritative hand that transfixes Lucy's subjectivated body within a written/spoken dynamic,. Both women bear Irish resonances that Dracula's evental subjectivity radically transforms. Mina's editorial re-writing not only links her to Lucy, but also foregrounds Empire's divergent instrumentality which is evoked in her authorial tool, a pen, and Arthur's authoritative tool, "a round wooden stake, some two and a half or three inches thick and about three feet long" (190). The pen and the stake, Empire's written and corporeal expressions of dominance, violently differentiate Mina's and the contingent's respective markings although both ultimately cohere in Mina's editorial hand. Writing denotes the contingent's imperial history, but screams presage its future colonial ramifications. Mina's transcription of Seward's oral diary includes Arthur's staking of Lucy and her body's emitted "hideous, blood-curdling screech." In response, the contingent musters the "courage" to answer this scream: "our voices seemed to ring through the little vault" (192). Lucy's scream is a pointed reference to colonial violence, especially in its spectacular representation as the British contingent's only recourse for dealing with a rebellious subject in an English space defined by otherness, a graveyard. Whereas the British contingent regards spatial and subjective otherness 
as a spectral threat, Lucy's and Dracula's spectral subjectivities register in profoundly material ways through corporeal screams. In parallel to Lucy, Mina's later subjectivated body also emits "a scream so wild, so ear-piercing, so despairing that it seems to me now that it will ring in my ears till my dying day" following Dracula's attack on her (247). Both screams are inscribed orally in Seward's diary, which further underscores the forced transition from oral to corporeal violence which is then sanitized within a corpus. This transitionary failure is lodged within Stoker's screams, which anticipate later modernist delineations of colonial violence, whether the "menacing[]" "whisper[s]" lilting off Kurtz's dying lips, "The horror! The horror!"”" (Conrad 163-164) or the Marabar Caves' reverberating echoes, “ou-boum” (Forster 149, 150), which Mrs. Moore admits "began in some indescribable way to undermine her hold on life" (149). Within Dracula, Lucy and Mina's screams are inarticulate colonial echoes whose pitch and circulation register as rupturing elements in the novel's formal structure. Dracula's epistolary composition translates these echoing colonial screams into repetitive, extended placeholders of brutally selfconscious and inarticulate signs of colonial violence.

Mina's subjectivated body grounds two paradoxical effects intimately tied to Dracula's epistolarity, destruction and creation. Following Dracula's subjectivation of Mina, Arthur relates via Seward's diary, “'All the manuscript had been burned, and the blue flames were flickering amongst the white ashes; the cylinders of your phonograph too were thrown on the fire, and the wax had helped the flames"' (Stoker Dracula 249). The contingent has combatted Dracula through an imperial archive, which the materially corporeal Dracula immolates prior to Mina's subjectivated transformation. Here, Dracula's inscribed victory over the literary corpus aligns with a corporeal victory over Mina, "their best beloved", who is "now to me, flesh of my flesh; blood of my blood; kin of my kin" (252). Mina's subjectivated body indexes both the limits of 
imperial narrative and the transformative ends of evental anti-colonial resistance. Her evental significations serve to literally outlive Dracula's subjectivity, which will be subjected to the Empire's material tools. Imperial instrumentality facilitates the contingent's tracking of Dracula across Europe and his eventual demise. Echoing Lucy's violent end, Jonathan Harker's "Kukri knife" and Quincey Morris' "bowie knife" replicate the authorial/authoritative marking of Van Helsing's "stake" $(266,325,190)$. In footnote 5, Dracula notes that Stoker originally inscribed the aftermath of Dracula's death with a forceful finality as the castle explodes with a "roar[ing]" "hollow boom" (325). The revisionary elision of this sound and its non-echoing of Lucy and Mina's screams further complicates Dracula's already ambiguous death.

The limits of the colonial body, even an evental "Irish" one, are finite, but the legacies of colonial resistance linked to the event are not. Dracula's death is not the definitively ritualized death marking Lucy and the three Transylvanian women nor is his subjectivated legacy effaced in spite of the British contingent's fervent desires. Jonathan's final "Note" reflects on the Harkers' child, noting that "it is an added joy to Mina and to me that our boy's birthday is the same day as that which Quincey Morris died. His mother holds, I know, the secret belief that some of our brave friend's spirit has passed into him. His bundle of names links all our little band of men together; but we call him Quincey" (326). Like Mina and Lucy's Irish-effacements, Quincey Harker's naming is a patriarchal assertion of imperial subjective power. In spite of this, Mina's incomplete subjectivated transformation nevertheless gestures toward "our brave friend," that while logically Quincey is nevertheless more ambiguously framed by her "secret belief." The British subjective hold on Quincey Harker is patronymic, but Dracula's paternal claim is far more corporeal as it penetrates to the blood. Quincey's superficial "bundle of names" binds him to the British contingent yet this pales in relation to Dracula's subjectivated transformation of 
Mina, especially as he forced her "mouth to the wound, so that [she] must either suffocate or swallow some of the—Oh my God! my God! what have I done?” (252). Like Jonathan Harker's mirror scene, Mina's "baptism of blood" occurs in intimately domestic confines (280). As opposed to the "bundle of names" that symbolizes British subjectivity fertility, "the" evental "subject is rare" and "is not a result—any more than it is an origin. It is the local status of a procedure, a configuration in excess of the situation" (Being and Event 392). The evental subject's rarity is indelibly linked to an irruptive origin out of the event. The domestic localizes Dracula's evental status both philosophically and colonially, as Homi Bhabha reminds us that "the recesses of the domestic space become sites for history's most intricate invasions" where "the borders between home and world become confused ... [and] the private and the public become part of each other" (13). Bravery for the British contingent is defined by retributive justice and the destruction of alternative subjects whereas Dracula gives new life; this contrast forces a rereading of Van Helsing's assertion, “'A brave man's blood is the best thing on this earth when a woman is in trouble"" (Stoker Dracula 136). Dracula's "brave" "blood" suffuses Quincey Harker's veins, as it does his ambiguously Irish mother. Her marks shadow his birth marks as an evental subject like Dracula who derives his radical nature out of an alternative constitution. This constitution manifests in the present a future alternative to contemporary hegemony. The subject materially manifests the event's immaterial change through linking "the elements of the body ... into the evental present ... In subjective terms, it is the realization in the present of a hitherto unknown possibility. In this sense it is indeed into the present, into the new present, that the escaped slave incorporates himself. It is clear that the body here is subjectivated to the extent that it subordinates itself to the novelty of the possible" (Logics of Worlds 52).

\section{Conclusion: Subjective Horizons of the Nation}


Stoker was a fixture in the Victorian literary marketplace who published twelve novels during his lifetime. The Lady of the Shroud (1909) is Stoker's most closely-related novel to Dracula. This epistolary narrative centers on a lone Englishman whose inheritance takes him to the Blue Mountains in Eastern Europe where he aligns himself with a wraithlike, vampiric woman in a battle against invading Turks. Although the novel's vampiric resonances are merely an illusive cover for the woman's safety, the overt national and political context of the novel clearly links it to Dracula. By the novel's end, Rupert St. Leger delivers the Blue Mountaineers from trouble and consolidates the nation around his kingship:

And then came through the darkness the most beautiful and impressive sound heard yet. That mighty concourse, without fugleman of any sort, began in low, fervent voice, to sing the National Anthem. At first it was of so low tone as to convey the idea of a mighty assembly of violinists playing with the mutes on. But it gradually rose till the air above us seemed to throb and quiver. Each syllable each word - spoken in unison by the vast throng was as clearly enunciated as though spoken by a single voice: 'Guide our feet through darkness, O Jehovah.' (Stoker Lady 234)

This lauding of a national anthem is followed up by the British royalty's visit and the king's marveling upon the "fine" people of the Blue Mountains: "It is good to have even one man eager to give his life for duty. But ten thousand! That is what makes a nation"' (257). The stirring anthem chords and dutiful sacrifice construct a mighty nation under siege from an expansive imperial power. These details echo the screaming chords and evental sacrifices that define Dracula's London penetrations and subjectivated transformations. 
Following Dracula by a decade, The Lady of the Shroud's national and political cries are more clearly seen in an oral speech given twenty-five years prior to Dracula. On November 13, 1872 in Dublin, Stoker delivered his "Trinity Address: The Necessity for Political Honesty." He argued that "as truth broadens out from individuals to nations, so should we have in view its teaching not only to persons, but to the world at large" (37). Strikingly, Stoker sees truth as an individually grounded movement that must "broaden[] out from individuals to nations." Like Badiou, Stoker is not interested in a state-grounded approach to nationalism, political representation, and subjective formations. He privileges the power of the individual outside of national frameworks and later in the speech focuses on the transatlantic Irish and their national powers redirected back upon Ireland: "Think for a moment how an idea developed in our own country would find its echo across the Atlantic, and become a watch-word even in the western wilds. How turning to home the people, imbued with reverence for all their fathers loved and lost, would carry on the cry till it found its echo in the deeds of the nation" (45). Across national and oceanic bounds, Stoker maintains that "an idea" must "develop[]" within a "people," like "home," and then connect to their subjective neighbors_-"fathers"- prior to its echoing consolidation in the nation. Individuals are linked and lauded while the state is made to wait rather than attempting to centralize authority and ideologically collate.

Dracula embodies this individuated subjective approach to the nation and truth-full transformations. The novel largely revolves around three interlinked tropes: blood, writing, and violence. It is no coincidence that these tropes signify a foundational triumvirate of the British colonial project. A slight predecessor and ideological opposite to Dracula is J.R. Seeley's The Expansion of England, based on his 1881 and 1882 Cambridge lectures. Seeley's history maps the British Empire's formation via "Englishmen in all parts of the world." This global 
Englishness is undergirded by "one blood and one religion ... one history and one language and literature" where "distance has no longer the important influence that it had on political relations" (61). The British Empire's geopolitical strength is systemically indexed to a singular imperial subjectivity. Blood and geography converge in equal consolidation of the imperial state, premised on a "people of one nation, speaking one language" under "one government" (37). What unites this singularly global subjectivity "is blood and religion, and ... they are strong ties, and will only give way before some violent dissolving force" (44). Blood is the Empire's foundational tie and writing its global inscription. The only threat to this material and immaterial hegemony is violence. Significantly, violence is both foreign and foreign to the Empire's constitution and these overlapping facets set the British Empire apart from prior empires because "it does not resemble them in that violent military character which has made most Empires shortlived and liable to speedy decay" (38). Seeley stresses the threat of colonial violence against the Empire while disavowing its constitutive force within the colonial project. The Expansion of England signifies the immaterially embodied statements that underwrite the actions of global imperial administrators, historians, and agents whose collected writings materially obfuscate the violence perpetrated against colonial subjects. Seeley's illusive assertions of the Empire's singularly historical progressive character and the global English subject are both asserted in diametric opposition to Badiou's delineation of evental subjectivity.

Seeley's triumphalist imperial history is predicated upon racial and linguistic delineations of the British nation, but his elision of violence and brutality allows for a historically utopian account of the British Empire. Although utopian in governing orientation, Seeley's account nevertheless betrays the explicit ideological processes of the British state as it works within an imperial network of colonial administrative posts to effect racial, linguistic, and cultural 
governance across different peoples. The narrative conflicts in Dracula are grounded on Renan's anxieties surrounding race and language. Dracula's de-racinated figure and his linguistic mastery both inflect these anxieties back upon a consolidated, imperial British state and threaten its coherence on a subjective level. In annulling the subjective foundations of the British state, Dracula extends the reach of the Empire towards various peoples while simultaneously rupturing its internal constitution through a colonially-grounded alternative. Seeley's historical account is the state attempting to keep submerged the violent resistance underwriting the British Empire's extension. Seeley's lectures are focused on the state and lauding the British Empire, and the crown jewel of the British Empire, and Seeley's lectures, is India, the subject of the next chapter.

Although Bram Stoker left little explicit political writings among his massive collection of written materials, the things he did leave behind situate him as a liberal Irishman committed to Home Rule living in London. ${ }^{85}$ Paul Murray further argues that "[i]n his politics, evident in his fiction, Stoker ... advoca[ted] [for] ameliorative reform, combined with detestation of Fenianism, expressed through the character of Mrs. O'Brien in Lady Athlyne" (51). In 1892, Stoker was a founding member of the London-based Irish Literary Society, whose "objectives were to bring together Irish people in London and to promote the study of Irish literature, history and art. Politics were to be eschewed as members included both Unionists and Home Rulers" (136). Members of the Irish Literary Society included Michael Davitt, Sir Charles Gavan Duffy, Alfred Perceval Graves, Douglas Hyde; G.B. Shaw, T.W. Rolleston, Katharine Tynan, and Lady Jane Wilde. Although morbid, Bram's "brother Thornley owned the table on which [Robert] Emmet's head had been cut off after he was hanged 'in accordance with the horrible code for treason of penalties attaching to conviction for high treason"' (142). Bram Stoker was committed to Irish cultural flourishing in all of its various forms, but he was also comfortably entrenched 
within political advocacy for Irish Home Rule. What Stoker just as clearly abhorred was anticolonial fanaticism, though even this is a necessarily nuanced position in light of his brother's patriotic fervor. 


\section{Chapter III. English Eyes and the Irish "I": Ireland's Famine, India's Mutiny, and Kim's Colonial Autonomy}

"What is to be done? asks every one; incapable of hearing any answer, were there even one ready for imparting to him. 'Blacklead those 2 million idle beggars,' I sometimes advised, 'and sell them in Brazil as Niggers,- - perhaps Parliament, on constraint, will allow you to advance them to be Niggers!'- In fact, the Emancipation Societies should send over a deputation or two to look at these immortal Irish 'Free men,' ... it would perhaps moderate the windpipe of much eloquence one hears on that subject!"

During the Famine, Thomas Carlyle embarked on "a "Tour in Ireland"” in which he remarked upon the "chaotic ruin" he saw in which "houses stand roofless, the lands unstocked, uncultivated, the landlords hidden from bailiffs" (TC to Ralph Waldo Emerson). Although rendered "farther from speech on any subject than ever," he nevertheless articulated a visionary “answer" to Ireland's excessive population "problem" in a 13 August 1849 letter to his friend, Ralph Waldo Emerson: “"Blacklead those 2 million idle beggars ... and sell them in Brazil as Niggers."' Strikingly, the Famine moderated Carlyle's early anti-Irish racism. Just a decade prior in the essay "Chartism" he regarded Ireland's cultural and agricultural intransigence-_'Ireland will be burnt into a black unpeopled field of ashes rather than this should last" — as requiring a more permanent solution: "The time has come when the Irish population must either be improved a little, or else exterminated" $(181,183)$. Carlyle's ocular apprehensions were ultimately cultivated not in Ireland but rather in England where "Crowds of miserable Irish darken (my emphasis) all our towns" (182). Throughout his various writings on the Irish, Carlyle exemplifies what Elleke Boehmer considers the "Most definitive" political and literary "organizing or concept-metaphor in colonialist narrative[:] ... the commanding perspective assumed by the European in the text, or what is called the colonial gaze[,] ... made manifest in ... activities of investigation, examination, inspection, peeping, poring over, which were accompaniments to the colonial penetration of a country" (Colonial and Postcolonial 71). 
Carlyle's Irish visions emblematize the stark ocular dichotomies that undergird imperial power, especially as its vision reifies an open and awaiting colonial space rich in resources. Whether through racial blackleading or extermination, the disappearance of Irish bodies and the exercise of English authority is necessary for the progression of white civilization opposed to its blackened colonial obverse. ${ }^{86}$

Within Carlyle's dichotomous vision, many contemporary critics also see Rudyard Kipling's reflection. Even Kipling's contemporaries shared these views, especially the AngloIndian George Orwell (1903-1950), who regarded him as the "prophet of British imperialism in its expansionist phase" (143). This prophetic tenor is seen by many as central to Kim (1901) as an novel that exemplifies the imperial worldview as it represents an "absence of conflict" in order to support "a reformed and more discreet style of imperial control" embodied by "an allseeing, far-sighted Raj” (Said Culture 146; McClintock Imperial Leather 70; Popplewell 30) ${ }^{87}$ And yet, another Kipling contemporary, Leonard Woolf (1880-1969), offers a very different assessment of Kipling's literary relations to empire. In his reflections on colonial administrators, Woolf was confounded, "The white people [colonial administrators] were ... in many ways astonishingly like characters in a Kipling story. I could never make up my mind whether Kipling had moulded his characters accurately in the image of Anglo-Indian society or whether we were moulding our characters accurately in the image of a Kipling story" (qtd. in McBratney 166). For Woolf, Kipling's representation mirrors the contested colonial terrain that contemporary scholars likewise highlight in reading Kim as anti-colonial. In this vein, Kim's depiction of a timeless India casts "imperial rule as temporary" and "Indian life [a]s a constant irrespective of the empires that come and go" (Childs 48). Further criticism emphasizes Kim's "deeper kind of vision ... to become the "other" premised upon "relentless mimesis" and the "panoramic 
view[s]" that further underscore the "multicultural ... implications ... for national identity" that ultimately frame the novel as "fractur[ing] the myth of a coherent empire" (Kinkead-Weekes 217; Suleri 114; Wurgaft 104; Moore-Gilbert "Kipling and postcolonial" 158; Tim Watson 96). ${ }^{88}$ Although these dominant critical vistas are essentially dichotomous, the novel's triangulation of Irish, Indian, and English facets underscore an even more multivalent and potentially divergent imperial vision. ${ }^{89}$

The novel's Irish-Indian protagonist, Kimball O’Hara, signifies a wider cross-colonial context than any dichotomous schema can encompass. Kim's embodied contexts are antithetical to Carlyle's earlier imperialized monology and cross-colonial solution to the Irish problem, but they are also indicative of sustained historical and literary links between Ireland and India. ${ }^{90}$ Both links are evident in Ellen Fitzsimon's (1805-1883) poem "Sonnet: 1849" written during the Famine. The fourteen line sonnet initially represents a "happless Erin, this sad isle of ours! / Though late fell Famine stalked throughout her bowers," and the passing of her "Lovely" and "Fertile" lands into a famished wasteland (11. 2-3, 5, 6). Fitzsimon (nee O'Connell, third child and first daughter of Daniel O'Connell the Liberator), ultimately transitions from famished Ireland to resistant Ireland through a cross-colonial connection to India:

Is then our Isle of Heaven accursed and banned,

That all desert her thus? Perish the thought!

Not in such spirit read we Erin's lot;

Full often is adversity's chill breath

More precious than the wealth of India's mine, (11. 8-12).

Ireland and India bookend lines that cast the Famine's specter as transgressing the boundaries of the natural world, the economy, and the social body; "desert" and "Perish" function in a number 
of signifying ways to mark geographical and migratory desolation, as well as a more general degradation. Crucially, the sonnet reads the colonial paradox of famine and fertility through a revolutionary lens, one that posits through rhyme "the wealth of India's mine" as the trajectory for thinking "High is the comfort of the text divine: / Whom the Lord loveth, them $\mathrm{He}$ chasteneth!" (11. 12-14). Whether Ireland's or India's natural distinctions, the sonnet expands them through a transgressive gesture towards the "divine" and a paradoxical strength in fragility. Fitzsimon's cross-colonial connections foreshadow, indeed reframe, the imperial nexus that bridges Ireland and India and eventually places the orphaned Kim in India. Fitzsimon's poetic resistance is also sympathetically inflective of Kipling's assessment of the later novel as "a long leisurely Asiatic yarn in which there are hardly any Englishmen ... I think it is a bit more temperate and wise than much of my stuff" (The Letters Vol. 3 11). Although different from Fitzsimon's English criticism, Kim's “wis[dom]” similarly derives from English absence, an absence from colonial narratives that is inadvertently re-presented in many contemporary proimperial readings of the novel that insist upon an English imperial subject and thereby reinforce the fundamental premise of imperial narratives: "the drama that there is is their drama. Almost without exception there is no narrative interest without European involvement or intervention" (Boehmer, Colonial and Postcolonial 64). Leaving this English absence allows various colonial subtexts to re-emerge including Irish and Indian crossings rooted in Ireland's Famine and subsequent diaspora.

My contention is that Kim offers a paradigmatic narrative of an autonomous colonial subject formed out of cross-colonial implications. Although critics still dispute the political implications of the novel, my argument focuses on Kim's form as integral to clarifying the fundamentally anti-colonial and resistant strands at the narrative's core, embodied by an Irish- 
Indian orphan. Kim's picaresque form, colonial setting, and cross-colonial subject, all framed by a largely unmarked formal division between narrator and subject, develop a distinctly dichotomous and fragmented narrative that actively unsettles colonial ideology by privileging its protagonist's assertions and actions against the powerless ones posited by the narrator and related imperial subjects. This chapter begins by re-presenting the historically tumultuous, violent, and revolutionary Irish contexts that are synonymous with Kim's development and thereby cast the novel's formal divide into sharper light. I then trace the historical implications of Kim's Irish-Indian connections within Ireland's post-Famine diaspora, India's Mutiny, and the subversive colonial alternatives realized as both events coalesce within the British Raj's power dynamics. In closing, I trace the failure of "hybridity" as a concept to delineate Kim's assertions and actions and instead conceptualize how cross-colonial implications in past atrocities-both Famine and Mutiny—progressively situate the lama and Kim at an irrevocable remove from imperial narratives, subjects, and ideologies. Ultimately Kim's embodied presence weaves together the novel's formal frameworks as a repudiation of British colonial monology that deforms the colonial project's ocular networks by shifting the narrative "I" from English presence to Irish absence. In locating an autonomous Irish subject born in India, Kim models a pan-colonial vision of resistance and subjective agency. Famine and Mutiny connections ground this pan-colonial vision within an atrocity paradigm that engages with localized colonial dynamics and broadly conceived anti-colonial agitation in the wider British Empire.

Kim's formal divisions accentuate and foreground the Kim's developing division as colonial subject apart from an implicitly English narrator. This division allows Kim to act against the grain of British imperial narrative practices and precepts that Edward Said describes as "narratives t[hat] make knowledge, intelligibility, and vision into functions of utterance" and 
thus reduce colonial distinctions into a simplified trajectory of "human history [a]s human actuality [a]s human activity [a]s human knowledge" (World, the Text 102, 112). Said's conception of the unbroken signifying power of imperial assertions informs a distinctly colonial facet of Alain Badiou's later delineation of "ontologies of presence" as the grounding force of hegemonic states like England (Being and Event 27). Events like the Famine and the Mutiny sharply constrast imperial plenitude and presence with degradation and absence and so they "leave traces, but these traces never have a univocal value in themselves" (Handbook 130). Further extrapolating this contrast is the event as essentially a fault line in hegemony or, especially relevant with the Famine, an "injection of lack into an instance of plenitude" (132). The indeterminate resonances and scarcity of these part colonial events in Kim foreground the role Kim plays in developing an autonomous subjectivity. The narrator's omnipresent monological and univocal capacities exemplify Simon Gikandi's axiomatic link that Empire is the "raison d'être of Britishness itself" (31). This raises the stakes of Kim's subversion of the narrator and related imperial subjects throughout Kim as he embarks on a journey that will not privilege monological surveillance, racial disguises, or black-ops daring, but a reformulation of the colonial subject outside of the binaries of colonizer and colonized through the cross-colonial legacies of Ireland's Famine and India's Mutiny.

\section{Colonial Revelations: Kim's Colonial (Di)Vision and (Anti)Colonial Forms}

When it comes to formal practice, Kipling is a critical anomaly. Although his contemporaries included leading figures in formal and modern experimentation like Henry James (1843-1916), Walter Pater (1839-1894), Oscar Wilde (1854-1900), and W.B. Yeats (1865-1939) yet he is rarely linked with them. ${ }^{91}$ Another Kipling contemporary, Virginia Woolf (1882-1941), anticipated contemporary disputes over Kipling's politics in her criticism of his prose as 
"lack[ing] suggestive power. And when a book lacks suggestive power, however hard it hits the surface of the mind it cannot penetrate within" (A Room of 101) ${ }^{92}$ Woolf's criticism on Kipling's putatively shallow prose is echoed by critics who deride his putatively unsophisticated literary form as an analogue for his regressive politics. Kim's formal unsophistication is charged according to Kipling's own description of the novel as "nakedly picaresque and plotless—a thing imposed from without" (Something of Myself 245) ${ }^{93}$ Far from a signifier of unsophistication, Kim's picaresque form is central to formulating an incisive colonial critique and anti-colonial alternative. After all, the picaresque is a literary form that derives not from Spain, but from a translated European import, "the oriental, Arabic Maqâmât" (Al-Dabbagh 25). This imported form textures "the seminal element of the picaresque structure, a double narrative voice," that anticipates "the kind of schizophrenia which results from the meeting of modernity and premodern traditions ... in most postcolonial writing" (Malkmus 28; Almond 97). Formally, this schizophrenic condition is accentuated by the picaresque's stylistically "perpetual rhythm of ... continuous dis-integration" that defies all "narrative act[s] ... [to] integrate the excluded picaro into a stable order of things" (Wicks 55, 59). Narrative disorder fundamentally privileges the picaro as an antihero precursor to later modernist social outsiders like "the prostitute and the artist" that "satirize society a[nd] ... represent ... social tensions" (Ardila 5; Rodríguez-Luis 45). The picaresque contexts prefigure Kim's outsider Irish status, as opposed to Anglo-Irish imperial sympathies, and further texture the formal facets of the novel that implicitly, if largely invisibly, resist imperial narrative and ideological tenets. Furthermore, the picaresque underscores the distance Kim achieves formally and subsequently contextually between imperial narrator and colonial subject. 
Kim's imperial and colonial divide is cast into sharper relief by the late-nineteenth- and early-twentieth-century contexts of Irish subjectivity and revolutionary activity. Significantly, Kim's Irish contexts extend further into narrative and stylistic congruence with "a distinctly Irish modernism" that Declan Kiberd premises upon "the significance of the father-son relation, the emergence of androgynous heroism, [and] a mingling of vernacular traditions with high art" (“Postcolonial Modernism?" 274-275). ${ }^{94}$ Kim stages each of these facets around a distinctly Irish protagonist born in India, which further resonates with the historical and literary contexts that shaped the novel. Although "Ireland was discursively and politically understood as a region on the edge," especially for the Anglo-Indian born Kipling, its colonial dynamics remained central to his literary development as a novelist (Wright 10). ${ }^{95}$ "Irish imperial networks in nineteenthcentury India were dynamic and constantly shifting vectors of cultural interaction, rather than frozen channels of an imperial "centre" that influenced Kipling's earliest novelistic attempt, Mother Maturin (1885), which focuses on a titular Irish vagabond in India who operates an opium den in Lahore and represents the "wholly untouched and unaffected ... life of the peoples of the land" (Crosbie 261 Irish Imperial Networks; Kipling Letters I 99). Kipling would abandon Mother Maturin —now lost—and begin another novel in 1891 or 1892 based upon "a vague notion of an Irish boy, born in India" that he "christened ... 'Kim of the 'Rishti'” (Something of Myself 147-148). Among three novels composed between 1885 and 1900, only The Light That Failed (1890) failed to focus on an Irish protagonist during a period of intense global Irish colonial conflicts including the Land War (1870-1890) in Ireland, a transatlantic Fenian dynamiting campaign originating in America and targeting England and Scotland (1881-1885), and Irish parliamentary agitation connecting with and intervening in Indian land and famine debates (1870s-1890s) (Crosbie Irish Imperial Networks 251). ${ }^{96}$ 
Kim's composition in the midst of these revolutionary contexts informs the ways we need to read the novel's central formal divide between narrator and Kim. Throughout the novel the narrator's assertions attempt to overwrite Kim's actions. In the context of an Irish subject, this relationship reflects the contemporaneous British "political belief that Irish autonomy was utterly unthinkable, the Irish were considered useful for acquiring knowledge but deficient analysts of their own customs, social mores, and political environment" and thus the novel's formal conflict maintains an analogous relationship to imperial responses to Irish unrest (Nally 91). Much more than a subservient imperial spy, Kim is a revolutionary Irish subject attempting to elude imperial narration. Kipling's own lexical choices further coincide with specifically Irish tensions as he overwhelmingly privileges "England" and "English" over "Britain" and "British." Privileging the lexical pairing of England/English over Britain/British "does not indicate cavalier disregard of Scotland and Wales," as historian Roy Foster explains, but "rather, that 'England' carries a historical charge, an implication of attempted cultural dominance, an assertion of power, which is not conveyed to an Irish ear by 'Britain"” (XII). ${ }^{97}$ Furthermore sociologist Mary Hickman attests that these are not semantic differences since "Britishness is a national identity constructed on the basis of a series of either forced or negotiated unions of different societies" so that "Being 'English' and being 'British' were synonymous if you were English” but not Irish (38). These lexical and ideological contexts further inform Kim's formal division as it becomes apparent in the novel's opening scene in Lahore as Kim sits "in defiance of municipal orders, astride the gun Zam-Zammah" after "kick[ing] Lala Dinanath's boy off the trunions" and winning a juvenile game of "King of the Hill" (Kipling Kim 3). The disembodied narrator, exemplifying John D. Dorst's definitional elaboration of the verb "To colonize [a]s to occupy a position from which the colonial object c[an] be seen coherently as ... available for appropriation," asserts Kim's 
victory as racially and politically affirming: "who hold Zam-Zammah, that 'fire-breathing dragon', hold the Punjab, for the great green-bronze piece is always first of the conqueror's loot ... the English held the Punjab and Kim was English" (Postcolonial America 306; Kipling Kim 3). Although "the narrator ... is the sharpest physiognomer in the novel," as Michael Hollington observes, his assertion is clearly at odds with Kim's paternity_-“Kimball O'Hara, [was] a young colour-sergeant of the Mavericks, an Irish regiment" and his "mother had been Irish too"-and Kim's interrelations: "he was burned black as any native," "spoke the vernacular by preference," "consorted on terms of perfect equality with the small boys of the bazar," and "was white-a poor white of the very poorest" (179; Kipling Kim 3, 14, 3).

In spite of narrative prerogative, Kim's embodied subjectivity and intersubjective acts and attitudes will persistently defy imperial monology. Although the narrator will persist in making assertions like "Kim could lie like an Oriental" or "Where[as] a native would have lain down, Kim's white blood set him upon his feet," Kim's emerging autonomy simultaneously consigns the imperial eye and voice, what Franz Fanon saliently terms "The old monologue," to speechless futility (Kipling Kim 23, 42; Studies in a 95). Kim's actions further accentuate the formal divide between imperial narrator and colonial subject and highlight the novel's resonances with Alain Badiou's event, especially in Kim's formally realized "ex-centered dimension ... which posits that all true universality is devoid of a center" (Saint Paul 19). This (de)voided center, occupied by a narrator attempting to overwrite the Irish subject through stereotypical, often Orientalist, assertions, is also inhabited periodically by passing imperial agents like Creighton Sahib whose most “English” assertion is, “"That boy mustn't be wasted if he is as advertised"' (Kipling Kim 95). The novel deploys a cadre of imperial bodies that, whether narrator, Creighton, or various others, manifest various imperial subjective forms 
constituted as 'territorially-bound national subjects with bodies that 'are', not discounting other possibilities, white, hetero-normative, productive, non-theatrical, and even, at times, disembodied" (Poon 15). Whether "disembodied" or "bodie[d]," Kim's narrator and Creighton both operate within hegemonic epistemologies premised upon "knowledge, in its encyclopaedic disposition, [that] never encounters anything" and "presupposes presentation" (Badiou Being and Event 395). For Badiou, presentation accords with an ideological façade, which in the imperial context "never encounters anything" as it postulates Kim as English and a faithful agent. Encyclopaedic presentation anchors an imperial vision at the heart of Kim that is formally and narratively deformed throughout the novel. Throughout Kim's youthful "years of indiscretion, he learned to avoid missionaries and white men of serious aspect who asked who he was, and what he did" (Kipling Kim 5). Beyond juvenile innocence, Kim's deliberate "indiscretion" and avoidance result in his encounters with colonial reality rather than imperial ideology and this bears resistant fruit as he matures and "h[o]ld views of his own"98

\section{Colonial Corpora: Embodied Histories and Famished Crossings}

As Kim's formal division widens between English narrator and Irish subject, crosscolonial connections between Irish and Indian events become more pronounced. The initial cross-colonial connection involves the parallel quests undertaken for the lama's "River of the Arrow" and Kim's "'Red bull on a green field,"” (Kipling Kim 12, 17). These distinct quests ultimately index wider cross-colonial connections amplified in Kim's interactions and rejoinders to various imperial subjects throughout his journey. Significantly, at both the inauguration of the lama's quest and Kim's initial fulfillment of his "prophecy," the lama comments on Kim focus on the latter's emergent, embodied signs of difference and shifting forms: "'But thou wast sent to me ... From beside the cannon didst thou come — bearing two faces — and two garbs"” and "“As a 
boy in the dress of white men — when I first went to the Wonder House. And a second time thou wast a Hindu. What shall the third incarnation be?"” $(73,32,79)$. Kim's "incarnation[s]" are formulated under the auspices of a prophetic admixture that is evocative of Elleke Boehmer's concept of "an interbraiding of lines of resistance derived from their different cultural and political traditions ... signifying crossings upon crossings" (Empire, The National 58). Kim's "crossings upon crossings" trace out a very different Irish colonial place in the Empire, one whose obverse, as summarized by historian Michael Silvestri, supported imperial expansion: "Although the Victorians at times stereotyped the Irish—and Irish Catholics in particular—as an inferior 'race,' in India 'the wild Irish' were seen as an important part of the colonial civilizing mission" (180). ${ }^{99} \mathrm{Kim}$ is superficially linked to this Irish aspect of the civilizing mission as his prophetic sign is the regimental marker of the Mavericks, an Irish imperial division of the Indian army: “'O Holy One!' he gasped. 'My horoscope!' ... It was no more than an ordinary camp marking-flag; but the regiment, always punctilious in matters of millinery, had charged it with the regimental device, the Red Bull, which is the crest of the Mavericks - the great Red Bull on a background of Irish green" (Kipling Kim 70). However, the Mavericks' crest retains subversive Irish significations, namely the "Red Bull on a background of Irish green," which conveys an interbraiding of symbolic Irish and Indian connections, the latter in terms of Hinduism and the “"holy bull of Shiv"” (15). The Mavericks' Red Bull bears further semantic resonances with "Donn Cuailnge," "the Brown Bull of Cuailnge" that is central to Ireland's eighth-century epic Táin Bó Cúailnge and its narrative of heroic resistance (The Táin 55). Kim's cross-colonial Indian setting further underscores the politicized connections embodied by the Irish-Indian Kim. Kim's destiny is further grounded within cross-colonial connections by an Umballa priest who initially "'said that thine was the sign of War"" and then "scratched, smoothed out, and scratched 
again in the dust mysterious signs" that ultimately convey in the Indian soil an Irish sign of radical colonial significations (Kipling $\operatorname{Kim} 70,37$ ).

Kim's Red bull is a symbolic and material sign of his emerging subjectivity framed within a wider cross-colonial framework. Added to these symbolic and material touchstones are the temporal disjunctions that afflict the colonial project and the colonized subject particularly. For the "subjects of empire," temporal disjunctions constitute "a destabilizing epistemological juncture: their past identities and narratives could not disappear entirely, nor could they remain central to their lives" such that they "function[n] on a temporal plane that was authorized by neither the past they had renounced nor the future they desired" (Gikandi Maps of Englishness 37). Gikandi usefully broadens the colonial import of Kim's localized sign as the bull's "destabilizing epistemological" significations radically extend its cross-colonial Irish/Indian meanings. Not only do the bull's cross-colonial significations extend beyond The Táin's cultural confines, but also beyond the geographic and "temporal plane[s]" that ostensibly demarcate Ireland's Famine from the British Raj's most pervasive and recurring narrative, the Mutiny. Whereas the Bull's symbolic interbraiding offers a complex and variegated colonial picture, the Mutiny's imperial representation coheres in a crystallized narrative unity as "a caesural moment in the history of the Indian empire ... when all was nearly lost only to be regained once more" (Chakravarty 4). On May 10, 1857, localized mutinies by sepoy regiments, largely consisting of Hindus and Muslims overseen by British officers, broke out in Agra, Allahabad, Ambala, Calcutta, and Meerut before spreading widely across north-central India and resulting in the fall of Delhi. As a colonial event, the "Mutiny" is variously denominated as the Indian Rebellion, the Indian Uprising, and the War for Indian Independence, among others, in reference to its contested narrative and historical status. ${ }^{100}$ Approximately fifty Mutiny novels were published 
between 1857 and 1900 and each was "aimed primarily at a juvenile readership" and emphasized "character-building, empire, military exploits, and state security and espionage" (6). In spite of different authorships and details, these Mutiny novels betray an ideological coherence that attempts to "reduce the complexity of racial and cultural antagonisms between two nations to an impertinent insubordination from the lower ranks or races" and "celebrat[e]" "British ... atrocities ... [like] hanging and shooting without trial, blowing prisoners from the mouths of cannons, looting, and massacring the Indian residents of recaptured towns ... as excesses of heroism, performed in the heat of battle" (Steve Attridge 142; Brantlinger Rule of Darkness 201). The Mutiny's highly racialized narratives reflect a localized Indian conflict that was articulated according to broader cross-colonial legacies deriving out of earlier Irish conflicts. Ireland's colonial proximity to England shaped a dynamic set of British representational practices that were deployed in more far-flung colonial locales. The British press particularly "looked to the empire and the dark corners of the world to analogize Irish violence and disorder" and vice-versa, as "British commentators widely abused the sepoys and Indians in general in 1857 and black Jamaicans in 1865 for their ingratitude and brutality, using many of the same criticisms levelled against the Irish" (de Nie 121, 126-127). By the late nineteenth-century, Irish colonial significations were commonplace throughout the Empire as British subjects in Nova Scotia, Canada deployed the pejorative "Irish Sepoys" to deride Irish immigrants settling there (Johnston 28). Although no similar rising broke out in Ireland coincident with the Mutiny, the event generated smaller disruptions: a mutiny broke out among militiamen in Tipperary; a potato riot in Galway; and sustained street rioting throughout Belfast during elections, with far larger ideological anxieties in the popular press. ${ }^{101}$ Similarly, Irish newspapers, whether nationalist or unionist, featured extensive commentary on the Mutiny's contested meanings within the global 
British Empire. In the nationalist Catholic Ulsterman, India's present Mutiny was a reflection of Ireland's colonial past, "'We have more than once written of the crimes of British rulers in India ... We have shown how like the system pursued there, is, in many respects to the fierce and sanguinary policy which desolated Ireland for so many centuries," and an intimation of a decolonized future: "“some great revolution of the native races, the domination of England will be swept away ... When that day comes there will not be very many wet eyes within the shores of Ireland"” (qtd. in Morris 109, 110). For Irish nationalists, the Mutiny was an emblematic "symbol of British oppression" added to a growing list of imperial vices that included the Famine (Hall, Mark 95). Conversely, British colonial administrators, particularly military officers, saw the Mutiny as a colonial specter that straddled Irish and Indian revolutionary anxieties. India's mutinous regiments, largely comprised of Indian recruits from Bengal, Bombay, and Madras, were recast as racially unfit subject groups for military recruitment through a martial race ideology that coalesced in the Mutiny's wake. A new racial paradigm dictated what the British imperial soldier looked like, including an ideologically-based rejection of Englishmen who were viewed as too "uneducated, immoral, and prone to drink and violence" (Streets 21). Rather, newly minted racialized groups that "possessed a 'ferocity natural to savages," "“martial' Highlanders, Gurkhas and Sikhs ... 'made' of the right 'material”" were seen as imperial soldiers par excellence: "obedient, loyal, strong, masculine, hardy, healthy and moral" $(8,138,157)$. By necessity, Irish recruits continued to fill out imperial army ranks throughout the twentieth century but martial race ideology dictated a strident reimagining of Celtic as an identity category for Scottish Highlanders, who were now imagined as "the positive Celtic alter ego to Ireland's reputedly degenerate - and disloyal - Celts" (167). ${ }^{102}$ 
The Mutiny's legacies had a significant, albeit largely absent influence on Kipling. The Mutiny novel was a rite of passage for Anglo-Indian writers and yet Kipling never wrote such a novel nor did he focus his short stories on the Mutiny or its legacies. ${ }^{103}$ Among the sole exceptions to this omission is “The Lost Legion," published in The Strand Magazine's January 1892 issue. "The Lost Legion" is a frame story narrated by an Afghani "greybeard" who begins with a memory of the Mutiny, specifically a "'great killing, done slowly" "more than thirty years" ago of a mutinous "regiment of Native Irregular Horsemen," the $55^{\text {th }}$ Native Infantry (Kipling "The Lost Legion" 476). ${ }^{104}$ Historically, the $55^{\text {th }}$ was massacred under the direction of Anglo-Irish officer John Nicholson (1822-1857), equally famous for his merciless command of sepoys and his brutal suppression of rebellions on British India's north-west frontier. ${ }^{105}$ A timeshift carries the narrative to its main focus, an account of the nocturnal capture of a notorious chieftain, Gulla Kutta Mullah, who murders British subjects with impunity, by a regiment of martial race soldiers and English officers: "a hundred English troops ... two hundred Goorkhas, and ... a hundred ... native cavalry" (478). As the cavalry close in on Mullah's stronghold they stumble through "what seem[s] to be a very graveyard of little cairns" and they "make so much noise" that a prominent British officer, Lieutenant Halley, is certain the Mullah's guard has noticed (480, 481). Eventually, an Afghan guardsmen is captured and explains why no alarm was raised: "The valley is full of the dead' ... 'It is better to fall into the hands of the English than the hands of the dead ... I saw them in the lightning'" (482). After the Mullah is apprehended without incident, "a grizzled native officer," Kurruk Shah, echoes the Afghanis' sightings of "a Dead Rissala in these hills” to which Halley subsequently derides, “"That is foolish talk, Kurruk Shah. The dead are dead'" (483). Halley's imperial assertion is confident in its clipped finality yet it quickly crumbles before Shah's responsive repudiation: “"The dead are dead, and for that 
reason they walk at night. What need to talk? We be men; we have our eyes and ears. Thou canst both see and hear them, down the hillside."' In Kipling's Mutiny narrative, the imperial eye is willfully blind to the lingering realities of the colonial situation. Rather than imperial triumph, “The Lost Legion" attests to the Mutiny's lingering realities of atrocity. Halley's inability to reconcile colonial past and present is central to the story's ending as both the dead and his reflections on the raid remain connected in silence: "but whether he saw or heard more than was natural Halley alone knows, and he does not choose to speak on the subject."

Kipling's Mutiny ghost story formulates a distinct albeit ephemeral obverse to the standard triumphalist Mutiny narrative that pervades Anglo-Indian revisions of the event. Representing the Mutiny's ghosts as tangible preserves both the conflicted core of the event and its lingering legacies. Ghosts further manifest a cross-colonial transgression, one David Lloyd further details in a broad yet personal historical trajectory: "ghosts are not merely the tattered remnants of our unpacified history, the unquiet afterbirths of historical trauma. They may also represent the survival, in unexpected times and places, of unexhausted possibilities, of potentials that exceed the confines of common sense or verisimilitude" (Irish Culture 50). Kipling's Mutiny narrative encompasses both afterbirth and alternative as its decidedly global and exceptionally unbounded representation is antithetical to imperial monology. Whereas a monological Mutiny narrative is premised upon clear colonial divides, such as colonial violence as hateful excess and imperial violence as uncontrollable heroism, Kipling's ghosts persist uncomfortably in delineating a unified colonial world. Such a world reflects the "first fundamental property" Alain Badiou notes about representation, namely that the concept of "world does not have a 'beneath' that would be external to it, a sort of pre-worldly matter. It is only a world to the extent that what composes its composition lies within its composition" 
(Logics of Worlds 307). The hierarchical demarcation Badiou thinks against is central to colonial progress; indeed it sustains the dichotomy between civilization and barbarism as the higher and lower forms of life. British imperial violence is justified in service to some higher end just as death, even mass death, amongst the ostensibly lower forms of life, those "beneath" and constitutive of a "pre-worldly" British civilization, are similarly justified as a necessary cost.

Ultimately, Kipling's ghosts refuse the logic that not only dictates a demarcated world but then attempts to dismiss this world's costs as a progressive necessity. "The Lost Legion" narrates colonial atrocity's violent silencing of subjects even as it represents lingering and irrepressible forms of colonial subjectivity, resistance, and autonomy. Kipling's Mutiny narrative, which predates Kim, importantly helps us to read the ways the Mutiny is allusively rendered in the later novel with even greater ephemerality and seeming nonchalance. Kim's first explicit reference to the Mutiny occurs during Kim's and the lama's travels on the Grand Trunk road as they encounter an elderly native officer. This "old, withered man, who had served the Government in the days of the Mutiny as a native officer" puts Kim up for the night and entertains him with "his cavalry sabre and, balancing it on his dry knees, t[ells] tales of the Mutiny and young captains thirty years in their graves" (Kipling Kim 42, 44, 45). This personal encounter with Kim extends to further references to the Mutiny in conversation with the lama the following day when the "Rissaldar Sahib" relates his participation in suppressing the rebellion and lauding British imperial rule: "“I do not speak without knowledge who have seen the land from Delhi south awash with blood."' $(52,47)$. He further attributes the Mutiny to providential origins, avowing, “"The Gods, who sent it for a plague, alone know. A madness ate into all the Army, and they turned against their officers."' Significantly, the Sahib's recasting of the Mutiny as a providential plague evokes the exact terms Charles Trevelyan used in justifying and 
explaining the Famine in Ireland as "a salutary revolution ... [t]ha[t] educed permanent good out of transient evil" through "some great intervention of Providence" $(1,6) .{ }^{106}$ The lama's response to the Sahib further links both events, Mutiny and Famine, in his choice of language, "'Some such rumour, I believe, reached me once long ago. They called it the Black Year, as I remember"' (Kipling Kim 47). The lama's contentious memory reconstructs the Mutiny and Famine within a shared space, one in which India's "Black Year" echoes Ireland's earlier Black '47 (the worst year of Famine suffering). The lama's confluence is striking since the Mutiny's common euphemistic parlance was not black, but rather red—“"red year"” or "“red revenge"” (Brantlinger Rule of Darkness 201). Black does echo a particular Indian colonial narrative, namely Charles James O'Donnell's highly critical The Black Pamphlet of Calcutta: The Famine of 1874 (1876). In his acerbic pamphlet, O'Donnell, an Irish Catholic officer in the Indian Civil Service, castigated Sir Richard Temple's inadequate relief measures during the Bengal Famine by drawing explicit connections between India and Ireland, specifically through the "prostituted" "English and Indian charity" of the Bengal Famine "that insults the memory of Mayo and decorates the Faminists" (qtd in Crosbie “"L'enfant terrible"” 124). ${ }^{107}$

The transgressive qualities of Kipling's earlier Mutiny ghosts parallel the transgressive allusive qualities that later tie Mutiny and Famine together in Kim. The ephemeral qualities of the ghosts and the events themselves have material touchstones in the characters who engage with them, whether Lieutenant Halley, Kurruk Shah, the lama, Kim, or the Rissaldar Sahib. Both Kim's formal divide and Badiou's account of the event's significance similarly manifest this relation between the ephemeral and the material. For the latter, the event gains significance through "retroactive mechanisms" in which "the trace of the event, is a general condition for the existence of bodies. In this respect, it is devoid of a singular connection to a determinate point of 
the world" (Philosophy and the Event 71; Logics of Worlds 488). Badiou's focus on "retroactive mechanisms" for recognizing a viable event expand the power of the event to impact various subjects and areas. This insight undergirds the connections made in Kim between Mutiny and Famine through subjects. As Badiou notes, such connections are powerful and disruptive to the extent that they are random and heterodox in form and function. The lama's allusive congruence between Mutiny and Famine in his response to the Sahib on the Grand Trunk road is suggestive of a later nondescript scene that embodies both events. As Kim and the lama ride a train to Benares, the latter "gaze[s] placidly up-stream, where in long, smudged perspective the ceaseless columns of smoke go up from the burning-ghats by the river. Now and again, despite all municipal regulations, the fragment of a half-burned body bobbed by on the full current" (Kipling Kim 165). Kim lacks any explicit ghosts yet this corporeal fragment, itself an excessive rem(a)inder of colonial events and their atrocious aftermath, dredges up the same kinds of transgressive and lingering impacts. The lama's earlier allusive joining of Mutiny and Famine prefigure a similar conjoining here of a distinctly Hindu practice, the burning of the dead by the Ganges, to the broader constitution of the modern subject. Critic Rod Edmond metaphorically conceives the modern subject as the "body in pieces, whether fragmented or mutilated ... as a way of expressing a distinctively modern sense of the loss of wholeness and coherence" (49). For Edmond, this is a metaphor, but in Kim, as well as "The Lost Legion," a "distinctly modern sense" of fragmentation and incoherence is intensely and uncomfortably corporeal as the fragmented, burnt, and floating body attests. Kipling's fragment signifies a dark underside, namely modernity's facilitation of mass atrocity. In deftly weaving Mutiny and Famine together through random allusions and corporeal rem(a)inders, Kipling offers a narrative whose formal division itself layers a dialectical range of "wholeness and coherence" that limns realist narrative 
modes. This mode is disrupted through form and Kim's emerging autonomy, both of which cause the realist façade to crumble beneath the barely perceptible weight of ghostly and corporeal figments and fragments.

\section{Famished Fragments: Deformed Bodies and Reformed Subjects}

Hybridity has long been the subjective modality for appraising Kim's relations and implications with colonizer and/or colonized. For many critics, Kim represents a "median category that transgresses the seemingly self-contained identities of sahib and native, coloniser and colonised" (Cronin 132). ${ }^{108}$ Kim's hybridity derives out of Homi Bhabha's seminal conception of hybridity as a "condition of subjection" whereby "differen[ce]" is "repeated" as "a mutation, a hybrid ... that disturbs the visibility of the colonial presence and" ultimately "causes the dominant discourse to split along the axis of its power to be representative [and] authoritative" grounds many critical appraisals $(159,162) .{ }^{109}$ Beyond just asserting Kim's ambiguities, though, several critics have persisted in utilizing hybrid paradigms that inexplicably disavow Kim’s Irishness, exemplified by Gail Ching-Liang Low’s and Satya P. Mohanty’s

respective claims "that Kim is, of course, English" and unquestionably "white” $(213 ; 319) .{ }^{110}$ This hybrid panorama has blunted the term's critical rigor, but more significantly it elides Kim's textual and historically contextual logic. Besides Kim’s obvious Irishness, “hybrid” as defined in the Oxford English Dictionary is initially solely indicative of non-human plants and animals, "half-breed, cross-breed, or mongrel," prior to its first human example in 1603: "She's a wildIrish borne! Sir, and a Hybride" ("hybrid"). A prominent complication of hybridity is tied to the novel's Mutiny allusions, specifically as Kim and the lama arrive at the Grand Trunk road and the Rissaldar Sahib offers them a parting song, "the story of Nikal Seyn (Nicholson) — the song that men sing in the Punjab to this day ... 'Ahi! Nikal Seyn is dead-he died before Delhi! 
Lances of the North, take vengeance for Nikal Seyn"” that merits Kim's "delighted" "compliments" in contrast to "the lama [who] was markedly silent" (Kiping Kim 51). The reference to Nicholson, the "Hero of Delhi," contrasts the Irish orphan who youthfully enjoys the song with the Lisburn, Ireland-born imperial hero who is recast "as 'English,' and ... a model for Victorian and Edwardian youth to emulate" and whose Irishness, if recognized, is envisioned "in a strictly loyalist Ulster Protestant mode" (Silvestri 77, 123). ${ }^{111}$ Nicholson, not Kim, signifies a clearly imperial "Irish" hero, one whose heroism clearly endows him as "English." Martial race ideology in post-Mutiny India further shift the lens we view the Irish, particularly through the martial heroism of Nicholson. It was English representation and political expression that hybridized "similarities between Highlanders, Sikhs, and Gurkhas ... as a united discursive front against the disruptive and dangerous challenges posed by Indian and Irish nationalists alike" and this imperial hybridity was far from essentializable as "even if one was not Highland by birth, by adopting the outward signs of Highlandness 'martial instincts' could be learned ... [and] one could 'convert' and still reap the benefits" (Streets 173, 177).

Critical hybridity paradigms too often present a general dichotomy that ignored and even disavows Kim's distinctly Irish identity and the novel's distinctly historical hybridity. As opposed to a threatening specter to imperial power or an index of anxieties over difference, hybridity functions throughout Kim as an elaboration of imperial power and one that Kim is increasingly counterpointed against. Anthropologist Nicholas Thomas' critique of Bhabha's hybrid paradigm clarifies the powerful intervention Kim makes within the novel's hybrid contexts: "What is unsatisfactory ... is the implication that the work of colonial discourse is essentially to diminish or deny difference, whereas it might be argued that in many contexts it is equally concerned to deny similarity" (51). At Kim's prophetic consummation in the Mavericks' 
campsite, once he is caught by the military chaplains, Bennett and Vincent, the former seeks to establish similarity with Kim- "Father Victor stepped forward quickly and opened the front of Kim's upper garment. 'You see, Bennett, he's not very black"'—whereas Kim explicitly repudiates similarities with them: ““Gorah-log (white-folk). No-ah! No-ah!' Kim shook his head violently. There was nothing in his composition to which drill and routine appealed. 'I will not be a soldier"' (Kipling Kim 75, 81). Father Vincent insists upon a color-coded corporeal binary as the marker for rendering similarity between the chaplains and this orphan boy. Kim's refusal repudiates precisely such marking with his vernacular response, "Gorah-log" and its racial and imperial implications. Additionally, unlike the aforementioned Nicholson, Kim also rejects the most explicit sign of Irish "loyalty" to the empire, a soldiering career. Later, having experienced St. Xaviers, where, according to the narrator, Kim "must never forget that one is a Sahib, and that some day, when examinations are passed, one will command natives," Kim has a decidedly oppositional view to the Sahibs of the school, as he makes clear in conversation with Mahbub Ali, who is shocked that Kim would allow the lama to be seen visiting him at school: "“A beggar and his bowl in the presence of these young $\mathrm{Sa}$-' 'Not all!' Kim cut in with a snort. 'Their eyes are blued and their nails are blackened with low-caste blood, many of them. Sons of meteranees - brothers-in-law to the bhungi (sweeper)"” (122). In castigating the "blued" "eyes" and "blackened ... low-caste blood" of hybrid Sahibs, Kim is not only denying similarity between himself and them, but in doing so rejecting hybridity's implication in consolidating imperial power in India through martial race ideology and the "command [of] natives."

Not only does hybridity fail to function in Kim according to critical expectations, but so too do broader racial paradigms. Seeing race within a binary in British literature and culture became increasingly clear in post-Mutiny India where "before 1857 the British in India had 
habitually referred to themselves as 'Indians' and to Indians as 'Natives', a word employed without negative connotations[,] [a]fter 1857 it became 'Anglo-Indians' and - among a sizeable segment of the British population - 'Niggers"' (Allen 20). Language reified the divide that hardened between "Anglo-Indians" and "Niggers" into a readily and putatively self-evident opposition. The narrative palette within texts like Kim engage with this construct in terms of the connotations and meanings of blackness and darkness as central tropes in signifying colonial difference. Darkness and difference were particularly marked in Joseph Conrad's Heart of Darkness (1899), a contemporaneous publication and colonial analogue for Kim. ${ }^{112}$ Marlow's account maps Africa according to ocular and epistemological binaries: "True, by this time it was not a blank space any more. It had got filled since my boyhood with rivers and lakes and names. It had ceased to be a blank space of delightful mystery—a white patch for a boy to dream gloriously over. It had become a place of darkness" (Conrad 22). Just as Marlow's journey begins with a vision, Kim's own journey begins with a prophetic catalyst grounded in darkness, as foretold by an Indian priest: "A thick darkness that clears slowly ... The Sun, leaving the House of the Bull, enters that of the Twins" (Kipling Kim 37). The colonial "heart of darkness" ultimately frames the trope of darkness as it's deployed in Africa, India, or Ireland, and Kim's prophetic origin in darkness prefigures the various ways this concept functions in the course of the novel (Conrad 22). At the prophecy's consummation in the Mavericks' campsite, Kim's past is rendered meaningful through darkness paradigms that ultimately signify nothing. The Anglican pastor Bennett "looked at him [Kim] with the triple-ringed uninterest of the creed that lumps nine-tenths of the world under the title of "heathen"” and Father Victor also contributes a meaningless set of repetitive euphemisms: "Powers o' Darkness" or "Powers of Darkness below!" (Kipling $\operatorname{Kim}$ 77, 75, 76, 81, 84, 91, 92, 94). Father Vincent further yokes Kim and India 
together in an ocular and epistemologically unhinged pronouncement-“"Powers of Darkness below, what a country!"'- that signifies even less (76). These nonsensical pronouncements attain meaning later in the novel once Kim is placed under the auspices of a drummer-boy. Although watching Kim, the drummer boy will not venture outside school boundaries as Kim secures the services of a native letter writer and returns, prompting the drummer boy's derogatory interrogation, “'What was you bukkin' to that nigger about?' ... 'I was watching you' ... 'You talk the same as a nigger, don't you?'” (88). Meaningfully, the drummer-boy's pronouncement is clear and stark, "[Kim] talk[s] the same as a nigger," and thus antithetical to Father Vincent's hopes for Kim that schooling will “make a man o' you ... a white man” (108). In opposition to the Sahib's cacophony, an an Indian street sweeper most clearly identifies Kim's subjectivity as he marvels at the "white boy by the barracks waiting under a tree who is not a white boy"'(87).

Just as the novel's formal divisions frustrate easy imperial readings, the cacophonous designations of Kim's subjectivity similarly frustrate easy hybrid and racial readings. Taken together, form and subject align Kim and Kim as both sets gesture towards the way Kim's subjectivity is radically different. Along these lines many models have been proposed for Kim yet a surprisingly ignored one, Sir Richard Francis Burton (1821-1890), is arguably the clearest lens for reading Kim's problematic hybridity and racial paradigms. ${ }^{113}$ Burton's fame rests on his disguised entry into Mecca in 1853 as recounted in A Personal Narrative of a Pilgrimage to AlMedinah and Meccah (1855), but he also attained infamy during his officially-sanctioned disguised treks through Singh as a soldier in the East India Company's independent army in 1842. ${ }^{114}$ Burton's British military colleagues were so unsettled by his abilities that his memoirs, written by his wife Isabel, include two episodic fragments penned by Burton that explain the 
pejorative given to him by the soldiers: "About that time, too, I began to acquire the ominous soubriquet of 'The White Nigger,' and what added not a little to the general astonishment was, that I left off 'sitting under' the garrison Chaplain, and transferred myself to the Catholic Chapel of the chocolate-coloured Goanese priest," and "Here I made the acquaintance with Mirza Ali Akhbar ... and ... Mirza Dud ... My life became much mixed up with these gentlemen, and my brother officers fell to calling me the "White Nigger"' (Burton, Isabel The Life of vol. I 123, 144). ${ }^{115}$ Burton's British colleagues expressed anxieties not over difference, but rather similarity and its spectral ties between themselves, Indians, and the ambiguous Burton. The pejorative "White Nigger" casts a clarifying light on the parallel disruptions evident in Kim as both Burton and Kim signify subjective forms that fail to register ocularly or epistemologically. Burton's anecdotes and Kipling's novel both focus on difference, but only because, as Alain Badiou conceptualizes it, "if differences are the material of the world, it is only so that the singularity proper to the subject of truth - a singularity that is itself included in the becoming of the universal—can puncture that material" (Saint Paul 101). Representing difference is precisely the provenance of the state and its statist ramifications of codified imbalances, silences, and justifications for violence. Burton's and Kim's cross-colonial frameworks trespass the representation of difference, particularly in its formulated triangulation of clarity, coherence, and boundedness. The various darkness euphemisms applied to Kim, like Burton's "White Nigger" moniker, attest to the state's inability to conceptualize and thus delimit these subjects. Significantly, even colonial subjects manifest a similar difficulty with Kim as Mahbub Ali's silence and Kim's answer demonstrates, “'Among Sahibs, never forgetting thou art a Sahib; among the folk of Hind, always remembering thou art—' He [Mahbub] paused, with a puzzled 
smile. 'What am I? Mussalman, Hindu, Jain, or Buddhist? That is a hard knot”' (Kipling Kim 140).

Kim's formal division ultimately foregrounds Kim's subjectivity, an interbraided "knot," as the most resonant textual site for thinking through anticolonial practices and formations. Kim's anticolonial resonances are particularly striking because they are not so much antagonistic as they are, in Bruno Bosteels' words, "a stubborn remainder that signals the failure of" a representational schema through its formal manifestation as an "impossibility that causes the inner decentrement of the" representational "structure" (129). Whereas Burton's "impossibility" is signified by the "White Nigger" soubriquet, Kim's "hard knot" remains marked by silent shifts and questions. The Mutiny's cross-colonial significations mark one clear shift in Kim's thinking as his earlier enthusiasm for the Rissaldar Sahib's song dramatically shifts by the time he arrives in Lahore to attend St. Xavier's. Alone, Kim enters a "ticca-gharri" and "establish[es]" "perfect understanding" with the driver through "fluent vernacular" kinship and his "compliment[s]" further result in the driver "t[e]1[ling] [h]im many astounding things where an English guide would have talked of the Mutiny" (103). Kim's earlier compliments to the Rissaldar Sahib's Mutiny tales now give way to an easy dismissal of "the Mutiny" as a symbolic signifier of English imperial identity rejected for the "astounding things" Kim learns in crosscolonial, interpersonal engagements. ${ }^{116}$ The fundamental questions formed by Kim's subjectivity initially register in clearly colonial contexts. On the eve of his journey to St. Xavier's, Kim reflects: “'No man can escape his Kismet. But I am to pray to Bibi Miriam and I am a Sahib.' He looked at his boots ruefully. 'No; I am Kim. This is the great world, and I am only Kim. Who is Kim?'” (Kipling Kim 101). Kim's referential fragments and self-questioning will recur again in the text, prompting the narrator to posit Kim's "natural reaction," unique to "a very few white 
people, but many Asiatics, [to] throw themselves into a mazement as it were by repeating their own names over and over again to themselves, letting the mind go free upon speculation as to what is called personal identity. 'Who is Kim-Kim-Kim?'” (156). In spite of the narrator's assertion, Kim's reaction embodies the colonial ramifications born out of modernity and atrocity that in Kim reflect the contexts Franz Fanon later takes in explicating colonialism's “systematic negation of the other person and ... furious determination to deny the $[\mathrm{m}] \ldots$ all attributes of humanity," "forc[ing] the people it dominates to ask themselves the question constantly: "In reality, who am I?"' (Wretched 250).

The various historical, cultural, and colonial fragments I have pointed out throughout Kim all share a common link, namely their constitutive ramifications out of colonial atrocity, whether the Famine, the Mutiny, or atrocity broadly conceived. Kim's self-questioning is a silent albeit insistent subjective marker of both colonial pressures and possibilities. Even when anchored to the ideological state apparatus of St. Xavier's school—“the best schooling a boy can get in India"-Kim retains his subversive appearance and disappearances, the latter prompting Creighton Sahib to "poin[t] out that vagabonding over India in holiday time was absurd" (Kipling Kim 81, 141). In addition to his autonomy, Kim also explicitly asserts his divergence from colonial Sahibs when speaking with Mahbub Ali: “"They say at Nucklao that no Sahib must tell a black man that he has made a fault ... I am not a Sahib, and I say I made a fault to curse thee" (115). Kim's actions and assertions coincide with the picaresque's general "journey" motif and its connotations, as defined by Ulrich Wicks, of "an infinite foray into a world that is forever falling apart, disintegrating" (54-55). These broad "infinite" and "disintegrating" facets further link Kim's form and Kim's subjective form with Alain Badiou's elaboration of "Truth” as “ $a$ power" whose irruption manifests an "infinite becoming" that "provide[s] a fragmented 
anticipation of a universe without completion" (Handbook 22). The picaresque's episodic form evokes an infinite narrative horizon that Kim stages in a colonial world marked by cross-colonial atrocities. In Kipling's representation of a colonial world "without completion," one scarred by atrocity and injustice, Kim's language regularly gestures to the paucity of imperial dreams in favor of colonial alternatives, "But I learn every day, and in three years the Colonel will take me out of the madrissah and let me go upon the Road with Mahbub hunting for horses' pedigrees, or maybe I shall go by myself; or maybe I shall find the lama and go with him. Yes; that is best. To walk again as a chela with my lama when he comes back to Benares.' The thoughts came more slowly and disconnectedly"” (Kipling Kim 116-117). Benares again reaffirms the later vision of the lama's corporeal fragment as a retroactive texturing of Kim's own linguistic fragmentation and randomness as his "thoughts" degrade "slowly and disconnectedly." In these variously fragmented corpuses, Kim signifies against imperial and later municipal regulations.

Kim's colonial fragments posit a subjective paradigm that subtends modernity's progressive histories and narratives. As Elleke Boehmer has theorized, in spite of imperial "assumptions of unassailable sovereignty," colonial alternatives are always/already apparent and Kim merely foregrounds their formal manifestation as "the signs of other subjectivities, both recalcitrant and subjugated, which [a]re emerging out of - or out from under-colonial contact with other cultures" (Empire, The National 170). At St. Xavier's, Kim is in perpetual contact with colonialism's culture and practices and even leaving the school is premised upon "Colonel Creighton ... sen[ding] for him" and "Cazalet [the principal] ... hinted very broadly that Colonel Creighton's interest in Kim was directly paternal" (Kipling Kim 148, 149). Kim's paternalistic ties to the Empire are immediately and clearly repudiated once he leaves the principal and reconnects with Mahbub Ali, greeting him significantly, “'It is indeed all finished, O my 
father?"' Kim's paternal colonial kinship is deepened as Mahbub takes him to "a house the very name of which would have crisped the Principal's hair with horror" under the cover of darkness so that "'none will mark thee in the bazar." Kim's unmarked passage to Huneefa's house, which "Those who know it call it The Birdcage - it is so full of whisperings and whistlings and chirrupings," further anticipates the opaque silences that will adhere to this space (150). In The Birdcage, Kim's various shifts—prophetic, cross-colonial interrelations, novelistic form-are each distilled into a radically altered subjectivity. Superficially, Mahbub's “"gift to thee, my son"" is "Huneefa['s] ... secret of a colour that catches. No painting of a day or two" that will facilitate Kim's safe passage on the road. Subjectively, this color defies Kim's previous guises, specifically a racial coloring he received from a prostitute who boldly proclaimed, "'Huneefa herself could not have given thee better stuff" (108). The depth of this transformative "dye-stuff ... blue and gummy" is explicitly made by Huneefa as "Kim experimented on the back of his wrist, with a dab of cotton wool; but Huneefa heard him. 'No, no,' she cried, 'the thing is not done thus, but with the proper ceremonies. The colouring is the least part"' (151).

Kim's transformation during Huneefa's ritual exceeds epidermal and easily apprehended epistemological distinctions. The ritual further highlights a consistent strand throughout the novel in strident opposition to the narrator's racial and Oriental assumptions. That "The colouring is the least part" even unsettles Mahbub Ali's "test[y]" apprehension of the event that is only tentatively alluded to: “Allah! How he fought! We should never have done it but for the drugs. That was his white blood, I take it,' said Mahbub testily 'Go on with the dawut (invocation). Give him full Protection" (151). In the context of The Birdcage's fragmented nonspeech, Kim's non-racialized reformulation, and the largely elided narrative of exactly what happens - the narrator significantly makes no comment on the ritual, its "Oriental" resonances, 
or Kim's reaction — firmly align the scene with Badiou's delineations of the truth and its manifest forms, which include "incorporeal bodies, languages devoid of meaning, generic infinites, unconditioned supplements ... suspended ... 'between the void and the pure event'” (Logics of Worlds 4). The void or pure ontological apprehension, remains disconnected from the world and the event, but truth allows us a glimpse of ontological purity that defies the binaries, injustices, and prejudices of colonial economies of the subject. Badiou's "languages devoid of meaning" resonate in the Birdcage's "whisperings and whistlings and chirrupings" just as Kim's effectively color-less passage underscores his removal from clear apprehension as an "incorporeal bod[y]" that increasingly fails to register in all imperial apprehensive frameworks (Kipling Kim 150). Within Badiou's range of abstract traces and paradoxes, Kim provides a material signifier of Kim's fundamental removal from the Empire and its ideological provenances through Hurree Babu. Once Kim has regained consciousness, Hurree presents him with a "small silver amulet, verree cheap. That is ours. Do you understand?" (154). These "cheap" "amulet[s]" mark fellow agents in the Great Game yet Hurree is quick to emphasize, "Huneefa makes them onlee for us ... It is strictly unoffeecial of course, but convenient for subordinates. Colonel Creighton he does not know. He is European" (154). Formally, the novel has maintained clear distinctions between the Irish Kim and English narrator that Hurree even further encodes amongst the novel's various imperial, colonial, and native subjects. Further accentuating this meaning is the novel's form, the picaresque, which, according to Howard Mancing, "is clearly unique in its conception that its characters have lives, rather than stories or misfortunes," which is reflected in the Birdcage's largely non-narrated scene (284). Here, form even further accentuates the autonomy Kim asserts through a disavowal of representational clarity in what exactly happened, but an avowal of 
transformation within Kim's body marked by “traits of separation, cohesion, synthetic unity, in short, organicity" (Badiou Logics of Worlds 67).

The elusive and organic components of the Birdcage's ritual are pivotal to reading Kim's subsequent journey across India. Although he variously accomplishes business for the British Empire under the auspices of the Great Game, he remains a clearly autonomous figure who ultimately pursues his own ends. In this context, Kim's clearest counterpoint is Hurree Babu, who presents him with a material sign of their difference from European subjects. During the ritual Hurree not only keeps his distance, but ultimately castigates the entire scene in language reminiscent of the colonial power: “'How am I to fear the absolutely non-existent?' said Hurree Babu, talking English to reassure himself. It is an awful thing still to dread the magic that you contemptuously investigate - to collect folk-lore for the Royal Society with a lively belief in all Powers of Darkness" (Kipling Kim 152). Far from "mimicry gone wrong," Hurree represents a clear distillation of hybridity as median category posited between colonizer and colonized; he speaks "English," professes "comtemp[t]" in the "lively belief[s]" of natives and their alignment with the "Powers of Darkness" yet even this assertion is undermined throughout by "dread" and failed "reassure[nce]" (McClintock Imperial Leather 70). At this pivotal moment in the text, Kim is now triangulated by the colonizer, colonized, and hybrid, all of which fail to pinpoint his subjectivity. Shortly after this scene, Kim reflects upon his imperial debts and casually dismisses them as he meets the lama again: “'I was made wise by thee, Holy One,' said Kim, forgetting the little play just ended; forgetting St. Xavier's; forgetting his white blood; forgetting even the Great Game as he stooped, Mohammedan-fashion, to touch his master's feet in the dust of the Jain temple" (Kipling Kim 160). Semi-colons again register the import of Kim's iterative "forgetting" that spans Huneefa's ritual, the Great Game, St. Xavier's, and even his putatively 
"white blood." As opposed to imperial discourse's settled representational forms and a consequently induced colonial crisis of self-questioning, Kim's connections to the lama crystallize his subjective remove and reformulate the fragmented colonial self into a singularly different form: "'I owe to the lama here. Also to Mahbub Ali—also to Creighton Sahib, but chiefly to the Holy One. He is right—a great and a wonderful world—and I am Kim—Kim— Kim —alone —one person — in the middle of it all. But I will see these strangers with their levels and chains..." (188). Kim's reformulation of the earlier fragmented questioning is here selfassured and posited on the precipice of Hurree Babu's dispensing of the amulets and their subversive sign.

In spite of Kim's recurring self-questions and even the ways his actions at times intersect with British imperial desires, he ultimately constitutes a radically different subject from almost every other character, including Creighton Sahib, Hurree Babu, and even to an extent, Mahbub Ali. Although Kim denominates the latter as "father," Mahbub still resents the obvious connection between Kim and the lama, "'My heart is a little angry, Friend of all the World, that thou shouldst see such worth in a man so little known"” (122). Mahbub's "little ang[er]" suggests a significant connection between Kim and lama that reaffirms the importance of the lama's philosophy in thinking about Kim: "'to those who follow the Way there is neither black nor white, Hind nor Bhotiyal ... No matter what thy wisdom learned among Sahibs, when we come to my River thou wilt be freed from all illusion — at my side'" (178). Evident in the lama's philosophical framework is Kim's subjective state, which is persistently defined by its binarydefying "neither" and "nor" offset. If, as Badiou has stated, "Truths exist as exceptions to what there is," then Kim's subjectivity brings into the colonial space an egalitarian truth, the viable right to humanity of all within the space, that defies the subjective binaries that proscribe 
colonizer and colonized vis-à-vis Kim's subjective reformulation into a "mode of being ... that] (in)exist[s]" (Logics of Worlds 4, 6). Perceptively, Kim's connections with the lama coincide with his subjective state and its exceptional status in the novel, as well as Kim's professions of the lama's philosophy. By the novel's end, the lama's corporeal fragment and quest for the River coincide with Kim's own subjective positing as the only material ghost in the novel: "A smoky lamp burned in a niche, but the full moonlight beat it down; and by the mixed light, stooping above the food-bag and cups, Kim moved like a tall ghost" (Kipling Kim 210). ${ }^{117}$ As Kim tends the lama, he is depicted as a subjective distillation of colonial past and present, forged out of lingering atrocities and their legacies. The "smoky lamp" provides an allusively sensual aftermath to the lama's earlier "fragment of a half-burned body bobb[ing $]$... on the full current" as well as a continued inflection of Kim's earlier subjective ease with hunger: "The pallor of hunger suited Kim very well” $(165,164)$. Fragmentation, hunger, and ghostly forms all triangulate the subjective transformation that Kim undergoes and eventually consummates with direct assertion. Importantly, although these fragments and cross-colonial intersections are important as evental signs, these ultimately "can[not] force the recognition of the event $a s$ event. The question of the chance of the event, of the undecidability of its belonging, is such that, as numerous as its traces may be, the event remains dependent on its declaration" (Badiou Handbook 139). Declaration, as the assertive and assured promulgation of the event's ramifications as truth, is finally and clearly made by the novel's end when Kim gently repudiates the lama's jibes on his connections to other Sahibs, “"Thou hast said there is neither black nor white. Why plague me with this talk, Holy One? Let me rub the other foot. It vexes me. I am not a Sahib. I am thy chela, and my head is heavy on my shoulders" (Kipling Kim 225). Kim's clear assertion of an alternative merely announces the subjective frameworks that the novel has 
already long posited within the confines of its formal division. This assertion will still not stem the crises of the colonial project, specifically a final insistent self-questioning: "II am Kim. I am Kim. And what is Kim?' His soul repeated it again and again” (234). Far from a futile or unconvincing note, Kim’s "repeated” questioning gestures towards an open-ended possibility inherent in the colonial project, namely the space and possibility for resistance and autonomy always, but also crucially the persistent threat colonial projects and their legacies pose, which can be superseded by the event's truth-full legacies.

\section{Colonial Forms and Multicultural Ends}

In an essay on Kipling, Salman Rushdie reflects, "There will always be plenty in Kipling that I will find difficult to forgive; but there is also enough truth in these stories to make them impossible to ignore" (80). These lingering truths continue to animate the critical disputes still reigning over Kipling and his works. Arguably, these lingering truths were clearly evident within a decade of Kim's publication when Rabindranath Tagore published Gora (1910), a novel Bart Moore-Gilbert characterizes "[a]s a clear riposte to Kipling's novel, and ... what Tagore deems to be Kipling's political vision" (“"I am going"” 41). ${ }^{118}$ These lingering truths mark the clear connections between Kim and Gora as they both center on Irish orphans who ultimately identify most clearly with India: "“And who are thy people, Friend of all the World?' 'This great and beautiful land,' said Kim" and "“To-day I have been told that I was a foundling at the time of the Mutiny — my father was an Irishman!' ... 'To-day I am really an Indian! In me there is no longer any opposition between Hindu, Mussulman, and Christian"” (Kipling Kim 115; Tagore 405, 406). As much as Gora shares with Kim, its differences are even more revealing. Although a complex and highly philosophical novel, Gora is a formally unadorned, highly realist, and linear narrative about Gora's maturation. Kim, as I have shown, is formally divergent and in many 
ways more radical than Gora's clearly postcolonial status. Kim features equal amounts of Orientalist and racist assertions alongside vernacular terms, both of which are reframed by the novel's formal choices. Tagore clearly wrote Gora with the intention of refuting and revising perceptions he felt lingered from Kim and Kipling. To the extent that Kim offers an egalitarian and open narrative, as many critics argue for, certainly "redeems" the novel. Even more importantly are the formal facets of Kim that clearly work against imperial ideological frameworks in ways that far surpass sympathetic critics and Gora alike.

Ultimately, whether Kipling planned, knew, or intended for Kim to possess the reading I have undertaken is irrelevant. Form ultimately registers the impact of colonial atrocities in a paradoxically acute yet largely invisible way. For those looking for a clear set of postcolonial tropes, such as mimicry or discursive play, this is not what Kim offers. What it does offer, and exemplarily so, is a strident albeit seemingly silent obverse to the workings of the colonial project's ideological plots and practices. In a scathingly anti-English essay, “The Murder Machine," Pádraic Pearse provides a clear outline of these plots, practices, and intentions: "A French writer has paid the English a very well-deserved compliment. He says that they never commit a useless crime. When they hire a man to assassinate an Irish patriot, when they blow a Sepoy from the mouth of a cannon, when they produce a famine in one of their dependencies, they have always an ulterior motive" (5). What is clear in Pearse's commentary is the explicit, apparent, and often spectacular presence of imperial practices and intentions. Whether an "assassination" or a "cannon" "mouth" execution or "a famine," Pearse highlights readily apparent actions that are nevertheless ideologically denied, minimized, and revised. Kim's formal and allusive frameworks constitute a strikingly different modality from these spectacular British "ulterior motive[s]." Furthermore, and more importantly, we are presented with the English 
colonial project's spectacular violence and dominance, but also a lingering inability for spectacle, violence, and power to completely dominate or control a colonial subject, Kim, who retains his own rebellious way. 


\section{Chapter IV Beasts, Birds, and Refuse: James Joyce's Famine Revisions}

"Up to the meeting of Parliament, the enemy concealed their intentions in mystery; they consulted nobody in Ireland about this Irish emergency, but prepared their plans in silence. In the meantime, the abundant and magnificent crops of grain and herds of cattle were going over to England both earlier in the season, and in greater quantities, than ever before ... The great point was to put the English Channel between the people and the food which Providence had sent them, at the earliest possible moment" (Mitchel The Last 104).

Although two decades removed from the Famine, John Mitchel's The Last Conquest of Ireland (Perhaps) (1873) continues to reflect the vitriol of his Famine-era writings in the Nation newspaper (1845-1848). Mitchel's rhetoric castigates the British "enemy" and its "silen[t]" "plans" against a generally helpless Ireland caught in an "emergency." For Mitchel, any natural elements to the Famine are subsumed beneath British colonial schemes that consumed "abundant and magnificent crops of grain and herds" by "put[ting] the English Channel between the people and the food which Providence had sent them." Whether writing in the 1840 s or 1870 s, Mitchel's writings disavow the Famine's natural or environmental origins as a façade masking colonial ideologies - "The Almighty, indeed, sent the potato blight, but the English created the famine"and the colonial practices that wrought "three seasons of famine-slaughter in the midst of heaven's abundance, at the point of foreign bayonets, with all its train of debasing diseases and more debasing vices" (The Last 219; Jail Journal 87). Mitchel's Famine experiences and representations, specifically of the English Channel, are framed by the Atlantic's fluid geographies. His vitriolic writings in The Nation newspaper earned him charges of treason and sedition that resulted in his transportation from Ireland to Ireland Island, Bermuda and ultimately to Van Dieman's Land, prior to an escape to America. This transportation "accustomed" Mitchel to "British "naval supremacy" and the broader ideological significations of "the English flag domineering over everything it meets" (160). The Famine ultimately informs a crucial subtext to British imperial supremacy vis-à-vis the Irish diaspora that follows in its wakes. Mitchel's 
writings, transatlantic and global in extent, are clearly preoccupied with the "shadow of the famine" and they both delineate and decry its global colonial contours within Ireland and beyond (XLVI).

Although six decades removed from the Famine, James Joyce's writings are far from absent of it. Terry Eagleton voices a broad critical consensus on the Famine's absence in modern Irish literature generally and Joyce specifically: "Where is the Famine in the literature of the Revival? Where is it in Joyce" (13). In spite of critical assertions, the Famine is present across Joyce's writings, particularly in his early critical essays and lectures. In "George Meredith" (1902), he highlights Meredith's “occasional power of direct compelling speech" by focusing "[o]n a picture of famine" and then provides even more direct allusions in "Ireland, Island of Saints and Sages" as Joyce relates the Famine Queen's miserliness and then asserts the Famine's continuing impact on modern Ireland: "Ireland is poor because English laws ruined the country's industries, especially the wool industry, because the neglect of the English government in the years of the potato famine allowed the best of the population to die from hunger, and ... [even now] Ireland is losing its population" (Critical Writings 89, 164, 167). ${ }^{119}$ Among Joyce's earliest works of fiction, the play A Brilliant Career — now lost—focuses on a city-wide plague, rehearsing common Famine experiences (Ellmann James Joyce 78-79). Far from absent, the Famine inflects Joyce's political and national perspectives, especially as he dismisses Queen Victoria and derides British colonial exploitation in modern Ireland, reduced by the Famine into an “emigrant nursery” (MacLaughlin Ireland: The Emigrant 10). Just as Mitchel's writings attest to the Famine's lingering shadows cast upon a global Irish population, Joyce bitterly bemoans how "England makes the Irish question the centre of all her internal ... [and] colonial politics," leaving "the observer ... [to] ask himself why St. George's Channel makes an abyss deeper than 
the ocean between Ireland and her proud dominator" (Critical Writings 199). Joyce's exile clearly differs from Mitchel's transportation yet both are indelibly linked by a subaltern viewpoint premised upon the geopolitical significance of channels. Joyce's "abyss[al]" channel links with Mitchel's earlier English Channel as both literally designate a narrow body of water and added subversive meanings: "line of action, thought"; "a medium of transmission, conveyance, or communication; means agency" ("channel, n.1."). These multivalent channels frame a Famine trajectory from Mitchel to Joyce whose legacies are lingering migratory and cultural fragmentations and deformations. Allusive links between channels and the sea equally localize Irish colonial conditions and contextualize them globally. These global ramifications further link Joyce's critiques with another colonial intellectual, Jacques Derrida. In his reflections on colonial Algeria, specifically its educational system, Derrida notes how in "the model called academic, grammatical, literary, on the one hand, and spoken language on the other, the sea (emphasis his) was there: symbolically an infinite space for all the students of the French school in Algeria, a chasm, an abyss" (Monolingualism 44). ${ }^{120}$ Like Joyce, Derrida figures "the sea" as a "symbolically" "infinite" "abyss" that geopolitically maps linguistic and cultural colonial divides. Within a global colonial framework the sea functions to reinforce the centrality of Joyce's localized critiques, particularly as they connect with the Famine.

My contention in this essay is that Joyce's Famine revision is premised upon forging radical subjective and narrative forms that counter contemporaneous colonial subjects and forms. Across Joyce's formal revisions and developments in Stephen Hero (1944), A Portrait of the Artist as a Young Man (1916), and Ulysses (1922) the Famine's putative absence reflects Joyce's second generational remove from the event and his understanding of the Famine's legacies and their impact upon contemporaneous Ireland. ${ }^{121}$ The Famine's legacies reinforce delimiting 
colonial subjective, narrative, and cultural forms, thus Joyce's Famine revision engages with these regressive forms by developing links between Stephen Dedalus and radical literary form. Throughout this essay, I use "revision" in several important senses, principally in terms of Joyce's formal development and amendments across these three novels, but also revision as envisioning again or reconceiving, especially in relation to the Famine's established tropes, representational practices, and forms ("revision"). Revision in these senses broadly frames the various interventions I see in Joyce's three novels in terms of Dedalus' development and recurring links to the Famine. ${ }^{122}$ This chapter opens with a cultural history of colonial Ireland's predominant subjective trope, the wolf, as a bestial signifier of Irish inferiority. I trace this wolfish form from its genesis in early Irish colonial texts up through the Famine and demonstrate how wolves and famine became indelibly linked as composite signifiers of colonial predation, inferiority, and savagery. Wolfish and famished signifiers became the dominant images in Famine literature for representing Irish victims and agitators in dehumanizing forms. The revisionary trajectory from Stephen Hero to Portrait shows how Joyce turns away from this legacy in pursuit of alternative forms. Epiphany provides a critical subtext for grounding the Famine's revision in Portrait as it intersects with a more mature and measured Dedalus from earlier Stephen Hero scenes. Portrait's Famine sequences provide the foundation for Ulysses' more extensive realization of the alternative Famine subject and legacy detailed most fully in "Proteus." Ultimately, Stephen's stream of conscious form aligns his own protean subjectivity with an allusive array of refuse littering both Sandymount Strand and Stephen's consciousness. Revision then posits far different terrains for a contemporaneous Ireland premised upon nonviolent and egalitarian anticolonial principles. 
Emphasizing the Famine in Joyce's work not only provides a corrective to its critically assumed absence, but it also provides compelling interventions in postcolonial theory, both specifically Joycean and more broadly literary. ${ }^{123}$ Joyce's Famine links clarify any sense of vacillating "semicolonial" intentions or positions yet a more forceful corrective is also made to wider postcolonial theory and its responses to literary form, specifically its "frequent reliance upon politics over aesthetics, post-colonialism over narrative," which critically defuses politically-charged texts like "Proteus" as it relegates them to putatively abstract and delimited aesthetic exercises (Attridge and Howes; Roos 162-163). When it comes to the Famine literary archive, there is no question about abstraction and delimitation when it comes to aesthetics and formal representation. In spite of a significant corpus of writings, novels, poems, plays, travel narratives, diaries, journals, pamphlets, and oral narratives, these various "writ[ings] about death on a massive, almost unimaginable scale" are nevertheless inscribed within a "relatively small and circumscribed" context that focuses on "iconic fragments" and recursive themes like "the feminization of famine" (Morash Writing the Irish 4; Morash "Literature, Memory" 113, 117; Kelleher 2). This literary circumscription also reflects a more general social, historical, and ideological circumscription that overwhelmingly views the Famine as a singularly "traumatized cultural memory" animated by "communal revulsion" (Winston 170; Lowe-Evans 11). Irish writers have strived to revise the Famine and conceptualize its alternative, but overwhelmingly, as the first section in this essay demonstrates, they offer regressive visions that inadvertently buttress the inherently exploitative and victimized tropes within established Famine paradigms.

\section{Famished Colonial Logics: English Forms and Irish Beasts}

In spite of localized differences between British, French, German, and American empires, imperial projections are generally grounded upon a congruent framework of dehumanized 
subjects. A general bestiality paradigm affirms colonizing superiority and colonized inferiority. Racism and history jointly delineate these subjective contexts around what philosopher and literary critic Etienne Balibar defines as “Man's animality, animality within and against man hence the systematic 'bestialization' of individuals and racialized human groups - is ... the means specific to theoretical racism for conceptualizing human historicity” (57). As Balibar highlights, bestiality and racism coincide in hierarchizing human histories and disparities. In a colonial schema this becomes the founding premise for the colonizer's presence. Philosopher and social theorist Achille Mbembe echoes these general precepts in a specifically African context, noting how the "discourse on Africa is almost always deployed in the framework (or on the fringes) of a meta-text about the animal - to be exact, about the beast" and the two primary signs of African presence remain the beast and intimacy (1). For these contemporary theorists, colonial bestiality is the grounding axis from which the entire colonial project, its exploitations, its discourses, and its violence, revolve around. As England's oldest and most proximate colony, Ireland is emblematic of this discursive model, especially as a variety of early English colonial texts represent "Ireland [a]s ... a wild, strange place full of weird and outlandish sights, and ... a pool of blackest ignorance, barbarity and superstition" in which "the real Ireland, is only to be found in those parts (suitably 'wild' and mountainous) where the 'old barbarities' are still current" (Leerssen Mere Irish 35, 66). Giraldus Cambrensis' (1146-1223) writings are among the earliest and most emblematic of Irish colonial texts, especially as they detail cursed Irish men and women in Ulster who "entirely [quit] the human form" and "assume that of wolves" (80, 124). Cambrensis is clear that these magical transformations are indicative of Irish realities in which "The Irish" signify primitive regression by "living themselves like beasts" "i[n] truly barbarous" conditions and ultimately "forming, as it were, another world" (125-126). These 
initial colonial forms attain aesthetic and political currency in Edmund Spenser's writings (15521599). Ireland particularly "pervades" The Faerie Queene $(1590,1596)$, which as an aesthetic "exercise of violence" is informed by Spenser's administrative experiences (1580-1592) in colonial Ireland (Greenblatt 186). ${ }^{124}$ The unfinished Cantos of Mutabilitie are particularly exemplary in representing a distinctly colonial Ireland:

To weet, that Wolves, where she was wont to space,

Should harboured be, and all those Woods deface,

And Thieves should rob and spoile that Coast around.

Since which, those Woods, and all that goodly Chase,

Doth to this day with Wolves and Thieves abound (Spenser 410, Canto VI.LV). Spenser's stanza repetitively establishes Ireland's wildness in "Woods" populated by "Wolves" and "Thieves." Formally, beast and man are separated by lines four and six, yet by line eight they jointly signify Irish colonial wilds where "Wolves and Thieves abound." Like Cambrensis, Spenser's colonial aesthetic deforms native Irish beliefs that "the borders between human and animal, culture and nature [are] fluid and sympathetic" in order to re-present, in Chris Morash's phrase, "Ireland as the demonic, barbaric Other" (Holdridge 39; Writing the Irish Famine 114). These early colonial frameworks are resonant of Jacques Derrida's general characterization of "analogy [a]s always a reason, a logos, a reasoning ... that moves back up toward a relation of production, or resemblance, or comparability in which identity and difference coexist" (Beast \& the Sovereign I 14). In this analogical context, English historical and aesthetic links between (Irish)man and wolf underscore how "political man is still animal but ... the animal is already political" and these colonial politics reify the wolf as a loaded signifier of colonial Irishness. 
Broadly-speaking, bestial analogies traverse identity and difference in order to recast political, cultural, and colonial inhumanity within putatively old world savages. Spenser's Irish wolves echo out of William Baldwin's earlier Beware the Cat (1561), arguably the first novel written in English, which spectacularly embodies its anti-Catholic ideology in Grimalkin, an Irish werewolf. Aesthetic wolves further inform Spenser's later political writings on a final solution to the Irish problem. In "A briefe note" delivered to Queen Elizabeth (1533-1603), Spenser averred, "'Great force must be the instrument, but famine must be the means; for, till Ireland be famished, it cannot be subdued"' (433). This colonial connection between wolves and famine cohered long past the extermination of the last wolf in Ireland (1786) and became integral to Famine representations. Initially, English writers and illustrators provided "sympathetic depictions of Irish suffering which showed the victims as brethren in need" yet as relief schemes failed and famine persisted, "the visual machinery of colonial representation ... privileged "the idea of Irish inferiority"' (Smart 58, 65). Irish inferiority was broadly conceived in economic, social, and cultural terms as the grounding premise for viewing the Famine as the necessary precursor to a productively transformed Ireland. English representational strategies thereby emphasized "the absence of the native Irish" whereas Irish representations emphasized the presence of the native Irish through a consistent "vocabulary of famine[:] 'apathy', silence', 'docks and nettles', 'walking ghosts', 'living skeletons', 'spectres', and 'wolfish voracity”' that provided "a powerful shorthand to conjure famine" in terms of bodily suffering (Fegan 210). In spite of representational conflicts, both English and Irish texts symbolized the Famine's ramifications through wolfish figures. William Carleton's The Black Prophet (1846) - arguably the genesis of Famine literature - subtly redefines Spenser's wolfish and famished signs of inferiority into signs of famine predation: "the hungry and wolfish spirit"; "Their cadaverous and 
emaciated aspects had something in them so wild and wolfish, and the fire of famine blazed so savagely in their hollow eyes, that many of them looked like creatures changed from their very humanity by some judicial plague"; "Sickness of various descriptions, giddiness, retchings, fainting-fits, convulsions, and, in some cases, death itself, were induced by this wolfish and frightful gluttony on the part of starving people" $(42,250,252)$. Across various iterations, Carleton's "wolfish" adjectives signify Irish suffering and victimhood rather than barbarism and progressive intervention. These wolves implicitly critique English colonial policies and inaction by representing an "emaciated" and "wolfish" body politic transformed by famine.

Wolfish imagery is particularly central to Famine-era texts yet it also persists as an evocative trope in post-Famine texts into the twentieth-century. Like Carleton's novel, the pseudonymous poem "The Famine," published in The Nation's 7 March 1846 issue, represents the Famine in wolf-form: "Striding nearer every day, / Like a wolf in search of prey, / Comes the Famine on his way_-" (Heremon 11. 1-3). The poem even more forcefully aligns the wolfish Famine with English colonial predation "Striding nearer every day." Both novel and poem further reconfigure the Famine within a metaphorical nexus that implicates the wolf in questions of colonial sovereignty. For Derrida, the implications of wolves and sovereignty underscore the political contours of metaphor, specifically as the "fable-wolf ... figures something elsesomething or somebody else" through an "absence [that] bespeaks at the same time power, resource, force, cunning, ruse of war, stratagem or strategy, operation of mastery" (Beast \& the Sovereign I 2, 5, 6). Derrida's notions highlight the seminally regressive frameworks deriving out of the "relations of beast and sovereign, and all the questions of the animal and the political, of the politics of the animal, of man and beast in the context of the state" that particularly "recogniz[e] some privilege to the figure of the "wolf" (9). In a specifically Irish context these 
regressive implications ensure that any wolfish representations, no matter how revolutionary, will persistently regress under colonial delimitations. Fenian Charles Joseph Kickham (18281882) included a local legend about the wolf in his 1879 novel Knocknagow; or The Homes of Tipperary: "a gaunt hound was sometimes observed prowling among the rocks in the loneliest recesses of the mountains, like the ghost of the last Irish wolf' (443). Kickham's novel is set during the Famine, but avoids all direct reference to the event and so this "gaunt" and "ghost[1y]" "wolf" remains a fugitive Famine marker haunting an isolated rural landscape. Yet another nationalist, Daniel Corkery (1878-1964), represented a far more revolutionary wolf in his short story “The Ember” (1920): “England's difficulty was Ireland's opportunity, and England had plainly never been in such difficulty. To those of us who had learned to read the Irish poets, their well-knit, stone-hard, wolf-fierce songs, and indeed the men themselves ... looked at us from the dark with wild eyes" (16-17). In spite of disavowal and redefinition, both writers' use of wolves remain stained by colonial and famished histories that revolve around British sovereignty over Ireland. Furthermore, reformulating wolves manifests the "risk" Margaret Kelleher identifies in "depictions of famine victims [that] ... move outside the boundaries of human identity, and hence beyond the possibility of identification, into subhuman or superhuman terms" (84).

Derrida's diagnosis and Kelleher's caution concerning intersections between wolves, bestiality, and sovereignty highlight Joyce's own engagement with the Famine in his criticism and prose. Joyce's reflections on the fall of Charles Stuart Parnell (1846-1891), born in a County Wicklow mansion during the Famine, in "The Shade of Parnell" (1912) are emblematic of the metaphoric centrality of wolves and colonial sovereignty: "In his final desperate appeal to his countrymen, he begged them not to throw him as a sop to the English wolves howling around them ... They did not throw him to the English wolves; they tore him to pieces themselves" 
(Critical Writings 228). By linking "English wolves" to Irish “countrymen,” Joyce criticizes as coterminous English sovereignty and Irish infighting. In his prose these ambiguous Irish countrymen attain greater clarity as the figure of the wolf disappears in the trajectory from Stephen Hero to Ulysses. ${ }^{125}$ Stephen Hero's early representation of Madden - the precursor to Portrait's Davin, based on Joyce's university friend, George Clancy (1881-1921), an eventual mayor of Limerick murdered by the Black and Tans - and Stephen Dedalus clarifies the political stakes of Joyce's early wolves. Madden's "nationalistic fever" inflects the conversation with Stepehen, especially as it addresses "tyran[ny]" and "revolutions" (Stephen Hero 53) as well as Stephen's interest in "learn[ing]" the Irish "language" (55). Within these topics, Stephen reflects upon sovereignty and the Catholic Church in a question about Irish Catholic priests: “-Do you not see ... that they encourage the study of Irish that their flocks may be more safely protected from the $<<$ wolves of disbelief $>>$; they consider it is an opportunity to withdraw the people into a past of literal, implicit faith?" (54). ${ }^{126}$ Joyce marks through the phrase "wolves of disbelief" with a red crayon, which in the context of his revision strategies means that he added this phrase to a subsequent draft. ${ }^{127}$ The wolves' annulment, particularly in a nationalist context that features Stephen's desire to learn Irish, gestures towards a recognizably allusive Famine context. Added references to "Sinn Fein" and "lessons in Irish" "by the Gaelic League" further foreground the Gaelic Revival's cultural program, which occurred within the shadow of the Famine as its legacies continued to manifest in late $19^{\text {th }}$ and early $20^{\text {th }}$ century Ireland through sustained migration and cultural erosion, particularly in Irish-speaking areas (56).

Joyce's red crayon signals the wolves' migration to a subsequent draft of Stephen Hero yet they are entirely absent from Portrait. Such an absence rings with a historical echo of the wolves' removal from Ireland, but it also suggests a more pervasive removal of life from 
Famine-era Ireland. The textual absence of the wolf marks out the wider "disappearance of wildlife and domestic creatures [that] accounted for one aspect of Famine in Ireland that was often remarked upon - that is, the eerie silence that hung over the landscape, in this period and later" (Ó Murchadha 82). This historically allusive absence is rendered more secure in light of Joyce's own rejection of the wolf, an image taken up by many Irish writers on the Famine, as an implicated figure of colonizing sovereignty. In Derrida's words, we can say that Joyce rejected the Famine narrative in which the wolves' central figure signifies a "resemblance ... or irresistible hallucination" that "makes us see, project, perceive, as in a X-ray, the face of the beast under the features of the sovereign ... [or] through the maw of the untamable beast, a figure of the sovereign were to appear" (Beast \& the Sovereign I 18). Joyce's revision and Derrida's insight highlight how absence and presence are jointly implicated in colonial dynamics of exploitation and dominance. Whatever Joyce's ultimate reasons for annulling the wolf in his novels is, their absence ensures a double disavowal of delimiting colonial ideologies. English colonial and Irish anticolonial violence derives from the same roots, an implication Joyce renders in his critique of "the usual flashes of Celtic temperament that lighten the shadows for a moment and leave behind a darkness blacker than before" (Critical Writings 189).

My assumptions on Joyce's wolfish intent become far stronger as one surveys the revisionary trajectory from Stephen Hero to Portrait. At the end of Stephen Hero, Stephen hears a "story" illustrating how Irish "peasants may be ignorant of many things" (242). In the story, a "learned young lady" recounts her knowledge of "prehistoric" "animals" to an "old man" who mutters in disbelief, "- $\mathrm{Aw}$, there must be terrible quare craythurs at the lather ind of the world" (243). Stephen haughtily responds with "laugh[ter]" (243) and later "chiefly delight[s]" "in the constant observance of the peasantry[,]" whom he considers "Mongolian types" that likewise 
return his gaze in seeing him as "some rare animal[s] (sic)" (244). These tensions between an ostensibly urbane Stephen and an undeveloped Irish peasantry reflect the wider Revival contexts dominated by "Anglo-Irish and Irish-Irish polemic[s] ... [that] both held ... the pure peasant as the quintessence of the nation" and shared an idealized representation of "the sanctity of Irish peasant life" (Cairns 71; George J. Watson 42). The Irish Revival's culture wars are represented in Stephen Hero through a bestial discourse that Joyce clearly rejects in his revisions to Portrait. Stephen's "14 April" diary entry recounts a peasant story whose central line, "—Ah, there must be terrible queer creatures at the latter end of the world[,]" is revised to eliminate the earlier peasant brogue and render Stephen's reaction in greater nuance: “John Alphonsus Mulrennan ... met an old man there [West of Ireland] in a mountain cabin. Old man had red eyes and short pipe. Old man spoke Irish. Mulrennan spoke Irish. Then old man and Mulrennan spoke English. Mulrennan spoke to him about universe and stars" (Portrait 251). Not only does the peasant know Irish and English, but Stephen's haughty laughter gives way to reflective conflict: "I fear him. I fear his redrimmed horny eyes. It is with him I must struggle all through this night till day come, till he or I lie dead, gripping him by the sinewy throat till ... Till what? Till he yield to me? No. I mean him no harm" (252). An initially mortal conflict gives way to docile acceptance, which is further underscored in the peasant's fatally "redrimmed horny eyes" as they allusively transform in "Proteus" during Stephen's reflections on "Houses of decay" that end with "clutching a monstrance, basiliskeyed" (Ulysses 3.105, 3.115-116). In linking the peasant's terrifying horny eyes with the basilisk's horny reptilian eyes, Joyce dismisses both as phantasmal threats consigned to mythic impotence.

\section{Epiphanic Politics: Postcolonial Renewal and the Modern Subject}


Joyce's disavowed wolves signify an essential colonial alternative to established representational paradigms. The wolf's prominence in Irish colonial culture necessitates its refusal and a remaking of the representational new. As Franz Fanon will later avow, "Decolonisation is the veritable creation of new men" and the counterpoint to colonialism's discursive representation of the colonized as a "corrosive" and "deforming element" that "disfigur[es] ... beauty or morality" as a "depository of maleficent powers" (Wretched of the Earth 30; 34). Fanon's emphasis on subjective newness reflects the endemic violence of colonial projects and their deformation of "Man in the technique and the style of Europe" which begets "a succession of negations of man, and an avalanche of murders" (253). This, then, is the colonial context for Ezra Pound's "make it new" that Joyce re-presents through new subjective and literary forms. In revising the Famine/wolf bind Joyce aligns with Alain Badiou's insight that the event's revolutionary power lies not in critical rejoinders but a deforming refusal in which established epistemological and subjective "categories must be absented from the process" in order to break the delimiting oscillati[on] between the abstract universal of capital and localized persecutions" (Saint Paul 11-12). Subjectively-speaking, the wolf is a regressive dead end in need of radical re-presentational practices that transform subjects and literary forms equally. In an evental context in which the Famine promulgates radical revisions in both, Joyce's formal developments trace through Stephen Dedalus. The subversive wolves accrue more explicit radical forms in Stephen's explicit formulation of "epiphany" and its sustained connections to Dedalus across Portrait and Ulysses. Dedalus defines epiphany in Stephen Hero as "a sudden spiritual manifestation" of the "whatness [and] ...[t]he soul of the commonest object, the structure of which is so adjusted, seems to us radiant" $(211,213)$. Critics have further elaborated the Joycean epiphany as constituting "messages in an unfamiliar tongue" that "reproduc[e] a 
significant moment without comment" (Scholes and Kain 4; Richard Ellmann James Joyce 84). Stephen's initial formulation in Stephen Hero emphasizes the commonality of a given "object" that anchors the epiphany, but as Joyce's various epiphanies illustrate the subject who apprehends the epiphany is just as important. Fundamentally, colonial discourses across cultural and geographic differences are premised, in Edward Said's phrase, in propagating "an essentially, basically unchanging Self" and a "fr[o]z[en] ... Other in a kind of basic objecthood" (Musical Elaborations 52). Joyce's epiphanies possess a metaphysical quality, what Stephen denotes as the "spiritual" and "radiant," yet they are also crucially material and in fact quotidian. This effervescent materiality is an incisive political obverse to hegemony's weighty abstraction, the latter of which Stephen will later formulate in the phrase, “"History ... is a nightmare from which I am trying to awake" (Ulysses 2.377).

Hegemony's accruing sediment is, especially in colonial contexts, the proliferating remains of progressive projects that buttress homogeneity and bury difference. Through an epiphany, Stephen's post-Famine subjective form manifests in a radically oppositional way to binary-based alternatives like Homi Bhabha's "Third Space" (Location 56) or "marginal" “otherness" (126). Although conceptualized as radical alternatives, Bhabha's concepts remain triangulated within a persistent dichotomy that stresses progress on the side of the colonizer and a divergent, pristine opposition of the colonized. Conceptualizing the Famine as a Badiouian event offers a very different alternative, one that mirrors the epiphany's effervescent materiality in the assertion of truth through an evental subject, in this case Dedalus. What a post-epiphany Dedalus will subjectively manifest is a "subjectivity of refuse," a radically "new discourse, and hence ... new subject" whose premise is an expansive refusal that disavows both the colonizer's progressive provenance and the colonized's regressive remains, or what David Lloyd terms the 
"waste of which no use can be made" (Saint Paul 56, 103; Irish Times 7). ${ }^{128}$ The subjectivity of refuse is posited outside of binary frameworks and is decidedly not a utopian "Third Space" for "elud[ing] the politics of polarity" or a laudatory conception of "marginal" "otherness" (Bhabha $56,126)$. Born out of the event and its truth-full ramifications, the subjectivity of refuse embodies a subjective form that collates a variety of refuse and refusals together: "anything that is rejected, discarded, or thrown away; rubbish, waste, residue"; "a despised, outcast, or worthless group of people"; "the leavings of someone or something"; "refuse heap"; "to reject or spurn ... (one of two or more alternatives) in making a choice or selection"; "To reject or turn away (a person); to exclude (a person) from a place, post, etc." ("refuse, n.1."). Refuse's lexical variance attests to the ways an ontologically-based framework can expansively and incisively critique various colonial and anticolonial legacies premised upon violence, domination, and xenophobic partitions. Refuse as resistance and materially retrograde is a key inflection of Joyce's wolfish circulation between Stephen Hero's absent placeholders and Portrait's refused bestial subjectivity. This circulating metaphor and transformative subjectivity is glimpsed within Stephen's epiphany at the Bull Wall outside of Dublin.

Epiphany's emphatically quotidian contexts, essentially to the point of almost disregard, further highlight the powerful registry such moments are pregnant with. In Portrait, Stephen takes an extra-ordinary walk through urban Dublin that is subversively framed throughout in colonial terms through a recurring trope of wildness radiating out of Stephen's countenance: "a wild spirit" "made radiant his eyes and wild his breath and tremulous and wild" and "An instant of wild flight" (169) that all underscores the "new wild life" (170) that grounds the epiphany to come. This wildness continues to shape Stephen's solitary revelation: "He was alone. He was unheeded, happy and near to the wild heart of life. He was alone and young and willful and 
wildhearted, alone amid a waste of wild air and brackish waters and the seaharvest of shells" (171). ${ }^{129}$ "Wild" resonates generally in Irish colonial culture, but also particularly in Famine narratives such as the correspondent's report for the Freeman's Journal on 25 November 1845 on the state of the Irish people: "“The panic is general, and I see a wildness in the countenances of some of the people"' (Ó Cathaoir 15). Counterpointing urban, modern Dublin is Stephen's epiphanic scene, which is contoured by the Famine's lingering legacies and a pervasive colonial framework. These contexts further politicize the epiphany Stephen enters into:

A girl stood before him in midstream, alone and still, gazing out to sea. She seemed like one whom magic had changed into the likeness of a strange and beautiful seabird. Her long slender bare legs were delicate as a crane's and pure save where an emerald trail of seaweed had fashioned itself as a sign upon the flesh. Her thighs, fuller and softhued as ivory, were bared almost to the hips where the white fringes of her drawers were like featherings of soft white down ... Her bosom was as a bird's soft and slight, slight and soft as the breast of some dark plumaged dove. But her long fair hair was girlish: and girlish, and touched with the wonder of mortal beauty, her face. (Portrait 171)

Stephen's epiphany operates through a litany of similes that reformulate the "girl." A simile chain of "like" and "as" signifies her "magic[al]" "likeness" to a "seabird" through materiallyanchored connectors: "bare legs"; "thighs"; "bosom"; 'hair"; and "the wonder of mortal beauty, her face." The girl/seabird's transformation results in a paradoxical form that equally refuses bestial and colonized subjective forms. The girl's metaphoric veneer as "a strange and beautiful seabird" manifests atop an emphatically material, human form. This paradoxical formulation is further premised upon the historical "sign" of "emerald ... seaweed" on her leg, which signifies a 
silent history and iconography of the Famine. Ciarán Ó Murchadha notes how Irish islanders and coastline populations subsisted in times of famine on "various kinds of seaweeds and seafoods" yet as the Famine persisted "seaweed gatherers, compelled to glean farther and farther out on exposed rocks, were often dashed to their death by dangerous waves" (82). ${ }^{130}$ Margret Kelleher further emphasizes the Famine literary archive's central representational figure was the "female victim" whose "explicit collective function, figuring both the crisis of famine and society's survival" (8), was to inscribe "[t]he effects of famine ... on and by means of the maternal body" (38). Famished maternal bodies were then often "located within the realm of 'nature', with occasional subhuman or superhuman features, safely removed from the 'human' and political spheres" and Joyce's epiphany, specifically in its materially paradoxical transformation of the girl/seabird, resists all "subhuman or superhuman” excesses (229). Joyce’s own allusive frameworks - the skyline deserts, westward-bound nomads, corpselike classmates, and Stephen's wild contexts - all clearly gesture toward Famine images without reproducing them, thereby further underscoring the epiphanic girl/seabird's reflective disavowals.

The girl/seabird's protean deformations exemplify Joyce's radical Famine revision and the abstract frameworks of Stephen's epiphany are more clearly linked with the Famine in a subsequent scene involving Stephen and Michael Davin, his devoutly Catholic, West Irish counterpoint. Like Stephen Hero's Madden, Davin's nationalism frames the "strange vision" in the West of Ireland he relates to Stephen:

At last ... I spied a little cottage with a light in the window ... A voice asked who was there and I answered I was over at the match in Buttevant and was walking back and that I'd be thankful for a glass of water. After a while a young woman opened the door and brought me out a big mug of milk. She was half undressed as 
if she was going to bed when I knocked and she had her hair hanging; and I thought by her figure and by something in the look of her eyes that she must be carrying a child. She kept me in talk a long while at the door and I thought it strange because her breast and her shoulders were bare. (Joyce Portrait 182-183) Davin's narrative is superficially congruent with standardized Famine accounts where a "female figure, as scene of hunger and 'bearer of meaning', receives a detailed physical inspection ... [that] highlight[s] the woman's nakedness or quasi-nakedness" and the predominantly male viewer's "discomfort" (Kelleher 24). Traditionally, such discomfort stems from perverse maternal images, such as a "dry-breasted mother unable to feed her child," yet in Davin's account a "young woman" offers him "a big mug of milk" rather than the requested "glass of water" (2; Joyce Portait 182-183). As opposed to a "hunger-ravaged, unclothed bod[y]" emblematic of Famine subjects, the young woman's "bare" "breast" equally attests to virility and seduction: she is "carrying a child" and suggestively offers "something in ... her eyes" (Kelleher 29; Joyce Portrait 183). The Famine's iconographic images and Joyce's inversion of many of them are indicative of the Famine literary archive's "relatively small and circumscribed" iconography and its trajectory whereby "the frequency with which such images had been repeated transformed them into a group of signs whose presence in a text signifies ... 'famine"' (Morash "Literature, Memory" 113; "Making memories" 51). In contrast to the girl/seabird's epiphanic expansion, Davin's “fever[ous]" narrative clearly indexes a singular Famine historical narrative through iconic fragments that are re-presented to anxious effect. Instead of a consistently famished "Hidden Ireland" populated by victimized women like the "famine mother, the ministering angel, [or] sacrificial victim," Joyce authors two convoluted and contradictory scenes that unsettle both Davin and the Famine literary archive (Scally 4; Kelleher 111). 
These two prior scenes in Portrait trace a radical Famine revision across narrative, formal, and iconographic facets. The epiphanic girl/seabird provides a subjective rupture that extends to a wider narrative frame in Davin's ambiguous Famine narrative in the West of Ireland. A third scene, also involving Davin, extends these Famine revisions even further. Portrait reenacts the earlier "wolves of disbelief" discussion between Stephen and Madden outside of University College, Dublin during a nationalist dispute between Stephen and "[his] little tame goose[,]" Davin (Joyce 201). Davin's nationalist frustrations boil over to a pointed question: "What with your name and your ideas ... Are you even Irish at all?" that Stephen eventually, evasively answers: “- This race and this country and this life produced me ... I shall express myself as I am" $(202,203)$. Stephen clearly asserts his sovereignty outside of prefabricated identitarian categories, whether "Irish" or its polar variations: English, Anglo-Irish, British, etc. He also just as clearly formulates his sovereignty out of existing conceptual knots and forms when he further details his self-expression to Davin: "You talk to me of nationality, language, religion. I shall try to fly by those nets" (203). Whereas a broad critical consensus reads Stephen's flight from and through restrictive "nets," Marian Eide reads these "nets" as "the means for [Stephen's] flight; he will fly by means of those nets" (149). In this critical revision, Stephen models a modern Daedalus by taking up and transforming "nationality, language, religion" as raw materials rather than regressive untouchables. Stephen's nets are ultimately the material means for consolidating a revolutionary transgression of regressive colonial forms, both Irish and English. Seeing nationalism, language, and religion solely as obstacles limits a comprehensive, indeed historical, decolonization that Joyce succinctly gestures towards in a phrase from his Trieste notebook that characterizes Irish revolutionary activity, "Her rebellions are servile wars." (“Trieste Notebook" 101). Both Stephen's metaphorical nets and Joyce's 
minimizing of revolutionary "wars" are political revisions that are decidedly neither apolitical nor cynical. Both turn on a necessarily poetical axis within politics, which Jacques Derrida later identifies as a key to repudiating hegemony: "As for ... the revolution as transfer of sovereignty, however violent and bloody it might be as a taking of power ... political revolution without a poetic revolution of the political is never more than a transfer of sovereignty and a handing over of power" (The Beast \& the Sovereign I. 290).

The poetic and political revolutions necessary for exorcising sovereign domination, especially in colonial contexts, requires extensive reformulations that Portrait's Famine trajectories emblematize. The epiphanic girl/seabird not only operates as a rejection of wolfish imagery, but also a broader rejection of bestial colonial discourse that during the Famine especially highlighted wolves, but also pigs. Whereas wolfish images signify sovereign predation and eventually Irish colonial aggression, swinish images signify a bestial obverse steeped in subjection and passivity. Charles Trevelyan, Assistant Secretary to HM Treasury and architect of Famine relief policies in Ireland, asserted an intimate connection between the Irish and pigs in The Irish Crisis, his memoir on the Famine: "The pigs and poultry, which share the food of the peasant's family, became, in course of time, inmates of the cabin also" (6). Trevelyan's commentary draws upon an established "paradigm of the barbarian" that "drew the Irish peasant as a brute creature whose food was that of the domestic animals, especially the pigs, of civilized Europe" (Scally 8). ${ }^{131}$ Irish and swinish were so pervasive as signifiers that even outsiders to Anglo/Irish colonial conflicts like Friedrich Engels (1820-1895) utilized them in explaining Irish poverty. Engels extensively quotes Thomas Carlyle, a noted anti-Irish racist, prior to detailing London's Irish poor: “The Irishman loves his pig ... he eats and sleeps with it, his children play with it, ride upon it, roll in the dirt with it ... The filth and comfortlessness that prevail in the 
houses themselves it is impossible to describe" (92). Although ostensibly "impossible," Engels' description continues in noting the "Milesian" propensity for "accumulat[ing] ... pools and dirtheaps which disfigure the working-people's quarters and poison the air." Engels reads specific Irish practices like allowing "the pig [to] sleep in the room with himself" as intrinsically Irish: "This new and unnatural method of cattle-raising in cities is wholly of Irish origin." 132 Engels further concludes that these intrinsically Irish practices are indicative of a general inferiority apparent in the "horde[s] of ragged women and children swarm[ing] about here, as filthy as the swine that thrive upon the garbage heaps" and ultimately prove that "this race must really have reached the lowest stage of humanity" (60).

Like the aforementioned wolf, the Irish pig was indicative of dehumanized discursive strands coalescing largely out of the Famine. Trevelyan's and Engels' Famine-era designations continued throughout the Victorian era, particularly in political cartoons in Punch that would "equate Irish rebels with the lean, even emaciated pigs of the countryside and ... endow United Irishmen with snouts instead of noses" (Curtis 31). Swinish imagery castigated Irish revolutionaries, symbolically distilled pervasive Anglo/Irish colonial conflicts, and also keyed British ideological anxieties about the "social body" as it was threatened by "noxious elements $\ldots$ and those elements were Irish ... The English were in danger of becoming like the Irish, who were represented as a cross between matter and beast" (Hall Defining the 209). This swinish trajectory from the Famine through Victorian Irish unrest further informs the most latent Famine icon in Portrait, Stephen's pig. At the conclusion of Stephen and Davin's discussion, Davin's hot patriotism - "Ireland first" - grates on Stephen's nerves and he finally asserts with "cold violence" that "Ireland is the old sow that eats her farrow" (Joyce Portrait 203). Stephen's metaphorical swine encapsulates the repeated critical reading of Portrait that emphasizes its 
formal schemata, what Jed Esty considers an "epicyclical scheme of five chapters split between repetition and progress," as an extension of critical conclusions on Joyce's "recursive patterns and sequential narration" $(147,152)$. This critical recursion is asserted in spite of Portrait's open-endedness as Stephen's abrupt diary entries give way to an Irish exit and entry to Paris, France. More significant is the way Stephen's cannibalistic sow not only repudiates Davin's patriotism but also counters critical recursion. When critics emphasize Portrait's recursiveness they unwittingly reify the metaphorical swine as formal Ouroboros, and in so doing foreclose the Famine subtext that figures Stephen's ultimate flight. Stephen's metaphorically famished and cannibalistic Ireland distills Davin's own patriotism as nationally cannibalistic just as easily as it repudiates critical formulations that are similarly cannibalistic in their formal regression. Like the earlier epiphanic girl/seabird, Stephen's sow superficially limns colonial bestial discourse yet only in order to deform and reformulate its terms into a potential alternative that derives out of the very nets these colonial forms are intended to restrict and confine. The Famine's trajectory in Portrait illustrates a literary, historical, and critical refusal on Joyce's part, through Stephen, of various colonial forms, whether imperial or anticolonial in impetus. The sow's cannibalistic metaphor is the clearest rejection of bestial and formal delimitations, but just as incisive is the resonating proteanism of the girl/seabird, variously human and animal yet also simultaneously neither. Formulating both paradoxes within variously virile and unstable feminine bodies further encapsulates an expansive reformation of the Famine, its legacies, and its emaciated colonial ramifications at the heart of "Proteus."

\section{Protean Refuse: Lookingglasses, Shellbones, and Graveclothes}

Portrait's Famine refuse illustrates a maternal, material trajectory across three scenes that link with the Famine's maternal bodily legacies and bestial inhumanity while reformulating both 
through consistent change and allusive alternatives. This reformulating trajectory informs its colonial obverse early in Ulysses' "The Telemachiad," specifically in the regressively delineated colonial panorama of "Telemachus" and "Nestor." Joyce's earliest direct Famine allusion occurs in "Nestor" when Mr Deasy, in the course of remitting Stephen's salary, castigates his putative nationalism in Famine terms: “- You think me an old fogey and an old tory ... I remember the famine in '46 ... You fenians forget some things" (Joyce Ulysses 2.268-272). Deasy's critique is emblematic of "English notions of history" that justify lingering colonial exploitation through historicized obfuscation, particularly evident in his divisively binary pronoun emphasis: "You" and "I" (Cheng 165). Deasy's critique further underscores what critics will similarly "remember" or "forget" about the Famine in Joyce, dramatically distilled in Stephen's Irish sow, namely the preeminence of form. Form, both literary and contextual, is key to shifting the "The Telemachiad"'s colonial materials into a Famine alternative that reformulates the various elements of "Telemachus" and "Nestor," whether subjective - Buck Mulligan, the "gay betrayer"; Haines, "an Englishman" and "Britisher" - or objective - the Martello Tower or Mr Deasy's school (Joyce Ulysses 1.405, 1.430, 1.666). A similarly encompassing colonial form is the "The Telemachiad"'s discursive dialectic between localized "stereotypes of Irish natives generated by the regime of panopticism" and the broader "politics of globalization" that signify the "imperial British state" (Duffy Subaltern Ulysses 20; Hagena 188; Joyce Ulysses 1.643). ${ }^{133}$ Portrait's cannibalistic sow and its colonial ramifications are formally analogous with Ulysses' “Stately, plump Buck Mulligan" and his "mirror" (1.1-2). The mirror attracts Stephen's attention as he "ben[ds] forward and peer[s] at the mirror ... cleft by a crooked crack. Hair on end. As he and others see me" (1.135-136). Not only is Mulligan's mirror cracked, but he admits to "pinch[ing] it out of the skivvy's room" and this broken, stolen piece of refuse inspires Stephen's 
designation of the mirror "[a]s a symbol of Irish art. The cracked lookingglass of a servant" $(1.138,146)$. From the tower's material heights, "gunrest" and "parapet" $(1.37,38)$, to the mirror's quotidian materiality, Stephen recognizes a reflective web implicating all of Ireland's people, whether Mulligan the "gay betrayer[,]" Haines the "conqueror" (1.405), or Stephen the “[en]rage[d] ... Caliban" (1.143). These cracked Irish reflections resonate broadly within the contexts of all colonial projects as they are "construed, misconstrued, adapted and enacted by actors whose subjectivities are fractured - half here, half there, sometimes disloyal, sometimes almost 'on the side' of the people they patronize and dominate," but also locally in post-Famine Ireland and its colonial economy with its "one principal raw material; people" (Greenslade 203; Thomas 60). ${ }^{134}$

Portrait's Famine scenes are indicative of the colonial and corporeal complexities Joyce focuses on reformulating through Stephen at the conclusion of "The Telemachiad" in "Proteus." A relatively limited critical corpus reads "Proteus" as an "abstract" engagement with "apolitical aestheticism" that is arguably influenced by Joyce's own commentary on the episode and its protagonist: “"It's the struggle with Proteus. Change is the theme. Everything changes—sea, sky, man, animals. The words change, too"" and "Stephen no longer interests me to the same extent. He has a shape that can't be changed" (Gibson Joyce's Revenge 38; Cheng 74; Budgen 48, 105). ${ }^{135}$ A litany of philosophical allusions - Aquinas, Aristotle, Berkeley, Boehme, and Newman - in "Proteus" further underscores this critical commentary along with Stephen's episodic opening: "Ineluctable modality of the visible: at least that if no more, thought through my eyes" (Joyce Ulysses 3.1-2). Joyce's initial commentary on "Proteus" gestures to an episodic revision, one predicated upon "struggle" and "change" that is far from apolitical or entirely abstract. Specifically, Stephen's opening thought is not focused on abstract perception at all, but 
rather physical struggle, as Andras Ungar clarifies in noting ineluctable's 'root 'luc' is only apparently connected to the Latin word for light. The word at the root is lucto, which means to 'wrestle, to grapple with'” (37). Ungar's clarification is further amplified by Richard Begam's reminder that in "Proteus" "the historical and cultural facticity of [Stephen's] situation continues to obtrude" on his interior stream of conscious (195). Material and conflictual "facticity" litters "Proteus," especially in Stephen's survey of the imbedded refuse in Sandymount Strand's beachhead: "Signatures of all things I am here to read, seaspawn and seawrack, the nearing tide, that rusty boot. Snotgreen, bluesilver, rust: coloured signs. Limits of the diaphane. But he adds: in bodies" (Joyce Ulysses 3.2-4). "Proteus"'s opening lines foreground the formal and contextual links between Stephen's colonial refusals and Dublin's proliferating colonial refuse. These links are animated by Stephen's initially passive "thought through my eyes" which then gives way to an active "read[ing]" "of all things," whether "seaspawn," "tide," "boot," or "bodies."

"Proteus"'s Sandymount Strand setting spatially links it to Stephen's epiphany by the Bull Wall in Portrait with both scenes unfolding around Dublin's seaside precipice. Beachheads further spatially correspond with Alain Badiou's evental site; although plenty of evental sites occur far removed from the beach, the latter is particularly evocative of "the ordeal of absence and of the bare place" that allows one to engage with "the place of truth ... as a null, absented, and deserted place" whose dearth is antithetical to the state's plenitude (Handbook 48, 50). The physical and theoretical bareness and desertion of the evental site corresponds with a similar subjective bareness that antithetically forms in opposition to established identitarian categories. In Portrait's epiphanic girl/seabird, Stephen glimpses this subjective refusal of clear distinctions between human and beast that have similar referents in the landscape highlighted in the aftermath of his epiphany as he retreats into bare solitude: "He turned away from her suddenly 
and set off across the strand ... singing wildly to the sea" until "[t]here was no human figure near him nor any sound" and he then "ran towards the shore and ... reckless of the sharp shingle, found a sandy nook ... and lay down there that the peace and silence ... might still the riot of his blood" (Joyce Portrait 172). Joyce accentuates the spatial congruence of Portrait and "Proteus" through formal and word choice parallels as in the latter Stephen approaches "the edge of the sea" and "[t]he new air greeted him, harping in wild nerves, wind of wild air of seeds of brightness" (Ulysses 3.265-266). Like the earlier epiphanic scene, iterative "wild[s]" frame the colonial dynamics and the aforementioned "riot" in Stephen's blood further carries the epiphanic girl/seabird's subjective ramifications from pre-Paris Bull Wall, Dublin to post-Paris, Sandymount Strand, Dublin. These connected scenes further pinpoint the importance of the epiphanic girl/seabird's transformation as a general subjective revision, one in which an evental subject forms as one "grasp[s] the fluxes and breaks by reaching a sort of furor of being" that constitutes a new "subjectivity ... signaled by the possibility of an Idea, of a new Idea" (Badiou Handbook 39; Philosophy 74). The Famine event ultimately represents this "new Idea" as an anticolonial subject conceived outside of identitarian binaries or prefabricated delimitations.

"Proteus" clarifies and represents the colonial resonances of Stephen's subjective reformulation in its panoply of various colonial refuse imbedded in the beachhead. Stephen's trek up Sandymount Strand begins with an internal injunction defined by its literal sensory revision: "Shut your eyes and see. Stephen closed his eyes to hear his boots crush crackling wrack and shells. You are walking through it howsomever" (Joyce Ulysses 3.9-11). The echoing shells continue to the bottom of the paragraph, recurring with an allusion back to Mr Deasy: "Crush, crack, crick, crick. Wild sea money. Dominie Deasy kens them a"” (3.19-20). Deasy's vestigially invasive figure and his exploitative "sea money" further frame the colonial dynamics 
of these echoing "Wild" shells as the echoes begin even earlier in "Nestor" in Deasy's "strongroom" holding "the shells heaped in the cold stone mortar: whelks and money cowries and leopard shells" that constitute his "old pilgrim's hoard, dead treasure, hollow shells" (2.212214, 215). These recurring colonial contexts situate Stephen's “crack, crick, crick" as a colonial signifier of "culturally unassimilable words and scenes of nonsense" that Homi Bhabha identifies in "the Horror, the Horror, the owl's deathcall, the Marabar caves - [that] suture the colonial text in a hybrid time and truth that survives and subverts the generalizations of literature and history" (183). Although perceptive, Bhabha's colonial sounds fail to capture the localized distinctions of Stephen's crackling shells which sonically capture specific Irish colonial invasions as "Lochlanns" and "Dane Vikings" invade Irish beachheads as merely two of a broad spectrum of colonial predators including Firbolgs, Tuatha Dé Danann, Celts, Normans, English invaders, and Phytophthora infestans — the Famine's pathogenic core (Joyce Ulysses 3.300, 301). "Proteus" later underscores the corporeal facets of these colonial echoes in Stephen's recurring reflections on the crackling shell-like refuse: "A sentinel: isle of dreadful thirst ... a maze of dark cunning nets" and "Human shells" $(3.1534,157)$. Crush, crack, cricking human shells materialize in the present a distant and potentially forgotten history of morbidly cracking human bone and sinew as each subsequent invasion and violent penetration allusively echoes out of nondescript refuse.

In these quotidian pieces of Dublin's coastal refuse we see an evocatively corporeal vein of Irish colonial history. Furthermore, the crackling shells echo both a distinctly Irish history as well as a global colonial dispensation that revolves around corporeal violence. Stephen's presence and apprehension thus instantiates in his present a litany of past lives that no longer exist. Similar, albeit in contradistinction to Spenserian wolves, Joyce transforms the Irish subject through its entanglements with an allusive web of natural and historical touchstones. "Proteus" 
grounds these touchstones in the shells that open its episode, but also threads this connections through various other allusive nodes such as the Spanish Armada's 1588 wreckage on Irish coastlines: "The grainy sand had gone from under his feet. His boots trod again a damp crackling mast, razorshells, squeaking pebbles, that on the unnumbered pebbles beats, wood sieved by the shipworm, lost Armada" (3.147-149). Stephen's "boots" again elicit a "crackling" colonial echo that signifies both Ireland's lost hope of Catholic deliverance and England's putative divinelysanctioned imperial apotheosis. Another subtext elucidated in the "crackling ... razorshells" and the ravenously bestial "shipworm" are Famine-era invasions, particularly the 1848 suspension of Habeas Corpus in which "English troops and weapons poured into Dublin and spread around the country" in order to support an inverse invasion, namely enforced British exports as "ship after ship—laden with wheat, oats, cattle, pigs, eggs, and butter—sailed down the Shannon bound for well-fed England from famine-stricken Ireland" (3.148, 149; Laxton 83; Sen 172). This allusive breadth reflects the range of colonial, not to mention Famine, experiences with exploitation, oppression, and death that mark Irish history and culture. Specifically, Stephen's allusive stream of conscious in "Proteus" traces out a general colonial history whose allusive deluge narrows into the Famine. The shells and Armada references continue to allusively point to "A bloated carcass of a dog" and "A point, live dog" that ultimately frame the cracking sounds in emphatically human and Famine terms (Joyce Ulysses 3.286, 294). Similar to the epiphanic girl/seabird's seaweed sign, the recurring crackling of shells or masts inflect the later canine allusions as a concentrated web of morbid Famine signs whose allusive dead end is the living dog "vulturing the dead" (3.363-364). So "vivid" and repeated were "scene[s] of ... emaciated dying bodies lying by the roadsides" in the Famine oral archive that they remained indelibly marked within eyewitness and subsequent generational memories "to this day" with many of 
these scenes rehearsing the horrific invasion of the dead by starving dogs who satiated themselves on exposed corpses (Harris 3). ${ }^{136}$ Strikingly, the famished canine allusions in "Proteus" precede Stephen's reflections on a drowned men, which further echoes the earlier epiphanic girl/seabird's dangerous shoreline foraging in another contemporary re-presentation of death and the dead: "Dead breaths I living breathe, tread dead dust, devour a ruinous offal from all dead" (Joyce Ulysses 3.476-480).

Stephen's echoing shells enact a colonial trajectory that allusively dredges up various histories of mass death that are far removed from Portrait's gorgeously sated girl/seabird. The latter's Famine resonances are even more emphatically rendered by the deathly focus in "Proteus" since, as Chris Morash notes, "the primary referent of the word 'famine' is 'death"” and "[t]he text $[\mathrm{a}] \mathrm{s}$... the site on which the absent dead of the Famine are brought into the present" re-presents the "dead a[s] not simply absent; their absence is no longer even recognized" (Writing the Irish 4, 181, 184). The Famine's absent dead explain the corporeal dissonance between Portrait and "Proteus" that nevertheless belies both scenes' allusive connections in deploying death as a means for reframing living alternatives. Stephen's epiphany dramatizes an initial polarization between life and death framed by the girl/seabird's epiphanic proteanism: "His soul had arisen from the grave of boyhood, spurning her graveclothes. Yes! Yes! Yes! He would create proudly out of the freedom and power of his soul, as the great artificer whose name he bore, a living thing, new and soaring and beautiful, impalpable, imperishable" (Joyce Portrait 170). Stephen's repetitive and emphatic "Yes!" highlights "new[ness]" as the radical change in his metaphorical rising from the "grave" and casting off its restrictive "graveclothes." Throughout this epiphany, the sea is a silent and spatial framework for tracing Stephen's subjective reckoning which ultimately and reflectively hinges upon "her 
graveclothes." The latter allusively connects Portrait's epiphany with another transformative feminine body in “The Telemachiad," Mary Dedalus' ghost. Mary's spectral appearance occurs in the opening of Ulysses during Buck Mulligan's elusive tangents atop the Martello tower, especially when he reflects on the Irish Sea: “Isn't the sea what Algy calls it: a great sweet mother? The snotgreen sea" (Joyce Ulysses 1.77-78). Mulligan's (snot)green texturing of the Irish Sea as "a great sweet mother" evokes a symbolically perverted version of "Erin or Hibernia, the 'Distressful Damsel"' and "intensely feminine symbol of Ireland, whose haunting beauty conveyed some of the sufferings of the Irish people" (Curtis 57, 31). Of further significance is Mulligan's evocation of a poeticized Ireland out of English poet Algernon "Algy" Charles Swinburne, which further emphasizes the passive and dominated nature of the symbol. In spite of Mulligan's English-centric evocation, the Irish seascape retains an unsettled potential through its connections to Mary Dedalus and the Famine.

In response to Mulligan's repeated "mother[ly]" allusions, Stephen remembers "a dream" he had "after her [Mary] death, her wasted body within its loose brown graveclothes giving off an odour of wax and rosewood, her breath ... a faint odour of wetted ashes" (Joyce Ulysses 1.80, 102-105). Mary's emaciated form appears in language reminiscent of Stephen's earlier epiphany by the Bull Wall, specifically in the repeated "graveclothes." Stephen's thoughts continue as "he saw the sea hailed as a great sweet mother by the wellfed voice beside him. The ring of bay and skyline held a dull green mass of liquid. A bowl of white china had stood beside her deathbed holding the green sluggish bile which she had torn up from her rotting liver by fits of loud groaning vomiting" (1.106-110). Stephen's allusive memory draws a direct connection between Mary's "wasted body" and Mulligan's "wellfed" one that is paralleled in the connections between Mulligan's snotgreen sea, what Stephen visualizes as "a dull green mass of liquid," and 
the "bowl" of "green sluggish bile" by his mother's "deathbed." Green-tinged snot and bile each signify intimately subjective refuse that underscores corporeal weakness and illness. They further signal complex connections between Mulligan's literary and colonial symbolism and Mary's spectral form. Stephen's silent reply accentuates the formal importance of her ghost in relation to Mulligan's allusive snotgreen sea: "Inshore and farther out the mirror of water whitened, spurned by lightshod hurrying feet ... Wavewhite wedded words shimmering on the dim tide" (1.243247). Like Mulligan, Stephen's imagination rests upon the sea and its connections to literary form, as the alliteratively "Wavewhite wedded words" attest, yet in doing so he reformulates Mulligan's snotgreen sea beneath repetitively "whitened" and (Wave)white resonances. In whitening the green and emphasizing a "wedded" relationship to "words," Stephen's reflection further reinforces as it rebukes Mulligan's allusive entanglement with an Irish discourse marked by irreverence and inferiority. This further clarifies the stakes of Mulligan's dismissal of Stephen early in the novel when he says, "O, it's only Dedalus whose mother is beastly dead" (1.198199). Mulligan's lightness belies a recycling of Irish bestiality, especially in light of his repeated adoption of English allusions, that is specifically dismissive of death, a key legacy of Famine devaluation within English relief policies. Even if Mulligan's irreverence is a full-blown refusal of all sanctity - Irish, English, or other - his allusive comments continue to implicate Mary's ghostly appearances within an imperial dismissal of Irish suffering during the Famine. William Carleton's The Squanders of Castle Squander clearly model this dismissal through the AngloIrish aristocrat, Margaret Squander, who disgustingly abhors entering the "“poor and miserable hovels, where filthy wretches, steaming with contagion, lie on the rotten straw, ... worthless creatures, who are better dead than alive"” (Vol I. 188).

\section{Acknowledging Infinity: Shakespeare, Sandymount, and the Limits of Colonialism}


Margaret Squander's imperial pronouncement that the Irish "are better dead than alive" highlights the absolute terms of colonial "knowledge": absolutely material, absolutely binary, absolutely settled. These ideological absolutes ground yet also constrain colonial projects and their congruent historical obfuscations and administrative exploitations. Such a paradoxical tension informs "colonial knowledge [that] often took the form of a panoptical, encyclopedic appropriation of indigenous customs, histories, relics and statistics, [yet] such displays of intellectual rapacity were frequently accompanied by a kind of despair, which found the space and social entity of the colony to be intangible" (Thomas 15-16). "Proteus" frames deep colonial resonances out of Stephen's ostensibly innocuous steps, particularly as they "Crush, crack, crick, crick" Sandymount's shells. Stephen's steps and the crackling shells attest to a material valence at odds with colonialism's panoptic absolutes and encyclopedic allusions that is underscored by the line immediately preceding this second apprehension of crackling shells: "Am I walking into eternity along Sandymount strand?" (Joyce Ulysses 3.18-19). Stephen's evocative question on "eternity" or infinity gestures toward those colonial forms that produce a sense of despair and intangibility in colonial ideologies. Coming directly prior to the allusive crackling of the shells, Stephen's "eternity" further underscores allusion as a formal repudiation of knowledge. Although allusive identifications superficially reinforce knowledge and understanding, thereby testifying to intellectual breadth, this knowledge is ultimately illusory. Allusiveness, like its semantic relation elusiveness, formally inundates knowledge with an overwhelming referential deluge. Especially in modernist form, which in part is marked by a thick, often excessive allusiveness, allusions overwhelm epistemological boundaries and recursively override knowledge as their multiplicity attests to an inescapable defiance of closure through infinite referential nexuses. Likewise, Alain Badiou echoes the primacy of eternity or infinity as a 
conceptual premise of the event, specifically as "[t]he infinity of a truth is the property whereby it subtracts itself from its pure and simple identity with the established forms of knowledge" (Handbook 10). This "pure and simple" annulment further situates allusion as a key predicate for realizing alternative possibilities. As Badiou elaborates and Stephen's question illustrates, allusion's infinite potential limns the frameworks of established knowledge while undermining and ultimately "subtract[ing]" from it.

Mary's ghost is an early and clear allusion throughout "The Telemachiad," but also between Portrait and Ulysses. In "Telemachus," Stephen remembers a vision of "Her glazing eyes, staring out of death" that later recurs in "Proteus" when he reflects on Mulligan's irreverent allusion to the sea- "like Algy, coming down to our mighty mother"- which prompts another remembrance of his mother, "a ghostwoman with ashes on her breath" (Joyce Ulysses 1.273, 3.31-32, 3.46-47). This allusive progression further synchs up with the broader Famine literary archive, especially as "writing the Famine will always, whether by inclusion or exclusion, inscribe the dead in discourses other than that of famine per se" as readers "encounter only the ghosts of the dead, who are, as ever, absent" (Morash Writing the Irish 187). Allusively, Mary's ghost oscillates between presence and absence, both literally as a specter and contextually as an allusion recurring in-and-out of the text. Mary's links to the sea and the Sandymount beachhead, themselves allusively echoing the epiphanic girl/seabird, likewise align her allusive form with ramifications within "the shore and the sea['s] coexist[ence] in a shifting liminality as the tide recedes and reclaims the land" (Beer 33). Although scholars highlight islands as spatially "natural colonies" and beachheads as particularly idealized "location[s] of hybrid cultures," Mary's spectral and spatial connections are decidedly antithetical to a Bhabhaian hybridity and liminality, but incisively evocative of chaos theory and its implications for beaches, specifically 
in theorizing that "the circumference of any shore is so shifting as to be infinite and depends upon the chosen scale of description" (Edmond and Smith 1, 12; Beer 33). Infinity is a concept that by its manifestation invalidates any attempt to absolutely delimit through hegemonic denomination. Joyce deploys infinity through an allusive web that indexes localized fragments in a broadly global and infinite expansion through Mary's ghostly subjectivity, Sandymount's shifting spatiality, and the "Proteus"'s formal allusiveness.

Allusion particularly underscores the infinite forms Joyce deploys within "Proteus." Established postcolonial hybridity and its relations so far in this essay have focused on the intertextual connections between Joyce's novels, but "Proteus" further highlights the importance of a Shakespearian intertext. Shakespeare's Hamlet has long been recognized as an important intertext in Ulysses, but also specifically in "Proteus," which traces Shakespearian intertextual connections out towards infinity and subjective possibility. Portrait's epiphanic girl/seabird and Mary's ghost each frame Stephen's subjective reflections in "Proteus" as well as key scenic precursors to later Shakespearian allusions. On Sandymount Strand, Stephen reflects on his future artistic production in an imaginary conversation: "Remember your epiphanies written on green oval leaves, deeply deep, copies to be sent if you died to all the great libraries of the world, including Alexandria? Someone was to read them there after a few thousand years, a mahamanvantara" (Joyce Ulysses 3.141-144). Stephen's stream emphasizes "epiphanies" and "green" in drawing connections between the aforementioned female forms and his future aesthetic writings. Both forms are further framed by the deep temporal framework asserted, "a few thousand years, a mahamanvantara" that includes yet exceeds standardized Greenwich Mean Time. Stephen's temporality is further excessive in the lines following that delineate his works to come: "When one reads these strange pages of one long gone one feels that one is at one with 
one who once ....." (3.144-146). In Stephen's thoughts, an infinite representation is sketched in the repetitive "one" and final variant "once" prior to the extended, open-ended ellipsis. In the context of his future corpus, Stephen's distillation of epiphanic, spectral, and infinite forms further emblematizes the radical implications of allusion, especially within stream of conscious form. Stephen's monographic and interior foci resonate with Ulysses' wider intertextual relationships with Shakespeare's Hamlet. "The Telemachiad" particularly links Stephen with Hamlet's discourse on the transience of man with Guildenstern and Rosencrantz as Hamlet enters the scene "reading a book" and then bemoans, "What a piece of work is a man! How noble in reason, how infinite in faculties, in form and moving how express and admirable" (Shakespeare Ham II.II.304-306). Hamlet's own "infinite ... faculties" and "forms" shapes man in an overly salient resonance with Stephen's later relations to Shakespearian allusion throughout Ulysses. Although Shakespeare figures most explicitly in "Scylla and Charybdis," largely framing the colonial culture wars that focused on Shakespeare as an example of "English culture [so] deeply and ineradicably rooted in Irish soil" that any putatively "significant Irish culture was English[,]" "The Telemachiad" contains important Shakespearian precursors for thinking about this conflict's roots in Ulysses and especially "Proteus" (Gibson Joyce's Revenge 62-63).

One of the earliest intertextual moments between Shakespeare's Hamlet and Joyce's Ulysses in "The Telemachiad" importantly recurs in "Proteus." As Stephen walks with Haines on the cliffs above the Martello Tower the latter quotes Hamlet to characterize the surrounding environs: " - I mean to say ... this tower and these cliffs here remind me somehow of Elsinore. That beetles o'er his base into the sea, isn't it?" (Joyce Ulysses 1.566-568). Haines alludes to Horatio's warning to Prince Hamlet about the Ghost- "What if it tempt you toward the flood, my lord, / Or to the dreadful summit of the cliff / That beetles o'er his base into the sea" 
(Shakespeare Ham I.IV.69-71). As allusively rendered, Haines, the Irish-speaking Englishman, renders a tangled mass of sovereign, spectral, and servile questions linked to an effacement of Irish cliffs into a Danish precipice, "Elsinore." Shakespeare is here deployed as an allusive projection that transmutes Ireland into Denmark and latently figures Spenser's Irish-less Ireland. This act of allusive colonization is countered in "Proteus" when Stephen, walking with closed eyes on the beach, is startled: “Open your eyes. No. Jesus! If I fell over a cliff that beetles o'er his base, fell through the Nebeneinander ineluctably (Joyce Ulysses 3.14-15). Although Haines' and Stephen's respective allusions are both rendered with material immediacy upon the Irish landscape, only Stephen deploys Shakespeare to signify the literal and ideological dangers of subjective blindness. Stephen's allusive introspection is a significant counterpoint to Haines' Shakespearian allusion, but also to another Shakespearian allusion that follows Haines' environmental revision. Furthermore, Haines' grounded colonial revision echoes Buck Mulligan's prior revision of the Irish Sea as "the sea [t]hat Algy calls ... a great sweet mother? The snotgreen sea" (1.77-78). This obvious English-inflection of the Irish Sea allusively includes a far darker colonial side, one clarified through a Shakespearian allusion in "Scylla and Charybdis" that combines Hamlet and Swinburne: "Khaki Hamlets don't hesitate to shoot. The bloodboltered shambles in act five is a forecast of the concentration camp sung by $\mathrm{Mr}$ Swinburne" (9.133-135). Swinburne's sonnet referenced here, "On the Death of Colonel Benson," memorializes a British military leader during the Boer War without any reference to concentration camp atrocities; its allusion here further politicizes earlier allusive references to Swinburne and Shakespeare (Gifford 202). Joyce's "Khaki Hamlets" is an allusive end that reconnects Haines' earlier reconfiguration of Irish cliffs into a Danish precipice within a 
comprehensive literary and cultural network of allusions whose political subtexts span geography, culture, and atrocity.

An additional allusive response occurs multiple times in "Proteus" as Stephen rethinks and revises Haines' Shakespearian references. Now situated below the Irish cliffs, Stephen glances out to the Irish Sea and allusively repudiates both Mulligan's and Haines' English colonial revisions: "Airs romped around him, nipping and eager airs. They are coming, waves. The whitemaned seahorses, champing, brightwindbridled, the steeds of Mananaan" (Joyce Ulysses 3.55-57). The Shakespearian allusion here is the "nipping and eager" Danish "air" that similarly affects Hamlet and Horatio:

HAMLET. The air bites shrewdly; it is very cold.

HORATIO. It is a nipping and an eager air. (Shakespeare Ham I.IV.1-2) As opposed to Mulligan's colonizing sea or Haines' Danish elision of Ireland, Stephen notes an allusively atmospheric convergence of Danish and Irish space through "nipping and eager airs" that transgress temporal, national, and geographic boundaries. Such transgressions extend to Stephen's reformulation of a Shakespearian Ghost into Irish "whitemaned seahorses" of the shape shifting sea deity Manannán mac Lir in order to recast the latter into Irish anticolonial specters. "Proteus" underscores the convergence between allusive resistance and bodily primacy as Stephen later dwells on a "Hunger toothache" immediately prior to linking the later allusive khaki Hamlets with immediate violence: "Shoot him to bloody bits with a bang shotgun, bits man spattered walls all brass buttons. Bits all khrrrrklak in place clack back. Not hurt? O, that's all right. Shake hands. See what I meant, see? O, that's all right. Shake a shake. O, that's all only all right" (Joyce Ulysses 3.186, 3.187-191). Stephen's violent thoughts anticipate through an echoing "bang" sound, "khrrrrklak," the later Hamlet concentration camp reference in "Scylla 
and Charybdis." In the repetitive "shake" we glimpse a phantom Shakespeare that parallels Mary's own ghostly allusiveness. Stephen's "Hunger toothache" establishes a tangential Famine legacy in his own body that has laced throughout Mary's ghostly allusions and even now inflects the various Shakespearian ones that arise and are subtly revised throughout "The Telemachiad."

Throughout the different Shakespearian allusions, Hamlet's Ghost is a recurring, albeit elusive figure that Stephen later revises as a protean Irish spirit, god, or mother. Its greatest lasting import is its connections to Elsinore, the material cliffs of Denmark, and these subsequent ramifications in "Proteus" which further extrapolate Mary’s connections to the sea, to Manannán, and ultimately to Stephen on Sandymount. As Stephen walks the beach, he explicitly figures this connection through the Ghost: "My soul walks with me, form of forms. So in the moon's midwatches I pace the path above the rocks, in sable silvered, hearing Elsinore's tempting flood" (3.278-281). The "sable silvered" specter on "Elsinore's tempting" Irish waves frames the following reflection on the beachhead itself as Stephen imagines its "heavy sands are language tide and wind have silted here. And these, the stoneheaps of dead builders ... Heavy of the past." (U 3.286-291). Befitting the stream of conscious form of "Proteus," Joyce clarifies through Stephen the episode's compositeness. This composite form aligns Stephen, Dublin's colonial refuse, and the natural grounds beneath within a single schema illustrating a fundamentally totalizing picture of colonial exploitation. If "language" is "silted here" "heav[ily]" just as the "sands" are recursively brought by the "tide and wind," then this "Heavy ... past" can be revised both discursively and spatially. Stephen's focus on Sandymount s(tr)and extends to and further inflects his apprehension of a similar discursive and physical revision to bodies. Dwelling upon the drowned man somewhere in the sea, he imagines a protean progression of the drowned body: "God becomes man becomes fish becomes barnacle goose becomes featherbed mountain. Dead 
breaths I living breathe, tread dead dust, devour a ruinous offal from all dead" (3.476-480).

Death is emphatically repeated at the conclusion of this reflection and then followed by a protean summation: "seachange" (3.482). The drowned man allusively reaches all the way back to Portrait as the historical obverse of the epiphanic girl/seabird's sated form, namely the drowned seaweed gathered that never returned to a famished family with sustenance or compassion. Significantly, both forms, along with Mary's ghostly variations - spectral, Shakespearian, famished - represent the complexities borne out of "Famine bodies [that] evince a materiality at once grossly substantial and elusively phantasmal, evoking a materialism that, far from offering a refuge of certitude, threatens instead to dissolve the familiar boundaries between self and world" (McLean 122). Mary's emaciated spectral form is objectively antithetical to the epiphanic girl/seabird's sated magical form yet both "dissolve the familiar boundaries between self and world" and initiate this action within Stephen. Both feminine forms ultimately coalesce in Stephen's mind through the Famine as he looks out to sea and reflects: "Famine, plague and slaughters. Their blood is in me, their lusts my waves. I moved among them on the frozen Liffey, that I, a changeling, among the spluttering resin fires. I spoke to no-one: none to me" (Joyce Ulysses 3.306-309). Stephen's self-ascribed "changeling" state aligns him with the allusive variance and spectral ramifications of both the epiphanic girl/seabird and his mother's ghost. Mary's "blood" is Stephen's genetic heritage while Stephen's "blood" is also an allusive heritage back to the epiphany by the Bull Way and "the riot of his blood" that precedes a rebirth from the "earth beneath him, the earth that had borne him, had taken him to her breast" (Portrait 172). Ultimately, Joyce's greatest revision in putting forth a renewed Famine subject is allusively drawing that subject out of the earth, the earth that had incubated an invisible pathogen and 
ultimately borne a famine that would depopulate Ireland is here finally figured as the means for a riotous and renewed subject.

\section{Conclusion: Stephen's Colonial Odyssey}

Within "Proteus" Joyce formalizes colonial Ireland's troubled state in parallel with Stephen's troubled state while further linking both through episode's literally pervasive refuse. This protean panoply allusively grounds a political and anticolonial subtext premised upon rapid and ever-shifting transformation. Throughout "Proteus" allusion functions in a radical vein that not only infinitely expands Ulysses' shortest episode, but potentially re-envisions other texts within an Irish context, such as Shakespeare's Hamlet. Although allusion is particularly radical within Joyce's formal contexts, it can also function regressively in other modernist texts. A potentially silent allusion between "Proteus" and W.B. Yeats' 1910 poem "At the Abbey Theatre" illustrates this divergence. Yeats" poem begins with flight, the "high and airy hundreds" who "hold that flight they'll leave the place" (Collected Poems 11. 2-3). These flights allude strongly to Dedalus and his nominal forebear, the "hawklike man flying sunward above the sea" and the "Fabulous artificer" (Joyce Portrait 169; Ulysses 9.952). Yeats' allusion is particularly evocative of "Proteus" as the poem ultimately situates Proteus at the Abbey Theater:

You've dandled them and fed them from the book

And know them to the bone; impart to us -

We'll keep the secret - a new trick to please.

Is there a bridle for this Proteus

That turns and changes like his draughty seas? (Collected Poems 11. 8-12) ${ }^{137}$ Yeats' poem, especially in the Irish political contexts of the Abbey Theater's culture wars, foregrounds what Mulligan's earlier Swinburnian Irish Sea also emblematizes: allusion as a 
bridling force akin to imperial control. As opposed to Daedalian flights, Yeats' and Mulligan's allusions are ideologically bridling and delimiting as they denote the aesthetic blind spots in postcolonial theory. Although ghosts have been read as alternative subjects and possibilities, their presence is too often unhinged from aesthetic and formal frameworks that they arguably most perceptively contribute to. Yeats" poem emphasizes materiality - "bone" and "bridle" - as the means for delimiting Protean unease, especially in light of ever-shifting "seas." Mary's ghost is also clearly aligned with the sea and her fully allusive form provides a radically unbridled poetic, political, and material vestige running throughout "Proteus."

In stark opposition, Joyce's "Proteus" emphasizes perpetual change in its shifting sands, tides, and various refuse and detritus that frame Stephen's trek up Sandymount Strand. In the wider context of Stephen Hero, Portrait, and Ulysses, Stephen's shape has changed, at times radically. Stephen ends "The Telemachiad" upon Sandymount Strand at the close of an episode whose radical emphases across form, context, and scenery all converge around change and infinity. It is ultimately the latter - infinity - that realizes the possibility of the former - change. As significant as closure is to Yeats' poem and its clear ending, Joyce's published novels with Stephen, both Portrait and Ulysses, are just as clearly open-ended. It is ultimately Stephen and not Leopold Bloom who holds the key to a radically engaged and purposeful subject who agitates for anticolonial freedoms and egalitarian equity. That Stephen is not currently and completely on June 16, 1904 that subject yet does not invalidate his trajectory or promise in the future. Joyce famously claimed that Ulysses "give[s] a picture of Dublin so complete that if the city one day suddenly disappeared from the earth it could be reconstructed out of my book" (Budgen 69). As Enda Duffy has noted, Ulysses' Dublin was a temporal hodge-podge of pre- and post-1916 Dublin cityscapes ("Disappearing Dublin"). Ulysses' picture of Dublin is complete in 
the sense that it provides a composite of Dublin's ancient, recent, and contemporary forms. It is also another level of complete in that, like Stephen, it anticipates future forms to come. Its openendedness indicates, among many possibilities, what might happen if we imagine Stephen really is "walking into eternity along Sandymount strand" (Joyce Ulysses 3.18-19). We might interrupt this eternity at a point nearer to contemporary Dublin, one in which Stephen's walk up Sandymount Strand carries him into Dublin and eventually leads the young artist to the Garden of Remembrance. Among the Garden's memorials is a prominent statue commemorating all Irishmen and women who gave their lives in the struggle against England, the "Children of Lir." Fittingly, like so many of Joyce's protean examples, the statue captures the fluidly transitory moment of three child-like forms rooted to the ground yet transforming into three separate swan forms lifting into the air. The children of Lir's transformation is forever in situ, much like Stephen on Sandymount, yet this does nothing to diminish either of these scenes' radical formal potential. 


\section{Coda: "A terrible beauty is born"; or, the Famine's Prose}

On Easter Monday, April 25, 1916, Pádraic Pearse read out the proclamation of the Irish Republic from steps of the General Post Office on Sackville Street (now O’Connell). The opening line, "IRISHMEN AND IRISHWOMEN: In the name of God and of the dead generations from which she receives her old tradition of nationhood, Ireland, through us, summons her children to her flag and strikes for her freedom" ("Proclamation of Republic"). The "Proclamation" is remarkable for its initial framing of the audience, men and women, God and the dead. Pearse, committed to a violent and fatal colonial revolution, further voiced such a commitment as transcending all human boundaries even unto death. His call no doubt affected many, not the least being Father Joseph Mallin, the then-infant son of Michael Mallin, Chief of Staff of the Irish Citizen Army and second-in-command to James Connolly. Michael Mallin was executed at Kilmainham Gaol on May 8, 1916 and later, in 2011 as the last surviving child of the Rising's leadership, Joseph Mallin reflected on Ireland prior to the Rising, "You know before 1916 there was rather despair - you feel it in Yeats, Conor Sheehan and others," and on the Rising's lingering legacy, "They did shape the country. What is gained with little or no effort is not valued. 1916 did set an ideal" ("Witness Statements"). Although an infant at the time, admittedly sleeping through his father's execution, Fr. Mallin attests to the received legacies of the Rising, its reaction against a cultural and colonial "despair" and also its revolutionary "shape" as "ideal." This latter ideal resonates in the force of Pearse's words addressed to "the dead generations" and the way this call crosses all boundaries, even those of the executions. A Capuchin priest, Fr. Aloysius, heard Pearse's and James Connolly's final confessions and was also present as Sean “JJ" Heuston was executed. Fr. Aloysius' reflection on the aftermath of the execution lends further shape to Pearse's prophetic call, "I scarcely had moved away a few yards when a volley 
went off, and this noble soldier of Irish freedom fell dead. I rushed over to anoint him. His whole face seemed transformed, and lit up with a grandeur and brightness that I had never before noticed."

This transformation is certainly understandable for the faces of those within the Rising's intimate circle, but it also reached out to those who were totally cut off from the Rising's planning and carrying out. Yeats, who knew many of the leaders in the Rising, penned "Easter, 1916 " as a complex memorial to the event and its reception. Echoing the contemporaneous shape of Heuston's face or the later reflective ideal of Fr. Mallin, Yeats' poetic refrain distills the Rising's transformative power in a repeated refrain, “A terrible beauty is born" $(11.16,40,80)$. The persistence of this refrain belies the mixed feelings the Rising engendered in Ireland yet what was constant, as the poem demonstrates, is the recognition of the Rising's transformative power. The poem attests to the event's power as shifting yet persistent in lines that cross different stanzas: "All changed, changed utterly"; "Transformed utterly"; "Are changed, changed utterly" (11. 15, 39, 79). The different lines preserve a dynamic reflection on the event, one that is both shifting and variegated yet also static. These two levels are staged by the differences in each line that nevertheless preserve a transformational core, "utterly." In terms of the event, Yeats' lines initially attest to transformation in its latent multiplicity in the "chang[e]" and "transform[ation]" that can lead to revolution or regression. Connecting these dynamic touchstones with a consistent "utterly" underscores the desired bedrock, a transformation that is total and irrevocable, that the poem distills into the recurring phrase, "A terrible beauty is born." "Easter, 1916" ultimately shares with the proclamations and reflections of Pearse, Mallin, and Aloysius the way an event preserves distinctive perspectives even as each perspective is drawn into a similar account of the event's potential transformation. The Rising necessarily invited a 
broad range of responses and representations, which need proper context, but what links so many of these responses is the transformative tenor of the event. The Rising like the Famine, function on a congruent level as events with a revolutionary core. In spite of their distinct differences in temporality, history, and detail, they both exemplify shared transformative potential, particularly in constructing subjects through a kind of "terrible beauty" that is capable of "transform[ing] utterly" the colonial situation.

Fr. Joseph Mallin emphasizes the pre-1916 "despair" in the works of "Yeats, Conor Sheehan and others" that the Rising penetrated. He names another priest, Canon Patrick Augustine Sheehan, whose novel The Graves at Kilmorna: A Story of '67 (1915) focuses on one of the many risings prior to the Rising. Early in the narrative, James Halpin, a rural school teacher, reflects on the Irish countryside and remarks to a group of schoolboys, "II is a beautiful view ... and ours is the most lovely country on the face of the earth. We ought to love every blade of grass in its fields, every stone in its hollows, every leaf in its trees, every stream that runs, every hill that begets the stream—' He lowered his voice. 'Every man that has shed his blood for Ireland"' (5-6). Halpin's Irish litany touches upon the landscape, whether "every blade of grass" or "every stone" or "every hill" that similarly is taken up in Yeats" "Easter, 1916," particularly in the third stanza, "Through summer and winter seem / Enchanted to a stone / To trouble the living stream" (11. 42-44). Both texts take up the natural terrain as a quotidian framing of an effervescent opposition, namely the revolutionary spirit of "'Every man that has shed his blood for Ireland."' Here poetry and prose again come up against each other. Badiou significantly sees the two as connected albeit different aesthetic strands revolving around the concept of "'the story' as that thing about which there is doubt" (Handbook of Inaesthetics 125). "That thing ... which there is doubt" is precisely the event and it is this axis point that prose and 
poetry revolve around and reveal their subtle differences. "'Prose"” is understood as "every articulation between the story and doubt. The art of prose is neither the art of the story nor the art of doubt, it is the art of proposing the one to the other." Significantly, what prose ultimately does is bring together the narrative broadly conceived and the enigmatic event, riddled with doubt. In relating the story we are presented with the doubtful circumstances of the event which constitutes an "enigma" and this enigmatic "doubt ... must resolve itself into affirmation without having the story as the material for its exercise" (126).

A long shadow of doubt, an iteration of Mallin's "despair," is cast over modern Irish literature, especially in the wake of the Rising as well as the earlier Famine. Both events cast into relief the problems for a successful decolonization. These problems are only secondarily those of revolutionary zeal in violence. Patrick MacGill's preface to his early novel The Rat-Pit (1915) articulates the primary formation of these problems: "The underworld, of which I have seen and known such a lot, has always appeared to me as a Greater Rat-pit, where human beings, pinched and poverty-stricken and ground down with a weight of oppression, are hemmed up like the plague-stricken in a pest-house" (The Rat-Pit XVII). MacGill's early twentieth-century experiences as an itinerant navvy and WW I veteran exposed him to a broad swathe of exploitation, suffering, and mass death and these latter experiences are the broad frameworks for the kind of revolutionary zeal that attempts to meet them. The Rat-Pit narrates a localized synecdoche of the "Greater Rat-pit" - the former the slums of Scotland that house his protagonist Norah Ryan - as exemplifying the colonial world's broader slums and migrations. MacGill's recounting of material poverty and oppression provide a quotidian mirror for the more spectacular narratives of decolonization that revolve around revolutionary spectacle. The legacies of the latter are the focus of Seán O'Faoláin's protagonist Frankie Hannafey in Come 
Back to Erin. Hannafey, a wanted gun-runner and violent revolutionary, reflects on what is lacking in the figure of the revolutionary committed to violence:

A great many of the fiercest Irish gunmen became, like him in his adult years, in love with books, and music, and painting, art of every kind: a form of recompense for those early days when they tried to live utterly in the body, devoting it like slaves to the one overmastering idea. Under the lash of their idealism they had become inhuman, as pitiless to themselves as to others, almost brutish. Like beasts they lived for beauty, and died without it, and if death let them go, their thirst for it afterwards was insatiable. (110)

Hannafey's distinction lies in the "utterly ... bod[ily]" existence of "the fiercest Irish gunmen" who lack the "beauty" that the arts cultivate in an individual. Lacking beauty, the revolutionary spirit is deformed within the "overmastering idea" that renders colonizer and colonized identical. For both subjects, colonialism reproduces the "inhuman, as pitiless to themselves as to others, almost brutish." In fact, Sheehan writes this brutality large in Irish history in Glenanaar (1905), a novel of Irish informants and revolutionaries, as his narrator recounts caustically:

Our corpses swinging here in the air of a wintry morning, and your brains blown out there under the black mountains of Limerick. A pretty cycle of events, is it not? Cause and effect; effect and cause, ad finitum! So runs the whole ghastly genealogy of Irish history:- Cromwell begat massacres and burning; and massacres and burning begat reprisals; and reprisals begat Penal Laws; and Penal Laws begat insurrection; and insurrection begat the Union; and the Union begat outlawry; and outlawry begat Whiteboyism; and Whiteboyism begat informers and judicial murders; and judicial murders begat revenge, et da capo. (41-42) 
Hannafey's later reflections on the individual, which leads from brutality to beauty through the arts, is a key piece of the larger issue Sheehan identifies in the colonial violence whose cyclic scarring "runs the whole ghastly genealogy of Irish history."

Within the historical and subjective genealogies of colonialism and its endemic violence, the event primarily and literature secondarily opens up the alternative. For Martin Duignan, the poor farmer turned literary artist and protagonist of Brinsley MacNamara's In Clay and in Bronze: A Study in Personality (1920), this alternative is the other side to the "mistake" great Irish writers make, "They had all attempted to express the Irish peasant through the medium of his talk, in what he said rather than in what he did" (242-243). Duignan's emphasis on action, "what he did," rather than speech, "what he said," is a privileging of activism, but an activism in the context of literary composition. Rather than the political activism of individuals out in the streets, what Duignan's focus attests to is the power of expression in literature, specifically in expressing the event. The Famine has been the focus of this study throughout, but here in the conclusion we also encounter the Rising. In their layering and an attendant condensation of Irish history, subjectivity, and postcolonial resistance, distinctions matter but these distinctions also foreground a core seam of oppression and exploitation in its many forms. The Famine and the Rising both evoke strong and conflicting reactions, but they remain united in their status as touchstones of action. In spite of the differences, these events draw us closer to profoundly engaging with the unsettling sedimentation of colonial history that defies any essentialist distinctions between colonizer and colonized. Such a perspective is unsettling precisely because distinctions and connections both equally disavow any easy conclusions on who is at fault and how. What remains paradoxically settled and most comforting is that despite temporal, historical, social, or cultural distinctions, colonial atrocities and their connected events all attest to the truly 
terrible beauty that is born, namely that no matter how violent or degrading or even

disempowering an event may be, it does nothing to revoke the always already possible rebellion and resistance that colonial populaces engage with. Such rebellion and resistance is always present. We have only to find it.

${ }^{1}$ Eliot's notes for The Waste Land identify the planted corpse as alluding to Cornelia's burial dirge in John Webster's (1580-1634) The White Devil (1612).

2 The point is echoed by a host of other scholars, including Boehmer Empire, The National (1314); Crosbie (9); Martin (9); and Silvestri (5-6).

${ }^{3}$ On the Royal Irish Constabulary (RIC) as an "Irish model' of colonial policing" then exported across the imperial global see Kinealy (Great Irish Famine 139-145); Lloyd (Anomalous 146); Watson (106). On early formations of anti-terrorism in Victorian culture see Martin (104-158).

${ }^{4}$ For a clear and concise positioning of Badiou's philosophy of the event against contemporary postmodernism and French Freudo-Althusserian Marxism see Bosteels.

${ }^{5}$ Although distinct, modernity and modernism are necessary entwined in their "relat[ion] to the loss of a meaningful context derived from the past" that is the impetus for, in Lawrence B. Gamache's analysis, "a search for a new context - cosmopolitan, not provincial," that "tends to an increasingly relativistic" and "disillusioned vision" of modernity and its progresses (33). Susan Stanford Friedman echoes the fundamentally "radical rupture" at the heart of both modernity and modernism where the latter's operative "center comes into being as it dissipates" (499-500, 510). Friedman's emphatic rupture is where modernity and modernism most closely align. For Simon Gikandi, the "European encounter with its others is also one of separation at the most subliminal level" in which any genesiac "energies" deriving from "the other" were always formulated within an "essentially Eurocentric framework" ("Africa and the Epiphany" 49).

Rupture and energies, whether subliminally or culturally, further define the symbolic terrain that links these two concepts with rupture according with both novelty and failure, the latter particularly resonant since "modernist narratives are about failure - the failure of traditional authority, inherited modes of representation, and the European subject - but they also derive their authority from the staging of this failure in the colonial space" (Maps of Englishness 161). What is an authoritarian or traditional failure in metropolitan perspectives, becomes an unavoidable failure at home for colonial subjects for whom, in Declan Kiberd's Irish-centric analysis, "Modernity, after all, was not a state which the Irish could choose or reject at will: to be Irish was to be modern in the sense that the Irish were seeking to find a home for themselves after a period of chaos and disruption" (Inventing Ireland 134). What these trajectories between modernity and modernism show is that distinctions between the concepts are important, but their conflation is just as importantly and arguably central aspect in colonial cultures. The often unclear ramifications of this very well might rest in contemporary definitions of "Modernism" that are often paradoxically in contention on the most basic levels as detailed by Peter Nicholls (5-23). 
${ }^{6}$ For insightful accounts of modernism and WW I see Allyson Booth, Cohen, and Sherry Great War.

${ }^{7}$ One example of a recovered event is the Influenza Epidemic's impact on modernist works as argued by Outka.

${ }^{8}$ Smyth critically engages with what he calls a "Liberal decolonizing discourse" in which the "equality to be achieved is already overwritten by the values of the dominant subject, and the language in which equality can be achieved is thus always inscribed with, because formed on the basis of, difference." On the one hand, as this quote makes clear, this is a reductive argument for decolonization and freedom. On the other, as Smyth further argues, difference as basis of a postcolonial freedom and resistance is too often conceived across "a range of specific temporal and spatial co-ordinates ... adopted uncritically from the colonial power" $(16,18)$.

${ }^{9}$ Universalism is particularly denigrated and dismissed in a broad swathe of postcolonial studies. Bill Ashcroft, Gareth Griffiths, and Helen Tiffin provide a concise and exemplary formulation of anti-universalism, positing as "a hegemonic European critical tool" (149). In spite of its conceptual breadth, universalism is in fact essentially singular in its application. In other words, as Patrick Colm Hogan notes, "Like laws of nature, cultural universals are instantiated variously, particularized in specific circumstances" ("Literary Universals" 40). Jacoby Russell further advocates, "The notion of the essential unity of mankind - a vast universalism - has been won in the face of an opposing and regressive belief in fundamental discontinuities," the latter of which are historically at the roots of colonial exploitation, xenophobic nationalism, and cultural superiority (35-36). It is only in the context of an anti-universalism that Charles Darwin confidently asserts an evolutionist "future ... not very distant as measured by centuries," in The Descent of Man (1871) in which the "civilized races of man will almost certainly exterminate and replace throughout the world the savage races" (201).

${ }^{10}$ For additional clear and concise outlines of Badiou's philosophy see Hallward ("Introduction") and Riera.

${ }^{11}$ Scholars increasingly recognize the inability to clearly bracket off an event like the Famine, whether in terms of the event itself or its legacies. Historian Christine Kinealy saliently frames it as "a process rather than a single event" that, in economist Cormac Ó Gráda's terms, "had no clear beginning and no clear end" ("The Great Irish" 248; Black'47 37).

${ }^{12}$ Throughout this project I will be using “postcolonial” in Gaurav Majumdar's terms to "indicate events and processes that occur (or have occurred) after the commonly defined moment of colonization: that is, after the literal, physical appropriation of a place or people by at least one other nation or non-indigenous force" (15). Majumdar's sense gets around the temporal problems McClintock has identified with "post-colonial" while also importantly recognizing the everpresent and persistent resistance colonial peoples always posed ("angel of progress").

${ }^{13}$ Sen notes that Ireland's Famine killed the largest percentage of the population in recorded history and that famines generally are never natural phenomenon, but entirely political in terms of food access, willpower, and ideology (161-170). For population statistics of the Irish Famine see Kinealy Death-Dealing (151); Miller "In the Famine's" (113); and Ó Murchadha (179). Significantly, even into 1914, first-generation American-born children of Irish parents constituted 4.5 million individuals, which was larger than the population of Ireland" (222). ${ }^{14}$ On Irish communal, social, and sexual upheavals see Líam Kennedy. Lunacy rates in Ireland quadrupled between 1850 and 1914 (Lacey 88; Lee 5-6). For additional accounts of mental 
illness specifically to Irish migrants see Greenslade "Blackbird Calls in Grief”; Mulcrone (223); and Percich.

${ }^{15}$ Brontë wrote the novel amidst newspaper accounts and reports on the Famine. For a detailed analysis of this novel as a Famine narrative see Eagleton (1-26).

${ }^{16}$ On the Famine and Poe see Percich. On the Famine and Jewett and O'Neill see Morgan (3-21, 42-51, 73-86).

${ }^{17}$ Carleton's novel, published at the onset of the Great Famine, actually bases its events on famines that afflicted Ireland in 1817 and 1822. Maud Ellmann provides a brief overview of the persistence of starvation and hunger in Irish history, politics, and culture (11-17).

${ }^{18}$ Scholars have since emphatically re-presented the Famine as already/always there in works by writers ranging from W.B. Yeats (1865-1939) to John Millington Synge (1871-1909) to Samuel Beckett (1906-1989). See the respective essays in Cusack and Gross.

${ }^{19}$ This characterization is recorded in the Irish Famine Oral Archives and attributed to Famine survivor Máire Ní Grianna, from Rannafast, County Donegal.

${ }^{20}$ For a broader analysis of the colonial politics of paralysis in Joyce see Gibbons "'Have you no.",

${ }^{21}$ Foucault's focus is on a discursive operation at the level of the unconscious, what he terms the "systematic description of a discourse-object" (esp. pp. 135-140).

${ }^{22}$ Critiques of contemporary postcolonial theory in its poststructuralist-inflected historicism have certainly focused on its putative ahistorical quality yet the most resonant and lasting critique is one historian Sumit Sarkar has laid comparatively against Subaltern Studies, "Domination is conceptualized overwhelmingly in cultural, discursive terms, as the power-knowledge of the post-Enlightenment West" and this generalized binary increasingly obfuscates the "original separation of the domains of power and autonomy [and] culminates ... in an oscillation between the 'rhetorical absolutism' of structure and the 'fragmented fetishism' of the subject" $(84,93)$. The "rhetorical absolutism" Sarkar highlights touches upon those moments in Bhabha's work when rehearses a distinctionless Manichean view of "Western imperialist discourse" or "Western sign[s]" across very the different imperial realities of England, America, France, and Germany (Location of Culture 138, 150).

${ }^{23}$ See also for comparison Patrick Wolfe's "Indebted Critique” of Spivak's own critical silencing of Muslim subjects.

${ }^{24}$ It also prompted historian Bernard Porter's argument that Empire did not influence the British public during the twentieth century.

${ }^{25}$ Although "Black '47" is a colloquial designation in origin, scholars continue to reaffirm its objective and subjective connotations (Fegan 5; Kinealy Death-Dealing 92; McLean 75; Rodgers 291).

${ }^{26}$ Trevelyan's revisionist histories are indicative of a cross-colonial, "classical family policy" that drew upon the various works of Adam Smith, Jeremy Bentham, Thomas Malthus, James Mill, and John Stuart Mill in thinking the relations between economics, society, and famines. Trevelyan's early experiences in colonial India influenced his expectation that the Famine would behave like an "Indian" one, that is last one year; these experiences also influenced his role in the British Famine Commission 1878-1880 (Haines 34-37; O’Sullivan and Lucking 216-221). Trevelyan was far from alone in taking the Irish Famine's localized distinctions and projecting them into cross-colonial explanatory frameworks; Scotsman James Caird and Englishman Henry Edward Sullivan authored reports on the Famine and served key roles in the Commission that 
oversaw at least nine famines in India during the 1860s and 1870s (216). Economicallyspeaking, English Famine policies over the first five years of the Famine consumed 0.3 per cent of United Kingdom GNP annually; in contrast, $£ 20,000,000$ was paid out as compensation for West Indian plantation owners who lost their slaves to abolition in 1833 and $£ 69,000,000$ was spent funding the Crimean War (1854-1856) (Ó Gráda Black' 47 132; Ó Murchadha 194). In contrast to a concerted rational and economic ideal, ascribing the Famine to Providence was not folk-like development among ostensibly superstitious Irish Catholic peasants but the British Protestant administrators like Trevelyan, Russell, and Robert Peel (Daly 84) who avowed, in Trevelyan's words, that "posterity will trace up to that famine the commencement of a salutary revolution in the habits of a nation long singularly unfortunate" through "some great intervention of Providence" that, in the context of British intervention, would result in a "nation [that] had never been better served" $(1,6,74)$.

${ }^{27}$ On the colonial nature of German atrocities in World War II, as well as broader definitions of colonialism within Europe, see Healy for a pre-war analysis of Prussian colonization and Mick for later German colonization in Poland.

${ }^{28}$ Atrocity, as defined in the Encyclopedia of Human Rights in the United States, underscores this fundamentally universal premise as "An act or a series of acts usually committed by human beings against other human beings that is particularly and completely brutal, wicked, barbaric and revolting in a civilized world." Note how, terminologically, "atrocity" inverts the colonial progressive relationship with its loaded language of "barbaric" practices "in a civilized world" that apply to the imperial power rather than the colonized. A similar definition in the Greenwood Encyclopedia of International Relations echoes these ideas. Furthermore, "Atrocity" is, fittingly, a modern word. Although the Oxford English Dictionary relates examples from the $16^{\text {th }}, 17^{\text {th }}$, and $18^{\text {th }}$ centuries, its more modern meaning as an act of widespread violence and violations of human rights don't clearly occur until World War I, especially in English castigations and propaganda against Germany and its Belgian atrocities. For a more detailed of genocide see Fein. ${ }^{29}$ In terms of modernity and postcolonial theory specifically, the subject as autonomous and locus for change is paramount yet Badiou's philosophy elaborates this necessity through "truthprocedures ... [t] hat constitut[e] the singularly human, within the animal universe" and this human singularity, far from abstraction, lies in "a procedure of truth [that] is never anything other than the seizing of materiality" (Ethics 132, 133). What truth underscores is the subject's singularly human dimension, marked by its ability to appropriate and act under the auspices of truth. Furthermore, truth is here as always a material engagement, a grappling that demands intervention rather than idealization. Truth-procedures arise out of events, themselves classifiable in four fields: artistic, political, amorous, scientific. Furthermore, truth-procedures manifest through three distinct processes: event, fidelity, truth. Fidelity to the event is the bridge between the event, specifically its ramifications, truth, and the manifestation of the final dimension, truth, into the world. Fidelity is essential because truth, although recurring and eternal, is never inevitable within the material and social realms of a society. Fundamentally, as Badiou puts it so well, fidelity is "the choice that binds the subject to a truth" and this choice is "the choice of continuing to be: fidelity to the event, fidelity to the void" (Handbook of Inaesthetics 55). Fidelity is a crucial component because events are always already the targets of states and the status quo, which seek to subvert them and reinforce hegemony.

${ }^{30}$ Timothy Bewes delineates this latter state in great detail, specifically through the figure of "shame" and its signification "[a]s condemnation to, or imprisonment within, the inadequacy of 
forms" (2). Furthermore, Bewes focuses on shame as a specific trope indicative of a wider pervasive delimitation in the postcolonial studies is framed, whether in critical or literary texts, as an "asymmetry ... between ... two regimes of perception" in which the latter is constituted "negatively, by an incommensurability" that in spite of its deprivation nevertheless reaffirms a "stable relation between what is present in the text and what is extrapolated from it: that is to say, between the aesthetic and the ethical (or political) dimensions of literature" $(6,7,52)$.

Ultimately, the event provides a necessary disruption, in fact irruption, of these critical and literary relations.

${ }^{31}$ David Lloyd identifies "differential" as a key way for framing the dynamic qualities of historical and cultural relations. In other words, Lloyd's differential understanding of colonial contexts is grounded upon an essential flexibility that both recognizes the distinctions and the close connections within the social, economic, and experiential transformations colonialism as a broad system enacts in disparate cultural scenes like Ireland, India, etc. (Anomalous 8). 32 Berman's study never mentions colonialism at all and only mentions "imperialism" or "imperial" in the case of early twentieth-century Russia. He is far from alone. "Empire" or "colonial" only appears four times in Anthony Giddens' lecture on modernity $(26,62)$; "Empire," as either Roman or within a quotation, appears just four times in Calinescu (158, 159, 162, 171); "Empire" appears three times in Jurgen Habermas' twelve lectures on modernity (27, 31, 62); neither colonialism, imperialism, nor empire figure explicitly in Touraine's critique of modernity.

${ }^{33}$ As modernist scholar Peter Nicholls emphasizes, this same link of modernity and the material subject was at the core of the earliest strands of metropolitan-centered modernist thought. Italian Futurism. for example, was rooted in a clearly biopolitical context in Filippo Tommaso Marinetti's powerful manifesto, which gives prominent place to the "triumph of the mechanical over the natural [which] encapsulates the capacity of the modern subject to experience himself as pure origin, as uncontaminated tradition" (86). As a distinct, early strand of modernist thought, Italian Futurism imagined this "pure origin" out of conflict as Marinetti explicitly avowed in "The Founding and Manifesto of Futurism": "We will glorify war - the world's only hygienemilitarism, patriotism, the destructive gesture of freedom-bringers, beautiful ideas worth dying for, and scorn for woman" (Marinetti). Marinetti centrally underscores ideas of purity and uncontamination through "war - the world's only hygiene," the latter an emphatically embodied register of Marinetti's understanding of modernity's links to subjects.

${ }^{34}$ Ellmann provides a concise overview of the significance of hunger in modernist literature and culture (26-27, 36-40; 55-70).

${ }^{35}$ Nandy is not addressing psychoanalysis in this passage. Rather, his assessment here pinpoints the clear differences in disciplinary ideals between religious-based conservatism and authoritarian fascism. Nevertheless, the ideas and wording fit exactly the criticism I see of Freudian interpretations of hunger.

${ }^{36}$ Adorno argues that since the mid-nineteenth century and the expansion of capitalism, newness and novelty have been central to Western culture (19-22).

${ }^{37}$ On Pound's finding and use of "Make It New" see North (16-17, 144-172). Pound's configuration was also even wider, encompassing Troubadourian poetry, contemporaneous Japanese Noh drama, and the at-times unwelcome radical forms of Irish novels like Joyce's Ulysses, which he eviscerated even as he previously celebrated Dubliners. 
38 "Revolution" from its beginnings in the English language was a term restricted solely to an astronomical designation of the recurring and cyclic motion of heavenly bodies (North 43-47). Only later was it made new in terms of a political resonance following the American and French revolutions, and thus, as Hannah Arendt's definition makes clear, political revolutions are inherently and "inextricably bound up with the notion that the course of history suddenly begins anew, that an entirely new story, a story never known or told before, is about to unfold" (On Revolution 21). Revolutionary renewal is also a key undercurrent in E.J. Hobsbawm's notion of revolution as "breaking-points" and the "consequences of such ruptures" (7). Certainly, the latter notions define the Famine, particularly its threatening revision by English administrators who looked at the Continental-wide revolutions in 1848 with trepidation. It is in a profoundly statist reinscription that the Famine functions a "salutary revolution" that, according to Trevelyan, "educed permanent good out of transient evil" (1). And so while novelty is a philosophically and even to an extent historically vacuous concept, as Trevelyan's Famine reflections radically make clear, its value remains as a persistent framing of modernism, especially in its metropolitan-based assertions.

${ }^{39}$ See ní Fhlathúin for an analysis of Pearse's short stories. I ultimately ní Fhlathúin's analysis of Pearse's modernist perspectives to his political writings.

${ }^{40}$ So pervasive was Irish swinish bestiality that even outsiders to Anglo/Irish colonial conflicts like Friedrich Engels (1820-1895) utilized them in explaining Irish poverty. Engels extensively quotes Thomas Carlyle, a noted anti-Irish racist, prior to detailing London's Irish poor during the Famine: "The Irishman loves his pig ... he eats and sleeps with it, his children play with it, ride upon it, roll in the dirt with it ... The filth and comfortlessness that prevail in the houses themselves it is impossible to describe" (92). Although ostensibly "impossible," Engels' description continues in noting the "Milesian" propensity for "accumulat[ing] ... pools and dirtheaps which disfigure the working-people's quarters and poison the air." Engels reads specific Irish practices like allowing "the pig [to] sleep in the room with himself" as intrinsically Irish: "This new and unnatural method of cattle-raising in cities is wholly of Irish origin." Engels further concludes that these intrinsically Irish practices are indicative of a general inferiority apparent in the "horde[s] of ragged women and children swarm[ing] about here, as filthy as the swine that thrive upon the garbage heaps" that prove "this race must really have reached the lowest stage of humanity" (60). Significantly, Engels adopts these images of anti-Irish prejudice in spite of his sympathies with Irish republican agitation, influenced no doubt by his Irish companion of twenty years, Mary Burns, and her sister, Lydia. The sisters were avowed republicans and Lydia is said to have harbored Fenians in the aftermath of the Manchester raid in September 1867 (Newsinger 69).

${ }^{41}$ On the Stage Irishman's currency in nineteenth century English literature see Leerssen, Remembrance and Imagination (62-63, 170-172, 196) and Mere Irish and Fior-Ghael for a broader history of English literature's development of the "fictional Irishman" (85-168).

${ }^{42}$ For a historical overview and nineteenth century-focused discussion on Irish racializations and apes see Curtis (Apes and Angels 29-65) and Nelson (17-54).

${ }^{43}$ Ireland specifically highlights resistance on a conceptual level as Luke Gibbons notes in recognizing the ways "a native population which happened to be white was an affront to the very idea of the 'white man's burden', and threw into disarray some of the constitutive categories of colonial discourse" (Transformations 149). A particularly pronounced form of this Irish anomaly in British popular culture was the depiction of "Paddy" in political cartoons, especially Punch, 
with "ape-like features" or elaborating an "Irish Yahoo" as the missing link between man and gorilla. Furthermore, a new chimpanzee at the London Zoo in 1892 was named "Paddy" (de Nie 11).In unsettling the constitutive categories of British modernity, the colonial event propels the next step towards elaborating a clear and present alternative.

${ }^{44}$ Writers like Chinua Achebe or Derek Walcott, to name two examples, have plumbed this filthy tide in its aesthetic and cultural implications in post-WW II colonial contexts. Achebe's Things Fall Apart (1958) and No Longer at Ease (1960) both draw their titles from, respectively, Yeats and Eliot poems. Walcott has been very explicit about the debt his poetry owes to Eliot and Joyce. Ramazani provides a compelling overview of the general modernist resurfacing in postcolonial writing.

${ }^{45}$ Sherry locates Eliot's poetry, specifically featuring "Sweeney," as a particular touchstone for thinking through the decline of empire through an Irish revolutionary lens (Modernism and the Reinvention 253-264). Douglass provides another general account of Eliot's poetry and empire.

${ }^{46}$ Whelan has also conceived the Irish colonial subject as a "hollowed-out identity" ("The Dead" 62).

${ }^{47}$ See Anne Williams for an analysis of Dracula's contentious deployment of technology, modernity, the archaic, and the spiritual.

${ }^{48}$ For foundational psychoanalytic readings of Dracula see Bentley, Demetrakopoulos, Fry, Griffin, Heilmann and Llewellyn, and Roth. See Bierman for a psychoanalytic reading that analyzes Stoker's biographical details along with Dracula. See Hopkins for a nuanced, concise biography of Stoker. Also see Hughes, Beyond Dracula, for a thorough refutation of psychoanalytic theoretical interpretations of the novel. See Glover for an assessment of Stoker's wider oeuvre, Dracula included, that argues for its "literariness," an argument Hughes also furthers.

${ }^{49}$ For culturally contextual sexual analyses of Dracula see Byers, Craft, Domínguez-Rue, Halberstam, McCrea, McGunnigle, Schaffer, Signorotti, and Stevenson.

${ }^{50}$ Moretti and Hatlen provide foundational Marxist readings of Dracula and McKee offers a recent critique that encompasses economic, racial, and aesthetic connections.

${ }^{51}$ Within the anxiety paradigm, Morash "'Ever under," Pick, Punter, Andrew Smith, and Spencer focus on "degeneration." Ferguson and Hennelly offer important divergent readings of Dracula and degeneration. Malchow, Spencer, and Weissman offer further contextual analyses of the novel's racial and colonial facets.

${ }^{52}$ For various analyses of the "Irish Dracula" school of criticism see Deane Strange Country, Ingelbien "Gothic Genealogies," Moses, Schmitt, Valente, and Wall.

${ }^{53}$ See Seigel, especially "Part I: Introductory," for a comprehensive overview of selfhood's reflexivity. For other accounts of selfhood see Giddens and Taylor.

${ }^{54}$ Jerrold Hogle argues that Dracula's corpse-like objectivity and vacillations allow for some of the most nuanced readings of the novel. In addition, see Ciasen and Tracy. See Scandura for an interesting historical analysis of the Victorian undertaker and corpses.

${ }^{55}$ Although Stoker and Collins both share epistolary forms, Collins' justification in The Woman in White is to present the multiple views of a court case, implying a clear connection with the state and a realistic connection with the ostensibly supernatural story. For Stoker, the epistolary form is a disconnected choice that unsuccessfully tries to contain a very real supernatural threat, Dracula. On the intertextual connections between Stoker and Collins see Bollen and Ingelbien, and Seed. 
${ }^{56}$ Richard Wasson instructively argues that Dracula's contemporary popularity derived, in part, from its political subtext as a warning against civilizational "progress" in opposition to the unfettered expansion of many pro-imperial novels.

${ }^{57}$ Significantly, Dracula contains two prominent imperial adventures related as textual asides by the British contingent. The first one is related in Quincey Morris' letter of 25 May to Arthur Holmwood that details a friendly gathering with "our old pal at the Korea, Jack Seward" (Stoker Dracula 62). The allusion to Korea knits the three men, Morris, Holmwood, and Seward, within an imperial hotspot in the 1890s Western attempts to deflect Japanese imperial ambitions (footnote 6). Van Helsing writes a second imperial adventure in a 2 September letter to his "good Friend" Jack Seward, recounting the time that "[Jack] suck from my wound so swiftly the poison of the gangrene from that knife that our other friend (Arthur), too nervous, let slip" (106). Most strikingly is the vampiric behavior between Van Helsing and Seward long before Dracula's entry into their consciousness.

${ }^{58}$ Significantly, Stoker's most explicitly national novel, The Lady of the Shroud, is also set in a colonial space - the Balkans — with a strong British presence and hints of vampirism throughout, very much like Dracula.

${ }^{59}$ Dracula's epistolary form has garnered relatively little scholarly attention in the context of its wider scholarly analysis. For formal arguments, see Case, Hogles, Hustis, Morrison, and Senf "Dracula: The Unseen." For several alternative aesthetic accounts of Dracula see Johnson and Kilgour.

${ }^{60}$ See Colley's Britons: Forging the for a discussion of English national formations during the eighteenth century.

${ }^{61}$ Michael Banton traces the historical trajectory of race in European thought from the sixteenth through twentieth centuries. His study focuses specifically on sociological constructions of race.

This context informs many of the claims on race I am making in this chapter.

${ }^{62}$ Catherine Hall's Civilising Subjects charts the construction of English identity in the period 1830-1867 as inextricably linked to a racial axis of imperial circulation between metropolis and colony. Her study examines how Baptist missionaries in Jamaica and abolitionists in Birmingham participated in a unified project of identity creation that initially viewed English and Africans as brothers united in freedom and humanism that subsumed racial difference to an identity that eventually resolved into stark differences based on racial incompatibility.

${ }^{63}$ See Warren for an analysis of Stoker's personal meeting with Buffalo Bill Cody and his attendance at Cody's "Wild West Show" in the 1890s. Warren argues that Dracula, like the "Wild West Show," is premised upon frontier race wars.

${ }^{64}$ See Angelia Poon for a discussion on Englishness as textually normative performative discourse ().

${ }^{65}$ The Oxford English Dictionary defines "white" as literally "[c]olourless" or "[b]lank, not written or printed upon," ("White, adj"), a definition that perfectly fits Dracula's colour-less complexion. Although contemporary critics, like Charles W. Mills in The Racial Contract, accord whiteness with invisibility as an ideological and politically powerful designation within race, Dracula's use of invisibility within Victorian colonial discourse is fundamentally in opposition to Victorian paradigms of blackness. Furthermore, Dracula's invisibility will gain even greater anti-colonial currency when figured within the novel's formal structure.

${ }^{66}$ Dracula's knowledge of grammatical English may also supersede Harker's. Footnote 5 on p. 26 in Norton Critical Edition of Dracula notes that Dracula's misspoken grammatical error 
occurs immediately after he enjoins Harker to help him with his English. If this is a test on Dracula's part then Harker blatantly fails.

${ }^{67}$ My focus on science is limited to brief discussions on cartography and physiognomy. For more thorough accounts of Dracula and science see Aikens, Byron, Greenway, Jann, Mulvey-Roberts, Olry and Haines, and Stiles.

${ }^{68}$ Harker first describes Dracula as the disguised calèche driver, a "tall man, with a long brown beard and a great black hat, which seemed to hide his face from us" (Stoker Dracula 17). I cite Harker's third description here because it is the first time he submits Dracula's undisguised body to a physiognomic reading. As I noted, Dracula's various physical descriptions occur pp. 17, 21, 23, 53, 126, 155, 251, and 276. Although Dracula's scent bears anti-Semitic residues this is never elaborated upon nor encoded as anti-Semitic by the characters involved; both scenes emphasizing Dracula's scent occur on pp. 71 and 201.

${ }^{69}$ Zanger's initial connection between Dracula and Jews has been supplemented by later critics Malchow and Halberstam.

${ }^{70}$ See footnote 5 on pp. 302 of Nina Auerbach and David J. Skal's edition of Dracula for a full discussion of Harker's anti-Semitism here.

${ }^{71}$ Stoker was also a physiognomist. In a letter written to Walt Whitman, Stoker confided "“I know you from your works and your photograph, and if I know anything about you I think you would like to know of the personal appearance of your correspondents. You are I know a keen physiognomist. I am a believer of the science myself and am in an humble way a practicer of it'" (Stoker The Lost Journal 61-62). Stoker even wrote about physiognomy in a highly metaphorical sense, perfect for fictional renderings, in noting that "[f] urrows in the brow are chain marks or galls of an imprisoned soul" (273). As a practicing believer and writer of physiognomy, it is significant that Jonathan Harker never reads Dracula's ostensibly racial corporeal features like many contemporary critics strive to.

72 The Stoker family was also not "Anglo-Irish." In Ireland, this identity requires a culturallyloaded economic and social clout that the Stokers did not possess during Bram's youth; instead, the family was decidedly "lower-middle-class bureaucracy" (Stoker The Dublin Years 260).

${ }^{73}$ Significantly, rural Irish areas were the hardest hit by the Famine in terms of starvation. Dublin was relatively insulated from starvation mortality by virtue of its commercial economy. It was nevertheless inundated by rural migrations that spread disease throughout the already overcrowded, poverty-stricken slums and the wider city. Dublin's incidence of disease and infectious mortality rates exceeded those of the surrounding countryside and rural counties. See Ó Gráda, especially Chapter Five: Famine in Dublin City, pp. 157-193.

${ }^{74}$ See Willis for a discussion of disease as a key thematic in Stoker's oeuvre spanning his short story "The Invisible Giant" through Dracula. The supernatural and subjective changes also figure prominently in The Snake's Pass, The Jewel of the Seven Stars, The Lady in the Shroud, and The Lair of the White Worm.

${ }^{75}$ For alternative analyses of race and blood in Dracula see McWhir and Tomaszewska.

${ }^{76}$ See Moses for an extensive catalogue and discussion of Irish vampiric imagery and tis convergence with Irish revolutionary activity in British popular culture.

77 The tensions between the past and the present are contextual points of early Irish nationalist references that Barry Crosbie historically links to Irish experiences with colonial India in the $19^{\text {th }}$ century. Crosbie's explanation that "[e]arly Irish nationalists, concerned with undermining what they perceived as being the colonial image of a backward and uncivilized Ireland, were reluctant 
to use the idea of the 'primitive', prevalent throughout the Ossian poetry, for in their minds it was too close to the traditional and disparaging English view of Gaelic Irish culture" encapsulates the tense negotiation Stoker's novel articulates in portraying Dracula as equally antique and emphatically modern, a combination encapsulated in his subjective superseding of English authority and imperial subjectivity (Irish Imperial 218).

78 The "bodies and languages system" is Badiou's account of postmodernism as "democractic materialism." This "system" delineates the postmodern binary drawn between bodies and language as the only verifiable reality. Badiou offers a materialist dialectical response: there are only bodies and languages, except that there are truths. See "Book 1" of Logics of Worlds: Being and Event, 2.

${ }^{79}$ For a further elaboration on Bhabha's description of the English book, see Chapter 6, Signs taken for wonders: Questions of ambivalence and authority under a tree outside Delhi, May 1817, pp. 145-174.

${ }^{80}$ See Chapter IV of this dissertation for a discussion of Stephen Dedalus' broken mirror and its colonial implications in James Joyce's Ulysses.

${ }^{81}$ For an analyses of Dracula as a "traumatic" novel see Khader.

${ }^{82}$ The Oxford English Dictionary's first definition of "marker, $n$ " emphasizes authorship: “A person who or implement which makes a mark or marks; a person who records, notes, or observes something." Connected definitions of "mark," both noun and verb, generate an astonishing array of authorial tasks.

${ }^{83}$ On gendered readings of Lucy's transformation and wider gender problematics in Dracula see Case, Mulvey-Roberts, and Senf “Dracula: Stoker's Response.” I would argue that Lucy's sexual transformation is generally overstated; she does, after all, express a pre-transformation desire to "marry three men" (Stoker Dracula 60).

${ }^{84}$ See Case and Wicke for accounts that argue for Mina as the primary author of Dracula.

${ }^{85}$ Bruce Stewart argues that Stoker was generally loyal to neither Ireland nor England, but to 'modernity' - a place or state which he looked upon as transcending such geo-political thinking" (239). Valente argues persuasively that Stoker had strong Irish loyalties.

${ }^{86}$ Historian Jonathan Schneer notes how socialist and radical critics and politics in London at the turn of the century struggled to mount criticisms and policies of empire that were not inherently racist (165-171).

${ }^{87}$ Juiper Ellis further argues that “Kim depicts a crucial instance of literature's and ethnology's complicity in colonial ordering of knowledge to maintain power (315). Additional pro-imperial readings of the novel include those by Low, McBratney, Mohanty, Benita Parry, Raskin, Patrick Williams, and Wilson.

${ }^{88}$ Bart Moore-Gilbert's "“I am going to rewrite Kipling's Kim"” provides a succinct overview of the novel's "enabling, rather than simply antagonistic" relations to postcolonial literature and theory (39). Additional readings of Kim's ambivalence and anti-colonial functions can be found in Brantlinger "Kim," Bristow, Howe, Roy, Sandison, and Wright.

${ }^{89}$ Several nuanced studies of "vision" and its ambivalent function in Kipling's fiction bear on my delineation of colonialism's visual economy in Ireland and India. See Hagiioannu, KinkeadWeekes, and Rushdie.

${ }^{90}$ In the aftermath of the Act of Union (1801), Syndney Owenson, Lady Morgan, wrote The Missionary: An Indian Tale (1811), a novel that details cross-colonial romance and failures between a Portuguese missionary and an Indian prophetess. See Lennon's discussion of 
Owenson's novels in relation to Irish Orientalism, which is distinctly different from Edward Said's British and French delineated Orientalism (141-155). On Irish and Indian political connections in London, see Schneer (162-183); Regan-Lefebvre's book-length study on the Irish politician Alfred John Webb, a president of the Indian National Congress, is further instructive. Also, Hight and Sampson historicize Orientalism as a discourse founded upon ocular apprehension, codification, and cross-connections (1-19).

${ }^{91}$ Kipling's high-water mark with the modernist elite was signified by Henry James' critical introduction to Kipling's 1891 short story collection Mine Own People, which furthered his global reputation.

92 Harold Orel provides a concise summary of the "Humanistic Dilemma" that critics have fought over concerning Kipling's writings and politics. He further advocates the necessity for recognizing distinctions between Kipling's politics and that of his created characters. Menand further supplements the aesthetic ramifications of Kipling's critical dilemma. Chaudhuri also notes Kipling's political limitations, but also lauds Kim's "larger unifying theme" which escapes both English critics and Kipling in excess of political themes (48).

${ }^{93}$ Havholm proposes an ethical argument that mediates between Kipling's "brilliantly wrought fiction" and "repel[lant]" "human actions" (5). Further attesting to Kipling's complexity as a writer is Gilbert's reading of Kipling's "silence" as radical and complex and Adrian Poole's analysis of Kipling's use of capitalization to signify meanings.

${ }^{94}$ Kiberd's delineation of an "Irish" modernism further links with critics who discuss Kipling's formal and technical connections to modernist literature. See Bromwich, Lodge, Montefiore, and Ricketts (288, 363-365).

${ }^{95}$ Kipling also had personal and familial interactions and connections with Ireland and the Irish throughout his youth. See O'Hara (1-15). Kipling had a lifelong, contested relationship with Ireland and Irish events. At Tunbridge Wells on May 16, 1914, he delivered arguably his most acerbic political speech in denouncing the Irish Home Rule Bill, though he " $\mathrm{d}[\mathrm{id}]$ not for one instant blame the [Irish] Nationalists," but "the [British] Cabinet [that] had done nothing which fatally and irretrievably compromised the unity of Great Britain or the safety of the Empire" until now (69). By 1920, he accepted a commission to write and edit The Irish Guards of the Great War, a history of Irish soldiers that served under his son, Jack, and a text Kipling considered "my great work" as he related to his secretary, Dorothy Ponton (qtd. in Ricketts 341).

${ }^{96}$ Boylan analyzes Charles Trevelyan's famine practices and their evolution as he oversaw the Great Famine in Ireland and later famines in India; Cronin illustrates how the early nineteenthcentury Ordnance Survey of Ireland provided a colonial model and the first successful mapping of colonial dominance for the later Survey of India; Laird explains how the British government's nineteenth-century translations of Ireland's Brehon Laws provided a grounds for colonial governance in Ireland and India; Tim Watson provides an overview of Indian and Irish revolutionary activities in Kim; and Ann Parry offers a different contextual argument on Kim and its "representation[al] implicat[ion] [in] the whole contemporary debate about imperial security in India" (190).

97 "England" and "English" are used approximately sixty combined times in Kim while "Britain" and "British" are used only about seven combined times. Furthermore, Kipling almost exclusively utilizes "England" and "English" over "Britain" and "British" across his entire fictional oeuvre. 
${ }^{98}$ See Lindeborg for a detailed argument on the vexed cultural and representational tensions inherent in the growth of empire constantly shifting definitions of the "British" subject.

99 Beginning with "The Three Musketeers," Kipling developed a sustained story arc focusing on three British imperial soldiers, privates Terence Mulvaney, Jack Learoyd, and Stanley Ortheris, respectively an Irishman, Yorkshireman, and Cockney (Kipling Kipling's Indian Tales 1-). Many of these narratives are marked by pseudo-slapstick conflicts yet one, "Black Jack," centers on an Irish revolutionary who joins the privates' battalion, attempts to recruit them to mutiny, and ends up dead after being caught sleeping with a soldier's wife (571-599).

${ }^{100}$ Zachariah notes how "the questions of 'what happened' have been overwritten by those of representations of 1857" (84). Erll analyzes the Mutiny as a "lieu de mémoire" for "British as well as Indian memory cultures" (109).

${ }^{101}$ Much like the European-wide revolutions in 1848 during the middle of the Famine in Ireland, the Mutiny's potential for fostering a rising in Ireland was never realized because of larger conflicts outside of Irish revolutionary's control. During the Mutiny, the Panic of 1857 froze large amounts of funding in Irish-America, thereby depriving Irish revolutionaries of crucial financial life support for any wide-scale rising (Morris 98-99).

${ }^{102}$ Irish and Anglo-Irish recruits comprised nearly 40\% of the British Empire's nineteenth century imperial army. Ireland's contribution to the British imperial army by percentage of United Kingdom population was always high, but continued to decline following the Mutiny. For more information on Irish military participation in the British Empire, see Fraser and Jeffery.

103 A significant exception is "On the City Wall" which deals with a rebellious period in India and an Anglo narrator who befriends an Anglo-educated Indian, Wali Dad, and is tricked into conveying an old political prisoner, Khem Singh, through a rioting Lahore to safety (Kipling Kipling's Indian Tales 293-331).

104 "The Lost Legion" is a further outlier in its setting upon the North-West frontier, itself a resonant narrative scene for Anglo-Indian fiction that overwhelmingly focused on soldiers and secret agents in "an unqualified celebration of heroic action and achievement on the frontier" during the late nineteenth-century (Wurgaft 81). Kipling did produce a significant amount of soldier stories, especially "The Three Musketeers" story arc, beginning in his first short story collection Plain Tales from the Hills (), with privates Terence Mulvaney, Jack Learoyd, and Stanley Ortheris, an Irishman, Yorkshireman, and Cockney, yet "The Lost Legion" defies all of these cultural and imperial expectations.

${ }^{105}$ Nicholson's brutality was central to consolidating his mythic imperial status. He frequently utilized summary executions of both sepoys and civilians. Michael Silvestri recounts one incident "[i]n the town of Sialkot" where Nicholson "ordered eight sepoys to be blown from cannons, but afterward regretted the "waste of good powder and soon abandoned the practice in favour of hanging"' (79).

${ }^{106}$ Multiple Indian sources also "common[ly] figur[ed]" the Mutiny "as a gigantic natural disaster or national cataclysm" (Herbert 2). J. Smith's Sketches in Indian Ink, a contemporaneous account of Anglo-Indian society, argued that pre-Mutiny India was "an antediluvian story" (247). Additionally, clear distinctions between English and Irish subjects and equally clear connections between Irish and Indian colonial subjects were often asserted, such as when Sir Richard Temple (1826-1902), lieutenant-governor of Bengal and governor of Bombay, justified his inadequate relief measures during the Madras Famine of 1877: "Some classes of natives look on land in the same light as the English landlords do - but the mass of the natives regard the land as the Irish 
[emphases his] do ... [and] there is apt to be the same trouble in India, as there would be in Ireland" (qtd. in Hambly 61).

${ }^{107}$ For a fuller history of O'Donnell's agitations within the Indian Civil Service, deriving from his Irish republican beliefs, as well as the related agitations of his brother, Frank Hugh O’Donnell, M.P., see Crosbie "“L'enfant terrible."”

${ }^{108}$ In addition to Cronin, Knoepflmacher focuses on Kim's "mixiness" (931); McBratney elaborates the "hybrid and the mixed-race creole" as "a figure who is neither clearly European nor non-European" (XIII-XIV)—see esp. "Chapter 6 Kim" (-); McClintock holds that "Kim is both cultural hybrid and racial mimic man" in service to imperial aims (Imperial Leather 69) see esp. 66-70; Randall utilizes "hybridity ... as a tool $\mathrm{t}[\mathrm{o}]$... measure and evaluate the impact of cross-cultural encounter within imperial representation" (6)—-see esp. "Kim: Disciplinary Power and Cultural Hybridity" (110-136); and Patrick Williams details "the Englishman who has such a mastery of Oriental culture that he can pass for one of "them"” ("Kim and Orientalism" (43). Although discussing Bram Stoker's fiction, Julia M. Wright's most extensive detailing of "hybrid subjects" casts them as pro-imperial signs that "shore up the borders of empire, drawing on their globally acquired expertise to protect the centre of power from its imminent collapse" (183). See her "Chapter 6. Bram Stoker and Oscar Wilde: All Points East" (182-210) immediately prior to a concluding chapter on Kim.

${ }^{109}$ Although subjectively-focused in terms of Kim, Bhabha, as well as later critics, utilize hybridity with broad equivocality, including, for example, "a hybrid cultural space that forms contingently, disjunctively"; "hybrid sites and objectives"; "the hybrid half-made colonial world"; "hybrid signifiers ... of colonial otherness"; and "a hybrid national narrative" $(11,37$, $153,177,240)$.

${ }^{110}$ Other critics who ignore Kim's Irish identity include JanMohamed (97-100), Sullivan (151), and Patrick Williams (43). Julia Wright historicizes Kim's Irishness (211-216) yet still persists in reading the novel as essentially "free of colonial history [so] he [Kim] can work for the British notion of progress" (214).

${ }^{111}$ Nicholson earned his moniker and lingering imperial fame for heroism during the Mutinyhe planned and lead the Siege of Delhi on September 14, 1857, suffering a mortal wound but living long enough to see the city retaken. Lord Baden-Powell's Scouting for Boys (1908) not only celebrated Kim as "a good example of what a Boy Scout can do" but also devoted a "Display" or theatrical piece to Nicholson (14). Significantly, Baden-Powell's tribute to Nicholson was such a particularly "vengeful, unpleasant pageant" that, as scouting quickly expanded from a provincially English enterprise to an international movement, "the Nicholson display disappeared as soon as the second edition" (note 279, XXIII).

${ }^{112}$ As Victor Kiernan phrases it, "darkness was one the invaders brought with them, the somber shadow of the white man" (Lords of Human 236; esp. "Ch. 2 India"). Broader studies of this colonial darkness include Bolt (130-132); Brantlinger (Rule of Darkness 21-34); and Garner, on the Irish in America (91-113) and the Irish in the British Empire (114-139).

${ }^{113}$ Dissimilarity further defines Kim's non-relations to Kipling's other fictional characters long proposed as models for the Irish orphan, the covert policeman, "Strickland Sahib," and the feral child, Mowgli (Kipling Kim 175). These latter figures originally signify difference, but their narrative ends suggest clear imperial transitions as Strickland "drop[s] his old ways, and stick[s] to Departmental routine, which pays best and leads to Simla" and Mowgli ends up "a forestguard ... [with] a pension ... i[n] Government service” (Plain Tales 34; The Jungle Books 348). 
${ }^{114}$ On Burton as an imperial figure, see Patrick Williams (43). See Kennedy for a broad overview of Burton's extremely complicated life and the meanings derived from his actions within the British Empire broadly and England specifically, esp. Ch. I The Gypsy and Ch. II. The Orientalist, pp. 10-57.

${ }^{115}$ Isabel Burton, his wife, authored this two volume posthumous biography of her husband, but both of these accounts are presented in the biography in Richard Burton's own written words.

${ }^{116}$ Kim's reaction and the Lucknow setting further align him with another Irish precursor to Burton and counterpoint to Nicholson, Thomas Henry Kavanagh (1821-1882), native to Mullingar, County Westmeath, who attained fame during the Mutiny after he donned "a 'complete Oriental suit' with his skin dyed black" in order to navigate Lucknow's besieged streets and buildings. Along with an Indian spy, Kunoujee Lal, Kavanagh evaded Indian rebels, located British relief forces under Sir Colin Campbell, and lead them back into Lucknow and the besieged residency (Silvestri 1). One of the few civilian recipients of the Victorian Cross and more apt model for Kim's own subterfuge, Kavanagh never attained mythic status across the Empire like Nicholson arguably because he publicly criticized British military excesses during and after the Mutiny.

${ }^{117}$ Including Kim's metaphorical ghostly state, there are eight additional references to "ghost" in Kim: one that references "A churel ... the particularly malignant ghost of a woman who has died in child-bed"; five references to "ghost-daggers"; the "ghosts" consigned to "the Hells" of the afterlife the lama details; and the "ghosts" the hill people speak of (Kipling Kim 118, 129, 145, $148,155,163,177,224)$.

118 See also Pandit.

${ }^{119}$ Queen Victoria's image as the "Famine Queen" derives from traditional Irish stories about her putatively misery contributions to Irish relief during the Famine, usually, Joyce relates, "ten pounds" (Critical Writings 164). Victoria actually contributed approximately $£ 2,000$ to Irish relief charities yet the "Famine Queen" moniker persisted as an index of wider governmental failings during the Famine.

${ }^{120}$ See also Roughley and van Boheemen-Saaf for critical studies of the intersections between Derrida and Joyce. Derrida's essays on Joyce are collected in Mitchell and Slote.

${ }^{121}$ My reading of Joyce is orientated front to back, Stephen Hero through Ulysses. An eloquent summation of the dangers of critically reading Joyce out of order, i.e. the "writer" of Finnegans wake in 1939 as the same "writer" of Dubliners in 1914, can be found in Augustine Martin "The Artist and the Labyrinth."

${ }^{122}$ See Gibson's "Prolegomena: The Development" for a sympathetic study of Joyce's revisions in "Proteus."

${ }^{123}$ Several critics have studies the Famine in Joyce including Dwyer, Lowe-Evans, and Roos.

${ }^{124}$ For an overview of Spenser's aesthetic and political entanglements with Ireland see also Scanlan (68-92).

${ }^{125}$ Neither "wolf" nor "wolfish" appears in Portrait. The latter term also never appears in Ulysses. "Wolf" appears three times in Ulysses, but never directly connected to Stephen nor in much consequence $(U 12.1666 ; 14.730 ; 16.1639)$. Significantly, "wolves" resurface in Finnegans Wake several times including a particularly Parnellian echo, "Do not flingamejig to the twolves!" (479).

${ }^{126}$ See Theodore Spencer's editorial note on representing Joyce's deletions in the Stephen Hero manuscript (Stephen Hero 18-19). 
${ }^{127}$ For further examples of crayon-carryover revisions, see James Joyce, "Proteus," 1917, The James Joyce Collection, MS V.A.3, University at Buffalo The State University of New York; Joyce, "Oxen of the Sun," 1920, The James Joyce Collection, MS V.A.11-18, University at Buffalo The State University of New York

${ }^{128}$ Refuse has also applied more widely throughout Irish history.

${ }^{129}$ Wild's Irish colonial significations recur across novels like Lady Morgan's The Wild Irish Girl (1806) or Charles Maturin's The Wild Irish Boy (1808) and various folk ballads like "The Wild Irish Boy" or the Irish/Australian "Wild Colonial Boy"-first published in 1881. For a detailed discussion of nineteenth-century Irish literature's "aesthetically pleasing ... wildness" cultivated for an English audience, see Joep Leerssen, Mere Irish and Fír-Ghael: Studies in the Idea of Irish Nationality, Its Development and Literary Expression Prior to the Nineteenth Century, $2^{\text {nd }}$ ed. (Notre Dame: Univ. of Notre Dame Press, 1997), 68 and esp. 60-76.

${ }^{130}$ For a political reading of the seaweed as a sign of symbolic Irishness see Kearney.

${ }^{131}$ See also Ó Murchadha (Great Famine 1-26).

132 Significantly, Engels adopts these images of anti-Irish prejudice in spite of his sympathies with Irish republican agitation, influenced no doubt by his Irish companion of twenty years, Mary Burns, and her sister, Lydia. The sisters were avowed republicans and Lydia is said to have harbored Fenians in the aftermath of the Manchester raid in September 1867 (Newsinger 69).

${ }^{133}$ See also Cheng, Joyce, Race, and Empire, esp. chapters 6, 7, and 8 and Andrew Gibson, Joyce's Revenge: History, Politics, and Aesthetics in Ulysses, (Oxford: Oxford Univ. Press, 2005), esp. chapter 1 .

${ }^{134}$ For another reading of this scene see Caraher.

${ }^{135}$ For additional readings of "Proteus" see: Ellmann, Maud; Livorni; McArthur; Rimon; Slote.

${ }^{136}$ On Famine-era foraging by dogs on Irish corpses see Lowe-Evans (11).

${ }^{137}$ See Tymoczko for an account of Irish literary and lingustic, as well as specifically Revival, elements in "Proteus." 


\section{Works Cited}

Acheraïou, Amar. Questioning Hybridity, Postcolonialism, and Globalization. Houndmills:

Palgrave Macmillan, 2011. Print.

---. Rethinking Postcolonialism: Colonialist Discourse in Modern Literatures and the Legacy of

Classical Writers. Houndmills: Palgrave Macmillan, 2008. Print.

Adorno, Theodore. Aesthetic Theory. Ed. Gretel Adorno and Rolf Tiedemann. Trans. Robert Hullot-Kentor. Minneapolis: U of Minnesota P, 1997. Print. Theory and History of Literature 88.

Aikens, Kristina. "Battling Addictions in Dracula." Gothic Studies 11.2 (November 2009): 4151. Academic Search Complete. EBSCO. Web. 24 June 2013.

Al-Dabbagh, Abdulla. Literary Orientalism, Postcolonialism, and Universalism. New York: Peter Lang, 2010. Print. Postcolonial Studies 9.

Allen, Charles. Kipling Sahib: India and the Making of Rudyard Kipling. New York: Pegasus Books, 2009. Print.

Almond, Ian. "Rogues of Modernity: Picaresque Variations in the Postcolonial Genre of the Enlightenment Missionary.” Orbis Litterarum 61.2 (2006): 96-113. Academic Search Complete. Web. 27 Feb 2015.

Altman, Janet Gurkin. Epistolarity: Approaches to a Form. Columbus: Ohio U.P., 1982. Print. Amin, Samir. Eurocentrism: Modernity, Religion, and Democracy A Critique of Eurocentrism and Culturalism. $2^{\text {nd }}$ ed. Trans. Russell Moore and James Membrez. New York: Monthly Review P, 2009. Print.

Anderson, Benedict. The Spectre of Comparisons: Nationalism, Southeast Asia, and the World. London: Verso, 2002. Print. 
Appiah, Kwame Anthony. Cosmopolitanism: Ethics in a World of Strangers. New York: W. W. Norton \& Company, 2006. Print.

Arata, Stephen D. "The Occidental Tourist: Dracula and the Anxiety of Reverse Colonization." Victorian Studies 33.4 (1990): 621-645. Academic Search Complete. EBSCO. Web. 20 Nov. 2010.

Ardila, J.A.G. “Introduction: Transnational Picaresque.” Philological Quarterly 89.1 (Winter 2010): 1-11. Print.

Arendt, Hannah. Eichmann in Jerusalem: A Report on the Banality of Evil. Rev. ed. London: Penguin, 1994. Print. Penguin Twentieth Century Classics.

---. On Revolution. Westport, CT: Greenwood P, Publishers, 1963. Print.

“Atrocity, n.” Def. 1, 3. The Oxford English Dictionary Online. Oxford University Press. 2015. Web. 7 Oct 2015.

Attridge, Derek and Marjorie Howes. "Semicoloniality.” Introduction. Semicolonial Joyce. Ed. Attridge and Howes. Cambridge, UK: Cambridge UP, 2000. 1-20. Print.

Attridge, Steve. Nationalism, Imperialism, and Identity in Late Victorian Culture: Civil and Military Worlds. Houndmills: Palgrave Macmillan, 2003. Print.

Baden-Powell, Robert. Scouting for Boys: A Handbook for Instruction in Good Citizenship. Ed. Elleke Boehmer. Oxford: Oxford U.P., 2004. Print.

Badiou, Alain. Being and Event. Trans. Oliver Feltham. London: Continuum, 2005. Print.

---. The Century. Trans. Alberto Toscano. Cambridge: polity p, 2007. Print.

---. Ethics: An Essay on the Understanding of Evil. Trans. Peter Hallward. London: Verso, 2001. Print. 
---. The Handbook of Inaesthetics. Trans. Alberto Toscano. Stanford: Stanford U.P., 2005. Print. Meridian: Crossing Aesthetics.

---. Logics of Worlds: Being and Event, 2. Trans. Alberto Toscano. New York: Continuum, 2009. Print.

---. Philosophy and the Event. Trans. Louise Burchill. Cambridge, UK: Polity Press, 2013. Print. ---. Saint Paul: The Foundation of Universalism. Trans. Ray Brassier. Eds. Mieke Bal and Hent de Vries. Stanford: Stanford U.P., 2003. Print. Cultural Memory in the Present.

Balibar, Etienne. "Racism and Nationalism." Race, Nation, Class: Ambiguous Identities. Balibar and Immanuel Wallerstein. London: Verso, 1991. 37-67. Print.

Banton, Michael. Racial Theories. Cambridge: Cambridge U.P., 1987. Print.

Beebee, Thomas O. Epistolary Fiction in Europe 1500-1850. Cambridge: Cambridge U.P., 1999. Print.

Beer, Gillian. "Island bounds." Edmond and Smith 32-42. Print.

Begam, Richard. "Joyce’s Trojan Horse: Ulysses and the Aesthetics of Decolonization.” Modernism and Colonialism: British and Irish Literature, 1899-1939. Eds. Richard Begam and Michael Valdez Moses. Durham: Duke U.P., 2007. 185-208. Print.

Belford, Barbara. Bram Stoker: A Biography of the Author of Dracula. New York: Alfred A. Knopf, 1996. Print.

Bentley, Christopher F. “The Monster in the Bedroom: Sexual Symbolism in Bram Stoker's Dracula." Literature and Psychology 22 (1972): 27-34. Print.

Bewes, Timothy. The Event of Postcolonial Shame. Princeton: Princeton U.P., 2010. Print. Translation/Transnation.

Bhabha, Homi K. The Location of Culture. London: Routledge Classics, 1994. Print. 
Bierman, Joseph S. “A Crucial Stage in the Writing of Dracula." Hughes and Smith 151-172.

Bloom, Harold ed. Rudyard Kipling. Philadelphia: Chelsea House Publishers, 1987. Print. Modern Critical Views.

Boehmer, Elleke. Colonial and Postcolonial Literature. $2^{\text {nd }}$ ed. Oxford: Oxford U.P., 2005. Print. ---. Empire, The National, and the Postcolonial, 1890-1920. Oxford: Oxford U.P., 2005. Print. ---. Introduction. Scouting for Boys. By Robert Baden-Powell. Ed. Boehmer. Oxford: Oxford U.P., 2004. XI-XXXIX. Print.

Boland, Eavan. "Famine Roads.” Hayden 212-222.

Bollen, Katrien, and Raphael Ingelbien. "An Intertext That Counts? Dracula, The Woman in White, and Victorian Imaginations of the Foreign Other." English Studies: A Journal of English Language and Literature 90.4 (2009): 403-420. MLA International Bibliography. EBSCO. Web. 12 July 2011.

Bolt, Christine. Victorian Attitudes to Race. London: Routledge, 2006.

Booth, Allyson. Postcards From the Trenches: Negotiating the Space Between Modernism and the First World War. New York: Oxford U.P., 1996. Print.

Booth, Howard J. ed. The Cambridge Companion to Rudyard Kipling. Cambridge: Cambridge U.P., 2011. Print.

---. and Nigel Rigby, eds. Modernism and Empire. Manchester: Manchester U.P., 2000. Print. Bosteels, Bruno. “Alain Badiou's Theory of the Subject: The Recommencement of Dialectical Materialism?" Lacan: The Silent Partners. Ed. Slavoj Žižek. London: Verso, 2006. 115168. Print. Wo Es War.

Bowker, Gordon. James Joyce: A New Biography. New York: Farrar, Straus and Giroux, 2012. Print. 
Boyce, D. George and Alan O'Day, ed. The Making of Modern Irish History: Revisionism and the Revisionist Controversy. London: Routledge, 1996. Print.

Boylan, Ciara. "Sir Charles Trevelyan in India and Ireland.” Foley and O’Connor 167-178.

Brantlinger, Patrick. “Kim.” Booth 126-140.

---. Rule of Darkness: British Literature and Imperialism, 1830-1914. Cornell: Cornell U.P., 1990. Print.

Brett, David. The Construction of Heritage. Cork: Cork UP, 1996. Print.

Bristow, Joseph. Empire Boys: Adventures in a Man's World. London: Harper Collins Academic, 1991. Print. Reading Popular Fiction.

Bromwich, David. “Kipling’s Jest.” Bloom 77-102.

Brontë, Emily. Wuthering Heights. Ed. Richard J. Dunn. $4^{\text {th }}$ ed. New York: W.W. Norton \& Company, 2003. Print. A Norton Critical Edition.

Budgen, Frank. James Joyce and the Making of Ulysses. Bloomington: Indiana U.P., 1964. Print.

Burton, Isabel. The Life of Captain Sir Richd. F. Burton, K.C.M.G., F.R.G.S. Vol. I. New York: D. Appleton \& Company, 1893. Print.

Byers, Thomas B. "Good Men and Monsters: The Defenses of Dracula." Carter 149-135.

Byron, Glennis. "Bram Stoker's Gothic and the Resources of Science.” Critical Survey 19.2 (2007): 48-62. Academic Search Complete. EBSCO. Web. 24 June 2013.

Byron, Lord. “301. Darkness.” The Complete Poetical Works. Vol IV. Ed. Jerome J. McGann. Oxford: Clarendon P, 1986. 40-43. Print.

Cairns, David. Writing Ireland: Colonialism, Nationalism, and Culture. Manchester, UK: Manchester U.P., 1988. Print. Cultural Politics. 
Camus, Albert. The Plague. Trans. Stuart Gilbert. First Vintage International Edition. New York: Vintage International, 1991. Print.

Caraher, Brian. "Edgeworth, Wilde and Joyce: Reading Irish Regionalism through 'the cracked lookingglass' of a Servant's Art." Ireland in the Nineteenth Century: Regional Identity. Ed. Leon Litvack and Glen Hooper. Dublin: Four Courts Press, 2000. 123-139. Print.

Carleton, William. The Black Prophet. Poole, UK: Woodstock Books, 1996. Print.

---. The Squanders of Castle Squander. Vol I. London: Office of the Illustrated London Library, 1852. Print.

---. The Squanders of Castle Squander. Vol II. London: Office of the Illustrated London Library, 1852. Print.

Carlyle, Thomas. "Chartism." English and Other Critical Essays. London: J.M. Dent \& Sons LTD., 1950. 165-238. Print.

---. "TC to Ralph Waldo Emerson; 13 August 1849." The Carlyle Letters Online: A Victorian Cultural Reference [CLO]. Ed. Brent E. Kinser. Duke U.P., 14 Sept 2007. Web. 18 Nov 2013.

Carter, Margaret L. Dracula, the Vampire and the Critics. Ann Arbor: U. of Michigan Research P., 1988. Print. Studies in Speculative Fiction 19.

Carter, Marina and Crispin Bates, ed. Mutiny at the Margins: Global Perspectives. Vol. 3. Delhi: Sage Publications, 2013. Print. Mutiny at the Margins: New Perspectives on the Indian Uprising of 1857.

Case, Alison. "Tasting the Original Apple: Gender and the Struggle for Narrative Authority in Dracula." Narrative 1.3 (October 1993): 223-243. JSTOR. Web. 25 June 2013. 
Césaire, Aimé. Discourse on Colonialism. Trans. Joan Pinkham. New York: Monthly Review P, 1972. Print.

Chakravarty, Gautam. The Indian Mutiny and the British Imagination. Cambridge: Cambridge U.P., 2005. Print. Cambridge Studies in Nineteenth-Century Literature and Culture. “channel, n.1.” Def. I.4.a., II.7.8. The Oxford English Dictionary Online. Oxford University Press. March 2014. Web. 27 Mar 2014.

Chatterjee, Partha. The Nation and its Fragments: Colonial and Postcolonial Histories. 1994. The Partha Chatterjee Omnibus. Oxford: Oxford U.P., 1999. Print.

Chaudhuri, Nirad C. “The Finest Story About India—in English.” Encounter 8 (1957): 47-53. Print.

Cheng, Vincent J. Joyce, Race, and Empire. Cambridge: Cambridge U.P., 1995. Print. Cultural Margins.

Childs, Peter. Modernism and the Post-Colonial: Literature and Empire 1885-1930. London: Continuum, 2007. Print. Continuum Literary Studies.

Ciasen, Mathias. “Attention, Predation, Counterintuition: Why Dracula Won’t Die.” Style 46.3/4 (2012): 378. MasterFILE Premier. Web. 10 Feb. 2014

Cohen, Milton A. "Fatal Symbiosis: Modernism and the First World War." The Literature of the Great War Reconsidered: Beyond Modern Memory. Eds. Patrick J. Quinn and Steven Trout. Houndmills, UK: Palgrave, 2001. -. Print.

Colley, Linda. "Britishness and Otherness: An Argument." The Journal of British Studies 31.4 (Oct. 1992): 309-329. JSTOR. Web. 5 Feb 2014.

---. Britons: Forging the Nation 1707-1837. New Haven: Yale Nota Bene, 2008. Print. 
Conrad, Joseph. Heart of Darkness: An Authoritative Text, Backgrounds and Sources Criticism. Revised. Ed. Robert Kimbrough. New York: W.W. Norton, 1971. Print. A Norton Critical Edition.

Corkery, Daniel. “The Ember.” The Hounds of Banba. Freeport, NY: Books for Libraries P., 1970. 11-34. Print.

Cronin, Nessa. "Monstrous hybridity: Kim of the 'Eye-rishti' and the Survey of India." Foley and O'Connor 131-139.

Craft, Christopher. “'Kiss Me with Those Red Lips': Gender and Inversion in Bram Stoker's Dracula." Representations 8 (Fall 1984): 107-133. Print.

Crosbie, Barry. Irish Imperial Networks: Migration, Social Communication and Exchange in Nineteenth-Century India. Cambridge: Cambridge U.P., 2010. Print.

---. “'L'enfant terrible of the ICS': C.J. O'Donnell and the British administration of Bengal, 1872-82." The British Empire and its Contested Pasts. Ed. Robert J. Blyth and Keith Jeffery. Dublin: Irish Academic P, 2009. 115-135. Print. Historical Studies XXVI.

Crossland, Zoë. Epilogue. Necropolitics: Mass Graves and Exhumations in the Age of Human Rights. Ed. Francisco Ferrndiz and Antonius C.G.M. Robben. Philadelphia: U of Pennsylvania P, 2015. 240-252. Print.

Curtis, Jr., L.P. Apes and Angels: The Irishman in Victorian Caricature. Washington: Smithsonian Institution P., 1971. Print.

Cusack, George and Sarah Gross, eds. Hungry Words: Images of Famine in the Irish Canon. Dublin: Irish Academic P., 2006. Print.

Daly, Mary. "Revisionism and Irish History: The Great Famine.” Boyce and O'Day 71-89. 
Darwin, Charles. The Descent of Man, and Selection in Relation to Sex. Vol. 1. The Complete Work of Charles Darwin Online. Ed. John van Wyhe. London: John Murray, 1871. Web. 12 Jan 2016.

de Nie, Michael. The Eternal Paddy: Irish Identity and the British Press, 1798-1882. Madison: U. of Wisconsin P., 2004. Print. History of Ireland the Irish Diaspora.

Deane, Seamus. Strange Country: Modernity and Nationhood in Irish Writing since 1790. Oxford: Oxford U.P., 1997. Print.

Deleuze, Gilles and Claire Parnet. Dialogues. Trans. Hugh Tomlinson and Barbara Habberjam. New York: Columbia UP, 1987. Print.

---. The Fold: Leibniz and the Baroque. Trans. Tom Conley. Minneapolis: U of Minnesota P, 1993. Print.

Demetrakopoulos, Stephanie. "Feminism, Sex Role Exchanges, and Other Subliminal Fantasies in Bram Stoker's Dracula.” Frontiers: A Journal of Women Studies 2.3 (Autumn 1977): 104-113. JSTOR. Web. 24 June 2013.

Derrida, Jacques. The Beast \& the Sovereign. Vol. I. Ed. Michel Lisse, Marie-Louise Mallet, and Ginette Michaud. Trans. Geoffrey Bennington. Chicago: U. of Chicago P., 2009. Print. The Seminars of Jacques Derrida.

---. Monolingualism of the Other; or, The Prosthesis of Origin. Trans. Patrick Mensah. Ed. Mieke Bal and Hent de Vries. Stanford: Stanford U.P., 1998. Print. Cultural Memory in the Present.

Dickens, Charles. A Christmas Carol and Other Christmas Books. Ed. Robert Douglas-Fairhurst. Oxford, UK: Oxford U.P., 2008. Print. Oxford World's Classics.

Dodd, Luke. "Famine Echoes." The South Atlantic Quarterly 95.1 (Winter 1996): 97-101. Print. 
Domínguez-Rue, Emma. "Sins of the flesh: anorexia, eroticism and the female vampire in Bram Stoker's Dracula." Journal of Gender Studies 19.3 (September 2010): 297-308. Academic Search Complete. EBSCO. Web. 24 June 2013.

Dorst, John. "Postcolonial Encounters: Narrative Constructions of Devils Tower National Monument.” Postcolonial America. Ed. Richard C. King. Urbana: U. of Illinois P., 2000. 303-320. Print.

Douglass, Paul. "Reading the Wreckage: De-Encrypting Eliot's Aesthetics of Empire." Twentieth Century Literature 43.1 (1997): 1-26. Academic Search Complete. Web. 4 Sept. 2014.

Du Bois, W.E.B. “The Negro and the Warsaw Ghetto.” The Oxford W.E.B. Du Bois Reader. Ed. Eric J. Sundquist. New York: Oxford UP, 1996. 469-473. Print.

Duffy, Enda. "Disappearing Dublin: Ulysses, postcoloniality, and the politics of space." Semicolonial Joyce. Eds. Derek Attridge and Marjorie Howes. Cambridge: Cambridge U.P., 2000. 37-57. Print.

---. The Subaltern Ulysses. Minneapolis: U. of Minnesota P., 1994. Print.

Dwyer, June. "Feast and Famine: James Joyce and the Politics of Food." Proteus: A Journal of Ideas 17.1 (2000): 41-44. Print.

Eagleton, Terry. Heathcliff and the Great Hunger: Studies in Irish Culture. London: Verso, 1995. Print.

Edmond, Rod. "Home and away: degeneration in imperialist and modernist discourse." Modernism and Empire: Writing and British Coloniality 1890-1940. Ed. Howard J. Booth and Nigel Rigby. Manchester: Manchester U.P., 2000. Print. 
Edmond, Rod and Vanessa Smith. Introduction. Islands in History and Representation. Ed. Edmond and Smith. London: Routledge, 2003. 1-18. Print. Routledge Research in Postcolonial Literatures.

Eide, Marian. "The Woman of the Ballyhoura Hills: James Joyce and the Politics of Creativity." Wachtel 137-157.

Eliot, T.S. The Complete Poems and Plays: 1909-1950. New York: Harcourt, Brace and Company, 1958. Print.

---. Selected Prose. Ed. John Hayward. Harmondsworth: Penguin, 1953. Print.

---. "Ulysses, Order, and Myth.” The Dial; A Semi-monthly Journal of Literary Criticism, Discussion, and Information (1880-1929) (Nov. 1923): 480-483. ProQuest. Web. 4 Sep. 2014.

---. The Waste Land: Authoritative Text, Context, Criticism. Ed. Michael North. New York: W.W. Norton \& Company, Inc., 2001. Print.

Ellis, Juniper. "Writing Race: Education and Ethnography in Kipling's Kim." CR: The Centennial Review 39 (1995): 315-329. Print.

Ellmann, Maud. The Hunger Artists: Starving, Writing, and Imprisonment. Cambridge: Harvard UP, 1993. Print.

---. “The Music of Joyce's Vernacular Voices.” Modernism/modernity 16.2 (2009): 383-390. JSTOR. Web. 20 Apr 2012.

Ellmann, Richard. James Joyce. New and Revised Edition. Oxford; Oxford U.P., 1982. Print. ---. Ulysses on the Liffey. New York: Oxford U.P., 1978. Print.

Engels, Frederick. The Condition of the Working-Class in England in 1844. Trans. Florence Kelley Wischnewetzky. London: George Allen \& Unwin Ltd, 1950. Print. 
Erll, Astrid. "Remembering across Time, Space, and Cultures: Premediation, Remediation and the 'Indian Mutiny."' Media and Cultural Memory: Mediation, Remediation, and the Dynamics of Cultural Memory. Ed. Astrid Erll and Ann Rigney. Berlin: Walter de Gruyter, 2009. 109-138. Web. 13 Feb 2014.

Esty, Jed. Unseasonable Youth: Modernism, Colonialism, and the Fiction of Development. New York: Oxford U.P., 2011. Print. Modernist Literature \& Culture.

Fanon, Frantz. Studies in a Dying Colonialism. Trans. Haakon Chevalier. New York: Monthly Review P, 1965. Print.

---. The Wretched of the Earth. Trans. Constance Farrington. New York: Grove Press, 1963. Print.

Fargnoli, A. Nicholas and Michael Patrick Gillespie. James Joyce A to Z: The Essential Reference to His Life and Writings. Oxford: Oxford U.P., 1996. Print.

Fegan, Melissa. Literature and the Irish Famine 1845-1919. Oxford: Clarendon Press, 2002. Print. Oxford Historical Monographs.

Fein, Helen. "Genocide, Terror, Life Integrity, and War Crimes: The Case for Discrimination." Genocide: Conceptual and Historical Dimensions. Ed.Andreopoulos, George J. Philadelphia: U of Pennsylvania P, 1994. 95-107. Print. Pennsylvania Studies in Human Rights.

Ferguson, Christine. "Nonstandard Language and the Cultural Stakes of Stoker's Dracula." ELH 71.1 (Spring 2004): 229-249. ProjectMuse. Web. 14 May 2013.

Fitzsimon, Ellen. "Sonnet: 1849." The Hungry Voice: The Poetry of the Irish Famine. Ed. Chris Morash. Dublin: Irish Academic P, 1989. 98. Print. 
Flannery, Eóin. Ireland and Postcolonial Studies: Theory, Discourse, Utopia. New York: Palgrave MacMillan, 2009. Print.

Foley, Tadhg and Maureen O'Connor, eds. Ireland and India: Colonies, Culture, and Empire. Dublin: Irish Academic P., 2006. Print.

Forster, E.M. A Passage to India. New York: Harcourt, Brace \& World, Inc., 1952. Print.

Foster, R.F. Paddy and Mr Punch: Connections in Irish and English History. London: Allen Lane, 1993. Print.

Foucault, Michel. The Archaeology of Knowledge and the Discourse on Language. Trans. A.M. Sheridan Smith. New York: Pantheon Books, 1972. Print.

Fraser, T.G. "Ireland and India." Jeffery 77-93.

Freud, Sigmund. Three Contributions to the Theory of Sex. $2^{\text {nd }}$ ed. Trans. A.A. Brill. New York: Nervous and Mental Disease Publishing, 1920. Print. Nervous and Mental Disease Monograph Series 7.

Friedman, Susan Stanford. "Definitional Excursions: The Meanings of Modern/Modernity/Modernism.” Modernism/Modernity 8.3 (2001): 493-513. Print.

Fry, Carrol L. "Fictional Conventions and Sexuality in Dracula." Victorian Newsletter 42 (1972): 20-22. Print.

Gamache, Lawrence B. "Toward a Definition of 'Modernism."” The Modernists: Studies in a Literary Phenomenon. Ed. Gamache and Ian S. MacNiven. Rutherford: Fairleigh Dickinson P, 1987. 32-45. Print.

Garner, Steve. Racism in the Irish Experience. London: Pluto Press, 2004. Print.

Gibbons, Luke. “'Have you no homes to go to?': James Joyce and the politics of paralysis.” Attridge and Howes 150-171. 
---. Transformations in Irish Culture. Notre Dame: U. of Notre Dame P., 1996. Print.

Gibson, Andrew. Joyce's Revenge: History, Politics, and Aesthetics in Ulysses. Oxford: Oxford U.P., 2005. Print.

---. "Prolegomena: The Development of the Historical Sense in The Revisions of 'Proteus."” Dublin James Joyce Journal 2 (2009): 106-127. Project Muse. Web. 12 Apr 2012.

Giddens, Anthony. Modernity and Self-Identity: Self and Society in the Late Modern Age. Stanford: Stanford U.P., 1991. Print.

Gifford, Don and Robert J. Seidman. Ulysses Annotated: Notes for James Joyce's Ulysses. $2^{\text {nd }}$ ed. Berkeley: U. of California P., 1988. Print.

Gikandi, Simon. "Africa and the Epiphany of Modernism." Geomodernisms: Race, Modernism, Modernity. Ed. Laura Doyle and Laura Winkiel. Bloomington: Indiana U.P., 2005. 31-50. Print.

---. Maps of Englishness: Writing Identity in the Culture of Colonialism. New York: Columbia U.P., 1996. Print.

---. "Picasso, Africa, and the Schemata of Difference." Modernism/modernity 10.3 (2003): 455480. Print.

Gilbert, Elliot L. "Silence and Survival in Kipling's Art and Life." Bloom 103-116.

Gilroy, Amanda and W.M. Verhoeven. "Introduction." Epistolary Histories: Letters, Fiction, Culture. Ed. Amanda Gilroy and W.M. Verhoeven. Charlottesville: U.P. of Virginia, 2000. 1-28. Print.

Giraldus Cambrensis, The Historical Works of Giraldus Cambrensis: Containing the Topography of Ireland, and The History and Conquest of Ireland. Trans. . London: George Bell \& Sons, 1905. Print. 
Gkotzaridis, Evi. Trials of Irish History: Genesis and evolution of a reappraisal, 1938-2000. London: Routledge, 2006. Print. Routledge studies in modern European history.

Glover, David. Vampires, Mummies, and Liberals: Bram Stoker and the Politics of Popular Culture. Durham: Duke U.P., 1996. Print.

Greenblatt, Stephen. Renaissance Self-Fashioning: From More to Shakespeare. Chicago: U. of Chicago P., 1984. Print.

Greenslade, Liam. “The Blackbird Calls in Grief: Colonialism, Health and Identity Among Irish Immigrants in Britain." Location and Dislocation in Contemporary Irish Society: Emigration and Irish Identities. Jim Mac Laughlin, ed. Notre Dame: U. Notre Dame P., 1997. 36-60. Print.

---. “'White skin, white masks: psychological distress among the Irish in Britain.” O'Sullivan Irish in New 201-225.

Greenway, John L. "Seward's Folly: Dracula as a Critique of 'Normal Science."” Stanford Literature Review 3.2 (1986): 213-30. Print.

Gribben, Arthur, ed. The Great Famine and the Irish Diaspora in America. Amherst: U. of Massachusetts P., 199. Print.

Griffin, Gail B. “'Your Girls That You All Love Are Mine': Dracula and the Victorian Male Sexual Imagination.” International Journal of Women's Studies 3.5 (1980): 454-465. Print.

Hagena, Katharina. "Towers of Babble and of Silence.” Joyce on the Threshold. Ed. Anne Fogarty and Timothy Martin. Gainesville: U.P. of Florida, 2005. Print. The Florida James Joyce Series.

Haggard, H. Rider. She \& King Solomon's Mines. New York: The Modern Library, 1957. Print. 
Hagiioannu, Andrew. The Man Who Would Be Kipling: The Colonial Fiction and the Frontiers of Exile. New York: Palgrave Macmillan, 2003. Print.

Haines, Robin. Charles Trevelyan and the Great Irish Famine. Dublin: Four Courts P, 2004. Print.

Halberstam, Judith. “Technologies of Monstrosity: Bram Stoker’s Dracula.” Victorian Studies 36.3 (Spring 1993): 333-352. Academic Search Complete. EBSCO. Web. 24 June 2013. Hall, Catherine. Civilising Subjects: Metropole and Colony in the English Imagination 18301867. Chicago: U. of Chicago P., 2002. Print.

---., Keith McClelland, and Jane Rendall. "The nation within and without.” Defining the Victorian Nation: Class, Race, Gender and the British Reform Act of 1867. Cambridge: Cambridge U.P., 2000. Print.

Hall, Mark Sullivan. "Fenians, Sepoys, and the Financial Panic of 1857." Carter and Bates 8797.

Hallward, Peter. Absolutely Postcolonial: Writing Between the Singular and the Specific. Manchester: Manchester U.P., 2001. Print. Angelaki Humanities.

---. “Introduction.” Badiou: A Subject to Truth. Minneapolis: U of Minnesota P, 2003. XXIXXXVI. Print.

Hambly, G. R. G. "Richard Temple and the Punjab Tenancy Act of 1868." The English Historical Review 79.310 (January 1964): 47-66. JSTOR. Web. 29 Sept 2014.

Harris, Ruth-Ann M. "Introduction." The Great Famine and the Irish Diaspora in America. Ed. Arthur Gribben. Amherst: U. of Massachusetts P., 1999. 1-20. Print.

Haslam, Sara. Fragmenting Modernism: Ford Madox Ford, the Novel, and the Great War. New York: Palgrave, 2002. Print. 
Hatlen, Burton. "The Return of the Repressed/Oppressed in Bram Stoker's Dracula." Carter 117-135.

Havholm, Peter. Politics and Awe in Rudyard Kipling's Fiction. Burlington: Ashgate Publishing Company, 2008. Print.

Hayden, Tom, ed. The Irish Hunger: Personal Reflections on the Legacy of the Famine. Boulder, CO: Roberts Rinehart Publishers, 1997. Print.

Healy, Róisín. "From Commonwealth to Colony? Poland under Prussia." Healy and Del Lago $109-125$.

--- and Enrico Del Lago, ed The Shadow of Colonialism on Europe's Modern Past. Houndmills: Palgrave Macmillan, 2014. Print. Cambridge Imperial and Post-Colonial Studies Series. Heidegger, Martin. Being and Time. Trans. John Macquarrie and Edward Robinson. New York: Harper \& Row, 1962. Print. Harper Perennial Modern Thought.

Heilmann, Ann and Mark Llewellyn. "What Kitty Knew: George Moore's John Norton, Multiple Personality, and the Psychopathology of Late-Victorian Sex Crime.” Nineteenth-Century Literature 59.3 (December 2004): 372-403. Academic Search Complete. EBSCO. Web. 24 June 2013.

Hennelly, Jr., Mark M. “Dracula: The Gnostic Quest and the Victorian Wasteland.” Carter 7992.

Herbert, Christopher. War of No Pity: The Indian Mutiny and Victorian Trauma. Princeton: Princeton U.P., 2008. Print.

Heremon. "The Famine." Killen 55-57. 
Hickman, Mary J. Religion, Class and Identity: The State, the Catholic Church and the Education of the Irish in Britain. Aldershot, UK: Avebury, 1995. Print. Research in Ethnic Relations Series.

Hight, Eleanor M. and Gary D. Sampson. "Introduction: Photography, 'race', and post-colonial theory." Colonialist Photography: Imag(in)ing race and place. Eds. Eleanor M. Hight and Gary D. Sampson. London: Routledge, 2002. 1-19. Print. Documenting the Image.

Hobsbawm, E.J. “Revolution.” Porter and Teich 5-46.

Hogan, Patrick Colm. Colonialism and Cultural Identity: Crises of Tradition in the Anglophone Literatures of India, Africa, and the Caribbean. Albany: State U of New York P, 2000. Print. Explorations in Postcolonial Studies.

---. "Literary Universals.” Introduction to Cognitive Cultural Studies. Ed. Lisa Zunshine. Baltimore: The Johns Hopkins UP, 2010. 37-63. Print.

Hogle, Jerrold E. "Stoker's Counterfeit Gothic: Dracula and Theatricality at the Dawn of Simulation." Hughes and Smith 205-224.

Holdridge, Jefferson. "Great Hunger, Unspeakable Home: Landscape, Nature and Original Sin in Lady Morgan's The Wild Irish Girl and William Carleton's The Black Prophet." Valone $39-56$.

Hollington, Michael. "Kim and Kipling: Concentration Camps and Their Sweet Opposites." Q/W/E/R/T/Y: Arts, Literature \& Civilisations du Monde Anglophone 4 (Octobre 1994): 175-188. Print.

Holy Bible with the Apocryphal/Deuterocanonical Books. New York: American Bible Society, 1989. Print. New Revised Standard Version.

Howe, Irving. "Pleasures of Kim.” Bloom 35-44. 
Hopkins, Lisa. Bram Stoker: A Literary Life. New York: Palgrave Macmillan, 2007. Print.

Hughes, William. Beyond Dracula: Bram Stoker's fiction and its cultural context. New York: Palgrave, 2000. Print.

Hughes, William and Andrew Smith, eds. Bram Stoker: History, Psychoanalysis and the Gothic. New York: St. Martin's Press, Inc., 1998. Print.

Hussain, Nasser. The Jurisprudence of Emergency: Colonialism and the Rule of Law. Ann Arbor: The U. of Michigan P., 2003. Print. Law, Meaning, and Violence.

Hustis, Harriet. “Black and White and Read All Over: Performative Textuality in Bram Stoker's Dracula." Studies in the Novel 33.1 (2001): 18-33. MLA International Bibliography. EBSCO. Web. 12 July 2011.

“hybrid, n. and adj.” Def. 1b. The Oxford English Dictionary Online. Oxford University Press. December 2013. Web. 24 Feb 2014.

Ingelbien, Raphaël. “Gothic Genealogies: Dracula, Bowen's Court, and Anglo-Irish Psychology.” ELH 70.4 (2003): 1089-1105. Project Muse. Web. 22 May 2011.

Jackson, Paul. Great War Modernisms and the New Age Magazine. London: Continuum, 2012. Print. Historicizing Modernism.

Jameson, Fredric. "Modernism and Imperialism.” Nationalism, Colonialism, and Literature. Minneapolis: U. of Minnesota P., 1990. 43-68. Print. A Field Day Company Book. JanMohamed, Abdul R. “The Economy of Manichean Allegory: The Function of Racial Difference in Colonialist Literature." "Race,” Writing, and Difference. Ed. Henry Louis Gates, Jr. Chicago: The U. of Chicago P., 1986. 78-106. Print.

Jann, Rosemary. “Saved by Science? The Mixed Messages of Stoker's Dracula!” Texas Studies in Language and Literature 31 (1989): 273-287. JSTOR. Web. 25 June 2013. 
Jeffery, Keith, ed. 'An Irish Empire'?: Aspects of Ireland and the British Empire. Manchester: Manchester UP, 1996. Print. Studies in Imperialism.

---. “The Irish military tradition and the British Empire.” Jeffery 94-122.

Johnson, Alan. "Bent and Broken Necks: Signs of Design in Stoker's Dracula." Carter 231-256.

Johnston, A.J.B. "Nativism in Nova Scotia: Anti-Irish Ideology in a Mid-Nineteenth-Century British Colony." The Irish in Atlantic Canada, 1780-1900. Ed. Thomas P. Power.

Fredericton, New Brunswick: New Ireland P., 1991. 23-29. Print.

Joyce, James. The Critical Writings of James Joyce. Eds. Ellsworth Mason and Richard Ellmann. New York: The Viking Press, 1964. Print. The Viking Portable Library.

---. Finnegans Wake. New York: Penguin Books, 1999. Print. Penguin Twentieth-Century Classics.

---. "The First Version of “A Portrait.”" Scholes and Kain 56-74.

---. Letters of James Joyce. Vol. II. Ed. Richard Ellmann. New York: Viking Press, 1966. Print.

---. "Oxen of the Sun." 1920. MS V.A.11-18. The James Joyce Collection. University at Buffalo Library. The State University of New York, Buffalo, NY.

---. A Portrait of the Artist as a Young Man: Text, Criticism and Notes. Ed. Chester G. Anderson.

New York: The Viking Press, 1968. Print. The Viking Critical Library.

---. "Proteus," 1917. MS V.A.3. The James Joyce Collection. University at Buffalo Library. The State University of New York, Buffalo, NY.

---. Stephen Hero. Ed. John J. Slocum and Herbert Cahoon. New York: New Directions, 1963.

Print. A New Directions Book.

---. "Trieste Notebook." Scholes and Kain 92-105. 
---. Ulysses. First Vintage Books Edition. Ed. Hans Walter Gabler, Wolfhard Steppe, and Claus Melchior. New York: Vintage Books, 1986. Print. The Gabler Edition.

Kafka, Franz. "A Hunger Artist.” Collected Stories. Ed. Gabriel Josipovici. New York: Alfred A. Knopf, 1993. 222-232. Print. Everyman's Library.

Kearney, Colbert. “Stephen's Green - The Image of Ireland in Joyce.” Martin 101-120.

Kelleher, Margaret. The Feminization of Famine: Expressions of the Inexpressible? Durham: Duke U.P., 1997. Print.

Kennedy, Líam. "Bastardy and the Great Famine: Ireland, 1845-50." Famine, Land and Culture in Ireland. Ed. Carla King. Dublin: U College Dublin P, 2000. 6-28. Print.

Kiberd, Declan. Inventing Ireland. Cambridge: Harvard U.P., 1995. Print.

---. . "Postcolonial Modernism?" Modernism and Colonialism: British and Irish Literature, 1899-1939. Eds. Richard Begam and Michael Valdez Moses. Durham: Duke U.P., 2007. 269-287. Print.

Kickham, Charles Joseph. Knocknagow or, The Homes of Tipperary. Otley, UK: Woodstock Books, 2002. Print. Hibernia: Literature and Nation in Victorian Ireland.

Kierkegaard, Søren. Provocations: Spiritual Writings of Kierkegaard. Ed. Charles E. Moore. Farmington, PA: The Plough Publishing House, 1999. Print.

Kiernan, Victor. "Imperialism and revolution." Porter and Teich 121-144.

---. The Lords of Human Kind: European Attitudes to Other Cultures in the Imperial Age. London: Serif, 1995. Print.

Kilgour, Maggie. "Vampiric Arts: Bram Stoker's Defence of Poetry." Hughes and Smith 47-61. Killen, John ed. The Famine Decade: Contemporary Accounts, 1841-1851. Belfast: Blackstaff Press, 1995. Print. 
Kinealy, Christine. A Death-Dealing Famine: The Great Hunger in Ireland. London: Pluto Press, 1997. Print.

---. “The Great Irish Famine-A Dangerous Memory?” Gribben 239-253.

---. The Great Irish Famine: Impact, Ideology and Rebellion. Houndmills: Palgrave, 2002. Print. British History in Perspective.

Kinkead-Weekes, Mark. "Vision in Kipling's Novels.” Rutherford 197-234.

Kipling, Rudyard. Indian Tales. New York: Tudor Publishing Company, 1936. Print.

---, ed. The Irish Guards in the Great War. Vol. I. The First Battalion. New York: Doubleday, Page \& Company, 1923. Print.

---. The Jungle Books. Ed. W.W.Robson. Oxford: Oxford U.P., 2008. Print. Oxford World's Classics.

--- Kim. Ed. Zohreh T. Sullivan. New York: W.W. Norton \& Company, 2002. Print. A Norton Critical Edition.

---. The Letters of Rudyard Kipling. Vol. 1: 1872-89. Ed. Thomas Pinney. Houndmills: MacMillan, 1991. Print.

---. The Letters of Rudyard Kipling. Vol. 3: 1900-10. Ed. Thomas Pinney. Iowa City: U. of Iowa P., 1996. Print.

---. “The Lost Legion.” The Strand Magazine: An Illustrated Monthly 3 (1892): 476-83. ProQuest. Web. 4 Nov. 2013.

---. Plain Tales From the Hills. Boston: Desmond Publishing Co., 1900. Print.

---. “At a Public Meeting Protesting Home Rule, Tunbridge Wells: 16 May 1914.” Rudyard Kipling's Uncollected Speeches: A Second Book of Words. Greensboro, NC: E \& L Press, 2008. Print. 
---. Something of Myself: For My Friends Known and Unknown. Garden City, NY: Doubleday, Doran \& Company, Inc., 1937. Print.

Knoepflmacher, U.C. “Kipling’s 'Mixy’ Creatures.” SEL: Studies in English Literature 1500190048.4 (Autumn 2008): 923-933. Print.

Knox, Robert. The Races of Men: A Fragment. London: Savill and Edwards, 1850. Print.

Kristeva, Julia. "The Pain of Sorrow in the Modern World: The Works of Marguerite Duras." Trans. Katharine A. Jensen. PMLA 102.2 (1987): 138-152). Print.

Lacey, Brian. “The People Lost and Forgot.” Hayden 79-90.

Laird, Heather. "India and the translation of the Irish Brehon Laws." Foley and O'Connor. 3-11.

Lawless, Emily. Hurrish: A Study. Dublin: Appletree P, 1992. Print. Classic Irish Novels.

Lawrence, D.H. Lady Chatterley's Lover. Garden City, NY: International Collectors Library, n.d. Print.

Laxton, Edward. The Famine Ships: The Irish Exodus to America. New York: Henry Holt and Company, 1997. Print.

Lee, Joseph. The Modernisation of Irish Society, 1848-1918. Dublin: Gill and Macmillan, 1973. Print. The Gill History of Ireland 10.

Leerssen, Joep. Mere Irish and Fior-Ghael: Studies in the Idea of Irish Nationality, its Development and Literary Expression prior to the Nineteenth Century. $2^{\text {nd }}$ ed. Notre Dame: U. of Notre Dame P., 1997. Print. Critical Conditions: Field Day Essays and Monographs.

---. Remembrance and Imagination: Patterns in the Historical and Literary Representation of Ireland in the Nineteenth Century. Notre Dame: U. of Notre Dame P., 1997. Print. Critical Conditions: Field Day Essays and Monographs. 
Lennon, Joseph. Irish Orientalism: A Literary and Intellectual History. Syracuse: Syracuse U.P., 2004. Print. Irish Studies.

Lindeborg, Ruth H. "The 'Asiatic' and the Boundaries of Victorian Englishness.” Victorian Studies 37.3 (Spring 1994): 381-404. JSTOR. Web. 17 Jun 2013.

Liu, Lydia H. The Clash of Empires: The Invention of China in Modern World Making. Cambridge: Harvard UP, 2004. Print.

Livorni, Ernesto. “'Ineluctable modality of the visible': Diaphane in the 'Proteus' Episode." James Joyce Quarterly 36.2 (Winter 1999): 127-169. JSTOR. Web. 18 Apr 2012.

Lloyd, David. Anomalous States: Irish Writing and the Post-Colonial Moment. Durham: Duke U.P., 1993. Print.

---. Irish Culture and Colonial Modernity 1800-2000: The Transformation of Oral Space. Cambridge: Cambridge U.P., 2011. Print.

---. Irish Times: Temporalities of Modernity. Dublin: Field Day Publications, 2008. Print.

Lodge, David. “'Mrs Bathurst': Indeterminacy in Modern Narrative.” Mallett 71-.

Low, Gail Ching-Liang. White Skins/Black Masks: Representation and Colonialism. Routledge: London, 1996. Print.

Lowe-Evans, Mary. Crimes Against Fecundity: Joyce and Population Control. Syracuse: Syracuse U.P., 1989. Print. Irish Studies.

MacGill, Patrick. The Rat-Pit. Edinburgh: Birlinn Limited, 1999. Print.

MacLaughlin, Jim. Ireland: The Emigrant Nursery and the World Economy. Cork: Cork U.P., 1994. Print. Undercurrents.

MacLean, Gerald. "Re-siting the Subject." Epistolary Histories: Letters, Fiction, Culture. Ed. Amanda Gilroy and W.M. Verhoeven. Charlottesville: U.P. of Virginia, 2000. 176-191. 
Print.

MacNamara, Brinsley. In Clay and in Bronze: A Study in Personality. New York: Brentano’s Publishers, 1920. Print.

Malchow, Howard L. Gothic Images of Race in Nineteenth-Century Britain. Stanford: Stanford U.P., 1996. Print.

Malkmus, Bernhard. German Picaro and Modernity: Between Underdog and Shapeshifter. London: Continuum, 2011. Print.

Mallett, Phillip ed. Kipling Considered. New York: St. Martin's Press, 1989. Print.

Mancing, Howard. "The Protean Picaresque." The Picaresque: Tradition and Displacement. Ed. Giancarlo Maiorino. 273-291. Print. Hispanic Issues 12.

Marinetti, F.T. "The Founding and Manifesto of Futurism.” Italianfuturism.org. Jessica Palmieri. 2014. Web. 22 Jan 2016.

Majumdar, Gaurav. Migrant Form: Anti-Colonial Aesthetics in Joyce, Rushdie and Ray. New York: Peter Lang, 2010. Print. Postcolonial Studies 4.

Martin, Amy E. Alter-Nations: Nationalisms, Terror, and the State in Nineteenth-Century Britain and Ireland. Columbus: The Ohio State U.P., 2012. Print.

Martin, Augustine. "The Artist and the Labyrinth.” Martin 11-24.

---, ed. James Joyce: The Artist and the Labyrinth. London: Ryan Publishing, 1990. Print. Mbembe, Achille. "Necropolitics.” Public Culture 15.1 (Winter 2003): 11-40. Print.

---. On the Postcolony. Berkeley: U of California P, 2001. Print. Studies on the History of Society and Culture.

McArthur, Murray. “'Signs on a White Field': Semiotics and Forgery in the 'Proteus' Chapter of Ulysses.” ELH 53.3 (Autumn, 1986): 633-652. 20 Apr 2012. 
McBratney, John. Imperial Subjects, Imperial Space: Rudyard Kipling's Fiction of the NativeBorn. Columbus: The Ohio State U.P., 2002. Print.

McClintock, Anne. "The angel of progress: pitfalls of the term 'postcolonialism." Colonial discourse/postcolonial theory. Ed. Francis Baker, Peter Hulme, Margaret Iversen. Manchester: Manchester U.P., 1996. 253-266. Print.

---. Imperial Leather: Race, Gender and Sexuality in the Colonial Contest. New York:

Routledge, 1995. Print.

McCrea, Barry. "Heterosexual Horror: Dracula, The Closet, And The Marriage-Plot." Novel: A Forum On Fiction 43.2 (2010): 251-270. MLA International Bibliography. Web. 26 Mar. 2012.

McGarrity, Maria and Claire A. Culleton, eds. Irish Modernism and the Global Primitive. New York: Palgrave MacMillan, 2009. Print. New Directions in Irish and Irish American Literature.

McGunnigle, Christopher. "My Own Vampire: The Metamorphosis of the Queer Monster in Francis Ford Coppola's Bram Stoker's Dracula." Gothic Studies 7.2 (November 2005): 172-184. Academic Search Complete. EBSCO. Web. 24 June 2013.

McKee, Patricia. "Racialization, Capitalism, and Aesthetics in Stoker's Dracula." Novel: A Forum on Fiction 36.1 (2002): 42-60. Academic Search Complete. EBSCO. Web. 14 Nov. 2010.

McLean, Stuart. The Event and its Terrors: Ireland, Famine, Modernity. Stanford: Stanford U.P., 2004. Print. Cultural Memory in the Present.

McWhir, Anne. "Pollution and Redemption in Dracula." Modern Language Studies 17.3 (Summer 1987): 31-40. JSTOR. Web. 25 June 2013. 
Menand, Louis. "Kipling in the History of Forms." High and Low Moderns: Literature and Culture, 1889-1939. Ed. Maria DiBattista and Lucy McDiarmid. New York: Oxford U.P., 1996. 148-165. Print.

Mick, Christopher. “Colonialism in the Polish Eastern Borderlands 1919-1939.” Healy and Del Lago 126-141.

Mighall, Robert. "Sex, History and the Vampire." Hughes and Smith 62-77.

Miller, Kirby A. “In the Famine's Shadow: An Irish Immigrant from West Kerry to South Dakota, 1881-1979.” Mulrooney 113-132.

Mills, Charles W. The Racial Contract. Ithaca and London: Cornell U P, 1997. Print.

Mitchel, John. Jail Journal: with an Introductory Narrative of Transactions in Ireland. Dublin: U.P. of Ireland, 1982. Print.

---. The Last Conquest of Ireland (Perhaps). Ed. Patrick Maume. Dublin: University College Dublin P., 2005. Print. Classics of Irish History.

Mitchell, Andrew J. and Sam Slote, ed. Derrida and Joyce: Texts and Contexts. Albany: State U. of New York P., 2013. Print. SUNY Series in Contemporary French Thought.

Mohanty, Satya P. "Drawing the Color Line: Kipling and the Culture of Colonial Rule.” The Bounds of Race: Perspectives on Hegemony and Resistance. Ed. Dominick LaCapra. Ithaca: Cornell U.P., 1991. 311-343. Print.

Montefiore, Janet. "Latin, arithmetic and mastery: a reading of two Kipling fictions." Modernism and Empire: Writing and British Coloniality 1890-1940. Ed. Howard J. Booth and Nigel Rigby. Manchester: Manchester U.P., 2000. Print. 
Moore-Gilbert, Bart. “'The Bhabhal of Tongues': reading Kipling, reading Bhabha.” Writing India, 1757-1990: The Literature of British India. Ed. Moore-Gilbert. Manchester: Manchester U.P., 1996. 111-138. Print.

---. “'I am going to rewrite Kipling's Kim: Kipling and Postcolonialism.' Journal of Commonwealth Literature 37.2 (June 2002): 39-58. Print.

---. Kipling and “Orientalism.” New York: St. Martin's Press, 1986. Print.

---. "Kipling and postcolonial literature." Booth 155-168.

Morash, Chris. "An afterword on silence.” Cusack and Gross 300-308.

---. “Ever under some unnatural condition': Bram Stoker and the Colonial Fantastic.” Literature and the Supernatural: Essays for the Maynooth Bicentenary. Ed. Brian Cosgrove. Dublin: The Columba Press, 1995. 95-119. Print.

--- and Richard Hayes, eds. 'Fearful Realities': New Perspectives on the Famine. Dublin: Irish Academic Press, 1996. Print.

---. "Literature, Memory, Atrocity." Morash and Hayes 110-118.

---. "Making memories: the literature of the Irish Famine." O'Sullivan 40-55.

---. Writing the Irish Famine. Oxford: Clarendon P., 1995. Print.

Moretti, Franco. "The Dialectic of Fear." new left review 136 (November-December 1982): 6785. Print.

Morgan, Jack. New World Irish: Notes on One Hundred Years of Lives and Letters in American Culture. New York: Palgrave Macmillan, 2011. Print. New Directions in Irish and Irish American Literature.

Morris, R.J. "Bowld Irish Sepoy.” Carter and Bates 98-119. 
Morrison, Ronald D. "Reading Barthes and Reading Dracula: Between Work and Text." Kentucky Philological Review: Bulletin of the Annual Meeting of the Kentucky Philological Association.

Moses, Michael Valdez. "The Irish Vampire: Dracula, Parnell, and the Troubled Dreams of Nationhood.” Journal x: A Journal in Culture and Criticism 2.1 (1997): 67-111. Print.

Mulcrone, Mick. "The Famine and Collective Memory: The Role of the Irish-American Press in the Early Twentieth Century." Gribben 219-238.

Mulrooney, Margert M., ed. Fleeing the Famine: North America and Irish Refugees, 1845-1851. Westport, CT: Praeger, 2003. Print.

Mulvey-Roberts, Marie. "Dracula and the Doctors: Bad Blood, Menstrual Taboo and the New Woman." Hughes and Smith 78-95.

Murray, Paul. From the Shadow of Dracula: A Life of Bram Stoker. London: Jonathan Cape, 2004. Print.

Nally, David P. Human Encumbrances: Political Violence and the Great Irish Famine. Notre Dame: U. of Notre Dame P., 2011. Print.

Nandy, Ashis. At the Edge of Psychology: Essays in Politics and Culture. Delhi: Oxford UP, 1980. Print.

---. Bonfire of Creeds: The Essential Ashis Nandy. New Delhi: Oxford UP, 2004. Print.

Nelson, Bruce. Irish Nationalists and the Making of the Irish Race. Princeton: Princeton UP, 2012. Print.

Newman, Robert D. and Weldon Thornton, ed. Joyce's Ulysses: The Larger Perspective. Newark: U. of Delaware P., 1987. Print. 
Newsinger, John. Fenianism in Mid-Victorian England. London: Pluto Press, 1994. Print. A Socialist History of Britain.

ní Fhlathúin, Máire. “The anti-colonial modernism of Patrick Pearse.” Booth and Rigby 156-174.

Nicholls, Peter. Modernisms: A Literary Guide. Berkeley: U. of California P., 1995. Print.

Ó Cathaoir, Brendan. Famine Diary. Dublin: Irish Academic P, 1999. Print.

O’Faoláin, Seán. Come Back to Erin. New York: Viking Press, 1940. Print.

Ó Gráda, Cormac. Black '47 and Beyond: The Great Irish Famine in History, Economy, and Memory. Princeton: Princeton U.P., 1999. Print.

---. Famine: A Short History. Princeton: Princeton UP, 2009. Print.

O’Hara, Daniel T. Visions of Global America and the Future of Critical Reading. Columbus: The Ohio State UP, 2009. Print.

O’Hara, Jessica Jane. Undercover Irishness: Espionage, Empire, and Identity in Irish Literature, 1880-2000. Diss. U. of North Carolina Chapel Hill. 2003. ProQuest: U of Michigan Dissertations Publishing, 2003.Web. 5 Jan 2014.

Ó Murchadha, Ciarán. The Great Famine: Ireland's Agony 1845-1852. London: Continuum, 2011. Print.

O’Sullivan, Patrick and Richard Lucking. "The Famine world wide: the Irish Famine and the development of famine policy and famine theory." O'Sullivan Meaning of the Famine 195-232.

---, ed. The Irish in the New Communities. Vol. 2. Leicester: Leicester U.P., 1992. Print. The Irish World Wide: History, Heritage, Identity.

---, ed. The Meaning of the Famine. Vol. 6. London: Leicester U.P., 1997. Print. The Irish World Wide: History, Heritage, Identity. 
Olry, Régis and Duane E. Haines. "Renfield's Syndrome: A Psychiatric Illness Drawn From Bram Stoker's Dracula." Journal of the History of the Neurosciences 20.4 (OctoberDecember 2011): 368-371. Academic Search Complete. EBSCO. Web. 24 June 2013.

Orel, Harold. "Rudyard Kipling and the Establishment: A Humanistic Dilemma." Critical Essays on Rudyard Kipling. Ed. Harold Orel. Boston: G.K. Hall \& Co., 1989. 213-228. Print. Critical Essays on British Literature.

Orwell George. "Rudyard Kipling.” Dickens, Dali \& Others: Studies in Popular Culture. New York: Reynal \& Hitchcok, 1946. 140-160. Print.

Outka, Elizabeth. "“Wood for the Coffins Ran Out': Modernism and the Shadowed Afterlife of the Influenza Pandemic.” Modernism/modernity 21.4 (2014): 937-960. Project MUSE. Web. 20 Aug. 2015.

Pandit, Lalita. "Caste, Race, and Nation: History and Dialectic in Rabindranath Tagore's Gora." Literary India: Comparative Studies in Aesthetics, Colonialism, and Culture. Ed. Patrick Colm Hogan and Lalita Pandit. Albany: State U of New York P, 1995. Print.

Parry, Ann. "History and Artifice in Rudyard Kipling's Kim." Q/W/E/R/T/Y: Arts, Literature \& Civilisations du Monde Anglophone 4 (Octobre 1994): 189-195. Print.

Parry, Benita. Postcolonial Studies: A Materialist Criqitue. London: Routledge, 2004. Print. Routledge Research in Postcolonial Literatures.

Pearse, Pádraic H. Collected Works of Pádraic H. Pearse: Political Writings and Speeches. Dublin: The Phoenix Publishing Co., Ltd., 1916. Print.

Pick, Daniel. 'Terrors of the Night: Dracula and 'Degeneration' in the Late Nineteenth Century." Critical Quarterly 30.4 (Winter 1988): 71-87. Print. 
Plotz, Judith. "The Empire of Youth: Crossing and Double-Crossing Cultural Barriers in Kipling's Kim." Children's Literature 20.1 (1992): 111-131. Print.

Poole, Adrian. “Kipling's Upper Case.” Mallett 135-159.

Poon, Angelia. Enacting Englishness in the Victorian Period: Colonialism and the Politics of Performance. Burlington, VT: Ashgate, 2008. Print.

Popplewell, Richard J. Intelligence and Imperial Defence: British Intelligence and the Defence of the Indian Empire, 1904-1924. London: Frank Cass, 1995. Print.

Porter, Bernard. The Absent-Minded Imperialists: Empire, Society, and Culture in Britain. New York: Oxford UP, 2006. Print.

Porter, Roy and Mikuláš Teich, ed. Revolution in History. Cambridge: Cambridge UP, 1986. Print.

Pound, Ezra. Poems and Translations. New York: The Library of America, 2003. Print.

“Proclamation of Republic.” Easter1916.net. 14 May 2013. Web. 27 Feb 2016.

Punter, David. The Literature of Terror: A History of Gothic Fictions from 1765 to the present day. London: Longman, 1980.

Raczymow, Henri. "Memory Shot Through With Holes." Trans. Alan Astro. Yale French Studies 85 (1994): 98-105. JSTOR. Web. 6 Jan. 2015.

"Radical, adj. and n." Def. A.1.a. The Oxford English Dictionary Online. Oxford University Press. 2016. Web. 17 Feb 2016.

Ramazani, Jahan. "Modernist bricolage, postcolonial hybridity.” Modernism and Colonialism: British and Irish Literature, 1899-1939. Ed. Richard Begam and Michael Valdez Moses. Durham: Duke U.P., 2007. 288-313. Print. 
Rancière, Jacques. The Aesthetic Unconscious. Trans. Debra Keates and James Swenson. Cambridge, UK: Polity, 2010. Print.

Randall, Don. Kipling's Imperial Boy: Adolescence and Cultural Hybridity. New York: Palgrave, 2000. Print.

Raskin, Jonah. The Mythology of Imperialism: a Revolutionary Critique of British Literature and Society in the Modern Age. New York: Monthly Review Press, 2009. Print.

"Refuse, n.1 and adj.; v.1." Def. 1a, 1b, 2; 1a, 3a. The Oxford English Dictionary Online. Oxford University Press. March 2014. Web. 25 Mar 2014.

Regan-Lefebvre, Jennifer. Cosmopolitan Nationalism in the Victorian Empire: Ireland, India and the Politics of Alfred Webb. Houndmills: Palgrave Macmillan, 2009. Print. Cambridge Imperial and Post-Colonial Studies Series.

Renan, Ernest. The Poetry of the Celtic Races, and Other Studies by Ernest Renan. Trans. William G. Hutchison. London: Walter Scott, LTD., 1896. Print.

“Revision, n.1 and v.1." Def. 1a, 1b, 2; 1a, 3a. The Oxford English Dictionary Online. Oxford University Press. March 2014. Web. 25 Mar 2014.

Ricketts, Harry. Rudyard Kipling: A Life. New York: Carroll \& Graf Publishers, Inc., 2000. Print.

Ricoeur, Paul. Evil: A Challenge to Philosophy and Theology. Trans. John Bowden. London: Continuum, 2007. Print.

---. Time and Narrative. Vol. 3. Trans. Kathleen Blamey and David Pellauer. Chicago: The U of Chicago P, 1990. Print. 
Riera, Gabriel. "Introduction: Alain Badiou: The Event of Thinking." Alain Badiou: Philosophy and its Conditions. Ed. Gabriel Riera. Albany: State U of New York P, 2005. 1-19. Print. SUNY Series, Intersections: Philosophy and Critical Theory.

Rimon, Patricia A. “"Proteus': From Thoughts to Things." Studies In The Novel 17.3 (1985): 296-302. JSTOR. Web. 19 Apr 2012.

Robinson, Mary. "Why Commemorate the Irish Famine? Address by Mary Robinson to the Irish Fellowship Club.” Multimedia \& Speeches. President of Ireland. 2016. Web. 19 Feb 2016.

Rodríguez-Luis, Julio. "Pícaras: The Modal Approach to the Picaresque." Comparative Literature 31.1 (Winter 1979): 32-46. Print.

Roos, Bonnie. "The Joyce of eating: feast, famine and the humble potato in Ulysses." Cusack and Gross 159-196.

Roughley, Alan. Reading Derrida Reading Joyce. Gainesville: U.P. of Florida, 1999. Print.

Roth, Phyllis A. "Suddenly Sexual Women in Bram Stoker's Dracula." Literature and Psychology 27 (1977): 113-121. Print.

Roy, Parama. Indian Traffic: Identities in Question in Colonial and Postcolonial India. Berkeley: U. of California P., 1998. Print.

Rushdie, Salman. “Kipling.” Imaginary Homelands: Essays and Criticism 1981-1991. London: Granta Books, 1992. 74-80. Print.

Russell, Jacoby. "Marginal Returns: The Problem with Postcolonial Studies." Lingua Franca 5.6 (Sep/Oct 1995): 30-37. Print.

Rutherford, Andrew ed. Kipling's Mind and Art: Selected Critical Essays. Stanford: Stanford U.P., 1964. Print. 
Ryder, Sean. "Reading Lessons: Famine and the Nation, 1845-1849." 'Fearful Realities': New Persepctives on the Famine. Ed. Chris Morash and Richard Hayes. Dublin: Irish Academic Press, 1996. 151-163. Print.

Said, Edward W. Culture and Imperialism. New York: Vintage Books, 1994. Print.

---. Musical Elaborations. New York: Columbia UP, 1991. Print. The Wellek Library Lectures at the University of California, Irvine.

---. Reflections on Exile and Other Essays. Cambridge: Harvard UP, 2000. Print. Convergences: Inventories of the Present.

---. The World, the Text, and the Critic. Cambridge, MA: Harvard UP, 1983. Print.

Sandison, Alan. "Kipling: The Artist and the Empire." Rutherford 146-167.

Sarkar, Sumit. Writing Social History. New Delhi: Oxford UP, 1999. Print. Oxford India Paperbacks.

Scally, Robert James. The End of Hidden Ireland: Rebellion, Famine, and Emigration. New York: Oxford U.P., 1995. Print.

Scandura, Jani. "Dracula, Undertakers, and the Embalmed Corpse." Victorian Studies 40.1 (Autumn 1996): 1-30. JSTOR. Web. 10 Feb 2014.

Scanlan, Thomas. Colonial Writing and the New World, 1583-1671. Cambridge: Cambridge UP, 1999. Print.

Schaffer, Talia. ““A Wilde Desire Took Me': The Homoerotic History of Dracula.” English Literary History 61.2 (1994): 381-425. Print.

Schmitt, Cannon. "Mother Dracula: Orientalism, Degeneration, and Anglo-Irish National Subjectivity at the Fin de Siècle." Bucknell Review: A Scholarly Journal of Letters, Arts, and Sciences 38 (1994): 25-43. Print. 
Schneer, Jonathan. London 1900: The Imperial Metropolis. Yale: Yale U.P., 1999. Print.

Scholes, Robert and Richard M. Kain, ed. The Workshop of Daedalus: James Joyce and the Raw Materials for A Portrait of the Artist as a Young Man. Evanston, IL: Northwestern U.P., 1965. Print.

Seed, David. "The Narrative Method of Dracula." Dracula, the Vampire and the Critics. Ed. By Margaret L. Carter. Ann Arbor: U. of Michigan Research P., 1988. 195-206. Print.

Seeley, J.R. The Expansion of England. Ed. John Gross. Chicago: U. of Chicago P., 1971. Print. Classics of British Historical Literature.

Seigel, Jerrold. The Idea of the Self: Thought and Experience in Western Europe Since the Seventeenth Century. Cambridge: Cambridge U.P., 2005. Print.

Sen, Amartya. Development as Freedom. New York: Alfred A. Knopf, 2000. Print.

Senf, Carol A. Dracula: Between Tradition and Modernism. New York: Twayne Publishers, 1998. Print. Twayne's Masterwork Studies.

---. “Dracula: Stoker's Response to the New Woman.” Victorian Studies 26.1 (1982): 33-49. JSTOR. Web. 25 June 2013.

---. "Dracula: The Unseen Face in the Mirror." Journal of Narrative Technique 9.3 (Fall 1979): 160-170. Print.

Shakespeare, William. The Complete Works of Shakespeare. Ed. David Bevington. $3^{\text {rd }}$ ed. Glenview, Ill: Scott, Foresman and Company, 1980. Print.

Sheehan, Canon Patrick Augustine. Glenanaar. Dublin: The O’Brien Press, 1989. Print.

---. The Graves at Kilmorna: A Story of '67. New York: Longsmans, Green, and Co., 1915. Print. Sherry, Vincent. The Great War and the Language of Modernism. Oxford: Oxford U.P., 2003. Print. 
---. Modernism and the Reinvention of Decadence. Cambridge: Cambridge UP, 2015. Print.

Signorotti, Elizabeth. "Repossessing the Body: Transgressive Desire in 'Carmilla' and Dracula." Criticism 38 (1996): 607-632. Print.

Silvestri, Michael. Ireland and India: Nationalism, Empire and Memory. Houndmills: Palgrave Macmillan, 2009. Print. Cambridge Imperial and Post-Colonial Studies Series.

Slote, Sam. "Protean Phenomenology and Genealogy." Dublin James Joyce Journal 2 (2009): 128-142. JSTOR. Web. 18 Apr 2012.

Smart, Robert. "Mapping the Imperial Body: Body Image and Representation in Famine Reporting." Valone 57-72

Smith, Andrew. "Demonising the Americans: Bram Stoker's Postcolonial Gothic." Gothic Studies 5.2 (November 2003): 20-31. Academic Search Complete. EBSCO. Web. 24 June 2013.

Smith, J. Sketches in Indian Ink. Ed. Keene, H.G. $2^{\text {nd }}$ ed. London: Macmillan and Co., 1891. Print. Macmillan's Colonial Library.

Smith, Mark M. how race is made: slavery, segregation, and the senses. Chapel Hill: U. of North Carolina P., 2006. Print.

Smyth, Gerry. Decolonisation and Criticism: The Construction of Irish Literature. London: Pluto Press, 1998. Print.

Southham, B.C. A Guide to the Selected Poems of T.S. Eliot. Sixth ed. San Diego: Harcourt Brace, 1996. Print.

Spencer, Kathleen L. "Purity and Danger: Dracula, the Urban Gothic, and the Late Victorian Degeneracy Crisis.” ELH 59.1 (Spring, 1992): 197-225. JSTOR. Web. 8 Sep 2013. 
Spenser, Edmund. "A brief note of Ireland." Calendar of the State Papers relating to Ireland, of the Reign of Elizabeth, 1598, January—1599, March. Ed. Ernest George Atkinson. London: Eyre and Spottiswoode, 1895. 431-433. Print.

---. "Two Cantos of Mutabilitie." Edmund Spenser's Poetry: Authoritative Texts Criticism. $2^{\text {nd }}$ ed. Ed. Hugh Maclean. New York: W.W. Norton \& Company, 1982. Print. A Norton Critical Edition.

Spivak, Gayatri Chakravorty. "Can the Subaltern Speak?" Marxism and the Interpretation of Culture. Ed. Cary Nelson and Lawrence Grossberg. Urbana: U of Illinois P, 1988. 271313. Print.

---. A Critique of Postcolonial Reason: Toward a History of the Vanishing Present. Cambridge: Harvard UP, 1999. Print.

Spurr, David. Joyce and the Scene of Modernity. Gainesville: U.P. of Florida, 2002. Print. Florida James Joyce Series.

Stevenson, John Allen. "A Vampire in the Mirror: The Sexuality of Dracula." PMLA 103.2 (March 1988): 139-149. Print.

Stewart, Bruce. "Bram Stoker's Dracula: Possessed by the Spirit of the Nation?" Irish University Review 29 (1999): 238-255. Print.

Stiles, Anne. "Cerebral Automatism, the Brain, and the Soul in Bram Stoker's Dracula." Journal of the History of the Neurosciences 15.2 (June 2006): 131-152. Academic Search Complete. EBSCO. Web. 24 June 2013.

Stoker, Bram. Bram Stoker's Notes for Dracula: A Facsimile Edition. Annotated and transcribed Robert Eighteen-Bisang and Elizabeth Miller. Jefferson, NC: McFarland \& Company, Inc., 2008. Print. 
---. Dracula. Ed. Nina Auerbach and David J. Skal. New York: W.W. Norton \& Company, 1997. Print. A Norton Critical Edition.

---. The Dublin Years: The Lost Journal of Bram Stoker. Ed. Elizabeth Miller and Dacre Stoker. London: The Robson Press, 2012. Print.

---. The Lady of the Shroud. Gloucestershire: Alan Sutton Publishing Limited, 1994. Print. Pocket Classics.

---. "Trinity Address: The Necessity for Political Honesty." A Glimpse of America and other Lectures, Interviews and Essays. Essex: Desert Island Books Limited, 2002. 31-47. Print. Desert Island Dracula Library.

Streets, Heather. Martial Races: The Military, Race, and Masculinity in British Imperial Culture, 1857-1914. Manchester: Manchester U.P., 2004. Print. Studies in Imperialism.

Suleri, Sara. The Rhetoric of English India. Chicago: U of Chicago P, 1992. Print.

Sullivan, Zohreh T. Narratives of Empire: The Fictions of Rudyard Kipling. Cambridge: Cambridge U.P., 1993. Print.

Tagore, Rabindranath. Gora. London: MacMillan and Col., Limited, 1924. Print.

The Táin. Trans. Thomas Kinsella. Oxford: Oxford UP, 2002. Print.

Taylor, Charles. Sources of the Self: The Making of the Modern Identity. Cambridge: Harvard U.P., 1989. Print.

Thomas, Nicholas. Colonialism's Culture: Anthropology, Travel, and Government. Princeton: Princeton U.P., 1994. Print

Tomaszewska, Monika. "Vampirism and the Degeneration of the Imperial Race - Stoker's Dracula as the Invasive Degenerate Other.” Journal Of Dracula Studies 6.(2004): 1-8. MLA International Bibliography. Web. 26 Mar. 2012. 
Toulmin, Stephen. Human Understanding, The Collective Use and Evolution of Concepts. Princeton: Princeton UP, 1972. Print.

Tracy, Robert. "Loving You All Ways: Vamps, Vampires, Necrophiles and Necrofilles in Nineteenth-Century Fiction." Sex and Death in Victorian Literature. Ed. Regina Barreca. Bloomington: Indiana U.P., 1990. 32-59. Print

Trevelyan, Charles. The Irish Crisis: Being a Narrative of the Measures for the Relief of the Distress Caused by the Great Irish Famine of 1846-7. London: Macmillan and Co., 1880. Tymoczko, Maria. “'What ish my Culture? Who talks of my Culture?': Interrogating Irishness in the Works of James Joyce." Irish and Postcolonial Writing: History, Theory, Practice. Eds. Glenn Hooper and Colin Graham. New York: Palgrave Macmillan, 2002. 181-201. Print.

Ungar, Andras. Joyce's Ulysses as National Epic: Epic Mimesis and the Political History of the Nation State. Gainesville: U.P. of Florida, 2002. Print. Florida James Joyce Series.

Valente, Joseph. Dracula's Crypt: Bram Stoker, Irishness, and the Question of Blood. Urbana: U. of Illinois P., 2002. Print.

Valone, David A., ed. Ireland's Great Hunger: Relief, Representation, and Remembrance. Vol. 2. Lanham: U.P. of America, Inc., 2010. Print.

van Boheemen-Saaf, Christine. Joyce, Derrida, Lacan, and the Trauma of History: Reading, Narrative, and Postcolonialism. Cambridge, UK: Cambridge U.P., 1999. Print.

Wachtel, Albert, ed. Critical Insights: A Portrait of the Artist as a Young Man. Wachtel. Pasadena, CA: Salem P., 2012. Print.

Walkowitz, Rebecca L. Cosmopolitan Style: Modernism Beyond the Nation. New York: Columbia U.P., 2007. Print. 
Wall, Geoffrey. “'Different From Writing': Dracula in 1897.” Literature and History 10.1 (1984): 15-23. Print.

Warren, Louis S. "Buffalo Bill Meets Dracula: William F. Cody, Bram Stoker, and the Frontiers of Racial Decay.” The American Historical Review 107.4 (October 2002): 1124-1157. Print.

Wasson, Richard. "The Politics of Dracula.” English Literature in Transition 9.1 (1966): 24-27. ProjectMUSE. Web. 25 June 2013.

Waters, John. "Confronting the Ghosts.” Hayden 27-31.

Watson, G. J. “The Politics of Ulysses.” Joyce’s Ulysses: The Larger Perspective. Ed. Robert D. Newman and Weldon Thornton. Newark: U. of Delaware P., 1987. , 39-58. Print.

Watson, Nicola J. Revolution and the Form of the British Novel 1790-1825: Intercepted Letters, Interrupted Seductions. Oxford: Clarendon Press, 1994. Print.

Watson, Tim. "Indian and Irish Unrest in Kipling's Kim." Postcolonial Theory and Criticism. Ed. Laura Chrisman and Benita Parry. Cambridge, UK: D.S. Brewer, 2000. 95-113. Print. Essays and Studies 1999.

Weissman, Judith. “Women and Vampires: Dracula as a Victorian Novel.” Carter 69-77. Whelan, Kevin. "Between Filiation and Affiliation: The Politics of Postcolonial Memory." Ireland and Postcolonial Theory. Ed. Clare Carroll and Patricia King. Notre Dame: U. of Notre Dame P., 2003. 92-108. Print.

"White, adj." Def. 2c, 2d. The Oxford English Dictionary Online. Oxford University Press. March 2013. Web. 16 May 2013.

Wicke, Jennifer. "Vampiric Typewriting: Dracula and Its Media.” ELH 59.2 (Summer 1992): 467-493. JSTOR. Web. 23 Sep 2013. 
Wicks, Ulrich. Picaresque Narrative, Picaresque Fictions: A Theory and Research Guide. New York: Greenwood P, 1989. Print.

Wilde, Jane Francesca. “The Famine Year.” The Famine Decade: Contemporary Accounts, 1841-1851. Ed. John Killen. Belfast: Blackstaff Press, 1995. 155-157. Print.

Williams, Anne. "Dracula: Si(g)ns of the Fathers." Texas Studies in Literature and Language 33.4 (Winter 1991): 445-463. Print.

Williams, Patrick. "Kim and Orientalism.” Mallett 33-55.

Williams, Trevor. "Mr. Leopold Bloom, Staunch Britisher.” Joyce, Imperialism, \& Postcolonialism. Ed. Leonard Orr. Syracuse: Syracuse U.P., 2008. Print. Irish Studies. $75-90$.

Willis, Martin. “"The Invisible Giant', Dracula, and Disease.” Studies in the Novel 39.3 (Fall 2007): 301-325. JSTOR. Web. 18 July 2013.

Wilson, Edmund. "The Kipling That Nobody Read.” Rutherford 17-69.

Winston, Greg. Joyce and Militarism. Gainesville: U.P. of Florida, 2012. Print. Florida James Joyce.

“Witness Statements.” Easter1916.ie. Griffith College Dublin, 2011. Web. 27 Feb 2016.

Wolfe, Patrick. "Can The Muslim Speak?: An Indebted Critique.” Rev. of A Critique of Postcolonial Reason: Toward a History of the Vanishing Present, by Gayatri Chakravorty Spivak. History \& Theory 41.3 (2002): 367-380. Academic Search Complete. Web. 5 Dec. 2015.

Woolf, Virginia. A Room of One's Own. Annota. and introd. by Susan Gabar. Orlando: Harcourt, Inc., 2005. Print. 
---. The Essays of Virginia Woolf: 1919-1924. Vol III. Ed. Andrew McNeillie. San Diego:

Harcourt Brace Jovanovich, 1988. Print.

---. Jacob's Room. Ed.Suzanne Raitt. New York: W.W. Norton \& Company, 2007. Print. A Norton Critical Edition.

---. "Modern Fiction.” The Common Reader: First and Second Series. New York: Harcourt, Brace and Company, 1948. 207-218. Print.

---. The Voyage Out. New York: Barnes \& Noble Books, 2004. Print. Barnes \& Noble Classics. Wright, Julia M. Ireland, India, and Nationalism in Nineteenth-Century Literature. Cambridge: Cambridge U.P., 2007. Print. Cambridge Studies in Nineteenth-Century Literature and Culture.

Wurgaft, Lewis D. The Imperial Imagination: Magic and Myth in Kipling's India. Middletown, CT: Wesleyan U.P., 1983. Print.

Yeats, W.B. The Collected Poems of W.B. Yeats. Rev. $2^{\text {nd }}$ ed. Ed. Richard J. Finneran. New York: Scribner Paperback Poetry, 1996. Print.

---. Yeats's Poetry, Drama, and Prose. Ed. James Pethica. $1^{\text {st }}$ ed. New York: W.W. Norton \& Company, 2000. Print. A Norton Critical Edition.

---. Uncollected Prose by W.B. Yeats. Vol. 2. Ed. John P. Frayne and Colton Johnson. New York: Columbia UP, 1976. Print.

Young, Robert J.C. Colonial Desire: Hybridity in Theory, Culture and Race. London: Routledge, 1995. Print.

Zachariah, Benjamin. "Histories and National Memory: 1857." Perception, Narration and Reinvention: The Pedagogy and Historiography of the Indian Uprising. Ed. Crispin 
Bates. Vol. 6. New Delhi: Sage Publications, 2014. 84-112. Print. Mutiny at the Margins: New Perspectives on the Indian Uprising of 1857.

Zanger, Jules. "A Sympathetic Vibration: Dracula and the Jews." English Literature in Transition 1880-1920 34.1 (1991): 32-43. Print. 